Pacific Northwest National Laboratory

Operated by Battelle for the

U.S. Department of Energy

\section{Vadose Zone Hydrogeology Data Package for Hanford} Assessments
G. V. Last
G. W. Gee
E. J. Freeman
W. E. Nichols
K. J. Cantrell
B. N. Bjornstad
M. J. Fayer
D. G. Horton

June 2006

Prepared for the U.S. Department of Energy under Contract DE-AC05-76RL01830 


\title{
DISCLAIMER
}

This report was prepared as an account of work sponsored by an agency of the United States Government. Neither the United States Government nor any agency thereof, nor Battelle Memorial Institute, nor any of their employees, makes any warranty, express or implied, or assumes any legal liability or responsibility for the accuracy, completeness, or usefulness of any information, apparatus, product, or process disclosed, or represents that its use would not infringe privately owned rights. Reference herein to any specific commercial product, process, or service by trade name, trademark, manufacturer, or otherwise does not necessarily constitute or imply its endorsement, recommendation, or favoring by the United States Government or any agency thereof, or Battelle Memorial Institute. The views and opinions of authors expressed herein do not necessarily state or reflect those of the United States Government or any agency thereof.

\author{
PACIFIC NORTHWEST NATIONAL LABORATORY \\ operated by \\ BATTELLE \\ for the \\ UNITED STATES DEPARTMENT OF ENERGY \\ under Contract DE-AC05-76RL01830 \\ Printed in the United States of America \\ Available to DOE and DOE contractors from the \\ Office of Scientific and Technical Information, \\ P.O. Box 62, Oak Ridge, TN 37831-0062; \\ ph: (865) 576-8401 \\ fax: (865) 576-5728 \\ email: reports@adonis.osti.gov
}

\begin{abstract}
Available to the public from the National Technical Information Service, U.S. Department of Commerce, 5285 Port Royal Rd., Springfield, VA 22161

ph: (800) 553-6847

fax: (703) 605-6900

email: orders@ntis.fedworld.gov

online ordering: http://www.ntis.gov/ordering.htm
\end{abstract}

This document was printed on recycled paper. 


\section{Vadose Zone Hydrogeology Data Package for Hanford Assessments}
G. V. Last
G. W. Gee
E. J. Freeman
W. E. Nichols
K. J. Cantrell
B. N. Bjornstad
M. J. Fayer
D. G. Horton

June 2006

Prepared for

the U.S. Department of Energy

under Contract DE-AC05-76RL01830

Pacific Northwest National Laboratory

Richland, Washington 99352 


\section{Preface}

This data package was originally prepared to support a 2004 composite analysis (CA) of low-level waste disposal at the Hanford Site. The Technical Scope and Approach for the 2004 Composite Analysis of Low-Level Waste Disposal at the Hanford Site (Kincaid et al. 2004) identified the requirements for that analysis and served as the basis for the data collection effort documented in this data package. Completion of the 2004 CA was later deferred, and the 2004 Annual Status Report for the Composite Analysis of Low-Level Waste Disposal in the Central Plateau at the Hanford Site (DOE 2005) indicated that a comprehensive update to the CA was in preparation and would be submitted in 2006.

However, the U.S. Department of Energy (DOE) has recently decided to further defer the CA update and will use the cumulative assessment currently under preparation for the environmental impact statement (EIS) being prepared for tank closure and other site decisions as the updated CA. Submittal of the draft EIS is currently planned for FY 2008.

\section{Acknowledgments}

The authors would like to acknowledge Thomas W. Fogwell and the Groundwater Remediation Project managed by Fluor Hanford, Inc. for supporting this work. We would like to thank Raziuddin Khaleel (Fluor Federal Services), and Charles T. Kincaid, Christopher J. Murray, Stephen P. Reidel, R. Jeffery Serne, and Robert W. Bryce for their technical reviews. The authors would also like to thank Anderson L. Ward for his technical support throughout the completion of this work, and Christopher A. Newbill for preparation of the site location map. We would also like to thank Launa F. Morasch for her technical editorial support, Kathy R. Neiderhiser, Shannon B. Neely, and the rest of the Publication Design team for their support in producing this document. 


\section{Executive Summary}

This data package documents the technical basis for selecting physical and geochemical parameters and input values that will be used in vadose zone modeling for Hanford assessments. This work was originally conducted as part of the Characterization of Systems Task of the Groundwater Remediation Project managed by Fluor Hanford, Inc., Richland, Washington, and revised as part of the Characterization of Systems Project managed by the Pacific Northwest National Laboratory (PNNL) for the U.S. Department of Energy, Richland Operations Office (DOE-RL).

This data package describes the geologic framework, the physical, hydrologic, and contaminant transport properties of the geologic materials, and deep drainage (i.e., recharge) estimates, and builds on the general framework developed for the initial assessment conducted using the System Assessment Capability (SAC) (Bryce et al. 2002). The general approach for this work was to update and provide incremental improvements over the previous SAC data package completed in 2001. As with the previous SAC data package, much of the data and interpreted information were extracted from existing documents and databases. Every attempt was made to provide traceability to the original source(s) of the data or interpretations.

Kincaid et al. (2004) identified 1,052 waste sites from the Waste Information Data System (WIDS) sites and several existing and future storage sites for inclusion in Hanford assessments, with analyses to be conducted on a site-by-site basis whenever inventory and release data permit. ${ }^{1}$ The complexity of these assessments, together with the lack of detailed characterization data for some of the fine-scale fate and transport processes necessitates simplification of site features, release events, and contaminant fate and transport processes to those factors considered most dominant. The dominant factors affecting modeling of transport of contaminants through the vadose zone include: (1) waste inventory and release estimates, (2) estimates of deep drainage (recharge), (3) the hydrogeologic profiles and properties of the vadose zone affecting aqueous phase advection and dispersion, and (4) estimates of geochemical reactions (e.g., sorption and precipitation) affecting the retardation of contaminants. The last three of these data types are addressed by this data package. The first one, waste inventory and release estimates, is addressed in the inventory and release model data packages.

Many large scale Hanford assessments will generally use a one-dimensional vadose zone model for computational efficiency (although the SAC framework is not inherently limited to a one-dimensional representation), configured to account for lateral spreading, and in selected cases, conditioned against multi-dimensional model results (Kincaid et al. 2004). In this report, and that of Kincaid et al. (2004), waste sites are grouped into a number of geographic areas assumed to have similar hydrogeologic structure and properties. Hydrogeologic units were identified and their thickness specified for each of these hydrogeologic provinces. To account for uncertainty in the model parameters, a stochastic distribution was developed for each process model parameter for each hydrogeologic unit.

\footnotetext{
${ }^{1}$ Originally 974 of 2,730 Waste Information Data System (WIDS) sites were identified for inclusion in a large-scale Hanford assessment. Further work identified 48 more waste sites bringing the total to 1,022. Subsequent reviews identified an additional 30 sites that have been included, many of which account for offsite transfers of waste and nuclear material. This brings the total to 1,052 .
} 
The vadose zone hydrostratigraphic profiles and hydrogeochemical property distributions for Hanford assessments are represented by 30 generalized one-dimensional vertical columns representing 17 general geographic areas and 13 site-specific locations. Each hydrostratigraphic profile (template) is configured with the hydraulic and geochemical parameters necessary to simulate the flow and transport through the vadose zone using the Subsurface Transport Over Multiple Phases (STOMP) code (White and Oostrom 2000). As many as five variations of a single hydrostratigraphic template are incorporated for some geographic areas in order to more accurately represent the depth of waste release, the thickness of the vadose zone beneath the point of release, and variations in contaminant distribution coefficients $\left(K_{d}\right.$ values) associated with different waste chemistry designations. Each template represents the vadose zone using a few major hydrostratigraphic units that are treated as horizontal layers with constant thicknesses, and that are homogeneous and isotropic. Hydraulic and geochemical parameters for each hydrostratigraphic unit are represented by stochastic distributions to facilitate sensitivity and uncertainty analyses.

This data package is a compilation of the data available to support Hanford assessments. As site characterization is completed at waste sites, and as investigations into contaminant behavior are completed, the uncertainty in this information will be reduced and, as a result, the uncertainty in future assessments will be reduced. 


\section{Contents}

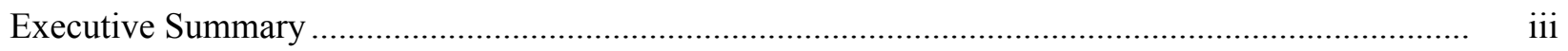

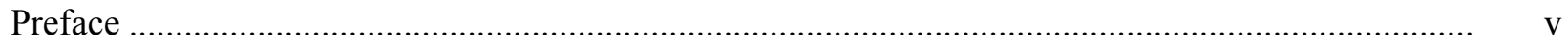

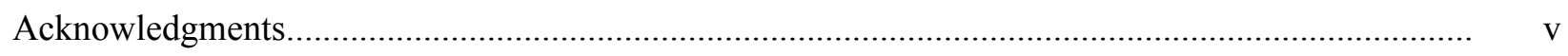

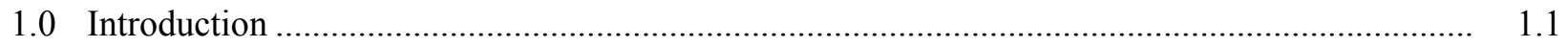

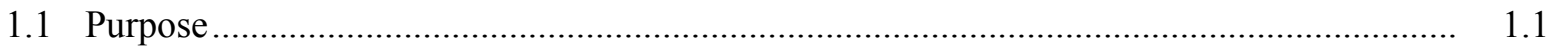

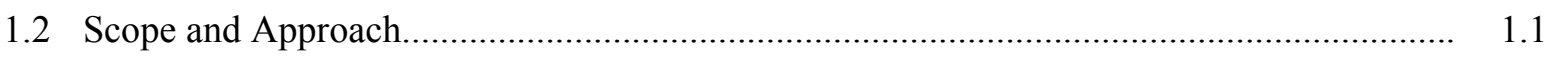

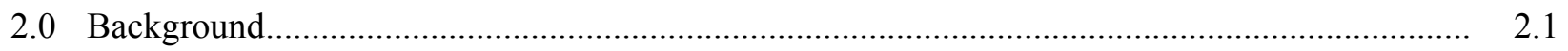

2.1 Conceptual Model of the Hanford Site Vadose Zone ...................................................... 2.1

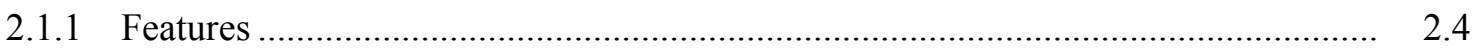

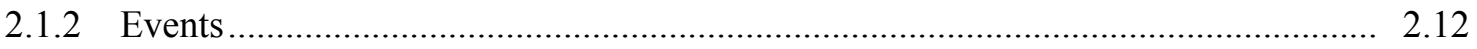

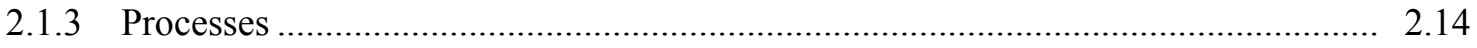

2.2 Uncertainty and Unresolved Technical Issues .......................................................... 2.18

2.2.1 Property Representation/Parameterization ..................................................... 2.19

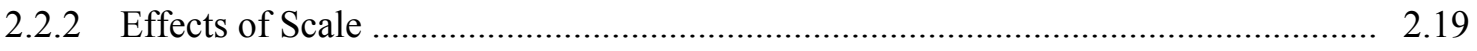

2.2.3 Spatial and Temporal Resolution of Site Data .................................................. 2.20

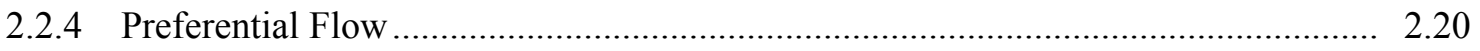

2.2.5 Temperature and Density Effects .................................................................... 2.22

2.2.6 Geochemical Processes ................................................................................... 2.22

2.3 Technical Basis and Approach for Vadose Zone Modeling........................................... 2.23

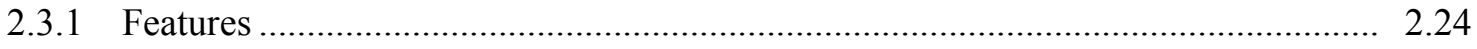

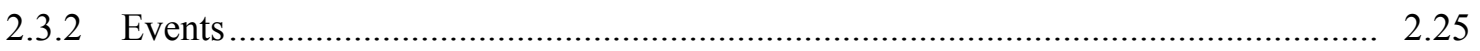

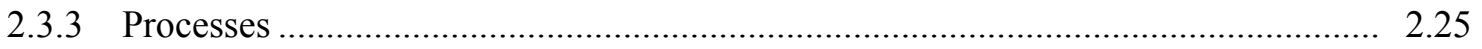

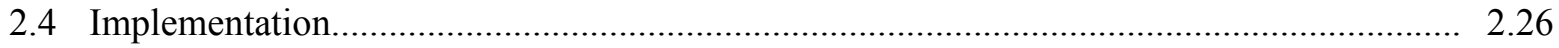

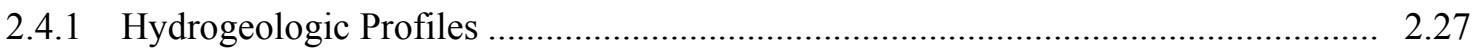

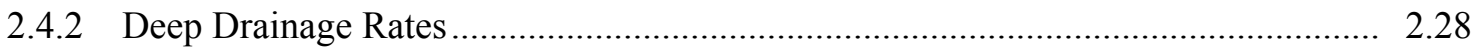

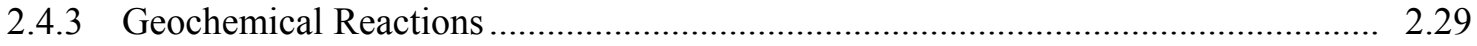

2.4.4 Interaction with the Inventory, Release, and Groundwater Modules ...................... 2.29

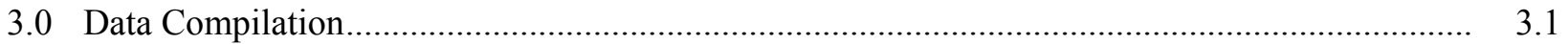

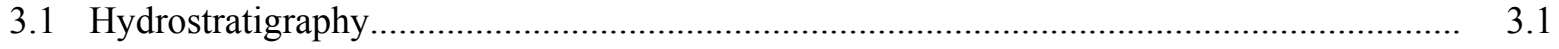

3.2 Hydrostratigraphic Templates ............................................................................. 3.3

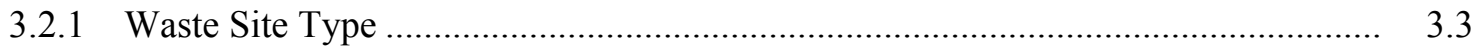

3.2.2 Geographic and Site-Specific Areas Designations.............................................. 3.4

3.2.3 Waste Chemistry Groupings ......................................................................... 3.5

3.2.4 Hydrostratigraphic Template Designations ..................................................... 3.9

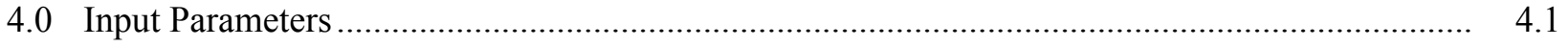

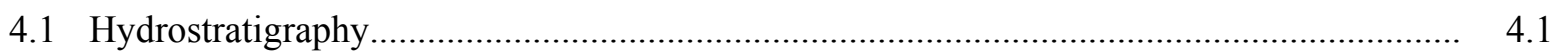




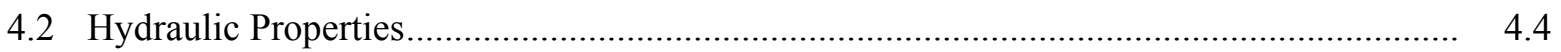

4.2.1 Site-Wide Hydraulic Property Distributions ...................................................... 4.8

4.2.2 Site-Specific Hydraulic Property Distributions..................................................... 4.10

4.2.3 Application to Vadose Zone Simulations............................................................ 4.10

4.2.4 Transport Parameters.................................................................................. 4.12

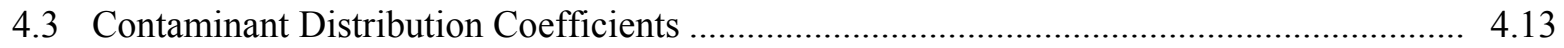

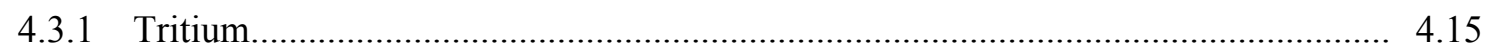

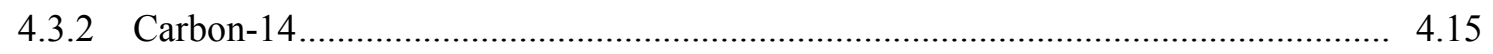

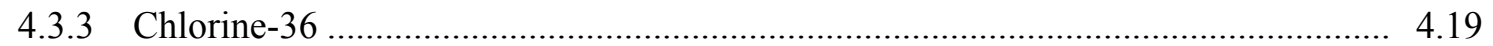

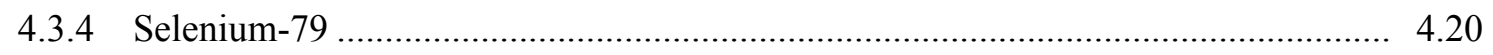

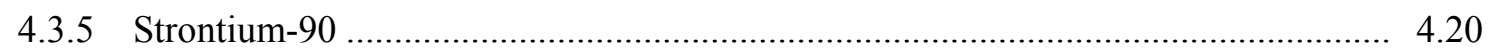

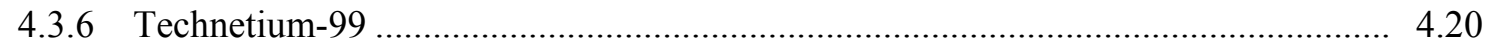

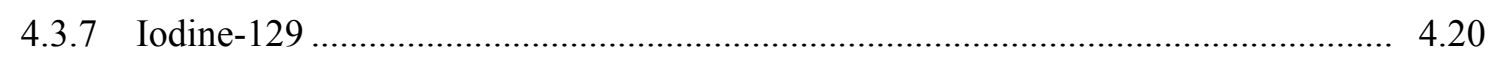

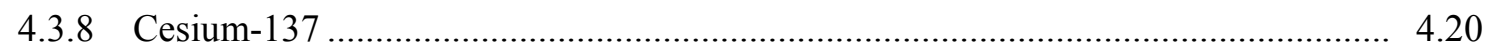

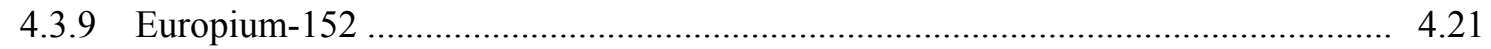

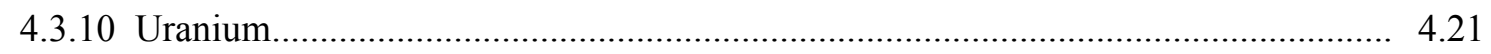

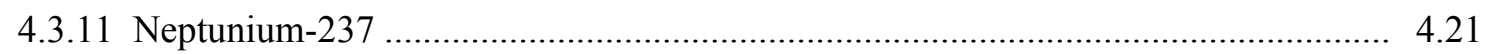

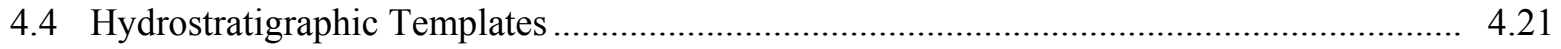

4.4.1 Assignment of Waste Chemistry Types ............................................................. 4.22

4.4.2 Facility Location, Dimensions, and Wetted Area ............................................. 4.22

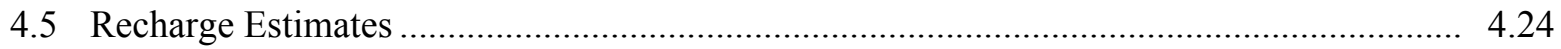

4.5.1 Natural and Disturbed Soil ......................................................................... 4.24

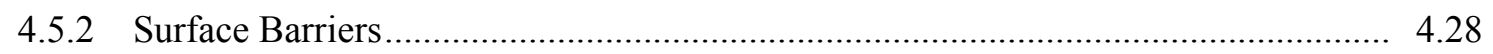

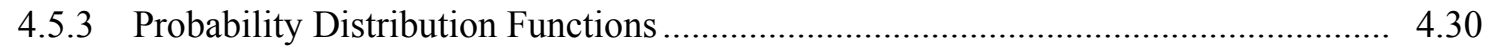

4.5.4 Integrated Drainage Calculations ............................................................. 4.31

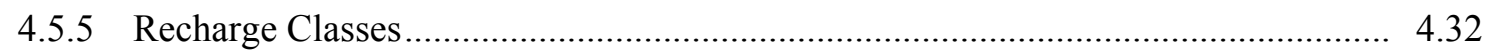

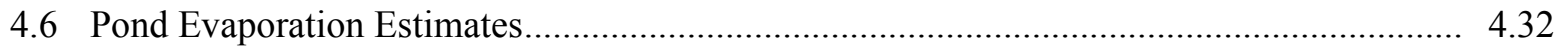

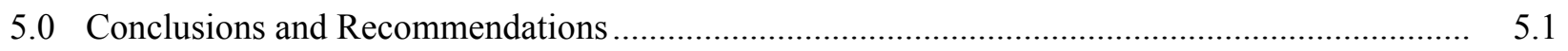

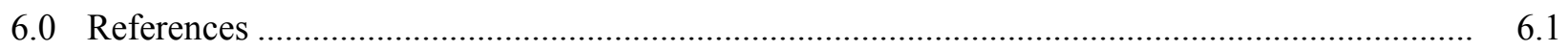

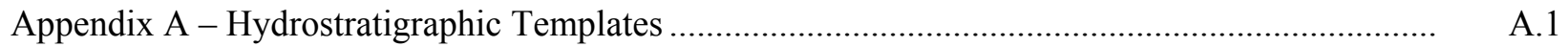

Appendix B - Hydraulic Property Distributions......................................................................... B.

Appendix C - Resolution of Discrepancies in the System Assessment Capability Vadose Zone Model for the BC Cribs and Trenches........................................................................... C. C.1 


\section{Figures}

2.1 General Vadose Zone Conceptual Model Concepts after Caggiano (1996) and

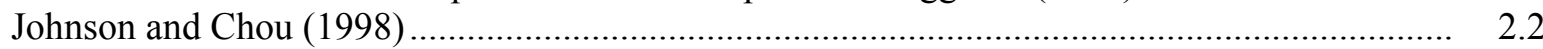

2.2 Process Relationship Diagram of Vadose Zone Flow and Transport ....................................... 2.3

2.3 Generalized West-to-East Geologic Cross Section Through the Hanford Site .......................... 2.7

2.4 Photograph of a Typical Clastic Dike as Found at the U.S. Ecology Site in Central Hanford..... 2.7

2.5 Schematic of Vadose Zone Implementation Model for Large-Scale Hanford Assessments ........ 2.27

3.1 Location of Geographic Areas Represented by Similar Hydrostratigraphic Columns ................ 3.2

3.2 Schematic of One-Dimensional Vadose Zone Simulation ..................................................... 3.3

4.1 Statistically Derived Water Retention Functions Calculated from the van Genuchten Parameters for Each Soil Class in the Site-Wide Distribution

4.2 Soil Class Specific Hydraulic Conductivity Curves for the Site-Wide Distribution Derived from the Saturated Hydraulic Conductivity Values Listed in Table 4.5 Using the Mualem Equation

4.3 Soil Class Specific Hydraulic Conductivity Curves Versus Effective Saturation for the Site-Wide Distribution. 


\section{Tables}

2.1 Options for a Large-Scale Hanford Assessment ............................................................... 2.24

3.1 Waste Site Type Designations Used in the Hydrostratigraphic Template Codes...................... 3.4

3.2 Geographic Area Designations Used in the Hydrostratigraphic Template Codes...................... 3.5

3.3 Site-Specific Area Designations Used in the Hydrostratigraphic Template Codes.................... 3.6

3.4 Waste Stream Designation and Assumed Compositions for Determination of $\mathrm{K}_{\mathrm{d}}$ Values.......... 3.8

3.5 Waste Chemistry Designations Used in the Base Template Codes .......................................... 3.8

3.6 General Hydrostratigraphic Templates for Each Geographic Area .......................................... 3.9

3.7 Site-Specific Templates Established for a Few Key Facilities ................................................ 3.11

4.1 Summary of Vadose Zone Input Parameter Data Sets Under Configuration Management ......... 4.1

4.2 Sources of Hydrogeologic Data for the Seventeen Geographic Areas to be Analyzed............... 4.3

4.3 Hydrostratigraphic Units Used in this Study ...................................................................... 4.4

4.4 Description of Hydraulic-Property Soil Classes .................................................................... 4.5

4.5 Statistical Mean Values for Site-Wide Samples ................................................................. 4.6

4.6 Statistical Mean Values for BC-Crib Samples ...................................................................... 4.6

4.7 Statistical Mean Values for U1 and U2 Samples................................................................ 4.6

4.8 Statistical Mean Values for 200-ZP-1 Samples.................................................................. 4.7

4.9 Statistical Mean Values for 200 West Area Samples ........................................................... 4.7

4.10 List of Contaminants of Concern to be Included in large-scale Hanford assessments ................ 4.15

4.11 Contaminant Distribution Coefficient Estimates by Waste Chemistry Type ............................ 4.16

4.12 Default Surface Areas.............................................................................................. 4.23

4.13 Estimated Recharge Rates for Predominant Soil Types and Sediment with a Shrub-

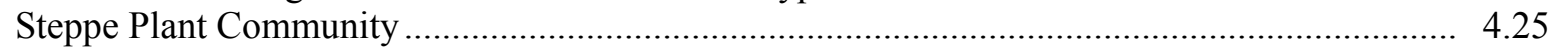

4.14 Estimated Recharge Rates for Disturbed Soil Types Without Vegetation ................................ 4.26

4.15 Estimated Recharge Rates by Soil Type/Sediment and Vegetation Condition in Each

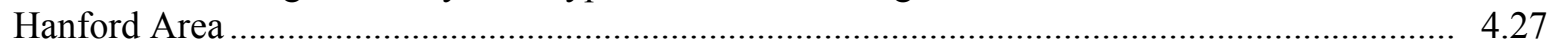

4.16 Barrier Design Life and Estimated Recharge Rates for Barrier Tops ...................................... 4.29

4.17 Initial Side Slope Recharge Rates for Hanford Site Climate Conditions ................................. 4.29

4.18 Estimated Recharge Rates for Baseline Soil Conditions ........................................................ 4.33

4.19 Estimated Recharge Rates for Disturbed Conditions and Sensitivity Tests ............................. 4.34

4.20 Estimated Recharge Rates for Surface Barrier Components ................................................... 4.35

4.21 Average Maximum Monthly and Yearly Total Evaporation from Hanford Surface Ponds ........ 4.36

4.22 Hanford Pond Identification, Surface Area, and Operational Life Taken from the Waste Information Data System. 


\subsection{Introduction}

In fiscal year (FY) 2003, the U.S. Department of Energy's Richland Operations Office (DOE-RL) initiated activities, including the development of data packages, to support Hanford assessments. This report describes the data compiled in FY 2003 and updated in FY 2005 to support vadose zone modeling for Hanford assessments. This work was originally conducted as part of the Characterization of Systems Task of the Groundwater Remediation Project (formerly the Groundwater Protection Program) managed by Fluor Hanford, Inc., Richland, Washington (Last et al. 2004b). It was revised in FY 2005 to incorporate updated approaches and parameter estimates as part of the Characterization of Systems Project managed by the Pacific Northwest National Laboratory (PNNL), for DOE-RL.

\subsection{Purpose}

The purpose of this data package is to summarize the conceptual understanding of flow and transport through the vadose zone (i.e., the conceptual model), describe how this model will be simplified for numerical simulation in support of Hanford assessments (i.e., implementation model), and finally to provide the input parameters needed for these vadose zone simulations.

\subsection{Scope and Approach}

The scope of this data package covers the geologic framework, the physical, hydrologic, and contaminant transport properties of the geologic materials in the vadose zone, and estimates of deep drainage (i.e., recharge). This data package builds on the general framework developed for the initial assessment conducted using the System Assessment Capability (SAC) as presented in:

- Preliminary System Assessment Capability Concepts for Architecture, Platform, and Data Management - Appendix C, Vadose Zone Conceptual Model (http://www.hanford.gov/cp/gpp/modeling/sacarchive/App\%20C.pdf)

- Draft 2001 SAC Data Package, Appendix C - Vadose Zone Data for Initial Assessment Performed with System Assessment Capability (Revision 0)

(http://www.hanford.gov/cp/gpp/modeling/sacarchive/dp_vadose.pdf).

- Vadose Zone Hydrogeology Data Package for the 2004 Composite Analysis (PNNL-14702, Rev. 0) (Last et al. 2004b)

The general approach for this work was to update and provide incremental improvements over the previous 2004 data package. As with the previous SAC data packages, much of the data and interpreted information were extracted from existing documents and databases. Every attempt was made to provide traceability to the original source(s) of the data or interpretations. 


\subsection{Background}

The vadose zone is the hydrogeologic region that extends from the soil surface to the water table (DOE 1998). At the Hanford Site, the vadose zone ranges in thickness from less than $1 \mathrm{~m}$ along the river in the 100 and 300 Areas to more than $100 \mathrm{~m}$ on the Central Plateau in the center of the Hanford Site. At discrete locations, the vadose zone contains waste inventories from past waste disposal practices (e.g., direct liquid waste disposal to the ground via engineered facilities) and from unplanned releases (e.g., spills and tank leaks).

The geologic framework of the vadose zone is very complex, with a high degree of heterogeneity and anisotropy in its physical, hydrologic, and geochemical properties. This complex hydrogeochemical framework, together with waste water and meteoric water fluxes, lead to a highly complex threedimensional movement of moisture and contaminants through the vadose zone. Wilson et al. (1995) describe flow within the vadose zone as dynamic and characterized by periods of unsaturated flow at varying degrees of partial saturation that is punctuated by episodes of preferential, saturated flow in response to hydrologic events or releases of liquids.

This section summarizes our conceptual understanding of flow and transport through the vadose zone and the technical basis and approach for modeling the vadose zone for large scale Hanford assessments. Conceptual models are evolving hypotheses that identify the important features, events, and processes controlling fluid flow and contaminant transport at a specific field site, within the context of a specific problem. Looney and Falta (2000) further describe a conceptual model as answering the question "How do we believe the system actually operates?" The conceptual model is one of the key initial elements in the overall modeling process. Once the site-specific problem has been defined and the important features, events, and processes conceptualized, quantitative descriptions can be prepared and implemented. Field and laboratory data are used to provide the input data, as well as to calibrate and independently test the predictive capabilities of the model. Of particular interest to this data package are the subsurface geologic, hydraulic, and geochemical parameters and the deep drainage estimates that control flow and transport through the vadose zone.

\subsection{Conceptual Model of the Hanford Site Vadose Zone}

Conceptual models of the vadose zone at the Hanford Site have been developed from information on the geology, geophysics, geochemistry, and hydrologic regime as well as the distribution and movement of waste in the subsurface. Most of the information has been obtained through borehole drilling, sediment sampling and analysis, and geophysical logging. This provides a considerable amount of information about the lithology and stratigraphy, but a more limited amount of hydrologic and geochemical information. These investigations into the vadose zone have traditionally been at or near the waste disposal sites; however, a few areas that represent background conditions or that provide representative test sites have also been studied. The integrated knowledge from these previous studies and ongoing work provides a conceptual understanding of the geologic, hydraulic, and geochemical controls on contaminant movement and distribution within the vadose zone of the Hanford Site (DOE 1999). Figure 2.1 illustrates some of these controls. However, there are still many outstanding technical issues, some of which require additional study and some of which may never be completely resolved. 


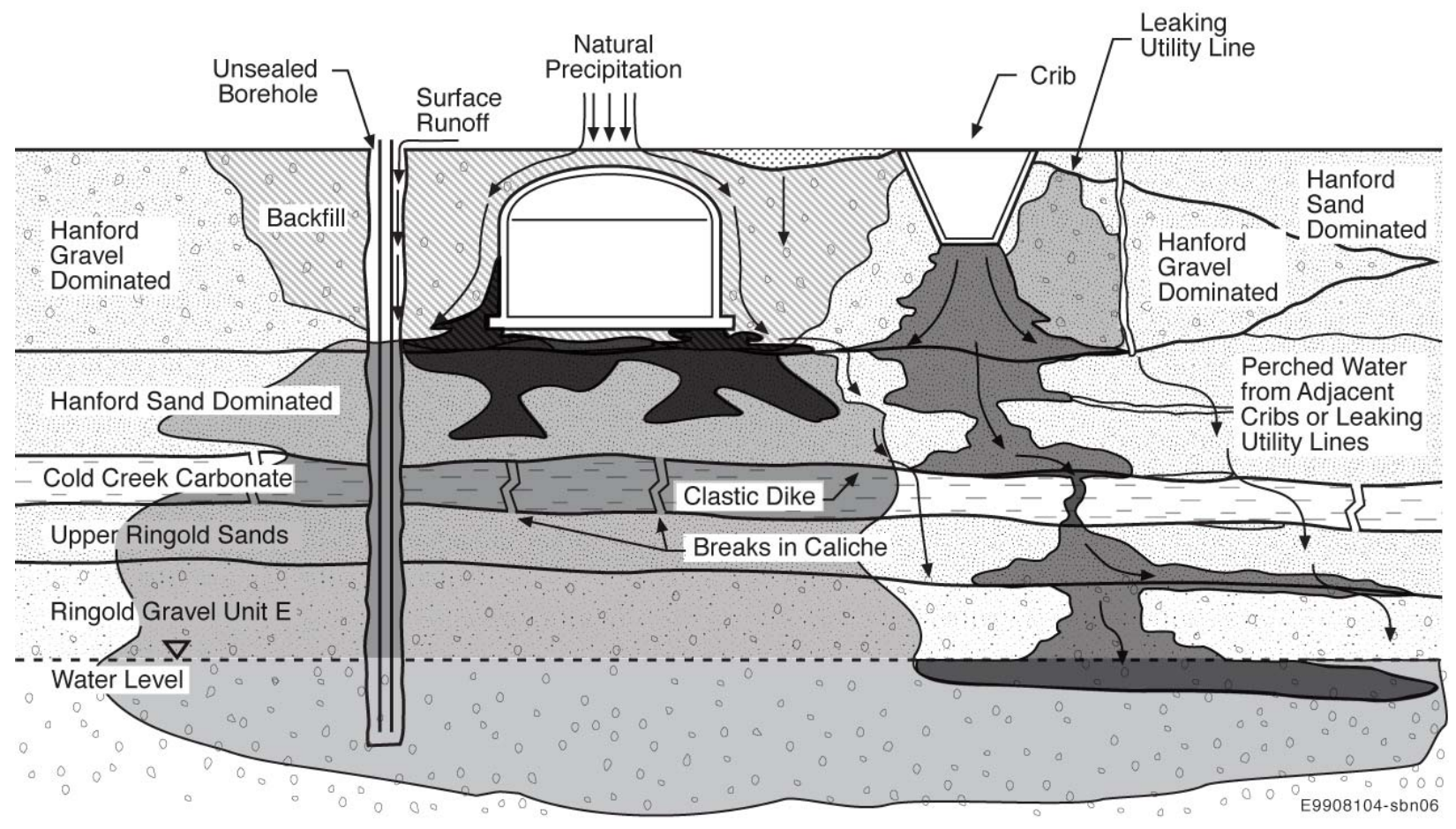

Figure 2.1. General Vadose Zone Conceptual Model Concepts after Caggiano (1996) and Johnson and Chou (1998)

The Preliminary System Assessment Capability Concepts for Architecture, Platform and Data Management, Appendix $C^{2}$ describes the conceptual models of vadose zone flow and transport and the preferred approach (and the rationale behind it) used for representing vadose zone transport in the initial assessments conducted using SAC. A common process to define the modeling requirements for a particular assessment is to break the conceptual model down into potentially relevant factors (i.e., features, events, and processes [FEPs]) and to logically screen and select the factors that should be included in the assessment (Last et al. 2004a). The process of identifying, classifying, and screening these factors is often called FEP analysis (NEA 2000) or FEP analysis methodology (Bailey and Billington 1998).

Kincaid's Candidate Sets Report ${ }^{3}$ and Soler et al. (2001) provide comprehensive compilations of the (1) features (the structure and transport properties of the various pathways); (2) events (e.g., recharge, source releases, etc.); and (3) processes (the fate and transport processes/mechanisms, including driving forces) considered potentially relevant to contaminant flow and transport within the vadose zone beneath the Hanford Site. Last et al. (2001) developed a process relationship diagram as a tool to illustrate the interrelations between factors and to facilitate analysis/screening of the dominant versus subordinate

\footnotetext{
${ }^{2}$ Groundwater/Vadose Zone Integration Project Preliminary System Assessment Capability Concepts for Architecture, Platform, and Data Management. September 30, 1999. http:/www.hanford.gov/cp/gpp/modeling/sacarchive/9-30rpt.pdf

${ }^{3}$ Kincaid CT et al. June 25 1999. Candidate Sets Report. http://www.hanford.gov/cp/gpp/modeling/sacarchive/candsets.pdf
} 
factors of a given conceptual model. Figure 2.2 illustrates the main features and processes potentially effecting flow and transport within the vadose zone.

The following sections (modified from Preliminary System Assessment Capability Concepts for Architecture, Platform, and Data Management - Appendix C, Vadose Zone Conceptual Model) ${ }^{4}$ describe these important features, events, and processes, and identifies those factors that are considered most dominant and have been selected as study sets for numerical representation (modeling) in large scale Hanford assessments.
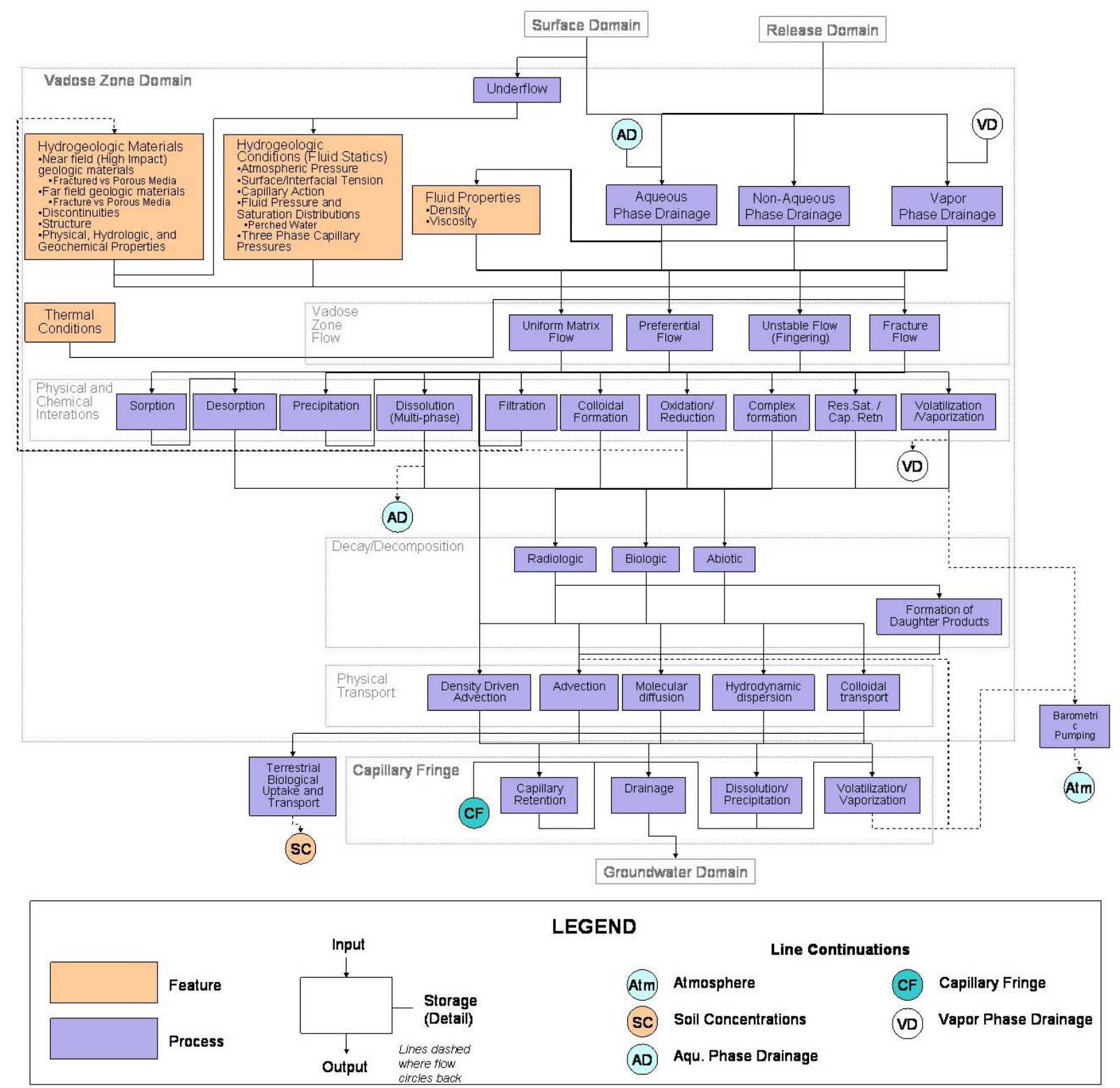

Figure 2.2. Process Relationship Diagram of Vadose Zone Flow and Transport

\footnotetext{
${ }^{4}$ Preliminary System Assessment Capability Concepts for Architecture, Platform, and Data Management - Appendix C, Vadose Zone Conceptual Model (http://www.hanford.gov/cp/gpp/modeling/sacarchive/App\%20C.pdf)
} 


\subsubsection{Features}

The primary features relevant to the vadose zone flow and transport include the hydrogeologic materials (and their physical, hydraulic, and geochemical properties); subsurface conditions (e.g., fluid statics and thermal conditions); and fluid properties. Other features relevant to the vadose zone conceptual model, such as climate and weather statistics, terrestrial ecology, and projected land use are not specifically discussed here. Instead, the reader is referred to Neitzel et al. (2005). Some aspects of the climate and weather phenomena are discussed later as they relate to precipitation, run-off, and infiltration (i.e., deep drainage) events.

There is a significant amount of hydrogeologic data available for the Hanford Site, primarily from borehole drilling in the vicinity of waste disposal operations. Interpretation of the geologic data are presented in numerous reports, including Tallman et al. (1979); DOE (1988, 1993a, 1994, 2002); Delaney et al. (1991); Connelly et al. (1992a and b); Lindsey (1992, 1995); Lindsey et al. (1992a, b); Lindsey and Jager (1993); Hartman and Peterson (1992); Peterson et al. (1996); Thorne et al. (1993, 1994); Hartman (2000); Williams et al. (2000); Williams et al. (2002); Reidel (2004); and Reidel et al. (2006).

The thickness of the vadose zone varies from less than $1 \mathrm{~m}$ along the river in the 100 and 300 Areas to more than $100 \mathrm{~m}$ beneath the Central Plateau. The vadose zone lies mostly within cataclysmic flood deposits of the Hanford formation, but in places such as the 200 West Area and portions of the 100 Areas it extends into the underlying Cold Creek unit, and/or the upper portions of the Ringold Formation. The physical structure and properties of the geologic framework and its principal transport pathways is complex, with a high degree of heterogeneity and anisotropy. To capture some of the site-wide variability in these features, this discussion is broken into three general physiographic areas (the 100, 200, and 300 Areas). While other areas, such as areas representative of background conditions and areas that have the potential to become contaminated in the future, are also important to the general vadose zone technical element, they are not specifically discussed here.

\subsubsection{100 Areas}

The average thickness of the vadose zone in the reactor areas ranges from $6 \mathrm{~m}$ (100-F Area) to over $30 \mathrm{~m}$ (100-B/C Area) with each reactor area being slightly different. During operations, groundwater mounding reduced the thickness of the vadose zone by 6 to $9 \mathrm{~m}$ directly under the retention basins or other liquid-waste disposal facilities.

Hydrogeologic Materials. The hydrogeologic framework of the vadose zone is complex; however, locally within the 100 Areas, it can be divided into two primary hydrostratigraphic units: (1) the graveldominated facies association of the Hanford formation and (2) the conglomeratic member of Wooded Island, Unit E, of the Ringold Formation (DOE 2002; Peterson et al. 1996; Hartman and Lindsey 1993; Lindberg 1993a, b; Lindsey and Jaeger 1993). The Ringold Formation makes up the lower portion of the vadose zone at the $100-\mathrm{K}, 100-\mathrm{N}$, and the $100-\mathrm{D}$ Areas. It is only partially present in the $100-\mathrm{B} / \mathrm{C}$ Area and absent in the 100-H and 100-F Areas. The Hanford formation extends from the surface to just above

the water table when the Ringold Formation is present. The Hanford formation extends beneath the water table and makes up the unconfined aquifer in the 100-H and 100-F Areas. 
The Ringold Formation Unit $\mathrm{E}$ is a fluvially deposited pebble-to-cobble gravel with a sandy matrix. It is characterized by complex interstratified beds and lenses of sand and gravel with low to moderate degrees of cementation.

The gravel-dominated facies of the Hanford formation is generally composed of uncemented, clastsupported pebble, cobble, and boulder gravel with a poorly sorted silty sandy matrix and minor sand and silt interbeds or stringers. It occasionally exhibits an open framework texture with little or no matrix. The clast size decreases in the lower portion of the Hanford formation. The Hanford formation is generally less cemented and more poorly sorted than the Ringold Formation and typically contains a higher percentage of angular basaltic detritus.

Although clastic dikes have been observed in the vadose zone beneath the 100 Areas (Fecht et al. 1999), this occurrence is fairly uncommon. Their limited distribution and lack of vertical continuity may render them insignificant as preferential pathways.

The contact between Ringold Unit E and the Hanford formation is important because the saturated hydraulic conductivity for the gravel-dominated sequence of the Hanford formation is one to two orders of magnitude higher than the more compacted and locally cemented Ringold Unit E. Since hydraulic conductivity varies with the formation, different groundwater level responses may occur where channels now filled with the Hanford formation have been scoured into the Ringold Unit E. These buried channels could become preferential pathways for contaminated groundwater during high river stages.

Hydraulic Properties and Conditions. The physical properties of the vadose zone in the 100 Areas are not well characterized. Peterson et al. (1996) reported saturated hydraulic conductivity, moisture content, specific gravity, and bulk density for samples taken from the single-pass reactor areas. No scaling of hydraulic conductivity based on particle-size distribution was done for that report. Khaleel and Relyea (1997) published moisture retention data for the 100-D, 100-F, and 100-H Areas. In the 100-N Area, Connelly et al. (1991) collected 10 surface samples for moisture retention data and DOE (1996a) collected four samples each from boreholes 199-N-108A and 199-N-109A. The measured physical properties for these samples vary widely, reflecting the heterogeneity of the vadose zone. These data are recorded in the catalog of vadose zone flow parameters for the Hanford Site (Freeman et al. 2002).

The large volume of liquid discharges during operations created water table mounds 6 to $9 \mathrm{~m}$ above the nominal water table under the retention basins and other liquid disposal facilities. The volumetric moisture content found in sediment under the 100-N Area liquid waste disposal facilities (DOE 1996a) appears to be high for the given sediment type and natural recharge rate. This suggests these soils are still draining.

Geochemical Properties and Conditions. Results from the geochemical characterization studies in the 100 Areas show a contaminant zoning (chromatographic) effect in the vadose zone. For radionuclides and inorganic contaminants that are not adsorbed (i.e., tritium, nitrate), the large releases of water to the vadose zone at the retention basin and liquid waste disposal facilities quickly pushed these contaminants through the vadose zone, into the unconfined aquifer, and subsequently out to the Columbia River. Crews and Tillson (1969), using iodine-131 isotopic analysis, estimated the travel time to the Columbia River from the 1301-N (116-N-1) liquid waste disposal facility to be approximately 10 days during active disposal (a distance of some $225 \mathrm{~m}$ ). 
Contaminants that show moderate adsorption such as strontium-90 show differential distribution (i.e., chromatographic zoning) within the vadose zone. Serne and LeGore (1996) examined characterization data from 12 boreholes within the 100-N Area and found that strontium-90 in the vadose zone is bound to sediment directly underneath the liquid waste disposal facilities in a relatively thin layer at depths that correspond to the elevated water table formed during operations. Serne and LeGore (1996) also reported the average bulk distribution coefficient $\left(\mathrm{K}_{\mathrm{d}}\right)$ for strontium- 90 to be $15 \mathrm{~mL} / \mathrm{g}$ for these sediments. Contaminants with strong adsorption such as cobalt-60, cesium-137, and plutonium-239/240 remained within $1 \mathrm{~m}$ of the bottom of the disposal facility. Contaminated sediment that is now part of the vadose zone should be considered a source term for further downward migration to the water table.

Further complicating the release of contaminants from the vadose zone in the 100 Areas is the seasonal and diurnal fluctuations of the Columbia River. A high river stage can cause the water table to rise into sediment that contains higher concentrations of contaminants. Additionally, the chemistry changes caused by the constant re-wetting of the soil due to diurnal fluctuations could affect the release of contaminants from the vadose zone (Petersen and Connelly 2001).

\subsubsection{200 Areas}

The 200 East and 200 West Areas are located on the Central Plateau of the Hanford Site. The vadose zone beneath the 200 Areas ranges in thickness from about $50 \mathrm{~m}$ in the western portion of the 200 West Area (beneath the former U Pond) to $104 \mathrm{~m}$ in the southern part of the 200 East Area. The stratigraphy of the vadose zone varies significantly across the up to 100-m-thick Cold Creek flood bar that makes up the Central Plateau. A generalized geologic cross section showing the general stratigraphy through the 200 Areas is shown in Figure 2.3.

Hydrostratigraphy. The geology and hydrology of the 200 Areas have been extensively studied because they contain major sources of groundwater contamination (Hartman 2000). The major stratigraphic units making up the vadose zone include (1) Ice Age flood deposits of the Pleistocene-Age Hanford formation, (2) alluvial, eolian, and pedogenic deposits of the Pliocene/Pleistocene-Age Cold Creek unit, and (3) the fluvial, overbank, and lacustrine deposits of the Miocene/Pliocene-Age Ringold Formation.

200 West Area. The vadose zone beneath the 200 West Area ranges from 50 to $80 \mathrm{~m}$ thick and can be subdivided into six principal hydrostratigraphic units (Lindsey et al. 1992a; Connelly et al. 1992a; Thorne et al. 1993; Williams et al. 2002; DOE 2002). These units include two facies associations of the Hanford formation (gravel-dominated and sand-dominated), two lithofacies of the Cold Creek unit (the fine-grained, laminated to massive facies, and the coarse to fine-grained carbonate-cemented facies) and two members of the Ringold Formation (Taylor Flat and Wooded Island, Unit E). Not all of these units are present everywhere within the 200 West Area, and as in any depositional system, the thickness, distribution, and continuity of these units vary significantly from site to site.

Clastic dikes (Figure 2.4) occur as near-vertical sediment-filled structures that cut across bedding planes. Clastic dikes have been observed to form multisided polygonal cells (up to $150 \mathrm{~m}$ across) enclosing the host sediment. Individual polygonal cells are bounded by other polygons to form polygonal-patterned ground (Fecht et al. 1999) that resembles giant mudcracks or a honeycomb pattern in plan view. Vertically oriented clay skins within clastic dikes can form a local impediment to lateral flow. 


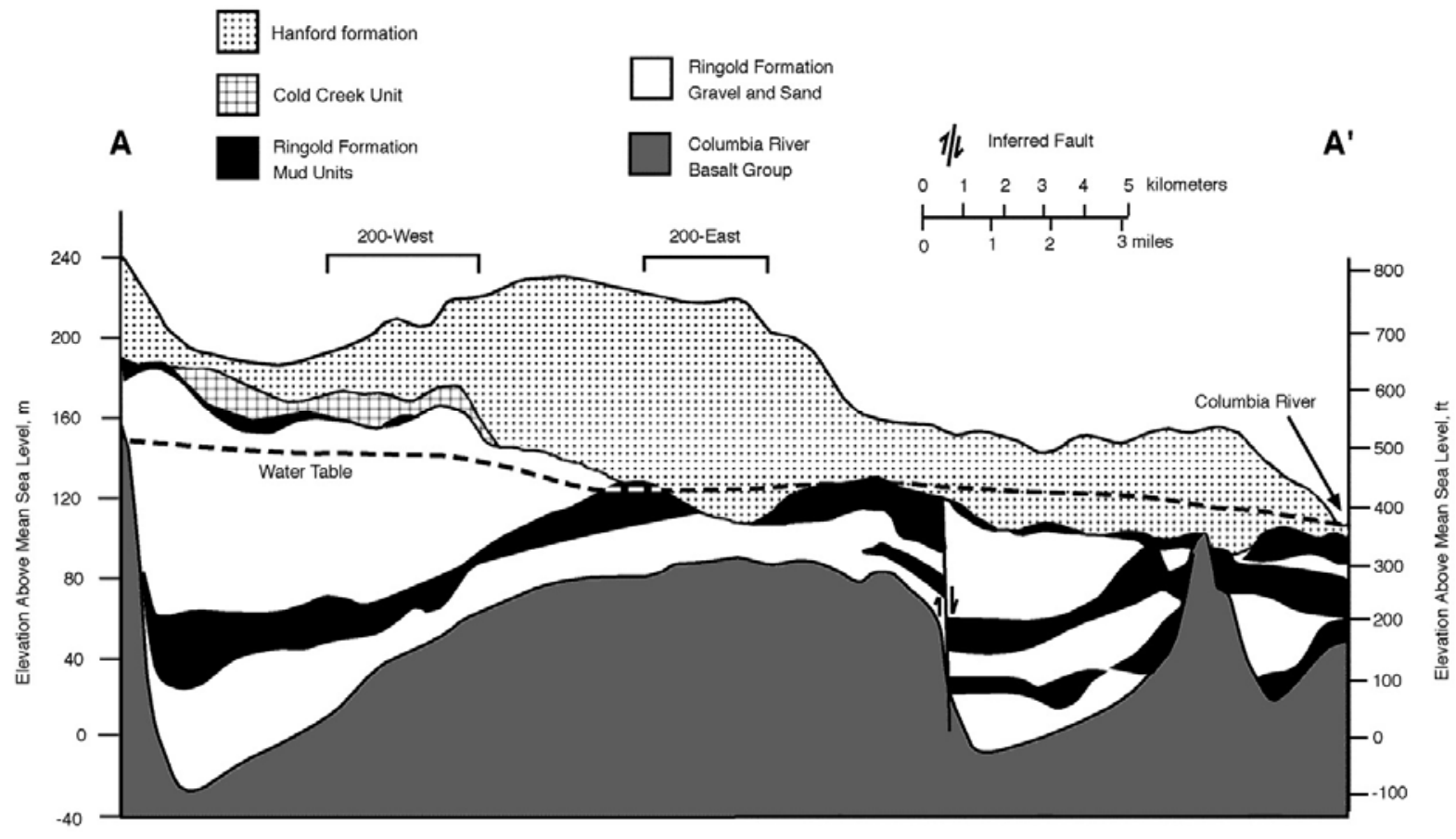

Figure 2.3. Generalized West-to-East Geologic Cross Section Through the Hanford Site (after Hartman 2000)

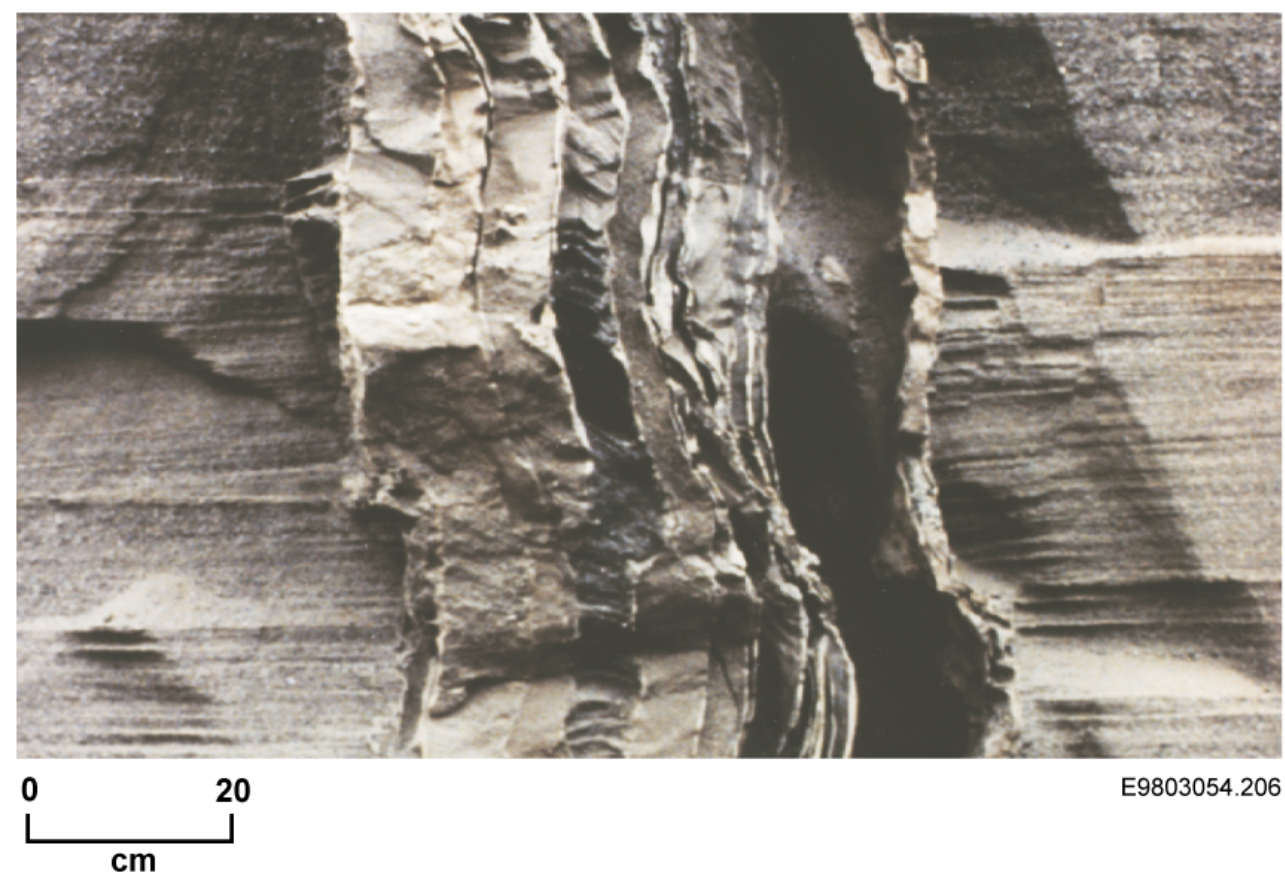

Figure 2.4. Photograph of a Typical Clastic Dike as Found at the U.S. Ecology Site in Central Hanford (after Fecht et al. 1999) 
Clastic dikes are most common in the Hanford formation, but have been noted within the Cold Creek unit and/or Ringold Formation as well. Elsewhere, clastic dikes have also been observed in the Columbia River Basalt Group.

Perhaps the most significant features in the 200 West Area affecting vadose-zone transport are the fine-grained siliciclastic and carbonate-cemented facies of the Cold Creek unit, previously referred to as the Plio-Pleistocene unit, (Rohay et al. 1994; DOE 2002), which represent an ancient buried calcic paleosol sequence (Slate 1996, 2000). Because of the cemented nature of the Cold Creek unit, it is often considered impervious; however, it is also structurally brittle and may contain abundant fractures that have developed during or since soil development. The degree of cementation varies considerably within the Cold Creek unit so that contaminants could breach the unit through discontinuities. The Cold Creek unit contains abundant weathering products (e.g., oxides and carbonates) and may chemically react on contact with transported wastes. Immediately overlying the carbonate-cemented facies of the Cold Creek unit is the fine-grained, laminated to massive facies (formerly referred to as the 'early Palouse soil'), which has a relatively high moisture-retention capacity with a corresponding low permeability that tends to retard the downward movement of moisture and contaminants.

200 East Area. The vadose zone beneath the 200 East Area can be subdivided into six principal hydrostratigraphic units, including three units with in the Hanford formation, a fluvial gravel facies of the Cold Creek unit (equivalent to the Pre-Missoula Gravels of Webster and Crosby 1982 and Delaney et al. 1991), and two units belonging to the Ringold Formation (Lindsey et al. 1992b; Connelly et al. 1992b; Thorne et al. 1993; Williams et al. 2000; DOE 2002). The Hanford formation units include (1) an upper gravel-dominated facies, (2) a sand-dominated facies, and (3) a lower gravel-dominated facies. Over most of the 200 East Area, the Hanford sand-dominated facies lies between the upper and lower gravel-dominated facies (Lindsey et al. 1992b; Connelly et al. 1992b; DOE 2002). Based on borehole samples, the upper and lower gravel-dominated facies appear to have similar physical and chemical properties. The Ringold Formation in the 200 East Area is, for the most part, eroded away in the northern half of the 200 East Area. Here, the Hanford formation lies directly on top of basalt bedrock. With the dropping water table, basalt crops out above the water table and, thus, is unsaturated beneath the northeastern portion of the 200 East Area. Just south of the 200 East Area, the top of the unconfined aquifer lies within the Ringold Formation. Because the physical and chemical characteristics of the Ringold Formation, Member of Wooded Island, Unit A and Unit E gravels are similar, and because only a small portion of the vadose zone lies within Unit A, these units can be combined into a single hydrostratigraphic unit.

Clastic dikes have also been observed in the Hanford formation beneath the 200 East Area. The vertically oriented clay skins within clastic dikes may locally form an impediment to lateral flow. This could then cause ponding (perching) of the water and eventual breakthrough to underlying strata.

Sublinear channel-cut scour and fill features occur within the Hanford formation and may act as preferential pathways in the horizontal direction. Other types of heterogeneity are associated with stratigraphic pinch out or offlapping/onlapping of facies.

Both the Ringold and the Hanford formations contain thin fine-grained stringers that can result in lateral spreading of moisture and may slow the vertical movement of contaminants within the vadose zone. Low-permeability layers, where they exist, are often solitary, relatively thick (meters or more), continuous layers within the Ringold Formation. Low-permeability layers within the Hanford formation, 
on the other hand, occur more frequently, are thin ( $0.5 \mathrm{~m}$ or less) and laterally discontinuous. Lowpermeability layers within the sand-dominated facies of the Hanford formation are generally thicker and more continuous than those in the gravel-dominated facies. Some paleosols and facies changes (i.e., the contact between fine grained and coarser grained facies) may be fairly continuous over the range of $100 \mathrm{~m}$ or so, with some lateral spreading of crib effluent noted on that same scale.

Hydraulic and Transport Properties. Accurate predictions of flow and transport in the vadose zone require a detailed characterization of the hydrologic properties and their variability, as well as estimates of transport parameters such as dispersivity. In particular, data that are essential for quantifying the water storage and flow properties of unsaturated soil include the soil moisture characteristics (i.e., soil moisture content versus pressure head, and unsaturated hydraulic conductivity versus pressure head relations) for sediment in various geologic units.

Data on particle-size distribution, moisture retention, and saturated hydraulic conductivity $\left(K_{s}\right)$ have been cataloged for over 284 samples from throughout the Hanford Site, including 12 locations in the 200 East and West Areas (Khaleel and Freeman 1995; Khaleel et al. 1995; Khaleel and Relyea 1997; Freeman et al. 2001, 2002; Freeman and Last 2003; and Khaleel and Heller 2003). Laboratory analyses of the hydraulic properties of samples collected at Hanford have been performed at a number of different laboratories using techniques similar to those described by Klute (1986).

Macrodispersivity estimates for non-reactive species have been estimated using the Gelhar and Axness (1983) equation where the longitudinal macrodispersivity depends on the mean pressure head. Khaleel (1999) estimated a longitudinal macrodispersivity of about $1 \mathrm{~m}$ for the sand-dominated facies of the Hanford formation in the 200 East Area. The transverse dispersivities have been estimated as onetenth of the longitudinal values (Gelhar et al. 1992).

Ward et al. ${ }^{5}$ obtained dispersivity estimates via field measurements at a location close to the immobilized low-activity waste site, using potassium chloride $(\mathrm{KCl})$ as a tracer. Analysis of the data provided dispersivities from 1.3 to $7.8 \mathrm{~cm}$ for travel distances ranging from 25 to $125 \mathrm{~cm}$. Dispersivity increased with depth to about $0.75 \mathrm{~m}$, after which it essentially became constant. These estimates are for the Hanford formation, but the transport distance within the vadose zone is of very limited extent. Nevertheless, results based on the limited data are consistent with the concept of a scale-dependent dispersivity. Thus, although no data exist on large-scale dispersivities for the vadose zone, it is expected that they will be larger (as is suggested by the longitudinal dispersivity estimate of $1 \mathrm{~m}$ ) than those based on the smallscale tracer experiment of Ward et $\mathrm{al}^{5}$

Based on a survey of literature, Gelhar (1993) examined the longitudinal vadose zone dispersivities as a function of the scale of the experiment, and found an increase of dispersivity with an increase in scale.

Geochemical Properties. The Hanford formation sediment consists of glaciofluvial materials deposited by cataclysmic Ice Age floods. The mineralogy of this sediment is highly variable, depending on grain size. Gravel-dominated sediment tends to have a high abundance of lithic fragments (mostly basaltic, with some plutonic, metamorphic, and detrital caliche fragments) (DOE 2002). Finer grained

\footnotetext{
${ }^{5}$ Ward AL, RE Clayton, and JS Ritter. 31 December 1998. "Hanford Low-Activity Tank Waste Performance Assessment Activity: Determination of In Situ Hydraulic Parameters of the Upper Hanford Formation.” In Letter to Dr. Fredrick M Mann (CH2M HILL Hanford, Inc., Richland, Washington) from AL Ward (Pacific Northwest National Laboratory, Richland, Washington), dated 31 March, 1999.
} 
facies have proportionally less lithic fragments and more quartz, feldspar, and mica grains. Microprobe analysis of the sand and finer-grained fraction indicates dominance by quartz ( 18 to $67.1 \%$ by weight), plagioclase (5.1 to 41.5\%) and microcline (1.8 to 30.1\%) (Tallman et al. 1979; Serne et al. 1993; Xie et al. 2003). Other common minerals include amphiboles up to $36.6 \%$, pyroxenes up to $27.5 \%$, Mica (Biotite/Illite) up to $13.1 \%$, and calcite up to $6.5 \%$ by weight. Smectite clays represent a few weight percent of the bulk sand fraction (3.3 to 5\% [Serne et al. 1993]) and generally dominate the clay fraction (Tallman et al. 1979). Reidel (2004) reported chlorite concentrations generally $<3 \mathrm{wt} . \%$ except for one sample that had 8 wt.\% chlorite.

Hanford formation sediment is typified as having low organic carbon content, generally $<0.1 \%$ by weight (Serne et al. 1993), and low-to-moderate cation exchange capacity (2.6 to 7.8 milliequivalents per $100 \mathrm{~g}$, Serne et al. 1993). The sediment has a slightly basic $\mathrm{pH}$ when wetted (Serne et al. 1993 found the $\mathrm{pH}$ of saturation extract ranging from 7.66 to 8.17). Small amounts of detrital calcium carbonate (calcite) are common and can act as a weak buffer.

Much less mineralogy data are available for the Cold Creek unit. Tallman et al. (1979) found that the sediments they referred to as Early 'Palouse' Soil are fairly similar in mineralogy to those of the Hanford formation ( 25.3 to $29.4 \%$ quartz, 15.1 to $18.2 \%$ plagioclase, 15 to $17.8 \%$ microcline, 7.9 to $10 \%$ amphiboles, 1.3 to $12.5 \%$ micas), but generally contain more calcite ( 8 to $8.8 \%$ ), and lack pyroxenes. Bjornstad (1990) found similar results for these fine-grained sediments, but found that drill cuttings of the carbonate-rich facies (referred to as the Plio-Pleistocene unit) consisted predominantly of calcium carbonate and/or sedimentary rock fragments, with lesser amounts of quartz and feldspars.

Thin beds of caliche along with variable amounts of ferric oxide exist in the 200 West Area in the Cold Creek unit just above the Ringold Formation.

Bjornstad (1990) and Xie et al. (2003) found significant mineralogical differences in electron microprobe and petrographic results between the Hanford and Ringold Formations. The Ringold Formation sediment is generally higher in quartz but lower in plagioclase and pyroxene. Deeper within the Ringold Formation, calcic/ferric oxide cements are often present. This cementation can significantly decrease the permeability of coarse-grained Ringold sediment.

Empirical $K_{d}$ data for Hanford formation and Ringold Formation sediments are fairly abundant for dilute waste solutions and groundwater (Cantrell et al. 2002, 2003a). Fewer $K_{d}$ data are available for the Cold Creek unit sediments, or for high ionic strength waste solutions with slightly acidic to slightly basic $\mathrm{pH}$ values. A relatively small amount of $K_{d}$ data exists for the combined high ionic-strength/highly-basic tank liquors for many common radionuclides. These distribution coefficient $\left(K_{d}\right)$ data have been well tabulated by Cantrell et al. (2003a); Kincaid et al. (1998); Serne and Wood (1990); Kaplan and Serne (1995); Kaplan et al. (1996, 1998); and Krupka et al. (2004). In most instances, adsorption appears to be the controlling geochemical process, but neutralization of acid waste by the alkaline sediment and neutralization of basic tank waste can cause precipitation of some contaminant species within the sediment pores. Outside the zone of $\mathrm{pH}$ neutralization, adsorption is considered to be the dominant contaminant retardation process in the vadose zone. 
The geochemical processes that affect contaminant migration and mineral alteration within the vadose zone sediment for both the 200 East and the 200 West Areas are quite similar. Some difference may occur, because the fine-grained sediment and caliche zones above the Ringold are less prevalent in the 200 East Area.

\subsubsection{300 Area}

The vadose zone beneath the 300 Area ranges in thickness from about $15 \mathrm{~m}$ to less than $1 \mathrm{~m}$ along the Columbia River.

Hydrostratigraphy. The geology of the vadose zone consists almost entirely of the Pleistocene Hanford formation with a thin veneer of Holocene eolian sand. Thin portions of the Ringold Formation may also extend above the water table in portions of the site. Schalla et al. (1988) described the eolian sand deposits as ranging from 0 to nearly $4.6 \mathrm{~m}$ thick. Where missing, these deposits are thought to have been removed by construction activities and often replaced by or covered with construction gravel. The geologic contact with the underlying Hanford formation is quite distinct.

Schalla et al. (1988) described the Hanford formation in this area as poorly sorted sandy gravel with some silt and local sand stringers. The upper portion contains pebble to boulder gravel that becomes finer with depth. The gravel fraction is mainly basaltic in nature, with some quartz-rich and metamorphic clasts. Rip up clasts of semi-consolidated fine-grained Ringold Formation materials up to a meter or more in diameter are also present. ${ }^{6}$ The thickness of the Hanford formation varies from 6.4 to $24.7 \mathrm{~m}$.

Gaylord and Poeter (1991) describe the Hanford formation beneath the 300 Area as consisting predominantly of three lithofacies: gravelly sand, sandy granule to pebble-size gravel, and sandy cobble to boulder-size gravel. The finer grained sand facies, comprising only a minor percentage of the 300 Area Hanford formation deposits, are concentrated in the southern part of the area, interwoven with the coarsegrained gravel dominated deposits.

In order to define the spatial distribution of hydrologic properties (particularly in the unconfined aquifer) Gaylord and Poeter (1991) divided the 300 Area sediment into four hydrofacies. These hydrofacies were based on grain size and sorting, and recognized the importance of the fine-grained component to hydraulic behavior.

The hydrostratigraphy of vadose sediment in the 300 Area can be broken into five different units: (1) backfill (or surface cover); (2) eolian sands (if present at the waste site); (3) sand-dominated Hanford sediment; (4) gravel-dominated Hanford sediment; and (5) gravel-dominated Ringold sediment (if present above the water table). Although these sediments are primarily coarse, some silt stringers and finegrained rip up clasts (some over $1 \mathrm{~m}$ in diameter) are present, particularly in the Hanford formation. ${ }^{6}$ The location and extent of these stringers is uncertain. Bjornstad described the Hanford formation in the 300 Area is relatively heterogeneous and anisotropic. ${ }^{6}$

Hydraulic Properties and Conditions. Schalla et al. (1988) presented the results of physical (e.g., field moisture content, water retention, particle-size analysis) and bulk geochemical analyses of selected samples. The field water content ranged from $<2$ to nearly $5 \%$ by weight.

\footnotetext{
${ }^{6}$ Bjornstad, BN. 2004. Sampling and Hydrogeology of the Vadose Zone Beneath the 300 Area Process Ponds. PNNL-14834 (Unpublished). Pacific Northwest National Laboratory, Richland, Washington.
} 
Geochemical Properties and Conditions. Gaylord and Poeter (1991) provided whole rock geochemical (via x-ray fluorescence) and rare earth/trace element (inductively coupled plasma/mass spectroscopy [ICP/MS]) analyses for the Hanford and Ringold Formations. These data are similar to those for Central Plateau sediment (Xie et al. 2003). Existing sorption data are somewhat limited for the 300 Area (Cantrell et al. 2003b; Brown et al. 2005); therefore, sorption parameters are generally derived from the waste chemistry and existing sorption values from other Hanford Site sediments (similar to the selection process used in the Hanford composite analysis [Kincaid et al. 1998]). Without site-specific geochemical data, values for the geochemical properties (i.e., $K_{d}$ values) have to be estimated from the sediment type (e.g., grain-size data and the presence of secondary mineralization) and waste type. The mineralogy and contaminant adsorption properties of the Hanford formation sediment in the 300 Area appear to be quite similar to those in the 200 Areas, thus, the available $K_{d}$ data base (Cantrell et al. 2003b) should be adequate for large scale Hanford assessments that includes the 300 Area.

\subsubsection{Events}

Various events considered for inclusion in the conceptual model include those that are naturally occurring (e.g., meteoric recharge), those that are manmade (e.g., intentional or unintentional contaminant and water releases), those that occur slowly over a long period of time, and those that represent extreme or unusual occurrences (e.g., 500 year storms, volcanism). A brief synopsis of some of the important types of events that should be considered is presented in the following sections.

\subsubsection{Recharge Events}

The long-term natural driving force for flow and transport through the vadose zone is precipitation that has infiltrated below the zone of evaporation and below the influence of plant roots. Such water eventually flows to the water table, carrying with it any dissolved species. Gee et al. (1992) presented evidence from multiple experiments showing that measurable diffuse natural recharge occurs across the lower elevations of the Hanford Site, with rates ranging from near zero in undisturbed shrub-steppe plant communities to more than $100 \mathrm{~mm}$ per year beneath the unvegetated graveled surfaces of tank farms.

The arid climate of the Hanford Site, with cool wet winters and dry hot summers, dictates that recharge potential is greatest in winter (Gee et al. 1992). During winter months, precipitation is greatest and evaporation potential is lowest; therefore, precipitation has the greatest chance to infiltrate into the sediments. This type of recharge can occur as either diffuse or focused recharge. The contribution of each event is site- and event-dependent. Winter water runoff from the higher elevations over frozen ground, while infrequent, can be extensive (e.g., Pearce et al. 1969). Cushing and Vaughan (1988) indicate runoff from higher elevations has a 3.8-year return period. Extensive water runoff does not appear prevalent between Highway 240 and the Columbia River, based on the absence of geomorphic features such as erosion rills and gullies. Undisturbed (natural) sites in the 100 and 200 Areas, typically have gentle terrain and coarse soils that foster diffuse recharge. In contrast, at disturbed waste sites, localized ponding can give rise to focused flow. Observations confirm that local runoff does occur at waste sites when there is a heavy rain or quick snowmelt and where the ground is frozen or compacted as a result of normal waste operations (e.g., Jones 1989; Ward et al. 1997, 2005). 


\subsubsection{Source/Release Events}

A second source of water that transports contaminants originates from industrial activities. Historically, millions of gallons of contaminated water were disposed to subsurface infiltration structures and surface ditches and ponds. Most waste water disposal ceased by the mid-1990s. Currently, two facilities are permitted to discharge to the vadose zone: the State-Approved Liquid Disposal (SALD) Facility and the Treated Effluent Disposal Facility (TEDF). Discharges from these facilities are closely monitored and regulated. Numerous discharges of water, collectively called miscellaneous streams, are also permitted but do not need to be monitored unless they exceed certain discharge rates and annual amounts (DOE 1998). These streams include hydrotesting, maintenance, construction, cooling water and steam condensate, sanitary wastes, and storm water control. Other possible sources of additional recharge water are roads, road shoulders, parking lots, power and fire lines, and all structures that do not have precipitation controls. These also fall under the miscellaneous streams permit.

Source events include accidental or intentional discharges of fluids, gases, and contaminants to the environment. Unintentional releases include spills, tank leaks, and distribution pipe leaks. The quantity, quality, duration, and phases of waste or fluid released are generally unknown. Other potential source events include remediation activities that involve the injection of liquid, chemicals, gases, and heat.

\subsubsection{Discharge/Exit Events}

Discharge or withdrawal events include all actions to remove fluids, gases, and contaminants from the environment. These events must be characterized for quantity, quality, duration, and phases of waste or fluid removed. These events include remediation activities such as groundwater pumping, vapor extraction, and heat removal (e.g., cryogenic barriers).

\subsubsection{Climate Events}

Abundant data indicate the Pacific Northwest is warming and that since the beginning of the $20^{\text {th }}$ century, average precipitation has increased $30-40 \%$ in eastern Washington. ${ }^{7}$ Scientists generally expect average temperatures in the Pacific Northwest to continue to rise, with temperatures increasing by approximately $1.5^{\circ} \mathrm{C}$ by 2030 and $3^{\circ} \mathrm{C}$ by 2050 . However, predictions regarding change in precipitation are very uncertain.

A change to a drier and/or warmer climate could result in a sparser plant community, a change in the mix of plant and animal species, increased wind erosion and deposition (e.g., re-activated sand dunes), and changes in natural recharge. The stress of this change could allow non-native plant and animal species to supplant native species.

\subsubsection{Volcanism}

Continental flood basalt volcanism and volcanism associated with the Cascade Range have repeatedly affected the Hanford Site during the past 16 million years. However, the recurrence of flood basalt volcanism that produced the Columbia River Basalt Group is not considered a credible volcanic event

\footnotetext{
${ }^{7}$ Scientific Consensus Statement on the Likely Impacts of Climate Change on the Pacific Northwest. Product of the Impacts of Climate Change on the Pacific Northwest scientific meeting, June 2004. Institute for Natural Resources, Oregon State University, Corvallis, Oregon. (http://inr.oregonstate.edu/reports_atmosphere, html)
} 
(DOE 1988). Volcanism associated with the Cascade Range does have the potential to deposit a few inches of ash on the Hanford Site. Such deposition could potentially reduce evaporation and plant activity for a few years that could increase the natural recharge rate. Probabilistic volcanic hazard studies have been completed by the U.S. Geological Survey (DOE 1988; Scott et al. 1995).

\subsubsection{Seismicity}

Earthquakes and other related events, such as fault rupture, landslides, or differential settlement could potentially affect the integrity of surface or subsurface structures, thus impacting recharge and vadose zone transport. Potential seismic sources determined to be major contributors to the seismic hazard in and around the Hanford Site include: fault sources related to the Yakima Folds, shallow basalt sources that account for observed seismicity not associated with the Yakima Folds, crystalline basement source region, and Cascadia Subduction Zone earthquakes (Reidel et al. 2006). Geomatrix (1996) completed a probabilistic seismic hazard analysis for the Hanford Site.

\subsubsection{Flooding Events}

Natural flooding of the Columbia River is predicted to affect low-lying areas along the river, but not the 200 Areas. Failure of the upriver dams has the potential to affect the entire Hanford Site. The probable maximum flood in the Cold Creek drainage basin could affect the southwestern portion of the 200 West Area (Skaggs and Walter 1981). Under this scenario, water from the flood would reach the Yakima River.

\subsubsection{Human Disturbance Events}

Human activities are capable of degrading surface covers over waste sites and exposing the waste to increased recharge and more direct contract with the biosphere.

\subsubsection{Processes}

The primary processes governing flow and transport through the vadose zone are complex and interrelated. These processes depend on the physical and chemical nature of the geologic materials that make up the vadose zone (described above) as well as the types, amounts, and compositions of the fluids that occupy the pore spaces (Looney and Falta 2000, p. 13). At a first order level, one can discuss these processes in terms of the mechanisms, rates, and routes by which contaminants move (or are moved) through the vadose zone to the water table (i.e., fluid flow, physical transport, and the capillary fringe) and the fate of the contaminants (i.e., physical and chemical interactions, decay and decomposition).

\subsubsection{Transport Mechanisms}

Gas, aqueous and non-aqueous phase liquids flow in response to phase pressure and gravitational forces. The phases interact with one another in such a way that the flow of each fluid is coupled with flow of the other fluids (Looney and Falta 2000). Chemicals move through the vadose zone by a variety of mechanisms, including advection with the bulk flow of the fluid phases, diffusion and dispersion within the fluid phases, and mass transfer between the phases. Many compounds interact physically or chemically with the solid phase matrix of the vadose zone. 
For the majority of contaminants, movement through the vadose zone is contingent on being dissolved within flowing water (i.e., aqueous phase drainage). The flow of water through the unsaturated soils depends on complex interactions between rate of water infiltration, moisture content of the soil, textural heterogeneity, and soil hydraulic properties. Infiltrating water provides the primary driving force for downward migration of contaminants. Perched water zones and lateral spreading may develop when vadose water accumulates on top of low-permeability soil lenses, highly cemented horizons, or along contrasting lithofacies boundaries (e.g., contacts between fine-grained horizons and underlying coarsegrained horizons). Unsaturated hydraulic conductivities may vary by several orders of magnitude depending on the water content of the soils.

Some contaminants (as well as water) are volatile and move in the gas phase. The bulk of this movement is diffusional, but convective flow can occur near the soil surface and near open boreholes in response to barometric changes. Remediation activities (e.g., vapor extraction, thermal treatment) can also affect local convective gas flow.

The geothermal gradient has a small but steady impact on the movement of water upward through the vadose zone. Enfield et al. (1973) used field measurements of temperature and matric (matrix) potential at a site about $1 \mathrm{~km}$ to the south of the 200 East Area to calculate an upward water flux of $0.04 \mathrm{~mm} /$ year.

\subsubsection{Transport Rates}

Fluids such as water move through the vadose zone at rates determined by the hydraulic, thermal, and vapor gradients and the relevant properties of the sediment. For many applications, common assumptions include a static air phase, isothermal conditions, and no density effects. With these assumptions, flow rates are calculated using Richards' equation with gravity and capillary potential gradients. When these assumptions are not appropriate (e.g., organic liquids, vapor flow, hot saline tank waste), more sophisticated equations are used to calculate rates.

The rate of diffuse recharge at a particular location is influenced by four main factors: climate, soil, vegetation, and topography. Other factors can significantly impact recharge by affecting one or more of the main factors. These other factors include soil development, animal activity, fire, water and wind erosion and deposition, plant community changes, surface flow from other areas, disturbance, and human structures (e.g., roads, buildings). The rate of recharge at each waste site will depend on the design of the surface cover. Plants and animals live within the upper 1 to $2 \mathrm{~m}$ of soil, and some plant roots can reach depths of $3 \mathrm{~m}$. Surface covers can be designed to protect against such intrusion by including biobarriers, which are layers that resist biotic intrusion. For thinner cover designs, the biobarrier may be closer to the surface and more susceptible to degradation. Intrusion of surface covers by plants and animals can create macropores that could become conduits for surface water to flow into the soil much deeper than expected. Inadvertent intrusion by humans can result in surface depressions that could become areas of focused recharge when surface runoff occurs.

Some of the liquids disposed or leaked to the vadose zone had properties that differed significantly from the properties of pure water, and their rates and routes of movement through the vadose zone may

differ as well. The specific gravity of waste leaked from single-shell tanks ranged from 1.1 to 1.65, which could enhance the transport of contaminants. Increased density has been demonstrated to elongate contaminant plumes vertically and reduce lateral spreading caused by stratigraphic variations in hydraulic 
properties (Ward et al. 1997). The properties of these fluids will change as contaminants are diluted, sorbed, or the fluid evaporates into the sediment air space.

Organic fluids were also disposed at Hanford. The movement of these fluids through the vadose zone and groundwater aquifer is complicated by multiphase flow of the organic non-aqueous phase liquid, the dissolved phase in water, and the vapor phase in the vadose zone air space. The movement of organic fluids can be enhanced if their density is much higher than the density of water. That is the case for the primary organic fluid contaminant at Hanford - the dense non-aqueous phase liquid, carbon tetrachloride. Between 1955 and 1973, roughly 577 to 922 metric tons of carbon tetrachloride was disposed to three subsurface infiltration facilities at the Hanford Site (Rohay et al. 1994). The current groundwater plume containing concentrations above $0.5 \mathrm{mg} / \mathrm{L}$ covers an area of about $11 \mathrm{~km}^{2}$ (Hartman et al. 2005). Soilvapor extraction and pump-and-treat technologies are being used to prevent further movement of the plume and reduce contaminant mass, and have been effective in reducing the area of highest concentrations. However, efficiencies of the vapor extraction activities have decreased, and carbon tetrachloride concentrations above the remedial action goal have been detected north of the Plutonium Finishing Plant, as well as deeper in the aquifer beneath the eastern portion of the 200 West Area. The behavior of carbon tetrachloride in the subsurface and in the vadose zone is poorly understood and requires additional characterization and assessment to determine the dominant processes governing its fate and transport.

The rate of gas movement in the vadose zone is affected by the magnitude of any temperature gradients. The vadose zone across the entire Hanford Site experiences temperature changes due to diurnal and seasonal temperature changes at the soil surface. The magnitude of the temperature changes diminishes with depth; at $10 \mathrm{~m}$, the seasonal change appears to be less than $1{ }^{\circ} \mathrm{C}$. Near-surface temperatures appear to have a minimal effect on recharge rates if the rates exceed $10 \mathrm{~mm} / \mathrm{year}$, but they could be important when rates are less. In addition to the near-surface temperature changes, a steady upward geothermal gradient exists that drives gas (and water vapor) upward. The elevated temperatures of the leaked waste from the single-shell tanks and previous operational discharges may have induced local movement of both liquids and vapor.

The formation of colloids and occurrence of colloid-facilitated transport of contaminants were identified by the Expert Panel as a potentially important processes affecting vadose zone transport (DOE 1997). At waste sites that received large-volume discharges or highly concentrated waste from leaking tanks, conditions may have existed for both colloid formation and colloid-facilitated transport. However, data are insufficient to adequately characterize the potential for colloidal transport. Zhuang et al. (2004) found that several interacting mechanisms might be involved simultaneously during colloid transport, but that their importance depends on the chemical and physical properties of the colloids and transport media as well as the environmental conditions. Current understanding of colloid-soil interactions and the ability to predict transport of colloids in natural subsurface media are limited. However, for most waste sites at Hanford, the low water contents and relatively simple geochemistry are not conducive to colloid formation or colloid-facilitated transport.

\subsubsection{Transport Pathways}

The predominant direction for contaminant movement in the vadose zone is downward, due to gravity. Variations in the hydraulic properties and the presence of impeding features such as bedding interfaces, caliche layers and disposal facilities can locally alter and redirect the movement laterally. 
Relatively simple stratigraphic layering can give rise to complex water content distributions and enhanced lateral spreading that impedes vertical migration of contaminants.

Various preferential pathways such as discordant clastic dikes and fractures are capable of concentrating or contributing to phenomena such as fingering and funnel flow. Preferential flow has been documented along poorly sealed well casings at the Hanford Site (Baker et al. 1988) and transport along clastic dikes may be potentially important (DOE 1997). Murray et al. (2003) suggest that clastic dikes might serve as a conduit for more rapid movement of mobile contaminants to the water table, but only under a restricted set of recharge (or leak) conditions. The relatively high content of reactive minerals, especially clay, within the dikes, suggests that movement of reactive contaminants may be restricted within the dikes, even if the dikes provide a fast path for downward movement of water.

Because of the nature of some waste, local routes of contaminant movement will vary. The Vadose Zone Expert Panel (DOE 1997) stated that the likely mode of transport for leaked or disposed tank waste in the Hanford geology is along preferential, vertical, and possibly tortuous pathways. They identified possible preferential flow caused by:

- Hot $\left(177^{\circ} \mathrm{C}\right)$ caustic tank waste leaking into the vadose zone, flashing to steam, fracturing the matrix, and enlarging pores

- Hot $\left(177^{\circ} \mathrm{C}\right)$ caustic tank waste leaking into the vadose zone with a self-healing nature, creating geothermal convection systems that could move contaminants upward with the hot alkaline slurry reacting with Hanford sediment

- Dissolution of siliceous sediment by the hot and alkaline tank waste, which may increase porosity in some places (by dissolution) and lower porosity in others (by precipitation)

\subsubsection{Contaminant Behavior}

The fate of contaminants in the vadose zone depends on geochemical conditions, the speciation of the contaminant, residence time, and microbial activity.

Sediment has the capacity to sorb most contaminants from solution. The amount of sorption is a function of many factors, including mineral surface area and type, contaminant type (speciation) and concentration, overall solution concentration, $\mathrm{pH}, \mathrm{Eh}$, and reaction rates for the controlling adsorption or precipitation, dissolution, and hydrolysis reactions.

Some contaminants do not sorb at all (i.e., soluble anions such as nitrate, chromate, and protectonate) and are moved along with the bulk solution. The movement of contaminants through the vadose zone is affected by their sorption in the far-field and sometimes by complex dissolution/precipitation reactions between waste liquids of extreme $\mathrm{pH}$ and the slightly alkaline sediment in the near field. Sorption delays downward movement of the contaminant and allows degradation processes to occur (e.g., radioactive decay) and, for some, irreversible incorporation into the sediment. Sorption can be described using a simple linear relationship (i.e., a distribution coefficient or $K_{d}$ ) that is determined empirically. Values of $K_{d}$ have been measured for a wide range of contaminants and waste types at the Hanford Site (Kincaid et al. 1998). The $K_{d}$ approach is applicable for conditions at Hanford where the contaminant concentrations are low and the chemistry is relatively constant. However, conditions near some waste sources 
are so variable due to the strong influence of the waste that the $K_{d}$ approach may not be applicable. This is the case for hot, highly concentrated tank wastes in contact with Hanford sediment. The general consensus is that the presence of this type of waste will likely decrease the sorption of contaminants (e.g., cesium-137). The net effect will be an increase in contaminant mobility until conditions in the sediment pore water (e.g., lower concentrations via waste dilution) become more appropriate for the $K_{d}$ approach. The complex reactions between the sediment and the highly acidic and (more importantly for Hanford) highly basic wastes are currently under study. Each specific Hanford assessment will have to determine if more complex chemical reaction processes should be considered to increase the accuracy of transport models for key contaminants.

Contaminants that exist in the gas phase (e.g., radon, carbon-14, carbon tetrachloride) are subject to atmospheric venting and remediation activities such as vapor extraction. Carbon-14 as carbon dioxide also reacts strongly with alkaline earth cations to form insoluble carbonates at neutral to basic $\mathrm{pH}$ values. Further it reacts with industrial cement, a common constituent of waste form containers and structures used in many solid waste burial grounds, to form carbonate precipitates (Krupka and Serne 1996; Serne et al. 1992).

Contaminants near the soil surface are subject to animal and plant uptake. Plants and animals live within the upper 1 to $2 \mathrm{~m}$ of soil, and some plant roots reach depths of $3 \mathrm{~m}$ or more. Waste present within this zone is subject to ecological uptake and dispersal above ground.

Contaminants that are consumed by microbes are subject to degradation into other compounds that may or may not be considered contaminants. This degradation process depends on the presence of a microbial population that is capable of degrading a given contaminant and on the availability of any additional nutrients that may be required for the microbes to be effective.

Sometimes the water is consumed, rather than the waste. Waste forms, such as the immobilized lowactivity waste, undergo a corrosion process that consumes water. In a dry disposal, this consumption process will create a water vapor gradient that draws vapor toward the waste form.

\subsection{Uncertainty and Unresolved Technical Issues}

Unresolved technical issues and sources of uncertainty affect the ability to predict the behavior of contaminants in the vadose zone. These include property representation, scale effects, spatial and temporal resolution of data, preferential flow, funneled flow, colloid transport, density effects, and thermal effects. Many of these issues are not specifically addressed in this data package but may be addressed in future revisions after resolution of key issues by the science and technology program.

Discussions of outstanding issues are generally focused on performance/risk assessment under future conditions and future releases. However, there are also site characterization and laboratory study needs related to interpreting observations from past tank leaks, spills, and nearby intentional discharges. Interpretation of site characterization data is important to estimate existing inventories for use as initial conditions, and also to demonstrate the validity of our understanding and the predictive ability of the models used for flow and transport of contaminants. Interpreting the mass and distribution of contaminants is difficult because much of the history and character of the leaks, spills, and water losses is difficult to characterize. The resulting uncertainties will hamper the ability of models to predict observed distributions of contaminants in the vadose zone, even if the distributions are well known. 


\subsubsection{Property Representation/Parameterization}

The physical, chemical, and hydraulic properties of the various solids, liquids, and gases in the subsurface are typically represented within numerical simulators using mathematical functions. The form of these functions, and their resulting suite of parameters, change with increased process knowledge and characterization information. Good examples are the water retention and hydraulic conductivity properties of the sediments. The parameters for these functions are determined by fitting them directly to data or by inferring them from physical properties. Many functions have been proposed to represent hydraulic properties. One of the most commonly used hydraulic models is the van Genuchten-Mualem model (Kosugi et al. 2002). A standard practice is to fit the van Genuchten retention model to retention data and the saturated conductivity value and use the resulting parameters with the Mualem conductivity model to predict unsaturated conductivity values. In this standard approach, the " $m$ " parameter is fixed equal to $1-1 / n$ and the pore interaction term is fixed at 0.5 . This approach has been shown to work for a number of soils, but it is not universally applicable and, for many soils, it becomes increasingly less applicable as the soil dries out (e.g., Stephens 1992; Khaleel et al. 1995). Predictions of dry-end conductivity can be improved by including one or more measured values of unsaturated conductivity in the fitting process and excluding the saturated conductivity value. Improvements can also be obtained by treating the ' $m$ ' parameter as independent and fitting both ' $m$ ' and the pore interaction term. The drawback to increasing the number of fitting parameters is the possibility of obtaining a non-unique set of parameter values during the fitting process. Some soils have unique structural features such as fractures and macropores that make them less amenable to characterization using a single function like the van Genuchten function. For such cases, Durner (1992) and others propose multiple functions, either linked or combined. The resulting fits to the data are better, but the number of parameters is so large that these techniques are not often used. To date, nearly all analyses at Hanford have used a single van Genuchten-Mualem function to represent hydraulic properties. Many analyses have used the standard approach of fitting to retention and saturated conductivity data, but a portion have included an unsaturated conductivity value in the fitting process (Khaleel et al. 1995). As more knowledge is gained and the original data evaluated more fully, the parameter values can be revised and uncertainty in the conductivity predictions can be reduced.

\subsubsection{Effects of Scale}

One of the greatest challenges facing Hanford assessments is adequately understanding the effects of spatial and temporal scale related to the processes, observations, modeling, and purpose of the assessment. Little is known about how vadose zone processes interact at various spatial and temporal scales, which processes are dominant, and how these interactions can be related to and interpreted from existing field and/or laboratory observations. It is also difficult to determine what must be measured and modeled to assess both risk, and the validity of the models to assess the risk, within useful uncertainty bounds.

In past assessments, the hydrogeologic units were generally assumed to be homogeneous and isotropic in character. In reality, these units display complex sedimentary structures at various scales. The effects of these complex structures are known to enhance lateral spreading and impede downward migration. However, the assignment of physical properties (e.g., effective permeability, porosity, moisture retention characteristics, anisotropy, dispersivity) to properly account for these effects in larger modeled units is still the subject of debate and uncertainty. The effects of small-scale structures on large scale flow and transport parameters needs to be assessed, in order to understand the degree of uncertainty, make appropriate choices for bounding calculations and determine the effects of simplification on assessment predictions. 
Scaling and volume averaging tools are needed that can help determine effective values of parameters from small scale (often disturbed) borehole samples in conjunction with soft information on the fine-scale structure of these sediments. Data are lacking for much of the vadose zone where subsurface contamination is present so scale-up and volume averaging will be required. The justification for upscaling and averaging methods will need to be evaluated either deterministically or by a probabilistic assessment that clearly reflects the uncertainties involved in the analysis.

\subsubsection{Spatial and Temporal Resolution of Site Data}

Our understanding of the nature and extent of various hydrogeologic units beneath a given waste site is primarily based on borehole samples. The resolution of these interpretations are generally about $1.5 \mathrm{~m}$ vertically and tens of meters or more horizontally, with the minimum discernable thickness of finegrained units at about $15 \mathrm{~cm}$. The internal structure of sedimentary units sampled during drilling is often disrupted or lost due to the drilling and sampling process. Vertical borehole data alone cannot provide the quality and quantity of data needed for accurate analysis of vadose zone transport, and much of our knowledge on the internal structure and heterogeneities of these units comes from extrapolation of qualitative examination of 'representative' outcrops. At the Hanford Site, only a few limited geostatistical studies have quantitatively described the internal structure and heterogeneities in outcrop and core samples. Thus, in many cases there is a lack of site specific data to support the development of detailed three dimensional geologic models for a given waste site.

\subsubsection{Preferential Flow}

Preferential flow (which may reduce the cross-sectional area of flow and bypass much of the unsaturated medium) has received increased emphasis recently. There has been some concern that preferential flow may be important for contaminant transport associated with tank-farm releases and/or other lowervolume discharges where mobile constituents remain in the vadose zone. It is important to differentiate between structurally controlled flow (e.g., funnel flow) and unstable flow. Structurally controlled flow occurs when the structure of the porous medium or the presence of a buried structure (e.g., tank) routes the water along a 'preferential path.' Unstable flow or wetting-front instability occurs during infiltration when an instability develops at the fluid-fluid interface (e.g., water-air, dense nonaqueous phase liquidwater). While there has been increased interest in preferential flow, Scanlon et al. (1997) suggest that piston-like flow (predominantly uniform flow through the unsaturated matrix) is the dominant flow mechanism at arid sites with unconsolidated sediments.

\subsubsection{Structure Controlled Flow}

Preferential flow is greatest when the preferred flow path consists of a series of connected large pore spaces. Because flux is proportional to the fourth power of the pore radius, large pores transmit very large quantities of fluid, but only when the pores are filled. Thus, water saturation determines the effectiveness of preferred pathways to conduct water: when water contents are at or near saturation, large pore pathways can conduct relatively higher quantities of water than the surrounding smaller pore materials. When water contents are low (dry vadose zone), preferred pathways with large pores do not conduct water because they cannot fill with water.

Whenever there are variations in sediment properties, the potential exists for water flow to be affected and perhaps funneled into preferential pathways. The capillary barrier effect is a good example. The 
arrangement of fine textured material over coarse-textured material delays the downward migration of water and allows it to be evaporated and transpired back into the atmosphere. The net effect is that deep drainage is reduced. Such textural breaks are used for surface covers, but they also occur naturally throughout the vadose zone. When such 'capillary breaks' are sloped, the water retained above the break can move laterally. This feature has been used to improve the performance of waste disposal facilities in the vadose zone (Frind et al. 1977). Scanlon et al. (1997) indicated that while funneled flow has not been found in arid settings, lateral flow in geologically layered materials may resemble funnel flow, where inclined beds and capillary barriers result in lateral flow.

Clastic dikes and unsealed boreholes may potentially act as preferential (macropore) flow paths for saturated flow by providing large connected pore spaces. These discordant features are of particular interest because they cut across the normally horizontally layered sedimentary sequences. The actual influence of clastic dikes on flow is somewhat uncertain: although some portions of clastic dikes have large connected pore spaces, other portions have fine-grained clay skins that may actually limit high rates of lateral flow (Murray et al. 2002). Wood et al. (1995, 1996) and Jacobs (1999) suggested that both clastic dikes and unsealed boreholes are insufficiently large and continuous to be significant to the overall contaminant mass transport through the vadose zone. A recent field study of clastic dikes suggested that dikes are not important preferential flow and transport pathways when the drainage flux was less than $100 \mathrm{~mm} /$ year (Murray et al. 2003). Thus, these potential pathways are not considered dominant enough to be incorporated into large scale assessments.

\subsubsection{Unstable Flow}

Unstable flow fingering may develop when a saturated fine-grained textured soil overlies a coarsegrained soil. Water accumulates in and over the fine-grained unit until the thickness of the perched water provides sufficient driving force to allow the water to 'drip' into the large pore spaces of the underlying coarse-grained sediment. This situation results in fingers with inner cores that are saturated surrounded by an unsaturated layer. However, fingers that are clearly caused only by the instability of a wetting front have been primarily observed in the laboratory. Experiments by Yao and Hendrix (1996) found that at low infiltration rates, wetting fronts stabilize and capillarity dominates over gravity; there is no mechanism to cause instability, and no fingers form. They also found an increase in the number, and decrease in the size, of fingers as the infiltration rate increased. Similar studies are needed to understand finger formation and its scale when the fluid properties differ from those of water at ambient temperatures (e.g., high density fluids, hot liquids). The unstable flow or fingering observed in laboratory experiments may be an artifact of the uniform, horizontal, and homogeneous layers (e.g., glass beads) used in the experiments, and the phenomena may not occur in natural layered geologic media. Scanlon et al. (1997) also suggest that unstable flow should be negligible in porous media in many arid regions because of the dominance of capillary and adsorptive forces over gravity forces in these areas.

\subsubsection{Temporal Effects}

In dry environments, deep vadose zone flow (i.e., recharge to the aquifer) can be dominated by the extreme transient events (e.g., snowmelt and run-on events) if they result in saturated or nearly saturated conditions in regions with fast preferential pathways. Proper assessment of deep recharge and effects related to enhanced transport down borehole annular space or any near surface preferential pathways and/or man-made structures must be addressed at a higher resolution both spatially and temporally. Interactions of spatial and temporal variations (particularly the extreme events) with sediment heterogeneity 
and interfaces (particularly sloping interfaces with breaks or holes) to change pathways and rates, needs more investigation. The interactions of geologic complexity with the spatial and temporal complexity of adjacent, interacting sources (e.g., water line leaks, fire hydrant flushing, adjacent cribs) have also not been adequately addressed.

\subsubsection{Funneled Flow Coupled with Colloid Transport}

The Tank Waste Remediation System (TWRS) Expert Panel (DOE 1997) hypothesized that structure controlled flow coupled with colloid transport was the most likely mechanism to move large quantities of contaminants that normally have limited mobility (such as cesium-137). This combination of processes needs more investigation. Research is currently underway to investigate the impact of colloids on contaminant transport in Hanford sediment (e.g., Zhuang et al. 2003, 2004; Cherrey et al. 2003).

\subsubsection{Temperature and Density Effects}

Other important issues raised by the TWRS Expert Panel include interaction between hot $\left(177^{\circ} \mathrm{C}\right)$ caustic waste from tank leaks and the geohydrologic system through time and the effects on fluid movement and contaminant transport processes. Many of the heat effects related to the high temperatures of the tanks, elevated temperatures surrounding the tanks, and self-heating nature of the leaked waste have yet to be investigated and resolved.

The high heat load of the single-shell tanks coupled with vapor transfer could potentially set up a system whereby soluble briny waste, leaked from the tank, could migrate toward the heat source (e.g., center of the bottom of the tank). Pruess et al. (2002) found that for temperatures in excess of the boiling point, the dominant mechanism for flow, heat transfer, and solute transport is a vapor-liquid counter flow 'heat pipe' process. The possibility of a heat pipe being created needs to be further investigated, as does the nature and scale of the effect. In addition, the possibility of high heat lowering infiltration rates needs to be investigated.

Density effects have been investigated to a limited degree (e.g., Ward et al. 1997). These studies did not fully investigate the interactions of density with temperature, unstable flow effects, structurally controlled preferential flow (e.g., clastic dikes), colloidal transport, and/or waste-soil chemical and physical effects to determine inter-relationships and importance among the processes.

\subsubsection{Geochemical Processes}

Geochemical processes in the vadose zone are not well quantified. Field studies are currently in progress on representative contaminated sites to improve the conceptual models for waste interactions, and on contaminant transport processes; directed laboratory research is underway to clarify details of the chemical processes. The goal of these studies is to evaluate the key short- and long-term processes controlling the key risk driving contaminants. Processes to be quantified include adsorption, mineral precipitation and dissolution, bio-mineralization, matrix diffusion, pore plugging, and colloid formation and transport.

Another activity in which geochemists contribute is through development of a credible reactive transport model. At the present time, large scale assessments will likely rely on the $K_{d}$ construct to 
describe all contaminant retardation reactions/processes. More sophisticated descriptions of contaminant/ sediment interactions may be required for some future assessments.

Field studies to characterize the near-field geochemical environments at representative inactive liquid waste disposal sites and past leaks at single-shell tanks focus on 'extreme-pH' chemical environments, including acidic process liquids and highly alkaline tank liquors. The latter were high temperature fluids, and both sometimes contained organic complexing agents. Our knowledge base is most sparse for the extreme-pH wastes that are far from chemical equilibrium with the sediments. Interactions of highly reactive solutions with sediments can be accompanied by significant mineral dissolution and precipitation. Such large changes in mass between phases can significantly change pore structure and hydraulics (permeability) of vadose zone sediments. Formation and sequestration of colloids may also be most active in this dynamic zone. This highly interactive near-field zone merits detailed study to improve current modeling approaches that rely on the simplistic $\mathrm{K}_{\mathrm{d}}$ construct. More detailed discussions of the planned field characterization and focused laboratory studies can be found in DOE $(1998,2000 \mathrm{a})$ and individual project work plans such the Office of River Protection's (ORP's) Phase I RCRA Facility Investigation/Corrective Measures Study Work Plan for Single-Shell Tank Waste Management Areas (DOE/RL 2000b) and the Immobilized Low-Activity Waste Multi-Year Statement of Work (LMHC 1999).

\subsection{Technical Basis and Approach for Vadose Zone Modeling}

Kincaid et al. (2004) describe the basis and technical approach for a large-scale Hanford assessment, to be conducted using SAC (Kincaid et al. 2000; Bryce et al. 2002; Eslinger et al. 2002 a, b). SAC consists of a set of modules (models and data) that allow the collective impact of all the waste that will remain at the Hanford Site to be estimated. These modules include: Inventory, Release, Air Transport, Vadose Zone Transport, Groundwater Transport, Soil, River, Riparian Zone, and Risk/Impact Modules. These modules have been organized to simulate the transport and fate of contaminants through the environment. In general, inventory feeds to release, which feeds to the atmospheric, vadose zone, groundwater, and Columbia River pathways. The atmosphere, groundwater, Columbia River and riparian zone modules provide media-specific concentration estimates used in the risk and impact assessment.

Kincaid et al. (2004) identified 1,052 waste sites from the 2,730 Waste Information Data System (WIDS) sites and several existing and future storage sites for inclusion in a large-scale Hanford assessment. ${ }^{8}$ They indicated that analysis of liquid discharge and unplanned release sites would be conducted on a site-by-site basis whenever inventory and release data permit, since the superposition of liquid discharge to a single soil column results in non-representative contaminant migration and release from the vadose zone. Solid waste burial grounds would be simulated at the burial ground scale; for example, individual burial trenches would be aggregated for a single burial ground. The inventory of solid waste disposal will be increased over time until all burial grounds are closed. Vadose zone flow and transport simulations for the assessment would be based on the following: 1) hydrogeologic profiles and properties for selected areas, 2) estimates of deep drainage rates that drive contaminant migration, 3) estimates of geochemical reactions between contaminants and the soil and sediment of the vadose zone profile, and

\footnotetext{
${ }^{8}$ Originally 974 of 2,730 Waste Information Data System (WIDS) sites were identified for inclusion in the large scale Hanford assessment. Further work identified 48 more waste sites bringing the total to 1,022. Subsequent reviews identified an additional 30 sites that have been included, many of which account for offsite transfers of waste and nuclear material. This brings the total to 1,052 .
} 
4) waste inventory and release projections. The first three of these data types are the focus of this data package. The fourth, waste inventory and release projections, is the subject of other data packages.

The behavior of contaminants in the vadose zone is complex and subject to many unresolved issues and levels of uncertainty. The options for numerically simulating this behavior can be equally as complex. Table 2.1 attempts to summarize some of the important features and processes that can be incorporated into the simulations, depending on the complexity of the model. On a large scale, and for the purposes of simulating the release of mobile contaminants from the vadose zone to the groundwater, the vadose zone can be simulated in a fairly simple manner to account for the most dominant features, events, and processes, as highlighted in Table 2.1.

Table 2.1. Options for a Large-Scale Hanford Assessment (after the Preliminary Concepts Document) ${ }^{(a)}$

\begin{tabular}{|c|c|c|c|c|}
\hline Model Type & $\begin{array}{l}\text { Dimensions and } \\
\text { Hydrogeology }\end{array}$ & Transport Processes & $\begin{array}{c}\text { Scale and Temporal } \\
\text { Factors }\end{array}$ & $\begin{array}{c}\text { Degradation and Decay } \\
\text { Processes }\end{array}$ \\
\hline Simple & $\begin{array}{ll}- & 1-\mathrm{D} \\
- & 4-6 \text { Horizontal Layers } \\
- & \text { Homogeneous, } \\
& \text { Isotropic }\end{array}$ & $\begin{array}{ll}- & \text { Aqueous Phase } \\
\text { Transport } \\
\text { - Linear Sorption } \\
\text { Isotherm }\left(K_{d}\right) \\
\end{array}$ & $\begin{array}{l}\text { - Step-Wise Steady } \\
\text { State } \\
\text { One Site per Area per } \\
\text { Waste Type }\end{array}$ & $\begin{array}{l}\text { Radioactive Decay } \\
\text { Biological Pseudo- } \\
\text { Decay }\end{array}$ \\
\hline Semi-Complex & $\begin{array}{ll}\bullet & \text { 2-D } \\
\text { - } & \text { Up to } 10 \text { Sloping } \\
& \text { Layers } \\
- & \text { Homogeneous, } \\
& \text { Isotropic }\end{array}$ & $\begin{array}{ll}\bullet & \text { Density and } \\
& \text { Temperature Effects } \\
\bullet & \text { Linear Sorption } \\
& \left.\text { Isotherms ( } K_{d} \text { values }\right) \\
- & \text { Peak Arrivals }\end{array}$ & $\begin{array}{l}\bullet \quad \text { Long Term Climate } \\
\text { Changes } \\
\text { - Sites on Finer Grid }\end{array}$ & $\begin{array}{ll}- & \text { Radioactive Decay } \\
\text { - } & \text { Biological Decay }\end{array}$ \\
\hline Complex & $\begin{array}{ll}- & 2 \text { and 3-D } \\
\text { - } & \text { Numerous Complexly } \\
\text { - } & \text { Formed Layers } \\
& \text { Heterogeneous and } \\
\text { - } & \text { Prisotropic } \\
\text { - } & \text { Chemically Enhanced } \\
& \text { Permeability }\end{array}$ & $\begin{array}{ll}\text { - } & \text { Multiphase Transport } \\
\text { - } & \text { Colloidal Transport } \\
\text { - } & \text { Barometric Effects } \\
\text { - } & \text { Reactive Transport } \\
& \text { Wind and Water } \\
& \text { Erosion }\end{array}$ & $\begin{array}{ll}\bullet & \text { Episodic, Seasonal } \\
\text { Variations } \\
\text { - } \\
\text { Cong Term Climate } \\
\text { - Scale on Site-Specific } \\
\text { Basis } \\
\text { Near and Long Term }\end{array}$ & $\begin{array}{ll}\bullet & \text { Radioactive Decay } \\
\text { Biological Decay } \\
\text { Inorganic Decay } \\
\text { (Oxidative/ } \\
\text { Reductive) }\end{array}$ \\
\hline \multicolumn{5}{|c|}{$\begin{array}{l}\text { Groundwater/Vadose Zone Integration Project Preliminary System Assessment Capability Concepts for Architecture, } \\
\text { Platform, and Data Management. September 30, 1999. http://www.hanford.gov/cp/gpp/modeling/sacarchive/9-30rpt.pdf } \\
\text { Shaded area identifies the model type options selected for a large-scale Hanford Assessment. }\end{array}$} \\
\hline
\end{tabular}

\subsubsection{Features}

The physical architecture (e.g., geology, hydrologic properties, geochemical properties) of the vadose zone and its principal transport pathways varies by location. Because the geometry and configuration of hydrostratigraphic facies and heterogeneities are not well defined, the effects of these features will be captured via sensitivity or uncertainty analyses, within the context of larger hydrostratigraphic units. The omission of small-scale stratifications and variations in texture will likely lead to an underestimation of lateral spreading.

The limited quantity of site-specific data requires that values for the hydraulic properties be estimated from existing hydraulic property values provided by Freeman et al. (2002) and Freeman and Last (2003). 
For a large-scale assessments, the relations between moisture content, pressure head, and unsaturated hydraulic conductivity are assumed to be nonhysteretic and representable using the van Genuchten (1980) and Mualem (1976) functions.

Predictions of unsaturated conductivity can be markedly improved by simultaneously fitting van Genuchten parameters to retention and unsaturated conductivity data (Kosugi et al. 2002). A subset of the Hanford samples were analyzed for unsaturated hydraulic conductivity. Because unsaturated conductivity data were unavailable for a majority of samples, the parameter database contains only those parameters determined from retention data, to provide an internally consistent set of parameters. Setting up the database in this manner allowed the generation of statistical distributions that support a Monte Carlo approach for assessments. For future assessments, methods are being developed to incorporate and benefit from actual unsaturated conductivity data. Just as important, methods will also be developed to scale lab-derived parameters to field-scale as well as methods to use field-derived parameters.

Again, with very limited site-specific geochemical data, values for the geochemical properties (i.e., $K_{d}$ values) must be estimated from the sediment type (e.g., textural data and the presence of secondary mineralization) and waste type, based on data from existing laboratory measurements (Cantrell et al. 2003a). For most circumstances, the linear sorption model approach is adequate for modeling transport, especially for the far-field and low impact sites, where geochemical conditions remain fairly constant and contaminant loading is low (Cantrell et al. 2003b). However, where large changes in chemical conditions occur within a small spatial zone (e.g., where highly concentrated, alkaline or acidic wastes have been discharged), a more sophisticated approach to surface adsorption modeling may be warranted. A simplified way to account for changes in mobility is to use a multitude of different $K_{d}$ values to represent the sorptive capacity of the soil as waste becomes more diluted or buffered by meteoric recharge and waste-sediment interactions (Kincaid et al. 1998 and Bryce et al. 2002).

\subsubsection{Events}

Events that could be considered in the implementation model for a large-scale Hanford assessment include those that are: naturally occurring (e.g., meteoric recharge), manmade (intentional or unintentional contaminant and water releases), long-term normally occurring, and those that represent extreme or unusual occurrences (e.g., 500 year storms, volcanism). Of primary importance to the composite analysis are the source release events that discharged large volumes of waste water to the vadose zone, and the deep drainage (recharge) of meteoric water. Climate change and disruptive events such as volcanism, earthquakes, flooding, or human disturbance are currently outside the scope of largescale Hanford assessments (Kincaid et al. 2004).

\subsubsection{Processes}

For the majority of contaminants, movement through the vadose zone is contingent on dissolution in flowing water. The primary long term source of flowing water is precipitation that has infiltrated below the zone of evaporation and below the influence of plant roots. Such water eventually flows to the water table, carrying dissolved species. Other transport mechanisms, including gaseous transport, temperature gradients, and colloidal transport, are not considered significant to large-scale Hanford assessments.

The rate of recharge (deep drainage) at a particular location is influenced by climate, soil, vegetation, topography, springs and streams, animal activity, fire, water and wind erosion and deposition, plant 
community changes, disturbance, and human structures (e.g., roads, buildings). For most applications, flow rates through the vadose zone can be calculated using Richards' equation with gravity and capillary potential gradients providing the dominant forces.

Zhuang et al. (2004) found that Hanford data are insufficient to adequately characterize the potential for colloidal transport. Although the formation of colloids and occurrence of colloid-facilitated transport of contaminants may be a potentially important process for the vadose zone (DOE 1997), the low water content and relatively simple geochemistry at most Hanford waste sites are not considered conducive to colloid formation or colloid-facilitated transport.

Preferential pathways such as clastic dikes and fractures are capable of concentrating or contributing to phenomena such as fingering and funnel flow. Local routes of contaminant movement will vary by waste type. The Vadose Zone Expert Panel (DOE 1997) concluded that a likely mode of transport for leaked or disposed tank waste in the Hanford geology is along preferential, vertical, and possibly tortuous pathways. However, detailed analyses of tank farm plumes and vadose zone transport field studies suggest that these mechanisms are not significant contributors to groundwater contamination under normal recharge environments (i.e., fluxes $<100 \mathrm{~mm} /$ year) (Knepp 2002; CH2M HILL Hanford Group 2002; Murray et al. 2003). Scanlon et al. (1997) suggest that the dominant flow mechanism in unsaturated unconsolidated fluvial sediments at arid sites is predominantly 'piston-like' flow.

The fate of contaminants in the vadose zone depends on geochemical conditions, the speciation of the contaminant, residence time, and microbial activity. Sediment has the capacity to sorb most contaminants from solution. The amount of sorption is a function of many factors, and some contaminants do not sorb at all. Sorption can be described using a simple linear relationship (i.e., a distribution coefficient or $K_{d}$ ) that is determined empirically. The $K_{d}$ approach is applicable for most analyses at Hanford where contaminant concentrations are low and the chemistry is relatively constant. In environments where wastes are highly concentrated, contaminant mobility may be strongly influenced by the chemical components of the wastes, resulting in decreased sorption of normally sorbed contaminants (e.g., cesium-137). However, as the wastes migrate through the subsurface, contaminant concentrations in the sediments decrease until they eventually reach the range appropriate for the $K_{d}$ approach.

Contaminants that can, under certain conditions, exist in the gas phase (e.g., radon, carbon-14, carbon tetrachloride, iodine-129) are subject to atmospheric venting and vapor extraction. Carbon-14 as carbon dioxide also reacts strongly with alkaline earth cations to form insoluble carbonates at neutral to basic $\mathrm{pH}$ values, and can also react with industrial cement (Krupka and Serne 1996; Serne et al. 1992). Contaminants near the soil surface are subject to animal and plant uptake and dispersal within the aboveground environment. Contaminants can also be consumed by microbes, degrading into other compounds that may or may not be considered contaminants. In some cases water, rather than waste, is consumed. For example, immobilized low-activity waste undergoes a corrosion process that consumes water and will create a water vapor gradient that draws vapor toward the waste form.

\subsection{Implementation}

The scale and complexity of an assessment that can cover the entire Hanford Site together with the existing limitations on characterization data and fate and transport processes, necessitates simplification of the site features, events, and processes to permit timely results. Thus, the simplified model approach shown in Table 2.1 was selected for large-scale Hanford assessments. 
Implementation of this modeling approach is schematically illustrated in Figure 2.5. The primary transport mechanism to be simulated is aqueous phase transport represented by 'piston-like' flow through porous media of the vadose zone, with radiological decay simulated using first order decay models.

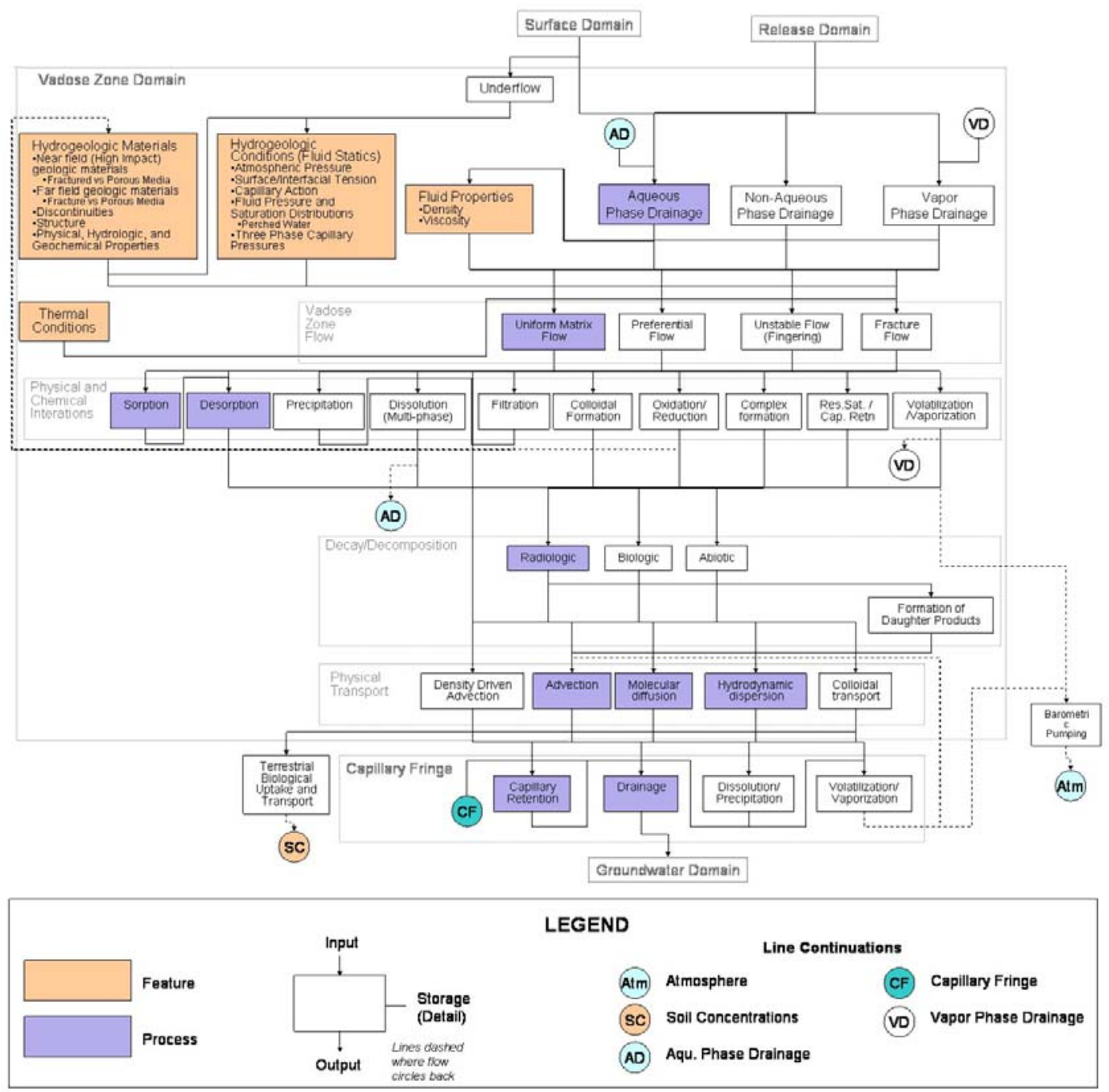

Figure 2.5. Schematic of Vadose Zone Implementation Model for Large-Scale Hanford Assessments

\subsubsection{Hydrogeologic Profiles}

Large-scale Hanford assessments will, in general, use a one-dimensional vadose zone model, with some subordinate analyses to explore the use of multidimensional models that explicitly account for structural features within the Hanford Site, and/or to condition the one-dimensional model results (Kincaid et al. 2004). To account for large scale variability in the hydrostratigraphy across the Hanford Site, the preparation of hydrogeologic profiles and hydraulic and transport property datasets for each site have been grouped into a number of geographic areas assumed to have similar hydrogeologic structure and properties. Hydrogeologic units are identified and their thickness ranges specified for each of these hydrogeologic provinces. To account for finer scale variability and uncertainty in the model parameters, probability distribution functions for the parameters were developed by hydrogeologic unit. 
Kincaid et al. (2000) selected the Subsurface Transport Over Multiple Phases (STOMP) computer code (White and Oostrom 2000) as the code of choice for the Vadose Zone Flow and Transport Module for SAC. Properties to be represented in the model include unsaturated hydraulic conductivity, porosity, water retention parameters, dispersivity, and diffusion coefficient. Data to support the vadose zone profile and property models have been assembled by geographic area. Kincaid et al. (2004) also indicated that care should be taken to develop and apply correlated model parameters (where such correlations have been derived), to appropriately model properties (for example, parameters of the van Genuchten and Mualem models - van Genuchten 1980) of unsaturated hydraulics and water retention. Although Carsel and Parrish (1988) have reported cross-correlations between a number of these parameters, recent examination of the Hanford Site data have not found any statistically significant correlations. ${ }^{9}$

\subsubsection{Deep Drainage Rates}

Deep drainage (recharge) rates are critical to Hanford assessments, as they affect both the release of waste from the disposal zone and the transport of waste to the water table. Deep drainage rates are a function of the climate, soil, topography, and vegetation. Kincaid et al. (2004) indicated that estimates of deep drainage for a large-scale Hanford assessment will be based on the assumption of a continuation of current climate as defined by Hanford Site weather records (Hoitink et al. 2005). Hanford weather data have been collected regularly since 1946 at the Hanford Meteorological Station (HMS), located between the 200 East and 200 West Areas.

For a large-scale Hanford assessment, a set of deep drainage rates have been assigned for four specific intervals of time. The first interval, the pre-Hanford period, is the natural environment that existed prior to the start of Hanford activities. The undisturbed soil profiles and the shrub-steppe plant community determine the rates during this interval.

The second interval is the operations period, during which much of the land surface at waste sites was disturbed (e.g., trenches excavated; cribs constructed; waste disposed and buried) and maintained free of vegetation. In most cases it has been assumed that at the beginning of the operations period, as the waste sites were being constructed, that the existing topsoil at a given site was excavated and stockpiled separately from the underlying sediments. Following construction of the waste site, the stockpiled topsoil was then used as the final surface materials. Thus, the soil type during the operations period is the same as that used for pre-Hanford conditions, except that is has been disturbed (no longer retains the structured soil profile) and is maintained free of vegetation.

The third time interval for simulation is the remediation period, during which sites will be covered with a protective surface barrier, remediated by retrieval and/or treatment, or left intact. For sites receiving a surface barrier, the remediation period begins with construction of the barrier and lasts throughout the period of institutional control and through out the design life of the barrier. For sites being remediated by retrieval, the remediation period follows removal of the contamination (and inventory) to a prescribed depth, its placement in the Environmental Remediation Disposal Facility, and placement of backfill over the excavated waste site. For sites being treated in place, the remediation period follows treatment of the contaminants so that they are altered or destroyed and the site restored. For both retrieval and treatment activities, the remediation period includes a period of institutional control during which a

\footnotetext{
${ }^{9}$ Freeman EJ and ML Rockhold. 2003. Estimation of Site-Specific Probability Distribution Functions for Soil Hydraulic Parameters using Bayesian Updating. Letter Report, Pacific Northwest National Laboratory, Richland, Washington.
} 
shrub-steppe plant community is re-established. In both cases, the vadose zone simulations will continue to predict the migration and fate of residual contamination in the vadose zone below the cleanup depth.

The fourth and final interval is the post-Hanford period. This time period represents the longest time interval simulated, and during which long-term changes can occur. This time period begins after the Hanford Site is no longer under active institutional control and the design life of the site's surface barrier has been exceeded. During the post-Hanford period, over an interval of time equivalent to the design life of the barrier, the deep drainage rate is changed in stages until it reaches the rate associated with an equivalent natural soil and native shrub-steppe plant community.

\subsubsection{Geochemical Reactions}

Kincaid et al. (2004) indicated that for large-scale Hanford assessments, interaction of contaminants with vadose zone sediment will be approximated using the linear sorption isotherm model. The mobility of contamination is highly dependent on its speciation and surrounding environment. It is assumed that upon introduction to the vadose zone environment, waste mobility is dominated by waste characteristics. After being in contact with vadose zone sediment and soil water for some distance, it is assumed that the waste undergoes a change in its mobility based on reaction buffering lag of the contaminant solution with the vadose zone hydrogeologic units. Finally, it is assumed once contaminants have migrated a short distance in the Hanford Site unconfined aquifer, another mobility state would be defined by the highly buffered, neutralized, and diluted contaminant. Distribution coefficients have been defined for each contaminant in several zones; for example, upper (near field) vadose zone, lower (far field) vadose zone, and unconfined aquifer. Where indicated, $K_{d}$ dependency on waste chemistry and hydrogeologic units have been included. Available empirical $\mathrm{K}_{d}$ data have been assembled to generate probability distribution functions for a suite of waste chemistry types. These broad ranges in $K_{d}$ for a given waste chemistry are used to represent the variability in waste speciation and surrounding environmental conditions.

\subsubsection{Interaction with the Inventory, Release, and Groundwater Modules}

The inventory and release modules of SAC provide input to the vadose zone module. In addition to curie or kilogram amounts of waste and waste volume, the inventory module provides data on the location and dimensions of each storage or disposal facility. The release module, in concert with the inventory module, provides the contaminant flux to the vadose zone. Large-volume contaminant releases to sites where the vadose zone is thin, such as the cooling water discharges to retention basins in the 100 Areas, are routed directly to the Columbia River, bypassing the vadose zone.

For areas with a thicker vadose zone, the vadose zone module provides estimates of the mass flux of contaminant entering the unconfined aquifer as a function of time. The estimates address releases from all operational areas for the radionuclide and chemical contaminants selected for the large-scale assessment. Released flux to the aquifer is provided for individual waste sites (for example, liquid discharge sites), and/or aggregations of waste sites where applicable (for example, the combination of trenches that comprise solid waste burial grounds). The vadose zone releases to the aquifer are aggregated to groundwater model nodes in order to introduce contaminants into the aquifer model. The vadose zone module provides estimates of mass flux of contaminants from the vadose zone to groundwater for the period of analysis. 


\subsection{Data Compilation}

Kincaid et al. (2004) selected a simplified model approach for simulating vadose zone flow and transport for a large-scale Hanford assessment (see Table 2.1). In this approach, flow and transport are treated as either one-dimensional processes or as a one-dimensional approximation of two-dimensional processes. Vadose zone simulations will use the STOMP computer code (White and Oostrom 2000). Input parameters include (1) hydrostratigraphy; (2) physical and hydraulic properties (e.g., unsaturated hydraulic conductivity, porosity, water retention parameters, dispersivity, diffusion coefficients); (3) contaminant distribution coefficients; and (4) estimates of deep drainage rates. These parameters have been derived from existing geologic, soil physics, and geochemical databases. To facilitate sensitivity and uncertainty analyses, probability distribution functions were developed for each of the primary transport parameters.

\subsection{Hydrostratigraphy}

The vadose zone stratigraphic profiles and hydrogeochemical property distributions for large-scale Hanford assessments are represented by 30 generalized one-dimensional vertical columns. These 30 stratigraphic profiles represent 17 general geographic areas and 13 site-specific locations. Each hydrostratigraphic profile (template) was configured with the hydraulic and geochemical parameters necessary for STOMP to simulate the flow and transport through the vadose zone. As many as five variations of a single hydrostratigraphic template were necessary to more accurately represent the depth of waste releases and thickness of the vadose zone beneath the point of injection. Additional variations of the hydrostratigraphic templates accommodate variations in $K_{d}$ values associated with different waste chemistry designations. Two additional template designations were added to facilitate special handling of those sites that discharged waste effluents directly to the river or those that represent pumping wells. Thus, a series of 72 templates were ultimately identified for application in the 17 geographic areas shown in Figure 3.1. These templates consist of the one-dimensional stratigraphy, hydrologic properties, and geochemical properties as well as the waste site type (e.g., crib, tank, etc.) and waste chemistry designation. A more complete discussion regarding the development of the templates is provided in Section 3.2 and in Last et al. 2006.

The preferred approach for modeling contaminant transport through the vadose zone uses these templates to represent the vadose zone beneath each waste site within a given geographic area. The actual simulation of each waste site assigned to a given template is implemented at that site's centroid coordinates.

Each template consists of three to eight major hydrostratigraphic units that are assumed to be horizontally layered with constant thicknesses, homogeneous, and isotropic (Figure 3.2). Hydrologic and geochemical parameters for each hydrostratigraphic unit are represented by stochastic distributions to facilitate sensitivity and uncertainty analyses. Once each site was assigned to a geographic area and representative stratigraphic template, site-specific parameters such as the site location (centroid), and recharge rates (based on surface cover changes) were added. Each site was then assigned a unique alphanumeric identifier (refer to Last et al. 2006). 


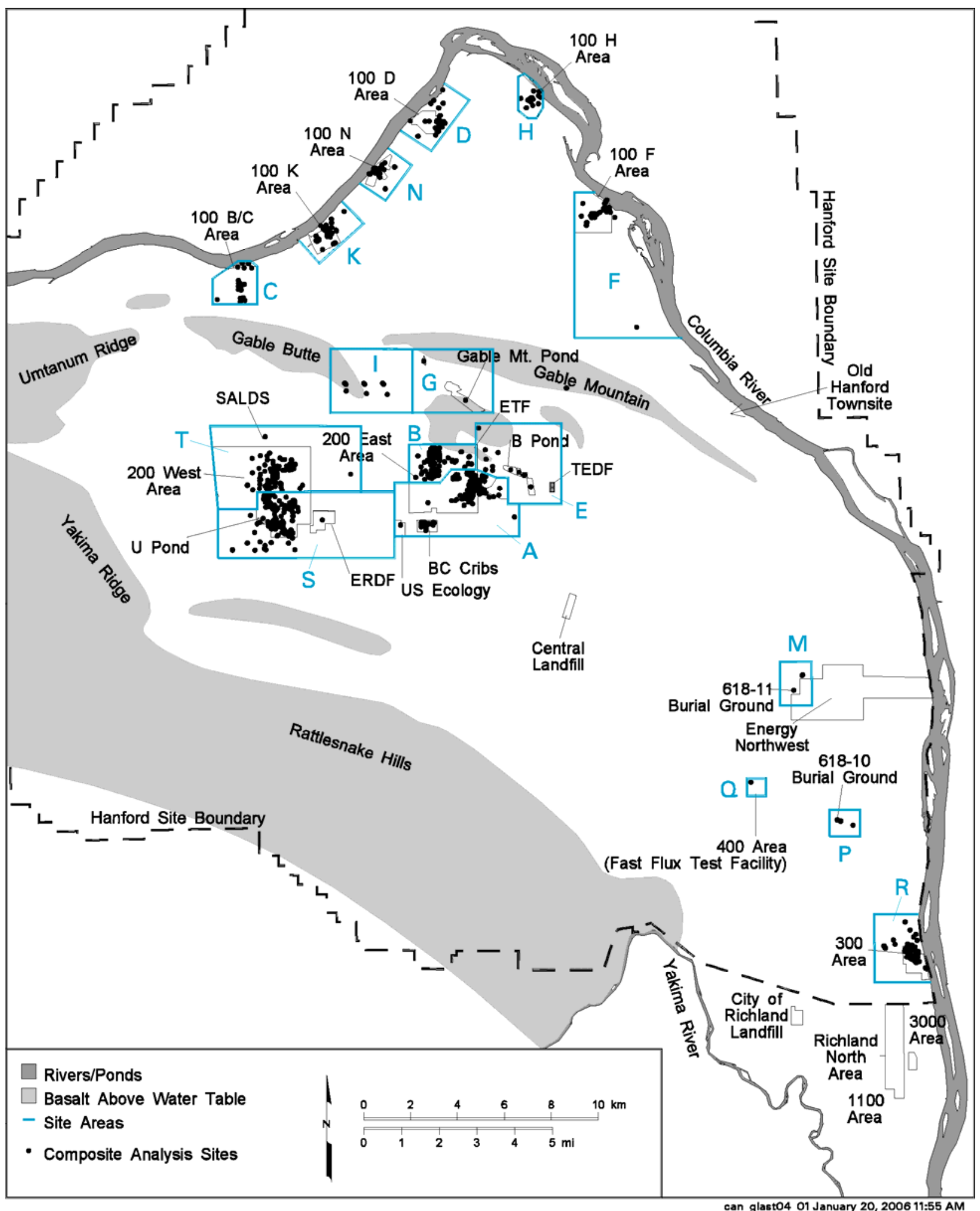

Figure 3.1. Location of Geographic Areas Represented by Similar Hydrostratigraphic Columns 


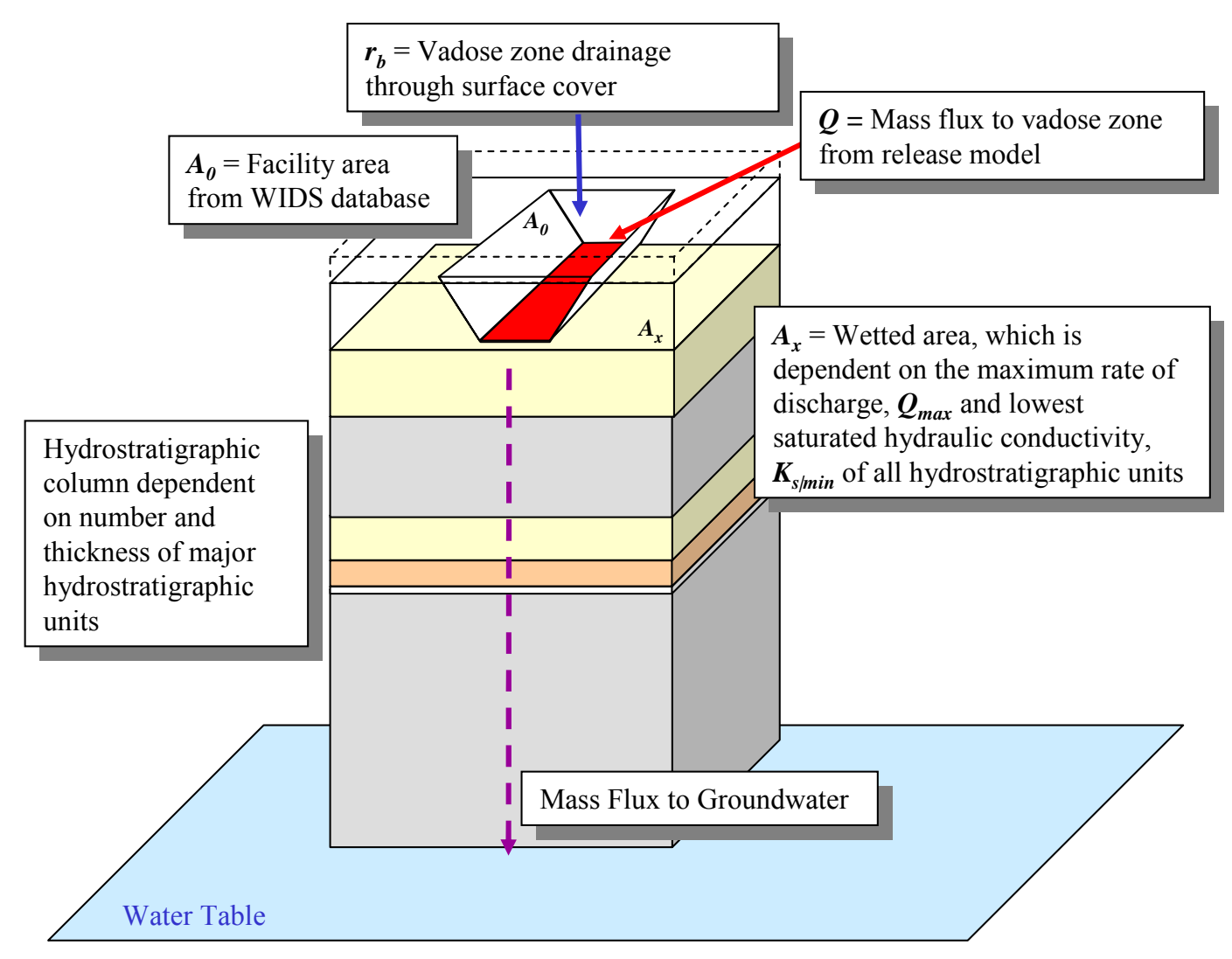

Figure 3.2. Schematic of One-Dimensional Vadose Zone Simulation

\subsection{Hydrostratigraphic Templates}

Seventy-two hydrostratigraphic templates were defined on the basis of (1) the types of waste sites, (2) the general hydrostratigraphy for 17 selected geographic areas (Figure 3.1), and (3) the chemical characteristics of the waste streams. To accommodate the large number of hydrostratigraphic templates, an alphanumeric code was developed to identify each unique hydrostratigraphic template. This code generally consists of a three-digit number that reflects the waste site type, a letter designating the geographic area, and a number designating the waste chemistry group for assigning $K_{d}$ values. Thirteen site-specific hydrostratigraphic templates were created by adding additional alphanumeric characters to the geographic area designation.

\subsubsection{Waste Site Type (reflecting the depth of waste injection)}

Nearly all waste sites selected for simulation in a large-scale Hanford assessment have a Waste Information Data System (WIDS) site code. This code generally includes a three-digit number, with the first digit identifying the operational area where the facility is located, and the second and third digits identifying the type of facility. For example, the site code 116 indicates that the facility is in the 100 Area and that it is a liquid disposal facility (i.e., crib, pond, ditch); the site code 241 indicates that it is in the 200 Area and that it is an underground high-level waste tank. For the purposes of defining the base templates, six main categories of waste sites were distinguished: (1) surface facilities such as ponds, ditches, retention basins, buildings, unplanned releases; (2) near surface facilities such as cribs, specific retention trenches, French drains, burial grounds; (3) underground storage tanks; (4) reverse (injection) 
wells; (5) very deep reverse (injection) wells, and (6) river outfalls. Each of these site types (except the river outfalls) release waste to the vadose zone at increasingly deeper depths, making the hydrostratigraphic column shorter, and moving the location of high impact versus intermediate impact $\mathrm{K}_{\mathrm{d}}$ zones deeper in the soil profile. The waste site designation scheme for implementation in the base template nomenclature is shown in Table 3.1.

Table 3.1. Waste Site Type Designations Used in the Hydrostratigraphic Template Codes

\begin{tabular}{|c|c|c|}
\hline $\begin{array}{l}\text { Site Type } \\
\text { Code }^{(a)}\end{array}$ & $\begin{array}{l}\text { Relative Depth of } \\
\text { Waste Release }\end{array}$ & Representative WIDS Site Types \\
\hline $\begin{array}{l}100,200,300 \\
400\end{array}$ & $\begin{array}{l}\text { Ground Surface (generally } \\
\text { less that } 3 \mathrm{~m} \text { deep). }\end{array}$ & $\begin{array}{l}\text { Surface and/or near surface facilities (e.g., process sewers, } \\
\text { reactor buildings, }{ }^{(b)} \text { laboratory buildings, storage, stacks, ponds, } \\
\text { ditches, valve pits, process unit/plants, }{ }^{(b)} \text { unplanned releases } \\
\text { except tank leaks). }\end{array}$ \\
\hline $\begin{array}{l}116,216,316 \\
616\end{array}$ & $\begin{array}{l}\text { Shallow Subsurface } \\
\text { (generally } 3-15 \mathrm{~m} \text { below } \\
\text { ground surface) }\end{array}$ & $\begin{array}{l}\text { Shallow liquid and/or dry waste disposal facilities (e.g., cribs, } \\
\text { burial grounds, retention basins, trenches, French drains, storage } \\
\text { tunnels, drain/tile fields, pipelines, sewers). }\end{array}$ \\
\hline 241 & $\begin{array}{l}\text { Intermediate Subsurface } \\
\text { (generally } 9 \text { to } 17 \mathrm{~m} \text { below } \\
\text { ground surface) }\end{array}$ & $\begin{array}{l}\text { High level waste tanks, settling tanks, diversion boxes, catch } \\
\text { tanks, tank leak unplanned releases. }\end{array}$ \\
\hline 166,266 & $\begin{array}{l}\text { Deep Subsurface (generally } \\
\text { greater than } 18 \mathrm{~m} \text { below } \\
\text { ground surface) }\end{array}$ & Deep injection sites (e.g., reverse [injection] wells) \\
\hline 276 & $\begin{array}{l}\text { Very Deep Subsurface } \\
\text { (generally near or into the } \\
\text { water table) }\end{array}$ & $\begin{array}{l}\text { Very deep injection sites (e.g., very deep reverse [injection] } \\
\text { wells) }\end{array}$ \\
\hline River $^{(\mathrm{c})}$ & River Level & River outfalls and associated pipelines \\
\hline Pump $^{(\mathrm{d})}$ & Not Applicable & Water supply wells \\
\hline \multicolumn{3}{|c|}{$\begin{array}{l}\text { (a) First digit represents the area: } 1=100 \text { Area, } 2=200 \text { Area, } 3=300 \text { Area, } 4=400 \text { Area, } 6=600 \text { Area. } \\
\text { Second and third digits indicate the general facility type and relative release depth. } \\
\text { (b) Some reactors and process unit/plants (such as canyon buildings) have basements and/or fairly deep } \\
\text { foundations, however for the ease of simulation, all above ground structures are treated the same. } \\
\text { (c) River outfall discharged waste directly to the river, thus there is no vadose zone flow and transport } \\
\text { component for these sites. } \\
\text { (d) Water supply wells withdraw water from the aquifer, thus there is no waste released, and no vadose zone } \\
\text { flow and transport component for these sites. } \\
\text { WIDS = Waste Information Data System. }\end{array}$} \\
\hline
\end{tabular}

\subsubsection{Geographic and Site-Specific Areas Designations}

Seventeen geographic areas (Figure 3.1) were identified that could each be represented by a single generalized hydrostratigraphic column. Each of the six 100 Areas were designated as separate geographic areas because each area is geographically distinct and has distinct hydrogeologic characteristics. The 200 Areas were divided into six geographic areas based on differences in hydrogeologic characteristics. The 200 West and 200 East Areas were each divided into two geographic areas. Additional geographic areas were designated for the 200 North, Gable Mountain Pond, and the B Pond areas. A single geographic area was designated to encompass waste sites in the 300 Area. Finally, three additional geographic areas were defined for isolated sites in the 400 and 600 Areas. Table 3.2 presents the letter 
designations and brief descriptions of each geographic area. Thirteen site-specific designations were created by adding additional alphanumeric characters to two of the geographic area designations (Table 3.3).

Table 3.2. Geographic Area Designations Used in the Hydrostratigraphic Template Codes

\begin{tabular}{||c|l||}
\hline \hline Designation & \multicolumn{1}{|c||}{ Geographic Area Description } \\
\hline \hline A & $\begin{array}{l}\text { Southern 200 East Area - encompassing the PUREX (A plant), hot semi-works (C-Plant), } \\
\text { associated facilities (including PUREX tunnels), BC cribs, US Ecology, and the A, AN, AP, AW, } \\
\text { AX, AY, AZ, C Tank Farms }\end{array}$ \\
\hline B & $\begin{array}{l}\text { Northwestern 200 East Area - encompassing the B-plant, associated waste disposal facilities, and } \\
\text { the B, BX, BY Tank Farms }\end{array}$ \\
\hline C & 100-B/C Area \\
\hline D & $100-$ D/DR Area \\
\hline E & East of 200 East - B Pond \\
\hline F & $100-$ F Area \\
\hline G & Gable Mountain Pond Areas \\
\hline H & $100-$ H Area \\
\hline I & 200 North \\
\hline K & $100-$ KE/KW Area \\
\hline M & 600 Area near Energy Northwest and the 618-11 burial ground \\
\hline N & $100-N$ Area \\
\hline P & 600 Area southwest of the 400 area near the 618-10 burial ground \\
\hline Q & 400 Area \\
\hline R & 300 Area (and a few isolated facilities in and near the 400 Area) \\
\hline S & $\begin{array}{l}\text { Southern 200 West Area - encompassing the REDOX (S-Plant), U-plant, Z-plant associated } \\
\text { facilities, ERDF, and the S, SX, SY, U Tank Farms }\end{array}$ \\
\hline T & $\begin{array}{l}\text { Northern 200 West Area - encompassing T Plant , associated facilities, and the T, TX, TY Tank } \\
\text { Farms }\end{array}$ \\
\hline
\end{tabular}

\subsubsection{Waste Chemistry Groupings (for assigning $K_{d}$ ranges)}

Six waste chemistry types were defined by Kincaid et al. (1998) for use in the Composite Analysis. These waste chemistry types describe chemically distinct waste streams that impact the sorption of contaminants. These same waste chemistry designations were adapted for use in the initial assessment conducted using SAC to assign $K_{d}$ values to the vadose zone base templates (Bryce et al. 2002). However, based on waste stream chemistry and potential impact on the fate and transport of contaminants of concern, the original six waste stream categories used in these assessments were reduced to four. ${ }^{10}$ Two additional waste stream categories were then later added to better represent waste releases from the Integrated Disposal Facility (Krupka et al. 2004).

\footnotetext{
${ }^{10}$ Cantrell KJ, RJ Serne, and GV Last, Pacific Northwest National Laboratory, Richland, Washington. A white paper, Waste Stream Descriptions, Impact Zones and Associated $K_{d}$ Estimates Including Rational for Selections, dated May 16, 2003.
} 
Table 3.3. Site-Specific Area Designations Used in the Hydrostratigraphic Template Codes

\begin{tabular}{||l|l||}
\hline \multicolumn{1}{|c|}{ Designation } & \multicolumn{1}{|c|}{ Site-Specific Area Description } \\
\hline \hline A_BC_W & Southern 200 East Area - representing the western portion of the BC cribs area \\
\hline A_BC_E & Southern 200 East Area - representing the eastern portion of the BC cribs area \\
\hline A_BCT_N & Southern 200 East Area - representing the northern portion of the BC trench area \\
\hline A_BCT_S & Southern 200 East Area - representing the southern portion of the BC trench area \\
\hline A_BCT_W & Southern 200 East Area - representing the western portion of the BC trench area \\
\hline A_C & Southern 200 East Area - representing the 241-C Tank Farm \\
\hline A_ILAW_C & Southern 200 East Area - representing the central portion of the ILAW site \\
\hline S_ERDF_E & Southern 200 West Area - representing the eastern half of ERDF \\
\hline S_ERDF_W & Southern 200 West Area - representing the western half of ERDF \\
\hline S_U & Southern 200 West Area - representing the 241-U Tank Farm \\
\hline S_U_N & Southern 200 West Area - representing the northern portion of the 216-U-1\&2 crib area \\
\hline S_U_S & Southern 200 West Area - representing the southern portion of the 216-U-1\&2 crib area \\
\hline S_Z9 & Southern 200 West Area - representing the 216-Z-9 trench area \\
\hline
\end{tabular}

$K_{d}$ values used in the 1998 Composite Analysis were initially tabulated for six source term categories (Kincaid et al. 1998, Table E.2) and three impact zone categories (Kincaid et al. 1998, Table E.3). In addition to the three impact zone categories (High Impact, Intermediate Impact and Groundwater), another $K_{d}$ category (Intermediate Impact Zone - Gravel) was included in the SAC initial assessment to represent very coarse lithologies composed of $\geq 90 \%$ by weight gravel. $K_{d}$ measurements are generally material are applicable. For materials that contain significant amounts of gravel, $K_{d}$ values will be much lower than those determined with $<2 \mathrm{~mm}$-size material because surface area and corresponding conducted on material that is $<2 \mathrm{~mm}$ in size. The first three impact zone categories mentioned assume that the material is sand size or smaller, and that $K_{d}$ values measured using $<2 \mathrm{~mm}$-size quantity of adsorption sites is much lower. For the Intermediate Impact Zone - Gravel category it is necessary to make a correction to $K_{d}$ values due to the high gravel content. For the Intermediate Impact Zone - Gravel case, it was assumed that the material is $90 \%$ gravel with the corresponding correction factor of 0.31 for relatively high $K_{d}$ contaminants (cesium, strontium, and plutonium) and 0.1 for low $K_{d}$ contaminants (see Kaplan and Serne 2000, Appendix A). In future Hanford assessments, stratigraphic correlations will be used to estimate gravel contents of sediment to make gravel corrections to the $K_{d}$ values rather than using an assumed gravel content of $90 \%$ for gravel rich sediment.

As indicated above, the original six waste stream designations defined by Kincaid et al. (1998) were reduced to four. The original six waste stream designations were:

1. High Organic/Very Acidic

2. High Organic/Near Neutral

3. High Salt/Very Basic

4. Chelates/High Salt

5. Low Organic/Low Salt/Acidic

6. Low Organic/Low Salt/Near Neutral 
These were simplified to the following four:

1. Very Acidic (simplified from 1 above)

2. High Salt/Very Basic (same as 3 above)

3. Chelates/High Salt (same as 4 above)

4. Low Salt/Near Neutral (same 6 above with incorporation of 2 and 5)

The reasons for these simplifications follow. The high organic designation can be eliminated because waste streams that were termed high organic generally refer to waste streams containing significant concentrations of tributyl phosphate, hexone, kerosene, lard oil, and/or carbon tetrachloride. These organics compounds do not complex metals and radionuclides under normal aqueous environmental conditions and as a result will not enhance their transport through chemical mechanisms. However, it is possible that if these materials were to occur as a free organic phase, they could significantly affect transport through multiphase flow and alteration of the hydrologic properties of the sediments.

Tributyl phosphate is a weak complexant and after any dilution is not capable of significantly mobilizing metals and radionuclides. These organic compounds, if disposed in large quantities and high concentration, could potentially affect radionuclide and metal migration by creating a reducing zone; however, no field evidence for such an occurrence has been found. As a result of this simplification, the High Organic/Very Acidic waste stream was re-designated as the Very Acidic waste stream and the High Organic/Near Neutral waste stream was combined with the Low Salt/Near Neutral waste stream. The Low Organic/Low Salt/Acidic waste stream was combined with the Low Salt/Near Neutral waste stream because mildly acidic waste streams will generally be neutralized relatively quickly near the disposal location by calcite that occurs naturally in most Hanford sediment. Slower reactions with aluminosilicate minerals could also account for some acid neutralization.

In addition to the four waste streams discussed above, two additional waste stream categories were added to better represent waste releases from the Integrated Disposal Facility (Krupka et al. 2004). These two waste stream categories are:

5. Integrated Disposal Facility (IDF) vitrified waste (new)

6. IDF cementitous waste (new)

To better describe the selection of the $K_{d}$ values for each waste stream designation, semi-quantitative values (chemical concentrations) were defined for each waste stream category. This provides a less ambiguous and more technically defensible approach for the assignment of $K_{d}$ values. These compositions are shown in Table 3.4. The compositions are meant to represent major components that are generic for each waste stream category and not an actual measured waste stream. Only major components that are expected to have a significant influence on adsorption are included. In the case of the Very Acidic waste stream, the composition is based largely on professional judgment. No actual acid concentration data could be located for this waste stream. The composition of the High Salt/Very Basic waste stream provided in Table 3.4 is meant to represent a generic composite composition of Hanford fuel processing waste that has leaked from single-shell tanks or been intentionally discharged to specific retention cribs. Because a large number of leaking single-shell tanks occur in the single-shell waste management areas (S-SX, B-BX-BY, T and TX-TY, and U), estimated compositions available for SX Tanks and Tank T-106 (Agnew et al. 1996) were used to guide the selected compositions. Similar to the High Salt/Very Basic waste stream, the composition selected to represent the Chelates/High Salt waste 
stream is a generic composite composition and does not represent any single or specific waste stream. The concentration of ethylenediaminetetraacetic acid (EDTA) is based on measured concentrations of chelating agents in actual tank waste (Campbell et al. 1998a, 1998b).

Table 3.4. Waste Stream Designation and Assumed Compositions for Determination of $K_{d}$ Values

\begin{tabular}{|c|c|}
\hline Waste Stream & Composition \\
\hline Very Acidic & $1.0 \mathrm{M} \mathrm{HNO}_{3}$ \\
\hline High Salt/Very Basic & $2 \mathrm{M} \mathrm{NaOH}, 4 \mathrm{M} \mathrm{NaNO}_{3}, 2 \mathrm{M} \mathrm{NaNO}_{2}$ \\
\hline Chelates/High Salt & $1.0 \mathrm{M} \mathrm{NaNO}_{3}, 0.05 \mathrm{M}$ EDTA, pH 12 \\
\hline Low Salt/Near Neutral & Same as Hanford Groundwater \\
\hline IDF vitrified waste & High $\mathrm{pH}$, high ionic strength \\
\hline IDF cementitious waste & High $\mathrm{pH}$, medium ionic strength \\
\hline
\end{tabular}

The two IDF waste streams are problematic in terms of assigning representative compositions. IDF waste form leach rates are functions of waste form composition and system variables (Bacon and McGrail 2005). Important system variables include temperature, $\mathrm{pH}$ and composition of the fluid contacting the waste forms. The temperature of the IDF disposal system is assumed to be known and constant. Both $\mathrm{pH}$ and the composition of the fluid contacting the glass are variables affected by flow rate, reactions with other engineered materials, gas-water equilibria, secondary phase precipitation, alkali ion exchange, and glass dissolution. As a result, the IDF waste form leach rates will be highly dynamic, being a function of both time, position in the disposal system, and other variables that are not yet known. Because of these factors, a specific composition to these waste streams are not provided in Table 3.4, instead only a generic composition is provided (Krupka et al. 2004).

Intermediate impact zone compositions are assumed to be $10 \%$ of the concentrations of the high impact zone (Table 3.4), except in the case of the Very Acidic waste stream where it is assumed that all the acid is neutralized in the High Impact zone. The un-impacted zone is assumed to have the composition of typical Hanford groundwater. Several typical compositions of Hanford groundwater (uncontaminated) are tabulated in (Cantrell et al. 2002). In general, Hanford groundwater is calcium bicarbonate dominated water with a $\mathrm{pH}$ that typically ranges from approximately 7.5 to 8.5 . Other prominent major ions are sodium, chloride, sulfate, and magnesium. Typically, total ion composition is between 4 and $10 \mathrm{meq} / \mathrm{L}$. Table 3.5 presents the waste chemistry designations used in the hydrostratigraphic templates.

Table 3.5. Waste Chemistry Designations Used in the Base Template Codes

\begin{tabular}{||c|l||}
\hline $\begin{array}{c}\text { Waste Chemistry } \\
\text { Designation }\end{array}$ & \multicolumn{1}{c||}{ Waste Stream Description } \\
\hline \hline 1 & Very Acidic \\
\hline 2 & High Salt/Very Basic \\
\hline 3 & Chelates/High Salt \\
\hline 4 & Low Salt/Near Neutral \\
\hline 5 & IDF Vitrified Waste \\
\hline 6 & IDF Cementitious Waste \\
\hline IDF = Integrated Disposal Facility. \\
\hline
\end{tabular}




\subsubsection{Hydrostratigraphic Template Designations}

A total of 72 hydrostratigraphic templates have been identified based on various combinations of geographic areas, site types, and waste chemistry types. Table 3.6 provides a description of the general hydrostratigraphic templates established for each geographic area. Table 3.7 describes the site-specific templates set up for a number of key facilities within two of these general geographic areas.

Table 3.6. General Hydrostratigraphic Templates for Each Geographic Area

\begin{tabular}{|c|c|c|c|c|c|}
\hline \multirow{2}{*}{$\begin{array}{c}\text { Template } \\
\text { Designation }\end{array}$} & \multicolumn{2}{|c|}{ Geographic Area } & \multicolumn{2}{|c|}{ Waste Site Types } & \multirow{2}{*}{$\begin{array}{c}\text { Waste } \\
\text { Chemistry } \\
\text { Designation } \\
\text { (d) }\end{array}$} \\
\hline & Area & Designation $^{(\mathrm{a})}$ & Description & Designation $^{(\mathrm{b})}$ & \\
\hline $100 \mathrm{C}-4$ & \multirow[t]{2}{*}{$100 \mathrm{~B} / \mathrm{C}$} & \multirow[t]{2}{*}{$\mathrm{C}$} & Surface Facilities & 100 & 4 \\
\hline $116 \mathrm{C}-4$ & & & Near Surface Facilities & 116 & 4 \\
\hline 100D-4 & \multirow[t]{2}{*}{$100 \mathrm{D}$} & \multirow[t]{2}{*}{$\mathrm{D}$} & Surface Facilities & 100 & 4 \\
\hline $116 \mathrm{D}-4$ & & & Near Surface Facilities & 116 & 4 \\
\hline $100 \mathrm{~F}-4$ & \multirow[t]{2}{*}{$100 \mathrm{~F}$} & \multirow[t]{2}{*}{$\mathrm{F}$} & Surface Facilities & 100 & 4 \\
\hline $116 \mathrm{~F}-4$ & & & Near Surface Facilities & 116 & 4 \\
\hline $100 \mathrm{H}-4$ & \multirow[t]{2}{*}{$100 \mathrm{H}$} & \multirow[t]{2}{*}{$\mathrm{H}$} & Surface Facilities & 100 & 4 \\
\hline $116 \mathrm{H}-4$ & & & Near Surface Facilities & 116 & 4 \\
\hline $100 \mathrm{~K}-4$ & \multirow[t]{3}{*}{$100 \mathrm{~K}$} & \multirow[t]{3}{*}{$\mathrm{K}$} & Surface Facilities & 100 & 4 \\
\hline $116 \mathrm{~K}-4$ & & & Near Surface Facilities & 116 & 4 \\
\hline $166 \mathrm{~K}-4$ & & & Reverse (Injection) Wells & 166 & 4 \\
\hline $100 \mathrm{~N}-4$ & \multirow[t]{2}{*}{$100 \mathrm{~N}$} & \multirow[t]{2}{*}{$\mathrm{N}$} & Surface Facilities & 100 & 4 \\
\hline $116 \mathrm{~N}-4$ & & & Near Surface Facilities & 116 & 4 \\
\hline $200 \mathrm{G}-4$ & Gable Mtn. & $\mathrm{G}$ & Surface Facilities & 200 & 4 \\
\hline $200 \mathrm{I}-4$ & $200 \mathrm{~N}$ & $\mathrm{I}$ & Surface Facilities & 200 & 4 \\
\hline $200 \mathrm{E}-4$ & \multirow[t]{2}{*}{\begin{tabular}{|l|} 
E 200 E (B-Pond) \\
\end{tabular}} & \multirow[t]{2}{*}{$\mathrm{E}$} & Surface Facilities & 200 & 4 \\
\hline $216 \mathrm{E}-4$ & & & Near Surface Facilities & 216 & 4 \\
\hline $200 \mathrm{~B}-2$ & \multirow[t]{8}{*}{ N 200 E (B-Plant) } & \multirow[t]{8}{*}{$\mathrm{B}$} & \multirow[t]{2}{*}{ Surface Facilities } & \multirow[t]{2}{*}{200} & 2 \\
\hline 200B-4 & & & & & 4 \\
\hline $216 \mathrm{~B}-2$ & & & \multirow[t]{3}{*}{ Near Surface Facilities } & \multirow[t]{3}{*}{216} & 2 \\
\hline $216 \mathrm{~B}-3$ & & & & & 3 \\
\hline 216B-4 & & & & & 4 \\
\hline $241 \mathrm{~B}-2$ & & & Tanks & 241 & 2 \\
\hline 266B-4 & & & \multirow[t]{2}{*}{ Reverse (Injection) Wells } & 266 & 4 \\
\hline $267 \mathrm{~B}-2$ & & & & $267^{(\mathrm{c})}$ & 2 \\
\hline $200 \mathrm{~A}-2$ & \multirow{7}{*}{$\begin{array}{c}\text { S 200 E (PUREX, } \\
\text { BC Cribs) }\end{array}$} & \multirow[t]{7}{*}{ A } & \multirow[t]{2}{*}{ Surface Facilities } & 200 & 2 \\
\hline $200 \mathrm{~A}-4$ & & & & & 4 \\
\hline $216 \mathrm{~A}-2$ & & & Near Surface Facilities & 216 & 2 \\
\hline $216 \mathrm{~A}-4$ & & & & & 4 \\
\hline $241 \mathrm{~A}-2$ & & & Tanks & 241 & 2 \\
\hline $241 \mathrm{~A}-3$ & & & & & 3 \\
\hline $266 \mathrm{~A}-4$ & & & Reverse (Injection) Wells & 266 & 4 \\
\hline $200 \mathrm{~S}-2$ & \begin{tabular}{|l|} 
S 200 W (Redox, \\
\end{tabular} & $\mathrm{S}$ & Surface Facilities & 200 & 2 \\
\hline $200 \mathrm{~S}-4$ & U-Plant, Z-Plant) & & & & 4 \\
\hline
\end{tabular}


Table 3.6. (contd)

\begin{tabular}{|c|c|c|c|c|c|}
\hline $\begin{array}{c}\text { Template } \\
\text { Designation }\end{array}$ & \multicolumn{2}{|c|}{ Geographic Area } & \multicolumn{2}{|c|}{ Waste Site Types } & $\begin{array}{c}\text { Waste } \\
\text { Chemistry } \\
\text { Designation } \\
\text { (d) }\end{array}$ \\
\hline $216 \mathrm{~S}-1$ & \multirow{7}{*}{\begin{tabular}{|l|} 
S $200 \mathrm{~W}$ (Redox, \\
U-Plant, Z-Plant)
\end{tabular}} & \multirow[t]{7}{*}{$\mathrm{S}$} & \multirow[t]{3}{*}{ Near Surface Facilities } & \multirow[t]{3}{*}{216} & 1 \\
\hline $216 \mathrm{~S}-2$ & & & & & 2 \\
\hline $216 \mathrm{~S}-4$ & & & & & 4 \\
\hline $241 \mathrm{~S}-2$ & & & \multirow[t]{3}{*}{ Tanks } & \multirow[t]{3}{*}{241} & 2 \\
\hline $241 \mathrm{~S}-3$ & & & & & 3 \\
\hline $241 \mathrm{~S}-4$ & & & & & 4 \\
\hline $266 \mathrm{~S}-4$ & & & Reverse (Injection) Wells & 266 & 4 \\
\hline 200T-2 & \multirow[t]{8}{*}{ N $200 \mathrm{~W}$ (T Plant) } & \multirow[t]{8}{*}{$\mathrm{T}$} & \multirow[t]{2}{*}{ Surface Facilities } & \multirow[t]{2}{*}{200} & 2 \\
\hline 200T-4 & & & & & 4 \\
\hline $216 \mathrm{~T}-2$ & & & \multirow[t]{3}{*}{ Near Surface Facilities } & \multirow[t]{3}{*}{216} & 2 \\
\hline 216T-3 & & & & & 3 \\
\hline 216T-4 & & & & & 4 \\
\hline $241 \mathrm{~T}-2$ & & & Tanks & 241 & 2 \\
\hline 266T-2 & & & \multirow[t]{2}{*}{ Reverse (Injection) Wells } & \multirow[t]{2}{*}{266} & 2 \\
\hline $266 \mathrm{~T}-4$ & & & & & 4 \\
\hline $300 \mathrm{R}-4$ & \multirow{2}{*}{$\begin{array}{l}300 \text { Area (North } \\
\text { Richland }\end{array}$} & \multirow[t]{2}{*}{$\mathrm{R}$} & Surface Facilities & 300 & 4 \\
\hline $316 \mathrm{R}-4$ & & & Near Surface Facilities & 316 & 4 \\
\hline 400Q-4 & 400 & $\mathrm{Q}$ & Surface Facilities & 400 & 4 \\
\hline $616 \mathrm{M}-4$ & 600 & $\mathrm{M}$ & Near Surface Facilities & 616 & 4 \\
\hline $616 \mathrm{P}-4$ & 600 & $\mathrm{P}$ & Near Surface Facilities & 616 & 4 \\
\hline Pump & - & - & Water Supply Wells & Pump & - \\
\hline River & - & - & River outfalls & River & - \\
\hline
\end{tabular}

(a) Assigned letter designation for geographic area.

(b) Assigned number designation for waste site type: First number designates traditional Hanford Site area (i.e., $100,200,300,400,600$ Areas $)$; last two numbers designate waste site type $(00=$ surface facilities, $16=$ near surface facilities, $41=$ tanks, $66 / 67=$ reverse wells).

(c) Two designations are used for reverse (injection) wells that have very different depths within a single geographic area. The "67" designation distinguishes the very deep reverse (injection) wells from those at a more intermediate depth (66).

(d) Assigned number designation for waste chemistry type (see Table 3.5). 
Table 3.7. Site-Specific Templates Established for a Few Key Facilities

\begin{tabular}{|c|c|c|c|c|c|}
\hline \multirow{2}{*}{$\begin{array}{l}\text { Template } \\
\text { Designation }\end{array}$} & \multicolumn{2}{|c|}{ Site-Specific Area } & \multicolumn{2}{|c|}{ Waste Site Types } & \multirow{2}{*}{$\begin{array}{c}\text { Waste } \\
\text { Chemistry } \\
\text { Designation }^{(\mathrm{c})}\end{array}$} \\
\hline & Area & Designation $^{(a)}$ & Description & Designation $^{(\mathrm{b})}$ & \\
\hline 216A_BC_W-3 & $\begin{array}{l}\text { S } 200 \text { E, BC Cribs, Western } \\
\text { Portion }\end{array}$ & A_BC_W & $\begin{array}{l}\text { Near Surface } \\
\text { Facilities }\end{array}$ & 216 & 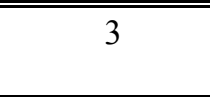 \\
\hline 216A_BC_E-3 & $\begin{array}{l}\text { S } 200 \text { E, BC Cribs, Eastern } \\
\text { Portion }\end{array}$ & A_BC_E & \begin{tabular}{|l} 
Near Surface \\
Facilities
\end{tabular} & 216 & 3 \\
\hline 216A_BCT_N-3 & \multirow{2}{*}{$\begin{array}{l}\text { S } 200 \text { E, BC Trenches, } \\
\text { Northern Portion }\end{array}$} & \multirow[t]{2}{*}{ A_BT_N } & \multirow{2}{*}{$\begin{array}{l}\text { Near Surface } \\
\text { Facilities }\end{array}$} & \multirow[t]{2}{*}{216} & 3 \\
\hline 216A_BCT_N-4 & & & & & 4 \\
\hline 216A_BCT_S-3 & $\begin{array}{l}\text { S } 200 \text { E, BC Trenches, } \\
\text { Southern Portion }\end{array}$ & A_BT_S & \begin{tabular}{|l|} 
Near Surface \\
Facilities
\end{tabular} & 216 & 3 \\
\hline 216A_BCT_W-3 & $\begin{array}{l}\text { S } 200 \text { E, BC Trenches, } \\
\text { Western Portion }\end{array}$ & A_BT_W & \begin{tabular}{|l|} 
Near Surface \\
Facilities
\end{tabular} & 216 & 3 \\
\hline 216A_ILAW_C-5 & \multirow{2}{*}{$\begin{array}{l}\text { S } 200 \text { E, ILAW Site, Central } \\
\text { Portion }\end{array}$} & \multirow[t]{2}{*}{ A_ILAW_C } & \multirow{2}{*}{$\begin{array}{l}\text { Near Surface } \\
\text { Facilities }\end{array}$} & \multirow[t]{2}{*}{216} & 5 \\
\hline 216A_ILAW_C-6 & & & & & 6 \\
\hline 216S_ERDF_E-4 & S $200 \mathrm{~W}$, ERDF, eastern half & S_ERDF_E & $\begin{array}{l}\text { Near Surface } \\
\text { Facilities }\end{array}$ & 216 & 4 \\
\hline 216S_ERDF_W-4 & $\begin{array}{l}\text { S } 200 \mathrm{~W} \text {, ERDF, western } \\
\text { half }\end{array}$ & S_ERDF_W & \begin{tabular}{|l|} 
Near Surface \\
Facilities
\end{tabular} & 216 & 4 \\
\hline 216S_U_N-4 & $\begin{array}{l}\text { S } 200 \mathrm{~W}, 216-\mathrm{U}-1 \& 2 \text { Area, } \\
\text { Northern Portion }\end{array}$ & S_U_N & $\begin{array}{l}\text { Near Surface } \\
\text { Facilities }\end{array}$ & 216 & 4 \\
\hline 216S_U_S-4 & $\begin{array}{l}\text { S } 200 \mathrm{~W}, 216-\mathrm{U}-1 \& 2 \text { Area, } \\
\text { Northern Portion }\end{array}$ & S_U_S & \begin{tabular}{|l|} 
Near Surface \\
Facilities
\end{tabular} & 216 & 4 \\
\hline $216 \mathrm{~S} \_Z 9-1$ & $\begin{array}{l}\text { S } 200 \mathrm{~W}, 216-\mathrm{U}-1 \& 2 \text { Area, } \\
\text { Northern Portion }\end{array}$ & S_Z9 & \begin{tabular}{|l|}
$\begin{array}{l}\text { Near Surface } \\
\text { Facilities }\end{array}$ \\
\end{tabular} & 216 & 1 \\
\hline 241A_C-2 & \multirow[t]{2}{*}{ S 200 E, 241-C Tank Farm } & \multirow[t]{2}{*}{ A_C } & \multirow[t]{2}{*}{ Tanks } & \multirow[t]{2}{*}{241} & 2 \\
\hline 241A_C-3 & & & & & 3 \\
\hline 241S_U-2 & S 200 W, 241-U Tank Farm & S_U & Tanks & 241 & 2 \\
\hline \multicolumn{6}{|c|}{$\begin{array}{l}\text { (a) Assigned letter designation for geographic area. } \\
\text { (b) Assigned number designation for waste site type: First number designates traditional Hanford Site area (i.e., } \\
100,200,300,400,600 \text { Areas); last two numbers designate waste site type }(00=\text { surface facilities, } 16=\text { near } \\
\text { surface facilities, } 41=\text { tanks, } 66 / 67=\text { reverse [injection] wells). } \\
\text { (c) Assigned number designation for waste chemistry type (see Table } 3.5) \text {. }\end{array}$} \\
\hline
\end{tabular}




\subsection{Input Parameters}

This section describes the input data sets assembled for use in vadose zone modeling for large-scale Hanford Assessments. These data sets are managed under a data configuration and communication management plan. ${ }^{11}$ A readiness review was conducted prior to placing each data set under configuration management. Any subsequent changes were managed and documented via a data change request (DCR). Each revised data set is uniquely identified with a descriptive name, the date the data set was revised, and the corresponding DCR number. For example:

\section{Sorption_2005-09-15_DCR-0014.xls}

identifies the $K_{d}$ input files that were accepted into configuration control on September 15, 2005 under DCR number 0014; the file extension identifies this as a Microsoft Excel spreadsheet. Table 4.1 summarizes the pertinent input data sets and the location of their representation in this or other companion documents.

Table 4.1. Summary of Vadose Zone Input Parameter Data Sets Under Configuration Management

\begin{tabular}{|c|c|c|c|}
\hline Description & File Name & File Type & Location \\
\hline $\begin{array}{l}\text { Hydrostratigraphy. These files provide } \\
\text { the hydrostratigraphic column for each } \\
\text { geographic area, including the layer } \\
\text { thickness, and their hydraulic and } \\
\text { geochemical property designations. }\end{array}$ & vadose_2006-01-31_DCR-0038 & $\begin{array}{l}\text { Folder containing } 26 \\
\text { Excel spreadsheets } \\
\text { (templates), plus a } \\
\text { change log. }\end{array}$ & Appendix A \\
\hline $\begin{array}{l}\text { Hydraulic properties important to } \\
\text { vadose zone simulations }\end{array}$ & $\begin{array}{l}\text { Hydraulic_Properties_2006-03- } \\
\text { 07_DCR-0045.xls }\end{array}$ & Excel workbook. & Appendix B \\
\hline Contaminant distribution coefficients & $\begin{array}{l}\text { Sorption_2005-12-20_DCR- } \\
\text { 0030.xls }\end{array}$ & Excel work book & Table 4.11 \\
\hline $\begin{array}{l}\text { Hydrostratigraphic template definition } \\
\text { and other geographic and operational } \\
\text { site parameters used to specify the } \\
\text { location, dimensions, recharge rates, } \\
\text { remedial actions, etc. }\end{array}$ & $\begin{array}{l}\text { GOSPL_2006-04-14_DCR- } \\
\text { 0047.xls }\end{array}$ & $\begin{array}{l}\text { Excel workbook; } \\
\text { worksheet 'Full } \\
\text { SAC Rev1 List' }\end{array}$ & $\begin{array}{l}\text { See GOSPL } \\
\text { Data Package } \\
\text { (Last et al. } \\
\text { 2006) }\end{array}$ \\
\hline Recharge rates & $\begin{array}{l}\text { GOSPL_2006-04-14_DCR- } \\
\text { 0047.xls }\end{array}$ & $\begin{array}{l}\text { Excel workbook; } \\
\text { worksheet } \\
\text { 'Infiltration Class' }\end{array}$ & $\begin{array}{l}\text { Tables } 4.19 \\
\text { through } 4.20\end{array}$ \\
\hline Pond evaporation estimates & $\begin{array}{l}\text { Evaporation_2005-07-20_DCR- } \\
\text { 0008.xls }\end{array}$ & $\begin{array}{l}\text { Excel workbook; } \\
\text { worksheet 'time- } \\
\text { evaporate' }\end{array}$ & Table 4.21 \\
\hline
\end{tabular}

\subsection{Hydrostratigraphy}

The geology of the vadose zone forms the framework through which contaminants move. The physical structure of the vadose zone, along with its hydraulic and geochemical properties, controls the

\footnotetext{
${ }^{11}$ Nichols, WE, PW Eslinger, and GV Last. February 3, 2006. Hanford Remediation Assessment Project Data Configuration and Communication Management Plan, Rev. 1.1. Pacific Northwest National Laboratory, Richland, Washington.
} 
migration and distribution of contaminants. Of particular interest are the interrelations between the coarse- and fine-grained sediments within the vadose zone, and the types and degree of contrast in their physical and geochemical properties.

As described by Kincaid et al. (2004), the large scale and complexity of an assessment for the entire Hanford Site necessitates the use of a simplified modeling approach. In this approach, industrial waste sites were grouped into one of 17 geographic areas that were identified as having unique hydrostratigraphic properties. The vadose zone beneath each geographic area is represented as a single onedimensional hydrostratigraphic column (Figure 3.2). The hydrostratigraphic information that describes a geographic area has been assembled into a common template for all waste sites within that area. These templates were assembled from existing information including:

- Published interpretive depths to the top and bottom surfaces of hydrogeologic units (as taken from tabulated geologic contact data or interpolated from structure contour maps, cross sections, log plots, or other graphical representations).

- Unpublished raw data (e.g., driller's logs, geologists' logs, and geophysical logs).

- Surface elevations (to convert hydrogeologic unit depths to elevations), interpolated from topographical maps (e.g., Hanford Quadrangle 15 Minute Series).

- Elevation of the 1944 water table (to define the bottom of the vadose zone prior to waste disposal), interpolated from historic water table maps (e.g., Kipp and Mudd 1974)

In general, the main hydrostratigraphic units, contact depths, and thicknesses were taken from available published tables, maps, and cross-sections. The estimated average strata thicknesses were used to assemble the generalized columns extending from the ground surface to the 1944 water table. However, because the sum of the average thicknesses did not always equal the distance from the ground surface to the water table, small adjustments were made to normalize the average strata thicknesses to equal the total thickness of the vadose zone. Table 4.2 lists the references used to assign hydrogeologic units to each of the hydrostratigraphic templates.

Since lithofacies identification and geologic nomenclature has varied over time and by published sources, some translation was necessary to relate the major geologic units to a common classification. Table 4.3 describes the generalized hydrostratigraphic nomenclature used in this study based on that defined by DOE (2002), and Lindsey (1996). Appendix A provides the hydrostratigraphic column for each geographic area, including the layer thicknesses and their hydraulic and geochemical property designations.

In the simplified modeling approach selected for large-scale Hanford assessments, the number and thicknesses of the hydrostratigraphic units within each template remain fixed. However, it must be recognized that there is uncertainty associated with these hydrostratigraphic representations. The primary source of information for these interpretations is borehole data. Uncertainties in the borehole data are related to the drilling and sampling techniques, the logging of the borehole, elevation control, and interpretation of the stratigraphy. Subtle differences between some stratigraphic units make identification of the stratigraphic contacts difficult (Reidel et al. 2006). In addition, there is spatial uncertainty due to variations in thickness and presence/absence of the stratigraphic units across the geographic areas represented in each template. 
Table 4.2. Sources of Hydrogeologic Data for the Seventeen Geographic Areas to be Analyzed

\begin{tabular}{|c|c|c|}
\hline Geographic Area & Designation & References \\
\hline $100 \mathrm{~B} / \mathrm{C}$ & $\mathrm{C}$ & Lindberg 1993a; Lindsey 1992; Peterson et al. 1996 \\
\hline $100 \mathrm{D}$ & $\mathrm{D}$ & Lindsey and Jaeger 1993; DOE 1993b; Lindsey 1992; Peterson et al. 1996 \\
\hline $100 \mathrm{~F}$ & $\mathrm{~F}$ & Raidl 1994; Lindsey 1992; Peterson et al. 1996 \\
\hline $100 \mathrm{H}$ & $\mathrm{H}$ & $\begin{array}{l}\text { Lindsey and Jaeger 1993; Liikala et al. 1988; Vermuel et al. 1995; DOE } \\
\text { 1993b; Peterson et al. } 1996\end{array}$ \\
\hline $100 \mathrm{~K}$ & $\mathrm{~K}$ & Lindsey 1992; Lindberg 1995; Peterson et al. 1996 \\
\hline $100 \mathrm{~N}$ & $\mathrm{~N}$ & Hartman and Lindsey 1993 \\
\hline $\begin{array}{l}\text { Gable Mountain Pond } \\
\text { Area }\end{array}$ & G & Lindsey et al. 1992b; DOE 1993c; DOE 1993d; Wurstner et al. 1995 \\
\hline $200 \mathrm{~N}$ & $\mathrm{I}$ & Lindsey et al. 1992b; DOE 1993c; DOE 1993d; Wurstner et al. 1995 \\
\hline E 200 E (B-Pond) & E & $\begin{array}{l}\text { Barnett et al. 2000; Cearlock et al. 2000; Lindsey et al. 1992b; Wurstner et al. } \\
1995\end{array}$ \\
\hline N 200 E (B-Plant) & B & $\begin{array}{l}\text { Lindsey et al. 1992b; Price and Fecht 1976a, b, c; Tallman et al. 1979; } \\
\text { Wurstner et al. 1995; Wood et al. 2000, Kephart et al. 2005; Reidel et al. } 2006 \\
\end{array}$ \\
\hline $\begin{array}{l}\text { S } 200 \text { E (PUREX, BC } \\
\text { cribs, BC Trenches, } \\
\text { ILAW) }\end{array}$ & $\begin{array}{l}\text { A } \\
\text { A_BC_E } \\
\text { A_BC_W } \\
\text { A_BCT_N } \\
\text { A_BCT_S } \\
\text { A_BCT_W } \\
\text { A-C } \\
\text { A_ILAW_C }\end{array}$ & $\begin{array}{l}\text { Lindsey et al. 1992b; Reidel and Horton 1999; Valenta et al. 2000; Reidel } \\
\text { et al. 2001; Reidel and Ho 2002; Tallman et al. 1979; Wurstner et al. 1995; } \\
\text { Wood et al. 2003; Kephart et al. 2005; Reidel et al. 2006. }\end{array}$ \\
\hline $\begin{array}{l}\text { S } 200 \mathrm{~W} \text { (Redox, U- } \\
\text { Plant, Z-Plant) }\end{array}$ & $\begin{array}{l}\text { S } \\
\text { S_U } \\
\text { S_U_N } \\
\text { S_U_S } \\
\text { S_Z9 } \\
\text { S_ERDF_E } \\
\text { S_ERDF_W } \\
\end{array}$ & $\begin{array}{l}\text { Johnson and Chou 1988; Lindsey et al. 1992a; Price and Fecht 1976d; Slate } \\
\text { 2000; Tallman et al. 1979; Wurstner et al. 1995; Rohay et al. 1994; Connelly } \\
\text { et al. 1992a; Last et al. 1989; Last and Rohay 1993; Swanson et al. 1999; } \\
\text { Weekes et al. 1996; Wood and Jones 2003; Kephart et al. 2005; Reidel et al. } \\
\text { 2006; Well logs for 299-W19-14, -15, and -16; and borehole data from wells } \\
\text { 299-W15-8, -9, -83,-84,-86, -95, -101, and -207. }\end{array}$ \\
\hline N $200 \mathrm{~W}$ (T-Plant) & $\mathrm{T}$ & $\begin{array}{l}\text { Lindsey et al. 1992a; Slate 2000; Tallman et al. 1979; Wurstner et al. 1995; } \\
\text { Wood et al. 2001, Kephart et al. 2005; Reidel et al. 2006, }\end{array}$ \\
\hline $\begin{array}{l}300 \text { Area (North } \\
\text { Richland) }\end{array}$ & $\mathrm{R}$ & $\begin{array}{l}\text { Gaylord and Poeter 1991; Lindberg and Bond 1979; Schalla et al. 1988; } \\
\text { Swanson et al. } 1992\end{array}$ \\
\hline 400 Area & Q & $\begin{array}{l}\text { HEDL 1975; Meier Associates Log Book Project V-749; Well logs from } \\
\text { 499-S1-8J, and 499-S1-7B. }\end{array}$ \\
\hline $\begin{array}{l}600 \text { Area }(618-10 \\
\text { Area) }\end{array}$ & $\mathrm{P}$ & Well Logs from 699-S6-E4A \\
\hline $\begin{array}{l}600 \text { Area }(618-11 \\
\text { Area, Energy } \\
\text { Northwest) }\end{array}$ & M & Well Logs from 699-13-3A \\
\hline
\end{tabular}


Table 4.3. Hydrostratigraphic Units Used in this Study (after DOE 2002 and Lindsey 1996)

\begin{tabular}{|c|c|c|c|}
\hline Formation/Unit & Facies/Subunit & Code & Description \\
\hline \multirow[t]{2}{*}{ Holocene } & Backfill & $\mathrm{HDb}$ & $\begin{array}{l}\text { Poorly sorted gravel, sand, and silt derived from the Hanford } \\
\text { formation and/or Holocene deposits }\end{array}$ \\
\hline & $\begin{array}{l}\text { Medium-grained, } \\
\text { Cross-Bedded, } \\
\text { Well Sorted } \\
\end{array}$ & HDs & $\begin{array}{l}\text { Medium-grained dune sand, moderate to well sorted, and cross } \\
\text { laminated to cross-bedded. }\end{array}$ \\
\hline \multirow[t]{7}{*}{$\begin{array}{l}\text { Hanford } \\
\text { formation }\end{array}$} & \begin{tabular}{|l|} 
Interbedded \\
Sand- to Silt- \\
dominated
\end{tabular} & HISSD & $\begin{array}{l}\text { Rhythmite sequences of slackwater deposits. Graded beds of } \\
\text { horizontal or climbing ripple laminated sand, to fine sand, to } \\
\text { silt (laminated to massively bedded). }\end{array}$ \\
\hline & $\begin{array}{l}\text { Sand-Dominated, } \\
\text { Silty Sand }\end{array}$ & $\mathrm{HSD}(\mathrm{f})$ & $\begin{array}{l}\text { Silt to fine sand, massively bedded to horizontally laminated or } \\
\text { cross laminated. }\end{array}$ \\
\hline & $\begin{array}{l}\text { Sand-Dominated, } \\
\text { Fine Sand }\end{array}$ & HSD-Sm & Fine to coarse sand, massively bedded, with or without silt. \\
\hline & $\begin{array}{l}\text { Sand-Dominated, } \\
\text { Coarse Sand } \\
\end{array}$ & HSD-Sh(c) & $\begin{array}{l}\text { Medium to coarse sand with minor amounts of pebbly sand, } \\
\text { exhibiting horizontal to low-angle cross stratification. }\end{array}$ \\
\hline & $\begin{array}{l}\text { Sand-Dominated, } \\
\text { Gravelly Sand }\end{array}$ & $\mathrm{HSD}(\mathrm{c})$ & $\begin{array}{l}\text { Medium to coarse sand to pebbly sand (with up to } 30 \mathrm{wt} \% \text { very } \\
\text { fine pebble to cobble), with high angle planar-tabular cross } \\
\text { stratification to trough cross-stratification }\end{array}$ \\
\hline & \begin{tabular}{|l|} 
Gravel- \\
Dominated
\end{tabular} & HGD & $\begin{array}{l}\text { Silty sandy pebble to boulder gravel (with } 30-60 \mathrm{wt} \% \text { gravel), } \\
\text { massive to cross stratified. }\end{array}$ \\
\hline & \begin{tabular}{|l|} 
Gravel- \\
Dominated, \\
Coarse
\end{tabular} & $\mathrm{HGD}(\mathrm{c})$ & $\begin{array}{l}\text { Pebble to boulder gravel (with greater than } 60 \mathrm{wt} \% \text { gravel), to } \\
\text { silty sandy gravel, massive to cross stratified. }\end{array}$ \\
\hline \multirow[t]{2}{*}{ Cold Creek unit } & $\begin{array}{l}\text { Fine-Grained, } \\
\text { Laminated to } \\
\text { Massive }\end{array}$ & $\begin{array}{l}\text { CCUf(lam- } \\
\text { msv) }\end{array}$ & $\begin{array}{l}\text { Fine sand, silt, and/or clay, buff, pale to dark brown, well sorted } \\
\text { to very well sorted, micaceous, and having high natural-gamma } \\
\text { activity }\end{array}$ \\
\hline & $\begin{array}{l}\text { Coarse to Fine- } \\
\text { Grained, } \\
\text { Carbonate } \\
\text { Cemented }\end{array}$ & $\begin{array}{l}\text { CCUf- } \\
\text { c(calc) }\end{array}$ & $\begin{array}{l}\text { Calcium-carbonate cemented clay, silt, sand, and/or gravel, } \\
\text { white to light gray, very poor to moderately sorted, with a } \\
\text { massive to platy structure and bioturbated with root casts } \\
\text { (rhyzoliths). }\end{array}$ \\
\hline \multirow[t]{2}{*}{$\begin{array}{l}\text { Ringold } \\
\text { Formation }\end{array}$} & $\begin{array}{l}\text { Fluvial Sand } \\
\text { (Member of } \\
\text { Taylor Flat) }\end{array}$ & Rtf & Interstratified sand and silt deposits \\
\hline & $\begin{array}{l}\text { Fluvial Gravel } \\
\text { (Member of } \\
\text { Wooded Island, } \\
\text { subunit E) }\end{array}$ & Rwi(e) & $\begin{array}{l}\text { Moderate to strongly cemented well rounded gravel and sand } \\
\text { deposits, and interstratified finer-grained deposits. }\end{array}$ \\
\hline
\end{tabular}

\subsection{Hydraulic Properties}

Hydraulic property data for the vadose zone simulations were derived from the laboratory measurements of 284 soil samples (both repacked and splitspoon samples) taken from the 100 and 200 Areas (Appendix B). These data were selected from a catalog of vadose zone hydraulic properties (Freeman et al. 2002) and a subsequent prototype database (Freeman and Last 2003). Because the hydraulic property data are limited in the spatial location of samples and the soil types represented, individual stochastic data sets were developed to represent ten different soil classes. These ten classes build on the six soil classes originally identified by Khaleel and Freeman (1995) and are based on texture (i.e., particle size), International Society of Soil Science (ISSS) classification, and moisture retention curve 
characteristics. Four additional soil classes were incorporated to separate out the Cold Creek unit (formerly referred to as the Plio-Pleistocene unit) sediment, add additional detail for the Hanford formation sand-dominated sediment, and add a new class for very coarse gravel. The resulting 10 soil hydraulic property classes and their associated hydraulic property distributions were later correlated to the hydrostratigraphic units used in the 17 geographic area templates. Table 4.4 describes the hydraulic-property soil classes assembled for a large-scale Hanford assessment.

Table 4.4. Description of Hydraulic-Property Soil Classes

\begin{tabular}{|c|c|c|c|c|}
\hline Formation & Soil Class & Code & Description & $\begin{array}{c}\text { Hydrostratigraphic } \\
\text { Unit Code(s) }\end{array}$ \\
\hline Holocene Deposits & Backfill & $\mathrm{Bf}$ & $\begin{array}{l}\text { Sand and gravel mixed with finer fraction. Same } \\
\text { as the SSG soil category identified by Khaleel and } \\
\text { Freeman (1995) }\end{array}$ & $\mathrm{HDb}$ \\
\hline \multirow[t]{6}{*}{ Hanford formation } & Silty Sand & Hss & $\begin{array}{l}\text { Sand mixed with finer fraction, containing }>50 \% \\
\text { fine sands, silt, and clay, with }>15 \% \text { silt and clay. } \\
\text { Derived from the SS soil category identified by } \\
\text { Khaleel and Freeman (1995) }\end{array}$ & HISSD/HSD(f) \\
\hline & Fine Sand & Hfs & $\begin{array}{l}\text { Sand, containing } 35-70 \% \text { fine sand, silt, and clay, } \\
\text { with }<15 \% \text { silt and clay. Derived from the S soil } \\
\text { category identified by Khaleel and Freeman (1995) }\end{array}$ & HSD-Sm \\
\hline & Coarse Sand & Hes & $\begin{array}{l}\text { Sand, containing }>60 \% \text { coarse sand. Derived from } \\
\text { the S soil category identified by Khaleel and } \\
\text { Freeman (1995) }\end{array}$ & HSD-Sh(c) \\
\hline & Gravelly Sand & $\mathrm{Hgs}$ & $\begin{array}{l}\text { Gravelly sand. Same as the GS soil category } \\
\text { identified by Khaleel and Freeman (1995) }\end{array}$ & $\mathrm{HSD}(\mathrm{c})$ \\
\hline & Sandy Gravel & $\mathrm{Hg}$ & $\begin{array}{l}\text { Sandy gravel for which gravel content is } \\
\text { approximately }<60 \% \text {. Same as the SG1 soil } \\
\text { category identified by Khaleel and Freeman } \\
(1995)\end{array}$ & HGD \\
\hline & Gravel & $\mathrm{Hrg}$ & $\begin{array}{l}\text { Very high gravel content soils ( }>60 \% \text { gravel) from } \\
\text { the } 100 \text { areas (along the river). }\end{array}$ & HGD(c) \\
\hline \multirow[t]{2}{*}{\begin{tabular}{|l} 
Cold Creek unit \\
(formerly referred \\
to as the Plio- \\
Pliestocene unit)
\end{tabular}} & Silt Dominated & PPlz & $\begin{array}{l}\text { Derived from the SS soil category identified by } \\
\text { Khaleel and Freeman (1995) but correlated to } \\
\text { Cold Creek unit silt. Includes additional samples } \\
\text { from borehole B } 8814 \text {. }\end{array}$ & CCUf(lam-msv) \\
\hline & Caliche & PPlc & $\begin{array}{l}\text { Derived from the SS soil category identified by } \\
\text { Khaleel and Freeman (1995) but correlated to the } \\
\text { Cold Creek unit carbonate. }\end{array}$ & CCUf-c(calc) \\
\hline $\begin{array}{l}\text { Ringold } \\
\text { Formation }\end{array}$ & $\begin{array}{l}\text { Gravel } \\
\text { Dominated }\end{array}$ & $\operatorname{Rg}$ & $\begin{array}{l}\text { Sandy gravel for which gravel content is approxi- } \\
\text { mately }>60 \% \text {. Same as the SG2 soil category } \\
\text { identified by Khaleel and Freeman (1995). }\end{array}$ & Rwi(e) \\
\hline
\end{tabular}

The statistical distributions of van Genuchten model (van Genuchten 1980) parameters $\left(\alpha, n, \theta_{R}, \theta_{s}\right.$, $S_{r}$ ), saturated hydraulic conductivity $\left(\mathrm{K}_{\mathrm{s}}\right)$, and bulk density data were developed from laboratory data described in a catalog of vadose zone hydraulic properties by Freeman et al. (2001, 2002), and a subsequent prototype database (Freeman and Last 2003). Ideally, all parameters in this database should be based on gravel-corrected data derived using the same gravel-correction procedure. Some of the parameters are known to have been based on gravel-corrected data derived using the Gardner method (e.g., Khaleel and Relyea 1997), but it is not clear that all samples were treated in a consistent manner. 
Gravel percentages are included in Tables 4.5 to 4.9 to indicate which soil classes might be affected. Future revisions of this database should address any disparity that might exist among samples. Values for residual saturation $\left(S_{r}\right)$ are statistically derived from the sample population where the raw residual water content $\left(\theta_{R}\right)$ for an individual sample was divided by the raw saturated content $\left(\theta_{S}\right)$ for that sample. Effective porosity is assumed to be equal to the saturated water content $\left(\theta_{s}\right)$.

Table 4.5. Statistical Mean Values for Site-Wide Samples

\begin{tabular}{|c|c|c|c|c|c|c|c|c|c|}
\hline \multicolumn{10}{|c|}{ Site Wide } \\
\hline $\begin{array}{c}\text { Soil } \\
\text { Class } \\
\end{array}$ & Count & $\begin{array}{c}\alpha \\
(1 / \mathrm{cm}) \\
\end{array}$ & $n$ & $\begin{array}{c}\theta_{R} \\
\left(\mathrm{~cm}^{3} / \mathrm{cm}^{3}\right) \\
\end{array}$ & $\begin{array}{c}\theta_{s} \\
\left(\mathrm{~cm}^{3} / \mathrm{cm}^{3}\right) \\
\end{array}$ & $\begin{array}{c}K_{s} \\
(\mathrm{~cm} / \mathrm{sec}) \\
\end{array}$ & $S_{r}$ & $\begin{array}{c}\% \\
\text { gravel } \\
\end{array}$ & $\begin{array}{c}\text { Bulk Density } \\
\left(\mathrm{g} / \mathrm{cm}^{3}\right)\end{array}$ \\
\hline $\mathrm{Bf}$ & 6 & 0.019 & 1.400 & 0.030 & 0.262 & $5.98 \mathrm{E}-04$ & 0.103 & 33.5 & 1.94 \\
\hline Hss & 38 & 0.008 & 1.915 & 0.072 & 0.445 & $8.58 \mathrm{E}-05$ & 0.162 & 0.2 & 1.61 \\
\hline $\mathrm{Hfs}$ & 36 & 0.027 & 2.168. & 0.032 & 0.379 & $3.74 \mathrm{E}-04$ & 0.086 & 0.6 & 1.60 \\
\hline Hes & 81 & 0.061 & 2.031 & 0.027 & 0.349 & $2.27 \mathrm{E}-03$ & 0.080 & 2.6 & 1.67 \\
\hline $\mathrm{Hgs}$ & 16 & 0.014 & 2.120 & 0.033 & 0.238 & $6.65 \mathrm{E}-04$ & 0.140 & 25.8 & 1.94 \\
\hline $\mathrm{Hg}$ & 28 & 0.017 & 1.725 & 0.022 & 0.167 & $3.30 \mathrm{E}-04$ & 0.134 & 51.4 & 1.93 \\
\hline $\mathrm{Hrg}$ & 40 & 0.007 & 1.831 & 0.020 & 0.102 & $1.46 \mathrm{E}-03$ & 0.200 & 67.6 & 1.97 \\
\hline $\mathrm{PPlz}$ & 9 & 0.005 & 2.249 & 0.040 & 0.419 & $5.57 \mathrm{E}-05$ & 0.097 & 0.4 & 1.68 \\
\hline PPlc & 14 & 0.011 & 1.740 & 0.054 & 0.281 & $8.45 \mathrm{E}-04$ & 0.185 & 16.7 & 1.72 \\
\hline $\mathrm{Rg}$ & 18 & 0.008 & 1.660 & 0.026 & 0.177 & $4.13 \mathrm{E}-04$ & 0.135 & 46.1 & 1.90 \\
\hline
\end{tabular}

Table 4.6. Statistical Mean Values for BC-Crib Samples

\begin{tabular}{||l|c|c|c|c|c|c|c|c|c||}
\hline \hline \multicolumn{10}{|c|}{ BC Cribs } \\
\hline $\begin{array}{c}\text { Soil } \\
\text { Class }\end{array}$ & Count & $\begin{array}{c}\alpha \\
(1 / \mathrm{cm})\end{array}$ & $n$ & $\begin{array}{c}\theta_{R} \\
\left(\mathrm{~cm}^{3} / \mathrm{cm}^{3}\right)\end{array}$ & $\begin{array}{c}\theta_{s} \\
\left(\mathrm{~cm}^{3} / \mathrm{cm}^{3}\right)\end{array}$ & $\begin{array}{c}K_{s} \\
(\mathrm{~cm} / \mathrm{sec})\end{array}$ & $S_{r}$ & $\begin{array}{c}\% \\
\text { gravel }\end{array}$ & $\begin{array}{c}\text { Bulk Density } \\
\left(\mathrm{g} / \mathrm{cm}^{3}\right)\end{array}$ \\
\hline \hline Bf & 6 & 0.019 & 1.400 & 0.030 & 0.262 & $5.98 \mathrm{E}-04$ & 0.103 & 32.5 & 1.94 \\
\hline Hfs_BC & 18 & 0.201 & 2.507 & 0.033 & 0.380 & $2.25 \mathrm{E}-03$ & 0.089 & 0.4 & 1.65 \\
\hline Hcs_BC & 46 & 0.072 & 2.047 & 0.026 & 0.357 & $5.32 \mathrm{E}-03$ & 0.074 & 2.7 & 1.67 \\
\hline \hline
\end{tabular}

Table 4.7. Statistical Mean Values for U1 and U2 Samples

\begin{tabular}{||l|c|c|c|c|c|c|c|c|c||}
\hline \multicolumn{1}{||c|}{$\begin{array}{c}\text { Soil } \\
\text { Class }\end{array}$} & Count & $\begin{array}{c}\alpha \\
(1 / \mathrm{cm})\end{array}$ & $n$ & $\begin{array}{c}\theta_{R} \\
\left(\mathrm{~cm}^{3} / \mathrm{cm}^{3}\right)\end{array}$ & $\begin{array}{c}\theta_{s} \\
\left(\mathrm{~cm}^{3} / \mathrm{cm}^{3}\right)\end{array}$ & $\begin{array}{c}K_{s} \\
(\mathrm{~cm} / \mathrm{sec})\end{array}$ & $S_{r}$ & $\%$ gravel & $\begin{array}{c}\text { Bulk Density } \\
\left(\mathrm{g} / \mathrm{cm}^{3}\right)\end{array}$ \\
\hline \hline Bf & 6 & 0.019 & 1.400 & 0.030 & 0.262 & $5.98 \mathrm{E}-04$ & 0.103 & 32.5 & 1.94 \\
\hline Hss_U & 6 & 0.007 & 2.347 & 0.066 & 0.437 & $2.49 \mathrm{E}-05$ & 0.147 & 0.0 & 1.58 \\
\hline Hfs_U & 4 & 0.013 & 2.451 & 0.042 & 0.347 & $1.71 \mathrm{E}-05$ & 0.122 & 0.0 & 1.72 \\
\hline Hg_U & 3 & 0.011 & 1.845 & 0.029 & 0.150 & $2.88 \mathrm{E}-04$ & 0.204 & 57.1 & 2.09 \\
\hline PPlz_U & 5 & 0.004 & 2.285 & 0.047 & 0.398 & $7.27 \mathrm{E}-06$ & 0.117 & 0.1 & 1.71 \\
\hline Rg_U & 7 & 0.014 & 1.675 & 0.047 & 0.315 & $7.83 \mathrm{E}-05$ & 0.138 & 16.5 & 1.82 \\
\hline \hline
\end{tabular}


Table 4.8. Statistical Mean Values for 200-ZP-1 Samples

\begin{tabular}{||l|c|c|c|c|c|c|c|c|c||}
\hline \hline \multicolumn{1}{|c|}{$\begin{array}{c}\text { Soil } \\
\text { Class }\end{array}$} & Count & $\begin{array}{c}\alpha \\
(1 / \mathrm{cm})\end{array}$ & $n$ & $\begin{array}{c}\theta_{R} \\
\left(\mathrm{~cm}^{3} / \mathrm{cm}^{3}\right)\end{array}$ & $\begin{array}{c}\theta_{s} \\
\left(\mathrm{~cm}^{3} / \mathrm{cm}^{3}\right)\end{array}$ & $\begin{array}{c}K_{s} \\
(\mathrm{~cm} / \mathrm{sec})\end{array}$ & $S_{r}$ & $\%$ gravel & $\begin{array}{c}\text { Bulk Density } \\
\left(\mathrm{g} / \mathrm{cm}^{3}\right)\end{array}$ \\
\hline \hline Bf & 6 & 0.0191 & 1.400 & 0.030 & 0.262 & $5.98 \mathrm{E}-04$ & 0.103 & 32.5 & 1.94 \\
\hline Hss_Z & 5 & 0.003 & 1.840 & 0.047 & 0.351 & $6.55 \mathrm{E}-06$ & 0.133 & 0.0 & 1.80 \\
\hline Hfs_Z & 4 & 0.008 & 1.903 & 0.042 & 0.366 & $7.88 \mathrm{E}-05$ & 0.113 & 0.8 & 1.68 \\
\hline Hes_Z & 5 & 0.067 & 1.692 & 0.021 & 0.292 & $1.49 \mathrm{E}-03$ & 0.069 & 0.0 & 1.56 \\
\hline Hg_Z & 8 & 0.016 & 1.703 & 0.022 & 0.155 & $3.65 \mathrm{E}-03$ & 0.133 & 53.4 & 1.79 \\
\hline PPlz_Z & 4 & 0.007 & 2.203 & 0.033 & 0.448 & $7.11 \mathrm{E}-04$ & 0.073 & 1.0 & 1.58 \\
\hline PPlc_Z & 13 & 0.011 & 1.750 & 0.056 & 0.286 & $1.03 \mathrm{E}-03$ & 0.190 & 15.07 & 1.68 \\
\hline \hline
\end{tabular}

Table 4.9. Statistical Mean Values for 200 West Area Samples

\begin{tabular}{|c|c|c|c|c|c|c|c|c|c|}
\hline \multicolumn{10}{|c|}{$200 \mathrm{~W}$} \\
\hline $\begin{array}{c}\text { Soil } \\
\text { Class }\end{array}$ & Count & $\begin{array}{c}\alpha \\
(1 / \mathrm{cm})\end{array}$ & $n$ & $\begin{array}{c}\theta_{R} \\
\left(\mathrm{~cm}^{3} / \mathrm{cm}^{3}\right)\end{array}$ & $\begin{array}{c}\theta_{s} \\
\left(\mathrm{~cm}^{3} / \mathrm{cm}^{3}\right)\end{array}$ & $\begin{array}{c}K_{s} \\
(\mathrm{~cm} / \mathrm{sec})\end{array}$ & $S_{r}$ & $\begin{array}{c}\% \\
\text { gravel }\end{array}$ & $\begin{array}{c}\text { Bulk Density } \\
\left(\mathrm{g} / \mathrm{cm}^{3}\right)\end{array}$ \\
\hline $\mathrm{Bf}$ & 6 & 0.032 & 1.4 & 0.03 & 0.262 & $1.50 \mathrm{E}-02$ & 0.102 & 32.5 & 1.94 \\
\hline Hss_2W & 11 & $4.53 \mathrm{E}-03$ & 2.116 & 0.057 & 0.398 & $1.91 \mathrm{E}-05$ & 0.141 & 0.00 & 1.67 \\
\hline Hfs_2W & 8 & $1.02 \mathrm{E}-02$ & 2.177 & 0.042 & 0.356 & $3.67 \mathrm{E}-05$ & 0.118 & 0.38 & 1.70 \\
\hline Hcs_2W & 7 & $4.15 \mathrm{E}-02$ & 1.759 & 0.026 & 0.318 & $1.09 \mathrm{E}-03$ & 0.077 & 2.14 & 1.65 \\
\hline Hgs_2W & 2 & 7.90E-03 & 2.223 & 0.030 & 0.273 & $2.35 \mathrm{E}-04$ & 0.133 & 24.00 & 1.81 \\
\hline Hg_2W & 12 & $1.65 \mathrm{E}-02$ & 1.745 & 0.027 & 0.154 & $1.48 \mathrm{E}-03$ & 0.172 & 54.36 & 1.89 \\
\hline $\mathrm{PPlz}$ & 9 & $5.57 \mathrm{E}-03$ & 2.101 & 0.034 & 0.420 & 5.57E-05 & 0.080 & 0.44 & 1.68 \\
\hline PPlc & 16 & $1.08 \mathrm{E}-02$ & 1.727 & 0.072 & 0.306 & $5.00 \mathrm{E}-04$ & 0.214 & 16.73 & 1.71 \\
\hline $\operatorname{Rg} \_2 W$ & 8 & 1.32E-02 & 1.753 & 0.126 & 0.297 & $1.06 \mathrm{E}-04$ & 0.334 & 22.18 & 1.84 \\
\hline
\end{tabular}

The high, low, mean, and standard deviation values were calculated for each soil hydraulic property class. However, most of these soil classes do not have enough data points to qualify as a statistically significant distribution (Warrick et al. 1986). The residual water content $\left(\theta_{r}\right)$, saturated water content $\left(\theta_{s}\right)$, bulk density $\left(\rho_{b}\right)$, gravel content, and fitting parameter $n$ are assumed as normal Gaussian distributions based, in part on the report of Khaleel and Freeman (1995). The saturated hydraulic conductivity $\left(K_{s}\right)$ and the fitting parameter $\alpha$, are treated as lognormal distributions, in accordance with Domenico and Schwartz (1990) and Carsel and Parrish (1988), respectively. In addition to the normal distribution statistics, the statistics for the log-normal parameters are also included and truncation values are calculated for all parameters. Although Carsel and Parrish (1988) have reported cross-correlations between a number of these parameters, recent examination of the Hanford Site data have not found any statistically significant correlations. $^{12}$

In addition to statistical tables for the full suite of samples, subsets of samples were also assembled near specific areas of interest; specifically, 200 West Area, BC cribs and trenches, 200-UP-1 (216-U-1

\footnotetext{
${ }^{12}$ Freeman EJ and ML Rockhold. 2003. Estimation of Site-Specific Probability Distribution Functions for Soil Hydraulic Parameters using Bayesian Updating. Letter Report, Pacific Northwest National Laboratory, Richland, Washington.
} 
and -2 cribs), and the 200-ZP-1 (216-Z-9 trench). The site-specific data for the 216-U-1 and -2 cribs were derived from the S-SX Tank Farm, 216-U-1 and -2 crib, and Environmental Restoration Disposal Facility samples. The 216-Z-9 site-specific data consists of samples from the T, TX-TY Waste Management Area, the 216-ZP-1 area, the 218-W-5 burial grounds, and project C-018-H. A composite table of all 200 West Area samples was created to provide a greater sample population that is unique to the unsaturated hydraulic properties of sediments found beneath the 200 West Area. The site-specific data for the $\mathrm{BC}$ cribs and trenches are derived from the closest sites to that facility, the immobilized low-activity waste (ILAW) site, the Sisson and Lu Injection test site, and the U.S. Ecology site. A disadvantage to including only those sample sets close to the site of interest is that the population size is greatly diminished, resulting in cases where the statistical distribution may not adequately represent the actual formation properties.

Methods to increase the sample size (e.g., use an inverse distance weighting) ${ }^{13}$ or otherwise incorporate information from large data sets (e.g., Bayesian Updating), ${ }^{13}$ and yet still account for sitespecific information are being examined. However, for the purposes of this data package, the site-specific parameter distributions are based on equally weighted parameter values from samples nearest the site of interest. Tables 4.5 to 4.9 present mean hydraulic property estimates for the Hanford site-wide data set as well as the site-specific data sets.

\subsubsection{Site-Wide Hydraulic Property Distributions}

The site-wide sample distribution (Table 4.5) uses all the data in each of the soil classes to calculate the statistical mean van Genuchten parameters that were then used to generate the hydraulic properties curves shown in Figures 4.1, 4.2, and 4.3. Figure 4.1 shows that the Hanford formation silty sand (Hss) and the Cold Creek unit silt (PPlz) attain the highest saturated water content, while the Hanford formation coarse gravels $(\mathrm{Hrg})$ and Hanford formation sandy gravels $(\mathrm{Hg})$ have the lowest water content. Table 4.5 illustrates that the finer textured sediments typically have greater saturated water content, lower saturated hydraulic conductivity and lower bulk density. In contrast, the coarser sediments typically have lower saturated water contents, higher saturated hydraulic conductivity, and higher bulk densities. The properties in Table 4.5 and Figure 4.1 represent matrix characteristics and do not account for preferential flow through cracks and fractures (Freeman et al. 2002; Freeman and Last 2003).

Uncertainties arise from the following: drilling and sampling methods used to collect the samples (e.g., core barrel, splits poon), how the samples are handled in the lab (e.g., repacked), subjectivity in assigning the samples to various geologic formations and facies (i.e., soil classes), systematic or measurement errors associated with the laboratory analyses, and scaling issues when using small sample data to represent larger field scale processes.

The saturated hydraulic conductivity is highest for the Hanford coarse gravel (Hrg) and lowest for the silty Cold Creek unit (PPlz) and Hanford formation silty sand (Hss). The hydraulic conductivity as a function of pressure head (Figure 4.2) does not drop off rapidly as would be expected for some of the coarse textured sediment (e.g., Hrg). This may indicate a higher fraction of fines than accounted for in those samples.

\footnotetext{
${ }^{13}$ Freeman EJ. May 14, 2003. Revised SAC Statistical Properties Tables of Vadose Hydraulic Properties. Letter Report, Pacific Northwest National Laboratory, Richland, Washington.
} 


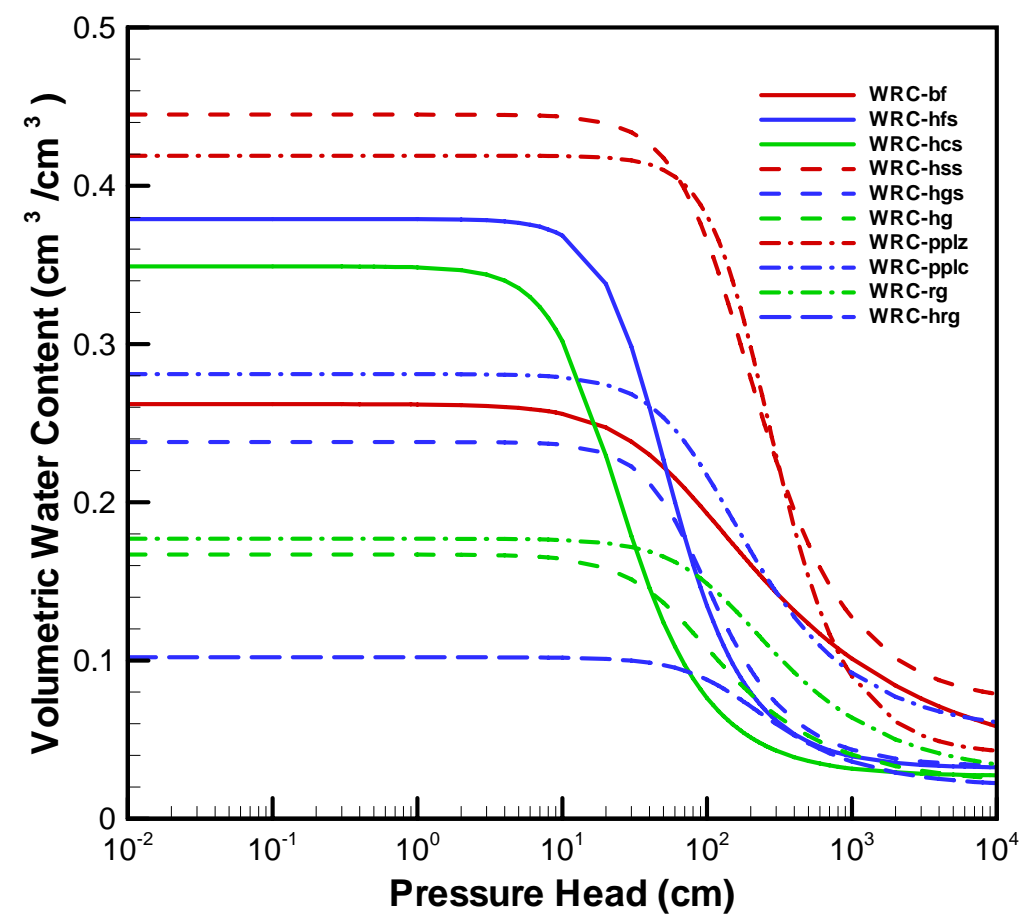

Figure 4.1. Statistically Derived Water Retention Functions Calculated from the van Genuchten Parameters for Each Soil Class in the Site-Wide Distribution (see Table 4.5) (Note that pressure head is negative.)

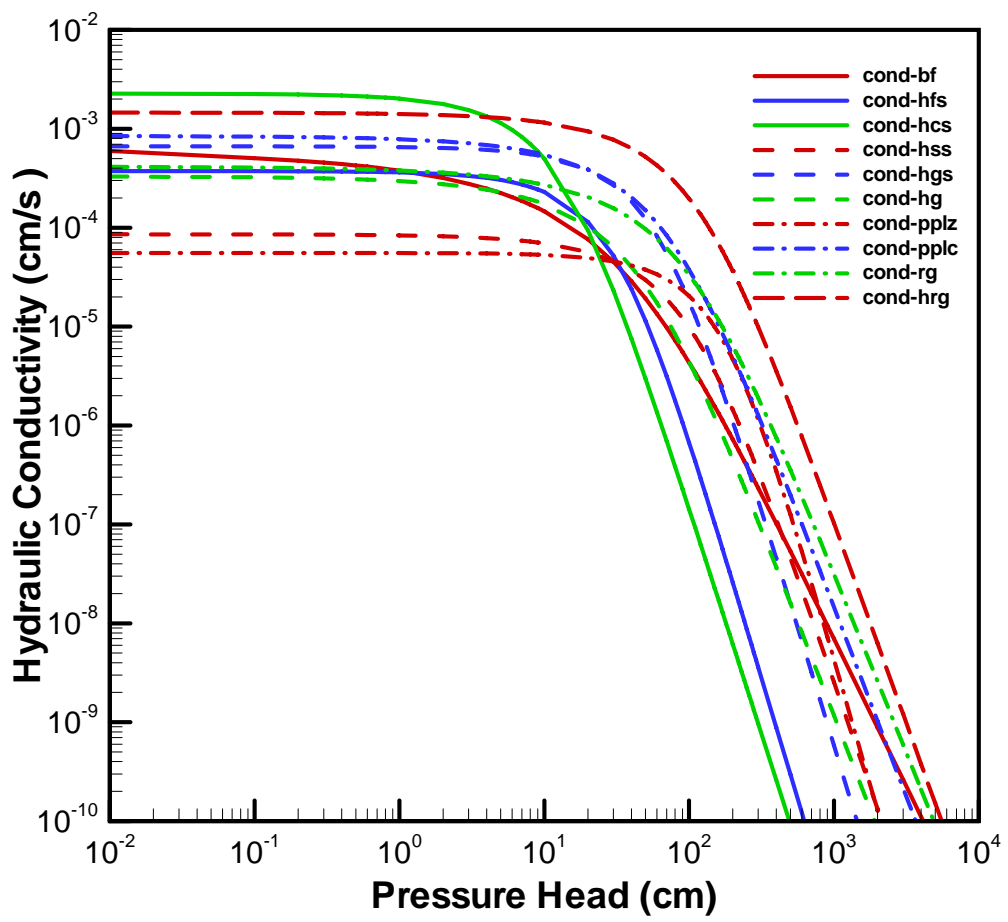

Figure 4.2. Soil Class Specific Hydraulic Conductivity Curves for the Site-Wide Distribution Derived from the Saturated Hydraulic Conductivity $\left(K_{s}\right)$ Values Listed in Table 4.5 Using the Mualem Equation (Note that pressure head is negative.) 


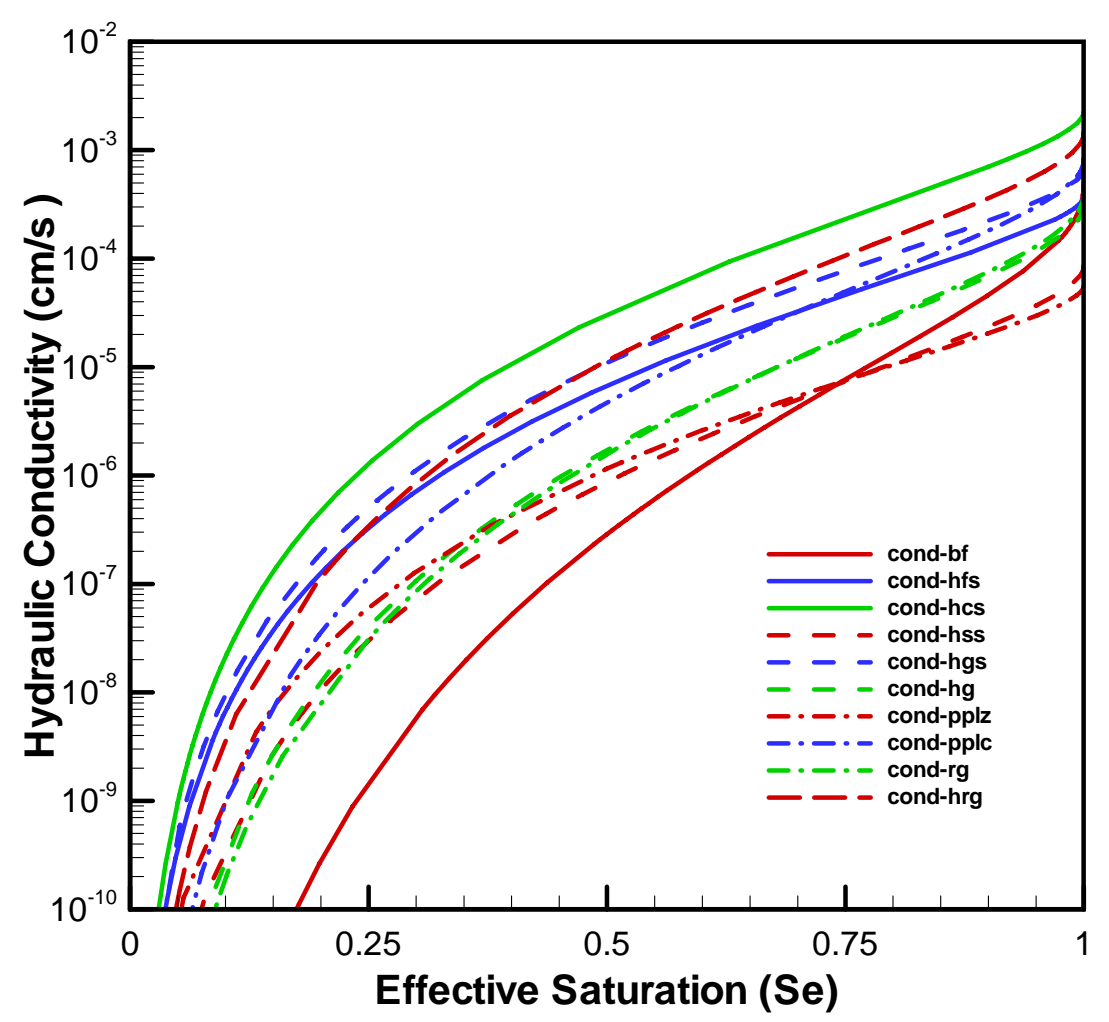

Figure 4.3. Soil Class Specific Hydraulic Conductivity Curves Versus Effective Saturation for the SiteWide Distribution

\subsubsection{Site-Specific Hydraulic Property Distributions}

When evaluating the hydraulic properties at a particular location it is valuable to only use those data that are most representative of the hydraulic properties at that site. Three sites were selected for generation of site-specific hydraulic properties data sets: (1) the BC cribs and trenches, (2) the 216-U-1 and -2 crib area, and (3) the 216-Z-9 trench area. A fourth set of hydraulic property data was generated for all 200 West Area samples. Tables 4.6 to 4.9 list the mean hydraulic property data derived for each of these specific areas. Appendix B provides the hydraulic property distributions for the each site-wide and site-specific soil class.

\subsubsection{Application to Vadose Zone Simulations}

Each vadose zone hydrostratigraphic template represents a one-dimensional soil column made up of several hydrostratigraphic units. Each hydrostratigraphic unit occupies a number of model nodes depending on the thickness of the hydrostratigraphic unit. The hydraulic properties for each hydrostratigraphic unit are determined by stochastically sampling the probability distribution function for each parameter, for a given simulation (realization). All model nodes within a single hydrogeologic unit are assigned the same hydraulic properties for a single realization. 


\subsubsection{Conditioning of One-Dimensional Flow Simulations Against Detailed Site-Specific Assessments}

Several studies were conducted to examine multiple hydrostratigraphic models and two-dimensional vadose zone simulations of selected waste sites where previous one-dimensional simulations failed to provide reasonable results. One of the main areas of interest was the $\mathrm{BC}$ cribs and trenches. Here multiple hydrostratigraphic profiles (templates) were developed to generate reasonable two-dimensional representations of the vadose zone. Multiple two-dimensional flow simulations were conducted to provide the basis with which to estimate the wetted column area needed as input for one-dimensional flow and transport simulations (Appendix C). Additional work was aimed at trying to incorporate the up-scaling techniques developed through the Science and Technology Project (Zhang et al. 2002) to improve hydraulic property estimates for the $\mathrm{BC}$ crib and trench area.

Another main area of interest was the 216-U-1 and -2 cribs. Here, the approach taken was to model this site as two separate sites to account for the multiple release mechanisms. Field data indicate this location experienced a fast path release (perhaps due to flow through a borehole annulus or similar mechanism) that allowed a significant quantity of contamination to effectively bypass the vadose zone and travel directly to the unconfined aquifer. Because the mechanism for this fast path is not characterized, the 216-U-1 and -2 site was modeled with an empirical two-site arrangement wherein a duplicate site, "216-U-1 and -2-Fast" was defined that uses a special hydrostratigraphic template that immediately releases any waste it receives directly to groundwater. No waste is routed to this "fast" site by the inventory model. However, a 'remedial action' is declared in the overall SAC model input set that declares that a fraction of the waste in the vadose zone in the year of the suspected fast path event (1988) is to be 'remediated' from 216-U-1 and -2 site and sent to the 216-U-1 and -2-Fast site (which effectively sends it immediately to the unconfined aquifer). The fraction transferred to the aquifer using this mechanism was determined by dividing the estimated contaminant mass in the aquifer after the fast path event (as determined by history matching data prepared by Murray et al. [2004]) by the total mass in the vadose zone at 216-U-1 and -2 in 1988 (as modeled in an initial median-inputs simulation of the 216-U-1 and -2 site). Thus, the model is effectively forced to deliver the field-observed mass of contaminant directly from the vadose zone to groundwater in a single event in 1988.

Several other sites (e.g., IDF [formerly the Immobilized Low-Level Activity Waste facility] and the tank farms) were the subject of more detailed site-specific performance assessments. Thus, efforts were made to incorporate the results of these performance assessments more directly into large-scale Hanford assessments so that the central tendency of the results mimics the deterministic results from these sitespecific assessments. None of these more detailed site-specific performance assessments are stochastic, so the results are used directly in SAC median-inputs runs in place of the embedded STOMP onedimensional model results. The results are also used to calibrate the STOMP one-dimensional model at these sites so that the stochastic simulations will better mimic the expected behavior of the site-specific assessments where they run stochastically with the SAC data. This is done by comparing the release rates of the median-inputs STOMP model in SAC for these sites to the more-detailed site-specific modeling results for a range of vadose zone wetted area scaling factors, and choosing the factor that results in the best agreement for use in later stochastic simulations. This is similar to the approach used for the $\mathrm{BC}$ cribs and trenches in which the one-dimensional model used in SAC was calibrated against idealized two-dimensional models. 


\subsubsection{Transport Parameters}

The two key parameters that govern transport of non-sorbed contaminants in the subsurface are the dispersion coefficient and the species-specific water-content-dependent diffusion coefficient. Dispersion is the mixing and spreading of contaminants that is caused by variations in water velocity. The dispersion process is represented by the dispersion coefficient, which relates the dispersive solute flux to the solute concentration gradient. The dispersion coefficient is the product of dispersivity $(\lambda)$ and pore water velocity. At the scale of soil core or laboratory column, the dispersivity reflects the variation in water velocity within pores and around grains and is sometimes called microdispersivity. In field settings, interbedding and interfingering of materials with different conductivities creates additional variations in water velocity that lead to higher dispersivities. These field-based values are typically referred to as macrodispersivities; it is these values that are needed for Hanford assessments.

The value of dispersivity depends on the direction of water flow. Longitudinal dispersivity addresses dispersion that occurs in the direction of flow. Transverse dispersivity addresses dispersion that occurs orthogonal to the direction of flow. Longitudinal dispersivity is typically larger than transverse dispersivity and both are scale dependent (Khaleel et al. 2002). Field measurements of dispersivity (i.e., macrodispersivity) are extremely rare and small-scale laboratory measurements have only marginal utility in estimating field values (Meyer et al. 2004). Estimates of longitudinal macrodispersivity for large-scale Hanford assessments were primarily taken from Ho et al. (1999) and are presented with the hydraulic property data in Appendix B. In the absence of data, longitudinal macrodispersivity values are often based on simple guidelines related to the size of the computational elements in numerical simulation codes. These simple guidelines (based on the work by Gelhar et al. 1985), generally assume that the vertically oriented longitudinal macrodispersivity is 0.01 times thickness (length) of the computational element.

Dispersion during transport of contaminants can potentially be enhanced when the contaminants react with either the sediments or the fluid or gas constituents. Although not entirely understood (e.g., Khaleel and Heller 2003), enhanced macrodispersion has been estimated at specific sites at Hanford. For example, the modeling data package for the S-SX FIR (Khaleel et al. 2001) suggested that dispersion of cesium was enhanced by 10 to $15 \%$ for all but the Cold Creek (a.k.a Plio-Pleistocene) unit, for which the enhancement factor was roughly a factor of 2. Enhanced macrodispersion is not addressed in the current version of the Hanford assessment tool but will be considered for future versions.

The diffusion coefficient is the proportionality factor in Fick's Law that relates the diffusive transport flux to the gradient in solute concentration (Meyer et al. 2004). According to Meyer et al. (2004), the diffusion process results in mass transport from regions of high solute concentration to regions of lower concentration and occurs as a result of the random thermal motion (Brownian motion) of molecules and atoms. The diffusion process will be represented in large-scale Hanford assessments. 
In the subsurface environment, porous medium and the water content affect the diffusion process. Thus, the effective diffusion coefficient $D_{\ell e}^{C}$ is computed using a conventional approach (White and Oostrom 2000):

$$
D_{\ell e}^{C}=\tau_{\ell} s_{\ell} n_{D} D_{\ell}^{C}
$$

where: $\quad \tau_{\ell}=$ the liquid phase tortuosity

$s_{\ell}=$ the liquid phase saturation

$n_{D}=$ the diffusive porosity

$D_{\ell}^{C}=$ the aqueous-phase molecular diffusion coefficient at $20^{\circ} \mathrm{C}$

The liquid phase tortuosity $\tau_{\ell}$ is computed from the methods of Millington and Quirk (1959) based on theoretical pore-size distribution models for partially and fully saturated two-phase systems (White and Oostrom 2000):

$$
\tau_{\ell}=\left(n_{D}\right)^{10 / 3}\left(s_{\ell}\right)^{4 / 3}
$$

The liquid phase saturation $s_{\ell}$ is computed from van Genuchten constitutive relations (van Genuchten 1980) that estimates aqueous-phase saturation as a function of liquid phase pressure, a state variable of the governing equations solved by the STOMP simulator. The diffusive porosity is an input parameter provided for each soil type by this data package; for Hanford assessments conducted using SAC Rev. 1, diffusive porosity is assumed equal to total porosity, $n_{T}$, (which is represented by the saturated water content, $\theta_{s}$, as provided in Appendix B and described earlier in this section). The aqueous-phase molecular diffusion coefficient at $20^{\circ} \mathrm{C}$ is $1.05 \times 10^{-5} \mathrm{~cm}^{2} / \mathrm{s}$.

\subsection{Contaminant Distribution Coefficients}

Geochemical properties were assigned to each hydrogeologic unit, in a manner similar to that in the 1998 Composite Analysis (Kincaid et al. 1998). The waste characteristics were assumed to dominate the near-field mobility of the contaminants in the vadose zone. After being in contact with vadose zone sediments and soil water for some distance, the waste undergoes a change in its mobility based on buffering of the contaminant solution by the vadose zone sediments. Thus, distribution coefficients were defined separately for each contaminant in the upper vadose zone (near-field or high impact zone) and in the lower vadose zone (far-field or intermediate impact zone) (Kincaid et al. 1998).

Distribution coefficient zones were defined as either high impact or intermediate impact depending on the nature of the contamination fluid. Zones in which the organic concentration, $\mathrm{pH}$, or salt concentration in the fluids may have affected the $K_{d}$ values were designated high-impact. Zones in which the acidic or basic nature of the wastes was estimated to have been neutralized by the natural soil were designated intermediate impact. Kincaid et al. (1998) estimated the depths of this transition zone by examining the peak location of beta/gamma contamination (as presented by Fecht et al. 1977) for the 200 Area cribs receiving very acid or high-salt/very basic waste. In general, these transition depths ranged from 10 to $40 \mathrm{~m}$. Given the limited data available on which to base further interpretations on the depths of transition, and the desire to simplify the numerical simulations, a slightly different approach is used here. Generally, the hydrogeologic unit into which waste streams were introduced was designated as high-impact regardless of waste stream characteristics. If those hydrogeologic units were thin (e.g., $<3 \mathrm{~m}$ ), then the 
hydrogeologic unit immediately below was also designated high-impact. All other hydrogeologic units lower in the profile were designated intermediate impact. This approach enables us to keep the numerical simulations relatively simple by using the existing number of hydrogeologic units (i.e., we did not have to add new layers to make the $K_{d}$ change within a single hydrogeologic unit). At the same time, the depths of change, corresponding to the thickness of the hydrogeologic units, are still on the same scale (tens of meters) as those used by Kincaid et al. (1998). Appendix A provides the detailed hydrogeologic columns and locations of the various $K_{d}$ zones, for each base template.

As described in Section 3.2.3, several $K_{d}$ classes were defined for mapping distribution coefficients to high or intermediate impact zones and chemical waste type. These $K_{d}$ classes were labeled using a two or three digit alpha-numeric code. The first digit represents the waste chemistry type (numbers 1 through 6 ) (see Table 3.5). The second digit represents the impact zone (i.e., $\mathrm{H}$ for high impact [i.e., near field vadose zone], I for intermediate impact [i.e., far field vadose zone], or $\mathrm{G}$ for the zone not impacted [i.e., very far field vadose] and groundwater). For $K_{d}$ values in the intermediate impact zone, a third digit was added to identify those $K_{d}$ classes adjusted for the gravel-dominated hydrostratigraphic units. Since significant gravel content decreases $K_{d}$ values (Kaplan and Serne 2000), each $K_{d}$ class in the intermediate impact zone was subdivided into gravel rich and gravel poor zones. $K_{d}$ classes with a third digit of '1' pertain to gravel poor (i.e., sand-dominated) strata and $K_{d}$ classes ending in a '2' pertain to gravel rich (i.e., gravel dominated) strata (See Section 3.2.3).

Kincaid et al. (2004) identified sixteen radionuclides as contaminants of concern to be addressed in a large-scale Hanford assessment, see Table 4.10. However, two of these radionuclides, radium-226 and protactinium-231 are to be simulated as progeny of uranium-234 and uranium-238, and will not be directly incorporated into the flow and transport simulations for large-scale Hanford assessments. Thus, $K_{d}$ estimates were not developed for those contaminants. For all other contaminants of interest, a best estimate $K_{d}$ value and range (minimum and maximum) were developed for each $K_{d}$ class. A brief discussion for each contaminant is presented below. Probability distribution functions for these $K_{d}$ values were generated according to the following set of rules and derived from the minimum, maximum, and best estimate $K_{d}$ values.

Case \#1: Where the minimum estimate, best estimate, and maximum estimate were all greater than zero, a lognormal distribution was assumed. The best estimate was assigned to the median value. The minimum estimate was assigned to the lower $1 \%$ tail of the distribution, and the maximum estimate was not used in defining the distribution.

Case \#2: Where the minimum estimate was zero, but the best estimate and maximum estimate were greater than zero. A lognormal distribution was used, with the best estimate assigned to the median value, the lower $1 \%$ tail of the distribution assigned to the value 0.001 , and the maximum estimate used to define a probability truncation limit for the upper tail of the distribution (if less than 0.99 probability, otherwise truncation was set to 0.99 ).

Case \#3: Where the minimum and best estimates were zero, but the maximum estimate was greater than zero. A composite distribution was used. The value zero was assigned a $50 \%$ probability. The other portion of the distribution was assigned a triangular distribution where the minimum and mode were both zero and the maximum was assigned to the upper tail estimate.

Case \#4: Where the best estimate is 'unsuitable' or not provided, a uniform distribution is assumed between the minimum and maximum values. 
Table 4.10. List of Contaminants of Concern to be Included in large-scale Hanford assessments (Kincaid et al. 2004)

\begin{tabular}{|c|c|c|}
\hline \multicolumn{3}{|c|}{ Contaminants of Concern } \\
\hline & Tritium & Carbon-14 \\
\hline & Chlorine-36 & Selenium-79 \\
\hline & Strontium-90 & Technetium-99 \\
\hline & Iodine-129 & Cesium-137 \\
\hline & Europium-152 ${ }^{(\mathrm{a})}$ & Radium-226 $6^{(b)}$ \\
\hline & Protactinium-231 ${ }^{(c)}$ & Uranium-233 \\
\hline & Uranium-234 ${ }^{(\mathrm{d})}$ & Uranium-235 ${ }^{(\mathrm{e})}$ \\
\hline & Uranium-238 $8^{(\mathrm{d})}$ & Neptunium-237 \\
\hline (a) & \multicolumn{2}{|c|}{$\begin{array}{l}\text { Europium-152 will be simulated using median values in a deterministic simulation. Because of its relatively } \\
\text { short decay half-life, the simulation will extend at most two or three hundred years beyond Hanford Site } \\
\text { closure. } \\
\text { Radium- } 226 \text { will be simulated as progeny of uranium- } 234 \text { and uranium-238. It will be further evaluated in } \\
\text { Hanford assessments because the chemical separation for uranium may have placed radium-226 in Hanford } \\
\text { waste at levels not in secular equilibrium with the uranium in the waste. }\end{array}$} \\
\hline (c) & \multicolumn{2}{|c|}{$\begin{array}{l}\text { Protactinium- } 231 \text { will be simulated as progeny of uranium- } 238 \text {. It will be further evaluated in Hanford } \\
\text { assessments because the chemical separation for uranium may have placed protactinium- } 231 \text { in Hanford } \\
\text { waste at levels not in secular equilibrium with the uranium in the waste. }\end{array}$} \\
\hline (d) & \multicolumn{2}{|c|}{$\begin{array}{l}\text { Uranium-238 and uranium- } 234 \text { will be summed and shown as uranium- } 238 \text { to represent both in this } \\
\text { simulation. It is assumed that these two uranium isotopes are always in secular equilibrium. }\end{array}$} \\
\hline (e) & \multicolumn{2}{|c|}{$\begin{array}{l}\text { Uranium- } 235 \text { is modeled separately to properly generate protactinium- } 231 \text { through radioactive decay and } \\
\text { progeny ingrowth. }\end{array}$} \\
\hline
\end{tabular}

In those cases where a lognormal distribution was assumed, the lognormal distributions were truncated at the $1 \%$ and $99 \%$ levels, thereby preventing the generation of values that could fall below the minimum estimate.

Table 4.11 provides the current compilation of distribution coefficients for each waste stream category and impact zone (derived from the Contaminant Distribution Coefficient Database and Users Guide by Cantrell et al. 2002, 2003a). The hydrostratigraphic templates provided in Appendix A identify the $K_{d}$ classes assigned to each hydrostratigraphic unit for each geographic and site-specific area. As with the hydraulic parameters, all model nodes within a single hydrogeologic unit are assigned the same $K_{d}$ values for a given realization.

\subsubsection{Tritium}

The best estimates for $K_{d}$ values of tritium are zero, and the ranges were selected to be zero for all source and impact zone categories. It is assumed that tritium atoms are incorporated into water molecules and, as a result, no adsorption or other significant geochemical interactions are expected.

\subsubsection{Carbon-14}

Under typical Hanford conditions, it is assumed that carbon-14 will occur predominately as the bicarbonate ion $\left(\mathrm{H}^{14} \mathrm{CO}_{3}{ }^{-}\right)$, though at high $\mathrm{pH}$ bicarbonate will deprotonate to carbonate $\left({ }^{14} \mathrm{CO}_{3}{ }^{2-}\right)$ and at low $\mathrm{pH}$ will protonate to form ${ }^{14} \mathrm{CO}_{2}(\mathrm{aq})$. In general, adsorption of any anion (through surface complexation) onto Hanford sediment in the alkaline $\mathrm{pH}$ range is expected to be negligible because the $\mathrm{pH}$ point 
Table 4.11. Contaminant Distribution Coefficient Estimates by Waste Chemistry Type

\begin{tabular}{|c|c|c|c|c|c|c|c|c|c|}
\hline \multicolumn{10}{|c|}{ Waste Chemistry/Source Category 1: Very Acidic } \\
\hline \multirow[b]{3}{*}{ Analyte } & \multicolumn{3}{|c|}{ High Impact $(1 \mathrm{H})$} & \multicolumn{3}{|c|}{$\begin{array}{l}\text { Intermediate Impact - } \\
\text { Sand (1I1) }\end{array}$} & \multicolumn{3}{|c|}{$\begin{array}{c}\text { Intermediate Impact - } \\
\text { Gravel (1I2) }\end{array}$} \\
\hline & \multicolumn{3}{|c|}{ Kd Estimate $(\mathrm{mL} / \mathrm{g})$} & \multicolumn{3}{|c|}{ Kd Estimate $(\mathrm{mL} / \mathrm{g})$} & \multicolumn{3}{|c|}{ Kd Estimate $(\mathrm{mL} / \mathrm{g})$} \\
\hline & Best & Min & Max & Best & Min & Max & Best & Min & Max \\
\hline \multicolumn{10}{|c|}{ Non-Adsorbing Radionuclides } \\
\hline H3 & 0 & 0 & 0 & 0 & 0 & 0 & 0 & 0 & 0 \\
\hline Tc99 & 0 & 0 & 0.1 & 0 & 0 & 0.1 & 0 & 0 & 0.01 \\
\hline $\mathrm{Cl} 36$ & 0 & 0 & 0 & 0 & 0 & 0 & 0 & 0 & 0 \\
\hline \multicolumn{10}{|c|}{ Moderately Adsorbing } \\
\hline I129 & 4 & 0 & 15 & 0.2 & 0 & 2 & 0.02 & 0 & 0.2 \\
\hline $\mathrm{U} 238$ & 0.2 & 0 & 4 & 0.8 & 0.2 & 4 & 0.08 & 0.02 & 0.4 \\
\hline Se79 & 5 & 3 & 10 & 5 & 3 & 10 & 0.5 & 0.3 & 1 \\
\hline $\mathrm{Np} 237$ & 0 & 0 & 2 & 10 & 2 & 30 & 1 & 0.2 & 3 \\
\hline $\mathrm{C} 14$ & 0 & 0 & 0 & 0 & 0 & 100 & 0 & 0 & 100 \\
\hline \multicolumn{10}{|c|}{ Highly Adsorbing } \\
\hline Sr90 & 10 & 5 & 15 & 22 & 10 & 50 & 6.8 & 3.1 & 15.5 \\
\hline Cs137 & 1000 & 200 & 10000 & 2000 & 200 & 10000 & 620 & 62 & 3100 \\
\hline $\mathrm{Pu} 239$ & 0.4 & 0.1 & 1 & 600 & 200 & 2000 & 186 & 62 & 620 \\
\hline Eu152 & 20 & 1 & 100 & 200 & 10 & 1000 & 62 & 3.1 & 310 \\
\hline
\end{tabular}

\begin{tabular}{|c|c|c|c|c|c|c|c|c|c|}
\hline \multicolumn{10}{|c|}{ "Waste Chemistry/Source Category 2: Very High Salt/Very Basic } \\
\hline \multirow[b]{3}{*}{ Analyte } & \multicolumn{3}{|c|}{ High Impact $(2 \mathrm{H})$} & \multicolumn{3}{|c|}{$\begin{array}{l}\text { Intermediate Impact - } \\
\text { Sand (2I1) }\end{array}$} & \multicolumn{3}{|c|}{$\begin{array}{c}\text { Intermediate Impact - } \\
\text { Gravel (2I2) }\end{array}$} \\
\hline & \multicolumn{3}{|c|}{ Kd Estimate $(\mathrm{mL} / \mathrm{g})$} & \multicolumn{3}{|c|}{ Kd Estimate $(\mathrm{mL} / \mathrm{g})$} & \multicolumn{3}{|c|}{ Kd Estimate $(\mathrm{mL} / \mathrm{g})$} \\
\hline & Best & Min & $\operatorname{Max}$ & Best & Min & Max & Best & Min & Max \\
\hline \multicolumn{10}{|c|}{ Non-Adsorbing Radionuclides } \\
\hline $\mathrm{H} 3$ & 0 & 0 & 0 & 0 & 0 & 0 & 0 & 0 & 0 \\
\hline Tc99 & 0 & 0 & 0.1 & 0 & 0 & 0.1 & 0 & 0 & 0.01 \\
\hline $\mathrm{Cl} 36$ & 0 & 0 & 0 & $\overline{0}$ & 0 & 0 & 0 & 0 & 0 \\
\hline \multicolumn{10}{|c|}{ Moderately Adsorbing } \\
\hline I129 & 0.02 & 0 & 0.2 & 0.1 & 0 & 0.2 & 0.01 & 0 & 0.02 \\
\hline U238 & 0.8 & 0.2 & 4 & 0.8 & 0.2 & 4 & 0.08 & 0.02 & 0.4 \\
\hline Se79 & 0 & 0 & 0.1 & 0 & 0 & 1 & 0 & 0 & 0.1 \\
\hline Np237 & 200 & 100 & 500 & 200 & 100 & 500 & 200 & 100 & 500 \\
\hline $\mathrm{C} 14$ & 100 & 0 & 100 & 7 & 0 & 100 & 7 & 0 & 100 \\
\hline \multicolumn{10}{|c|}{ Highly Adsorbing } \\
\hline Sr90 & 22 & 10 & 50 & 22 & 10 & 50 & 6.8 & 3.1 & 15.5 \\
\hline Cs137 & 10 & 0 & 500 & 100 & 10 & 1000 & 31 & 3.1 & 310 \\
\hline Pu239 & 200 & 70 & 600 & 600 & 200 & 2000 & 190 & 62 & 620 \\
\hline Eu152 & 200 & 10 & 1000 & 200 & 10 & 1000 & 62 & 3.1 & 310 \\
\hline
\end{tabular}


Table 4.11. (contd)

\begin{tabular}{|c|c|c|c|c|c|c|c|c|c|}
\hline \multicolumn{10}{|c|}{ "Waste Chemistry/Source Category 3: Chelates/High Salts } \\
\hline \multirow[b]{3}{*}{ Analyte } & \multicolumn{3}{|c|}{ High Impact $(3 \mathrm{H})$} & \multicolumn{3}{|c|}{$\begin{array}{c}\text { Intermediate Impact - } \\
\text { Sand (3I1) }\end{array}$} & \multicolumn{3}{|c|}{$\begin{array}{c}\text { Intermediate Impact - } \\
\text { Gravel (3I2) }\end{array}$} \\
\hline & \multicolumn{3}{|c|}{ Kd Estimate $(\mathrm{mL} / \mathrm{g})$} & \multicolumn{3}{|c|}{ Kd Estimate $(\mathrm{mL} / \mathrm{g})$} & \multicolumn{3}{|c|}{ Kd Estimate $(\mathrm{mL} / \mathrm{g})$} \\
\hline & Best & Min & Max & Best & Min & Max & Best & Min & Max \\
\hline \multicolumn{10}{|c|}{ Highly Mobile Elements } \\
\hline $\mathrm{H} 3$ & 0 & 0 & 0 & 0 & 0 & 0 & 0 & 0 & 0 \\
\hline Tc99 & 0 & 0 & 0.1 & 0 & 0 & 0.1 & 0 & 0 & 0.01 \\
\hline $\mathrm{Cl} 36$ & 0 & 0 & 0 & 0 & 0 & 0 & 0 & 0 & 0 \\
\hline \multicolumn{10}{|c|}{ Somewhat Mobile Elements } \\
\hline I129 & 0.2 & 0 & 2 & 0.2 & 0 & 2 & 0.02 & 0 & 0.2 \\
\hline $\mathrm{U} 238$ & 0.2 & 0 & 4 & 0.8 & 0.2 & 4 & 0.08 & 0.02 & 0.4 \\
\hline $\mathrm{Se} 79$ & 0 & 0 & 0.1 & 0 & 0 & 1 & 0 & 0 & 0.1 \\
\hline $\mathrm{Np} 237$ & 2 & 1 & 15 & 5 & 2 & 30 & 0.5 & 0.2 & 3 \\
\hline $\mathrm{C} 14$ & 0 & 0 & 100 & 0 & 0 & 100 & 0 & 0 & 100 \\
\hline \multicolumn{10}{|c|}{ Moderately Immobile Elements } \\
\hline Sr90 & 1 & 0.2 & 20 & 10 & 5 & 20 & 3.1 & 1.6 & 6.2 \\
\hline Cs137 & 10 & 0 & 500 & 100 & 10 & 1000 & 31 & 3.1 & 310 \\
\hline $\mathrm{Pu} 239$ & 10 & 1 & 100 & 600 & 200 & 2000 & 190 & 62 & 620 \\
\hline Eu152 & 20 & 1 & 100 & 200 & 10 & 1000 & 62 & 3.1 & 310 \\
\hline
\end{tabular}

\begin{tabular}{|c|c|c|c|c|c|c|c|c|c|c|c|c|}
\hline \multicolumn{13}{|c|}{ Waste Chemistry/Source Category 4: Low Organic/Low Salt/Near Neutral } \\
\hline \multirow[b]{3}{*}{ Analyte } & \multicolumn{3}{|c|}{ High Impact (4H) } & \multicolumn{3}{|c|}{$\begin{array}{l}\text { Intermediate Impact - } \\
\text { Sand (4I1) }\end{array}$} & \multicolumn{3}{|c|}{$\begin{array}{c}\text { Intermediate Impact - } \\
\text { Gravel (4I2) }\end{array}$} & \multicolumn{3}{|c|}{ Groundwater (4G) } \\
\hline & \multicolumn{3}{|c|}{ Kd Estimate $(\mathrm{mL} / \mathrm{g})$} & \multicolumn{3}{|c|}{ Kd Estimate $(\mathrm{mL} / \mathrm{g})$} & \multicolumn{3}{|c|}{ Kd Estimate $(\mathrm{mL} / \mathrm{g})$} & \multicolumn{3}{|c|}{ Kd Estimate $(\mathrm{mL} / \mathrm{g})$} \\
\hline & Best & Min & Max & Best & Min & Max & Best & Min & Max & Best & Min & $\operatorname{Max}$ \\
\hline \multicolumn{13}{|c|}{ Highly Mobile Elements } \\
\hline H3 & 0 & 0 & 0 & 0 & 0 & 0 & 0 & 0 & 0 & 0 & 0 & 0 \\
\hline Tc99 & 0 & 0 & 0.1 & 0 & 0 & 0.1 & 0 & 0 & 0.01 & 0 & 0 & 0.1 \\
\hline $\mathrm{Cl} 36$ & 0 & 0 & 0 & 0 & 0 & 0 & 0 & 0 & 0 & 0 & 0 & 0 \\
\hline \multicolumn{13}{|c|}{ Somewhat Mobile Elements } \\
\hline I129 & 0.2 & 0 & 2 & 0.2 & 0 & 2 & 0.02 & 0 & 0.2 & 0.2 & 0 & 2 \\
\hline U238 & 0.8 & 0.2 & 4 & 0.8 & 0.2 & 4 & 0.08 & 0.02 & 0.4 & 0.8 & 0.2 & 4 \\
\hline $\mathrm{Se} 79$ & 5 & 3 & 10 & 5 & 3 & 10 & 0.5 & 0.3 & 1 & 5 & 3 & 10 \\
\hline $\mathrm{Np} 237$ & 10 & 2 & 30 & 10 & 2 & 30 & 1 & 0.2 & 3 & 10 & 2 & 30 \\
\hline $\mathrm{C} 14$ & 0 & 0 & 100 & 0 & 0 & 100 & 0 & 0 & 10 & 0 & 0 & 100 \\
\hline \multicolumn{13}{|c|}{ Moderately Immobile Elements } \\
\hline $\mathrm{Sr} 90$ & 22 & 10 & 50 & 22 & 10 & 50 & 7 & 3 & 16 & 22 & 10 & 50 \\
\hline Cs137 & 2000 & 200 & 10000 & 2000 & 200 & 10000 & 620 & 62 & 3100 & 2000 & 200 & 10000 \\
\hline $\mathrm{Pu} 239$ & 600 & 200 & 2000 & 600 & 200 & 2000 & 190 & 62 & 620 & 600 & 200 & 2000 \\
\hline Eu152 & 200 & 10 & 1000 & 200 & 10 & 1000 & 62 & 3.1 & 310 & 200 & 10 & 1000 \\
\hline
\end{tabular}


Table 4.11. (contd)

\begin{tabular}{|c|c|c|c|c|c|c|c|c|c|}
\hline \multirow[b]{4}{*}{ Analyte } & \multicolumn{9}{|c|}{ Waste Chemistry/Source Category 5: IDF Vitrified Waste } \\
\hline & \multicolumn{3}{|c|}{ High Impact $(5 \mathrm{H})$} & \multicolumn{3}{|c|}{$\begin{array}{l}\text { Intermediate Impact - } \\
\text { Sand (5I1) }\end{array}$} & \multicolumn{3}{|c|}{$\begin{array}{c}\text { Intermediate Impact - } \\
\text { Gravel (5I2) }\end{array}$} \\
\hline & \multicolumn{3}{|c|}{ Kd Estimate $(\mathrm{mL} / \mathrm{g})$} & \multicolumn{3}{|c|}{ Kd Estimate $(\mathrm{mL} / \mathrm{g})$} & \multicolumn{3}{|c|}{ Kd Estimate $(\mathrm{mL} / \mathrm{g})$} \\
\hline & Best & Min & Max & Best & Min & Max & Best & Min & Max \\
\hline \multicolumn{10}{|c|}{ Non-adsorbing Radionuclides } \\
\hline $\mathrm{H} 3$ & 0 & 0 & 0.1 & 0 & 0 & 0.1 & 0 & 0 & 0.01 \\
\hline Tc99 & 0 & 0 & 0.1 & 0 & 0 & 0.1 & 0 & 0 & 0.01 \\
\hline $\mathrm{Cl} 36$ & 0 & 0 & 0.1 & 0 & 0 & 0.1 & 0 & 0 & 0.01 \\
\hline \multicolumn{10}{|c|}{ Moderately Adsorbing } \\
\hline I129 & 0.1 & 0.04 & 0.16 & 0.1 & 0 & 0.2 & 0 & 0 & 0.02 \\
\hline $\mathrm{U} 238$ & 0.2 & 0 & 800 & 0.2 & 0 & 500 & 0.2 & 0.02 & 5 \\
\hline $\mathrm{Se} 79$ & 1 & 0 & 3 & 2 & 0 & 10 & 0.04 & 0.02 & 1 \\
\hline Np237 & 0.2 & 0.1 & 4 & 0.8 & 0.2 & 5 & 0.08 & 0.04 & 0.5 \\
\hline $\mathrm{C} 14$ & 0 & 0 & 0 & 20 & 5 & 50 & 2 & 0.5 & 5 \\
\hline \multicolumn{10}{|c|}{ Highly Adsorbing } \\
\hline Sr90 & 15 & 4 & 70 & 10 & 0.2 & 50 & 1 & 0.02 & 5 \\
\hline Cs137 & 1.5 & 1 & 25 & 80 & 40 & 2000 & 8 & 4 & 200 \\
\hline $\mathrm{Pu} 239$ & 10 & 5 & 100 & 200 & 80 & 1000 & 20 & 8 & 100 \\
\hline Eu152 & 5 & 2 & 10 & 350 & 100 & 1500 & 35 & 10 & 150 \\
\hline
\end{tabular}

\begin{tabular}{|c|c|c|c|c|c|c|c|c|c|}
\hline \multicolumn{10}{|c|}{ "Waste Chemistry/Source Category 6: IDF Cementitious Waste } \\
\hline \multirow[b]{3}{*}{ Analyte } & \multicolumn{3}{|c|}{ High Impact $(6 \mathrm{H})$} & \multicolumn{3}{|c|}{$\begin{array}{c}\text { Intermediate Impact - } \\
\text { Sand (6I1) }\end{array}$} & \multicolumn{3}{|c|}{$\begin{array}{c}\text { Intermediate Impact - } \\
\text { Gravel (6I2) }\end{array}$} \\
\hline & \multicolumn{3}{|c|}{ Kd Estimate $(\mathrm{mL} / \mathrm{g})$} & \multicolumn{3}{|c|}{ Kd Estimate $(\mathrm{mL} / \mathrm{g})$} & \multicolumn{3}{|c|}{ Kd Estimate $(\mathrm{mL} / \mathrm{g})$} \\
\hline & Best & Min & Max & Best & Min & Max & Best & Min & Max \\
\hline \multicolumn{10}{|c|}{ "Non-Adsorbing Radionuclides } \\
\hline H3 & 0 & 0 & 0.1 & 0 & 0 & 0.1 & 0 & 0 & 0.01 \\
\hline Tc99 & 0 & 0 & 0.1 & 0 & 0 & 0.6 & 0 & 0 & 0.06 \\
\hline $\mathrm{Cl36}$ & 0 & 0 & 0.1 & 0 & 0 & 0.1 & 0 & 0 & 0.01 \\
\hline \multicolumn{10}{|c|}{ Moderately Adsorbing } \\
\hline I129 & 2 & 1 & 5 & 0.25 & 0 & 15 & 0.02 & 0 & 1.5 \\
\hline U238 & 100 & 70 & 250 & 1 & 0.1 & 4 & 1 & 0.01 & 7 \\
\hline Se79 & 1 & 0 & 300 & 7 & 3 & 15 & 0.7 & 0.3 & 1.5 \\
\hline Np237 & 200 & 140 & 500 & 15 & 2 & 25 & 1.5 & 0.2 & 2.5 \\
\hline $\mathrm{C} 14$ & 0 & 0 & 0 & 5 & 0.5 & 1000 & 0.5 & 0.05 & 100 \\
\hline \multicolumn{10}{|c|}{ Highly Adsorbing } \\
\hline Sr90 & 10 & 7 & 25 & 14 & 5 & 200 & 1.4 & 0.5 & 20 \\
\hline Cs137 & 30 & 20 & 50 & 2000 & 500 & 4000 & 200 & 50 & 400 \\
\hline $\mathrm{Pu} 239$ & 500 & 100 & 1000 & 150 & 50 & 2000 & 15 & 5 & 200 \\
\hline Eu152 & 500 & 400 & 1000 & 300 & 60 & 1300 & 30 & 6 & 130 \\
\hline
\end{tabular}

of zero charge (pzc) or $\mathrm{pH}_{p z c}$ for most minerals is below the typical $\mathrm{pH}$ of Hanford groundwater. For example, the $p H_{p z c}$ for montmorillonite and feldspar is approximately 3 (Stumm and Morgan 1996). The $p H_{p z c}$ for calcite (at $p_{\mathrm{CO} 2}=10^{-3.5} \mathrm{~atm}$ ) is approximately 8.2 and goes down to 6.5 at $p_{\mathrm{CO} 2}=1 \mathrm{~atm}$. This indicates that Hanford sediments will be dominated by negatively charged sites in the alkaline $\mathrm{pH}$ range; conditions which are not conducive to adsorption of anions. This is clearly demonstrated with $\mathrm{CrO}_{4}{ }^{2-}$ (Cantrell et al. 2002). 
Although surface adsorption of $\mathrm{H}^{14} \mathrm{CO}_{3}{ }^{-}$or ${ }^{14} \mathrm{CO}_{3}{ }^{2-}$ is not likely to be significant under Hanford conditions, two other processes could potentially remove these species from solution. These two mechanisms are isotopic exchange and precipitation. Calcite is common within Hanford sediment (often as caliche or mineral grain coatings) and is the most readily available carbonate phase for solid surface exchange with ${ }^{14} \mathrm{CO}_{3}{ }^{2-}$. Like ion exchange, isotopic exchange can be written as a chemical reaction (Garnier 1985):

$$
{ }^{12} C_{s}+{ }^{14} C_{m}={ }^{14} C_{s}+{ }^{12} C_{m}
$$

where $C_{s}$ and $C_{m}$ refer to the carbon content in the stationary and mobile phases, respectively. The equilibrium constant can be defined as:

$$
K\left({ }^{14} C /{ }^{12} C\right)=\left[\left({ }^{14} C /{ }^{12} C\right)_{s} /\left({ }^{14} C /{ }^{12} C\right)_{m}\right]
$$

This equilibrium constant is a pure thermodynamic constant. At a given temperature, it leads to a selectivity that is based only on the mass difference. Application of this concept to selection of a $K_{d}$ value for ${ }^{14} C$ is problematic. Previous laboratory work using columns of a natural carbonate sand (aragonite and calcite) has demonstrated that the exchange process occurs at the first mono-molecular layer (Garnier 1985); however, the adsorption process was found to be complicated by kinetic and other factors. Kinetic factors that affected the results included flow rate and sediment aging. Adsorption of other ions such as $\mathrm{HPO}_{4}^{-}$was also found to significantly reduce uptake of $\mathrm{H}^{14} \mathrm{CO}_{3}^{-}$by the carbonate surfaces.

In addition to isotopic exchange, the migration of $\mathrm{H}^{14} \mathrm{CO}_{3}{ }^{-}$or ${ }^{14} \mathrm{CO}_{3}{ }^{2-}$ could potentially be retarded through precipitation of sodium/calcium carbonates during exposure to high $\mathrm{pH}$, high salt concentrations in high level waste within tanks, or released from leaking tanks or disposed in trenches. Because of the high $\mathrm{pH}$ conditions within the tanks, any $\mathrm{CO}_{2}$ within the system will be in the form of $\mathrm{CO}_{3}{ }^{2-}$. As a result of the extremely high sodium concentrations within the tanks, most of the $\mathrm{CO}_{3}{ }^{2-}$ will precipitate as $\mathrm{Na}_{2} \mathrm{CO}_{3}$. Initially the ${ }^{14} \mathrm{CO}_{3}{ }^{2-}$ within the tanks is likely to be at trace concentrations and could be below the solubility limit; however, as $\mathrm{CO}_{2}$ from the atmosphere enters the system from openings in the tank, $\mathrm{Na}_{2} \mathrm{CO}_{3}$ will precipitate, removing ${ }^{14} \mathrm{CO}_{3}{ }^{2-}$ in the process. If a tank leak were to occur, this process would continue within the vadose zone as $\mathrm{CO}_{2}$ from the atmosphere diffuses through the vadose zone into the tank leak impact zone.

Because of the complex processes that impact the mobility of ${ }^{14} C$, a simple linear adsorption model will not adequately describe its transport from a tank leak and through groundwater. As a result of these uncertainties with regard to $\mathrm{H}^{14} \mathrm{CO}_{3}{ }^{-}$or ${ }^{14} \mathrm{CO}_{3}{ }^{2-}$ retardation within Hanford sediments, a large range in $\mathrm{K}_{d}$ values has been selected. The best estimate was taken to be zero and the minimum and maximum were taken to be zero and $100 \mathrm{ml} / \mathrm{g}$, respectively.

\subsubsection{Chlorine-36 (as chloride)}

Chloride $K_{d}$ value measurements are not available for Hanford sediment. This species is not expected to form complexes in Hanford groundwater, nor is it expected to undergo significant adsorption. Chloride is generally considered to exhibit conservative behavior. Measurements of chloride adsorption on clay, sandstone and granite indicated no adsorption (Stenhouse 1995). In acidic soil rich in kaolinite, and iron and aluminum hydrous oxides, some chloride adsorption can occur (Higgo 1988); however, Hanford sediment does not have these characteristics. As a result the minimum, maximum, and best value for the chloride $K_{d}$ value is taken to be $0.0 \mathrm{ml} / \mathrm{g}$. 


\subsubsection{Selenium-79 (as selenate)}

A fair number of $\mathrm{Se}(V I) K_{d}$ values have been determined using natural Hanford sediment (Cantrell et al. 2002). These results indicate that at trace concentrations, adsorption of $\mathrm{Se}(V I)$ is low to moderate with $K_{d}$ values ranging from 3 to $10 \mathrm{~mL} / \mathrm{g}$. At higher $S e(V I)$ concentrations, the $K_{d}$ values are lower ( 0 to $3 \mathrm{~mL} / \mathrm{g}$ ). Acidic conditions typically increase adsorption for anions such as selenate, but this cannot be confirmed for Hanford sediments with the available data. Basic conditions significantly reduce adsorption.

\subsubsection{Strontium-90}

The best estimate $K_{d}$ value for strontium selected for most Hanford impact zones and source categories is $22 \mathrm{ml} / \mathrm{g}$ with a range of 10 to 50 . In acidic high impact zones the best estimate is reduced to $10 \mathrm{ml} / \mathrm{g}$ with a range of 5 to 15 . For the chelates/high salts waste category, the best estimate for the high impact zone is $1 \mathrm{ml} / \mathrm{g}$ with a range of 0.2 to 20 and for the intermediate impact zone the best estimate is $10 \mathrm{ml} / \mathrm{g}$ with a range of 5 to 20 . It is expected that future work will incorporate ongoing multi-component ion exchange data to provide a more scientifically defensible approach for estimating $K_{d}$ values for strontium-90.

\subsubsection{Technetium-99 (as pertechnetate)}

The best estimates for the $K_{d}$ values of pertechnetate are zero. The ranges were taken to be from zero to $0.1 \mathrm{ml} / \mathrm{g}$ for all waste and impact zone categories (except gravel corrected). When comparing this range to values tabulated in Cantrell et al. (2002), the range may appear to be somewhat narrow; however, in most cases when higher $K_{d}$ values were measured, the $K_{d}$ values were not significantly greater than the standard deviation. As a result of this and the fact that it is known that pertechnetate is a very weak adsorbate, this narrow range for the $K_{d}$ values was selected. It should be noted that in environments where reducing agents are present, significantly higher immobilization of pertechnetate could potentially occur that is not represented by this range of $K_{d}$ values.

\subsubsection{Iodine-129 (as iodide)}

The best estimate value selected for the iodide $K_{d}$ appropriate for most Hanford impact zones and waste categories is $0.2 \mathrm{ml} / \mathrm{g}$ with a range of 0 to 2 . For acidic high impact zones, the best estimate value selected is 4 with a range of 0 to 15 . Because $\mathrm{pH}$ effects resulting from acidic discharges were assumed to impact only the high impact zone categories, intermediate impact zones $K_{d}$ values are assumed to be the same as for groundwater. High $\mathrm{pH}$ and high salt appear to reduce $K_{d}$ values. This would result from increasing negative charges on sediment surfaces at high $\mathrm{pH}$ and increased competition with other anions at high salt concentrations. As a result, for high $\mathrm{pH}$ and high salt in the high impact zone a range of $K_{d}$ values of 0 to 0.2 was selected with a best estimate of $0.02 \mathrm{ml} / \mathrm{g}$. For the intermediate impact zone, the best estimate is $0.1 \mathrm{ml} / \mathrm{g}$.

\subsubsection{Cesium-137}

For cesium, the best estimate $K_{d}$ value selected for most Hanford impact zones and waste categories is $2,000 \mathrm{ml} / \mathrm{g}$ with a range of 200 to 10,000 . For acidic source categories and high impact zones, the best estimate is reduced somewhat to $1,000 \mathrm{ml} / \mathrm{g}$. For the high impact zones of the very high salt/very basic 
and chelates/high salts source categories, the best estimate is $10 \mathrm{ml} / \mathrm{g}$ with a range of 0 to 500 ; for the intermediate impact zone the best estimate is $100 \mathrm{ml} / \mathrm{g}$ with a range of 10 to 1,000 . It is expected that future work will incorporate available multi-component ion exchange data to provide a more scientifically defensible approach for estimating $K_{d}$ values for cesium-137.

\subsubsection{Europium-152}

$K_{d}$ value data are not available for adsorption of $E u^{3+}$ on Hanford sediments; however, the chemistry of $\mathrm{Eu}^{3+}$ is very similar to $\mathrm{Am}^{3+}$ (Cantrell 1988; Allard 1982), so $K_{d}$ data available for $\mathrm{Am}^{3+}$ adsorption onto Hanford sediments has been used as an analog for $\mathrm{Eu}^{3+}$ (Cantrell et al. 2002). Review of these data suggests a best estimate of $200 \mathrm{ml} / \mathrm{g}$ with a range of between 10 and 1,000 .

\subsubsection{Uranium}

The best estimate $K_{d}$ value for uranium selected for most Hanford impact zones and source categories is $0.8 \mathrm{ml} / \mathrm{g}$, with a range of 0.2 to 4 . For high impact zones with sources that are acidic or contain chelates, the best estimate value is reduced to $0.2 \mathrm{ml} / \mathrm{g}$ and with a range of 0 to 4 . Although the $K_{d}$ value for very basic conditions is taken to be the same across each impact zone, no reliable data are available at high $\mathrm{pH}$ (one measurement is available at $\mathrm{pH} 11$, but precipitation of the uranium is believed to have occurred in this case).

\subsubsection{Neptunium-237}

$N p(V) K_{d}$ values for Hanford sediment compiled in Cantrell et al. (2002) indicate $N p(V)$ adsorption is generally moderate, with $K_{d}$ values in the general range of 2 to $30 \mathrm{ml} / \mathrm{g}$. Lower values can result at contact times of 1 day or less, and high calcium or chelate concentrations in solution. High solution $\mathrm{pH}$ values can result in very high $K_{d}$ values; however, this may actually be due to precipitation. These results indicate that $N p(V)$ migration from a tank leak should be minimal except when the tank wastes contain chelates. Moderate migration of $N p(V)$ could occur in the vadose zone and groundwater under natural Hanford conditions. Because precipitation is the most likely removal mechanism for $N p(V)$ retardation at high $\mathrm{pH}$, the same range of high $K_{d}$ values was used for the High Impact, Intermediate Impact and the Intermediate Impact - Gravel Zones of the Very High Salt/Very Basic waste category.

\subsection{Hydrostratigraphic Templates}

Of the more than 2,730 waste sites at Hanford and several storage sites, a subset of 1,052 sites has been selected for inclusion in a large-scale Hanford assessment. A unique alphanumeric identification tag (i.e., the site code as given in the Hanford WIDS system), was used to identify each waste site for vadose zone simulation. For example, the 241-T-106 tank was identified by its WIDS site code "241-T-106." Initially each site was assigned to a hydrostratigraphic template based on its location within one of the 17 geographic areas, its site type (surface, near surface, tank, or injection well), and its waste chemistry designation. Other waste site-specific information (location, facility dimensions, and surface cover) was assigned to define the site-specific parameters needed to perform the vadose zone simulations (refer to Last et al. 2006, PNNL-14725, Rev. 1). 


\subsubsection{Assignment of Waste Chemistry Types}

As described in Section 3.2.3, a waste chemistry designation was assigned to each facility to be simulated in the large-scale Hanford assessments. This assignment was based on the original waste chemistry designations used in the 1998 Composite Analysis (Kincaid et al. 1998) and translating these six waste chemistry categories to the six categories used in this study (see Section 3.2.3). In assigning waste chemistry designation to facilities not included in the 1998 Composite Analysis, the following approach was taken:

- Burial grounds, process sewers, ponds, retention basins, buildings, cooling water, stacks, steam condensate, and sand filters were assigned a 'low salt, near neutral' waste type (waste type 4).

- All 241 facilities (e.g., high-level waste tanks) were assigned to either a 'high salt, very basic' waste type (waste type 2) or were designated as containing 'chelates and high salt' (waste type 3) (Kincaid et al. 1998). This simplifying assumption to group essentially all tank waste into just two waste types on which to assign $K_{d}$ values does have obvious limitations.

- Liquid waste facilities that lacked a waste type designation by Kincaid et al. (1998), were assigned a waste type based on waste descriptions by Maxfield (1979) and/or the various Source Aggregate Area Management Study Reports (e.g., DOE 1992; DOE 1993a, c, d, e).

- The WIDS was consulted for all remaining facilities. If the WIDS indicated a waste type description or source for the effluent discharged to a facility, the facility was assigned the comparable waste type based on professional judgment. In a few instances, WIDS provided no information and a waste type 4 was assigned.

- Unplanned releases associated with a facility were assigned the waste type given to the facility.

- Unplanned releases of solids (e.g., animal waste, contaminated equipment, particulates), and atmospheric releases were assigned waste type 4 .

- Unplanned releases with insufficient information were assigned waste type 4.

- Petroleum spills are obviously high organic but they do not fit the idea of waste type 3. Therefore, petroleum spills were assigned waste type 4.

The waste chemistry designations for all facilities represented in Hanford assessments are provided in a master spreadsheet of site-specific parameters and model designations (the General Operational Site Parameters List [GOSPL], see Last et al. 2006).

\subsubsection{Facility Location, Dimensions, and Wetted Area}

The facility location is used to assign geohydrologic properties and specify where waste that is leaving the vadose zone enters the groundwater model. The locations of most waste facilities were obtained from the WIDS. If a facility location was not in WIDS at the time data was being gathered, the location was estimated using other available resources such as the Hanford Site Waste Management Units Report (DOE 2003), the Hanford Site Atlas (BHI 1998) and Maxfield (1979). Facility locations were 
assumed to be the centroid of the facility (in state-plane coordinates). Long linear facilities (such as ditches) generally do not have center coordinates listed in WIDS, so their coordinates were estimated based on visual inspection of the Hanford Site Atlas and/or other site maps.

The facility surface area (also called the facility footprint) was used to estimate the waste release area (e.g., the bottom area of a crib) and the dimensions of the surface barrier (if any). Facility surface areas of many sites were obtained from the WIDS. If the WIDS did not contain the facility surface area, the area was estimated using the facility length and width or the facility diameter. If no data were found to estimate facility area, a default value was assigned. The default values are combinations of three ' $9 \mathrm{~s}$ ' for easy recognition as default values. Table 4.12 lists the default values used for various site types.

Table 4.12. Default Surface Areas

\begin{tabular}{||l|c||}
\hline \multicolumn{1}{|c|}{ Facility (site) Type } & Default Area $\left(\mathrm{m}^{2}\right)$ \\
\hline \hline Unplanned Release, French Drain & 0.999 \\
\hline Storage Tank, Trench & 9.99 \\
\hline Radioactive Process Sewer, Crib & 99.9 \\
\hline Burial Ground & 999 \\
\hline \hline
\end{tabular}

The wetted column area (in essence, the wetted vadose zone area) represents the maximum areal extent of the waste as it migrates to the water table. For at least some sites, the facility area in WIDS represents the fenced boundary rather than the actual waste release area, which can be significantly smaller. It is also possible that the waste at some sites could spread laterally and extend beyond the facility boundaries. Until the waste-zone area of each individual waste site is determined, we will continue to assume, as was done for the 1998 CA (Kincaid et al. 1998), that the waste zone area equals the facility area. The result of this assumption is that, whenever the waste zone area is significantly smaller than the wetted column area, the source term will be dispersed over the larger wetted column and migrate downward more slowly. Conversely, when the waste zone area is larger than the wetted column, the source term will be dispersed over the smaller wetted column area and migrate downward more quickly.

In certain simulation cases, the volume of liquid disposed per facility area exceeds the capacity of the vadose zone to transmit it. Either the vadose zone sediments have very low conductivity values or the facility area is inordinately small (e.g., reverse [injection] wells listed as having a facility area equivalent to the borehole diameter). In the field, this situation would result in significant lateral spreading beyond the facility footprint. The impact of lateral spreading will be represented in large-scale Hanford assessments using the $K_{s}$-dependent approach. In this approach, the wetted vadose zone area $A_{x}\left(m^{2}\right)$ is related to the facility footprint by the scaling factor $\lambda$ (dimensionless), as follows:

$$
A_{x}=\lambda A_{0}=\left[\frac{\left|Q_{\max }\right|}{K_{s / \min } A_{0}}\right] A_{0} ; \lambda \geq 1
$$

where $\quad Q_{\max }=$ the maximum artificial liquid discharge rate $\left(\mathrm{m}^{3} / \mathrm{s}\right)$

$K_{s \mid \min }=$ the minimum hydraulic conductivity $(\mathrm{m} / \mathrm{s})$ of all layers for the given site and realization $A_{0}=$ the facility area $\left(\mathrm{m}^{2}\right)$ from the WIDS database 
The major assumptions underlying Equation 4.3 are that the vadose zone layer with the lowest $K_{s}$ controls flow, a unit gradient is always present across the controlling layer, and flow is steady. The scaling factor, $\lambda$, is constrained by the SAC Environmental Settings Definition keyword file to be equal to or greater than 1.0 so that the effective area is not less than the facility footprint area, unless specified for a specific site. For example, $\lambda$ is usually permitted to be less than 1.0 for the underground storage tanks, for which the actual wetted area from leaks is commonly less than the facility footprint. For most sites with little or no artificial discharges, $\lambda$ usually resolves to 1.0 (no scaling) and hence the assigned WIDS area is used. For large-volume discharge sites, $\lambda$ values greater than 1.0 are common.

\subsection{Recharge Estimates}

This section provides recharge (deep drainage) estimates for use in Hanford assessments. The recharge estimates were derived from a suite of available field data and computer simulation results (Fayer and Walters 1995; Murphy et al. 1996; Prych 1998; Fayer et al. 1999; Wittreich et al. 2003; Fayer and Szecsody 2004; Gee et al. 2005; Ward et al. 2005; Fayer and Gee 2006). The estimates do not account for overland flow from roadways or roofs, water line leaks, or any other manmade additions of water, the impacts wrought by future climate change or land use alterations, variations within soil types, or dune-sand deposition. The estimates were developed for fairly large geographic areas and may not represent the local recharge rates at specific locations. Estimates of manmade additions of water (i.e., liquid discharges) are provided by the Inventory Data Package for Hanford Assessments (Kincaid et al. 2006). However, at surface disposal sites such as ponds, ditches, and retention basins, evapotranspiration can reduce the volume that actually infiltrates into the subsurface and recharges the unconfined aquifer. Estimates of the evapotranspiration rates are discussed in Section 4.6.

The following sections provide recharge estimates for natural and disturbed soils and for surface barriers for each of four time periods: pre-operations, operations, post-remediation, and final state. The conditions during these periods include natural soil and shrub-steppe plant communities, disturbances that alter the surface soil and vegetation, emplacement of surface barriers, and long-term changes that occur as the waste sites stabilize and return to natural conditions. These sections also describe the probability distributions of the recharge estimates. These distributions support Monte Carlo analyses to represent the expected range of recharge rates. This section describes a method to examine the impact of surface barrier side slopes and the terrain surrounding surface barriers, both of which could significantly affect waste release and vadose zone transport. Finally, this section summarizes the recharge estimates for all conditions.

\subsubsection{Natural and Disturbed Soil}

Prior to the establishment of the Hanford Site in 1943, the mostly undisturbed soil and shrub-steppe plant communities generally resulted in very low recharge rates throughout the interior portions of the Hanford Site. Some portions of the Hanford Site along the Columbia River were farmed under irrigation and thus may have experienced increased recharge rates. However, the low rates throughout most of the Hanford Site led to very dry vadose zone conditions that characterize the pre-Hanford period beneath most waste sites. During the subsequent operations period, the soil and vegetation at most waste sites were disturbed, which increased recharge rates; similar conditions will exist during the remediation period. In addition to the recharge that occurs directly in a waste site, recharge in the immediate vicinity of the site could affect transport of contaminants to the groundwater. 
Examination of the Hanford soil map produced by Hajek (1966) revealed four natural soil types prevalent in and around the waste areas: Rupert sand $\left(\mathrm{R}_{\mathrm{p}}\right)$, Burbank loamy sand $\left(\mathrm{B}_{\mathrm{a}}\right)$, Ephrata sandy loam $\left(E_{1}\right)$, and Ephrata stony loam $\left(E_{b}\right)$. Fayer and Szecsody (2004) suggested that the soil in the southeast quadrant of the 200 East Area in the vicinity of the Integrated Disposal Facility (IDF) should be treated as a separate soil type because of extensive subsurface layers. Therefore, for this data package, a soil type in that area was labeled as Rupert sand IDF $\left(\mathrm{R}_{\mathrm{pi}}\right)$. The State Environmental Policy Act environmental impact statement (SEPA-EIS) for the US Ecology Site (DOH 2004) used an infiltration/recharge rate different from those of other soils in the area, so yet another soil typed was defined and labeled as Rupert sand US Ecology $\left(\mathrm{R}_{\mathrm{pu}}\right)$. All six soils are assumed to be nominally 0.5 to $1 \mathrm{~m}$ thick (at most) and easily disrupted during construction activities. Experience shows that the dominant soil condition following construction is the underlying sediment, i.e., the Hanford sands. The only other soil type that might occur in the waste areas is a silt loam (Wa). Such soil does not currently exist in these areas. However, surface barriers constructed using 1-2 m of silt loam as the topsoil will eventually age and resemble a silt loam soil. Recharge estimates were assigned to the five undisturbed soil types and two sediment types for the following four plant community conditions:

1. Shrub-Steppe Plant Community. This condition is a mature plant community consisting of shrubs and bunchgrasses and associated fauna and flora. Table 4.13 lists the recharge estimates for the five soil types that dominate the areas to be evaluated in large-scale Hanford assessments. It is assumed that these soils, when undisturbed, support a shrub-steppe plant community.

Table 4.13. Estimated Recharge Rates for Predominant Soil Types and Sediment with a Shrub-Steppe Plant Community

\begin{tabular}{|c|c|c|}
\hline Soil Type & $\begin{array}{l}\text { Recharge Rate Estimate } \\
\qquad(\mathrm{mm} / \mathrm{yr})\end{array}$ & Description \\
\hline $\begin{array}{l}\text { Ephrata stony loam } \\
\left(E_{b}\right)\end{array}$ & 1.5 & No data; used estimate for $\mathrm{E}_{\mathrm{l}}$, which is a similar soil \\
\hline $\begin{array}{l}\text { Ephrata sandy loam } \\
\left(E_{l}\right)\end{array}$ & 1.5 & $\begin{array}{l}\text { Avg. of two estimates }(1.2 ; 1.8) \text { from deep }(>10 \mathrm{~m}) \text { chloride data collected } \\
\text { from the two boreholes B17 and B18 (Prych 1998) }\end{array}$ \\
\hline $\begin{array}{l}\text { Burbank loamy sand } \\
\left(B_{a}\right)\end{array}$ & 3.0 & $\begin{array}{l}\text { Avg. of three estimates }(0.66,2.8,5.5) \text { from deep }(>10 \mathrm{~m}) \text { chloride data } \\
\text { collected from the three boreholes B10, B12, and B20 (Prych 1998) }\end{array}$ \\
\hline Rupert Sand $\left(R_{p}\right)$ & 4.0 & $\begin{array}{l}\text { Estimated from chloride data collected from a borehole near the Wye } \\
\text { Barricade (Murphy et al. 1996). Murphy et al. described the site as a } \\
\text { stabilized dune area with low shrub cover. }\end{array}$ \\
\hline $\begin{array}{l}\text { Rupert Sand }\left(R_{p i}\right) \\
\text { near the IDF in } 200 \\
\text { East }\end{array}$ & 0.9 & $\begin{array}{l}\text { Avg. of seven estimates from deep ( } 5 \text { to } 30 \mathrm{~m} \text { ) chloride data collected from } \\
\text { the boreholes around the IDF site (Fayer and Szecsody 2004) }\end{array}$ \\
\hline $\begin{array}{l}\text { Rupert Sand }\left(R_{p u}\right) \\
\text { near the US Ecology } \\
\text { site }\end{array}$ & 5.0 & Taken from the SEPA EIS (DOH 2004) \\
\hline $\begin{array}{l}\text { Hanford-formation } \\
\text { sand (Hs) }\end{array}$ & 4.0 & No data; used estimate for Rupert sand outside the 200 East Area \\
\hline $\begin{array}{l}\text { Warden silt loam } \\
\text { (Wa) }\end{array}$ & $\begin{array}{l}0.04 \\
(0.11) * \\
(1.0) * *\end{array}$ & $\begin{array}{l}\text { Average of four estimates }(0.013 ; 0.008 ; 0.024 ; 0.11) \text { from chloride data } \\
\text { collected in silt loam soil (Prych 1998). } \\
* \text { Value is the highest of these four estimates, and may be used in sensitivity } \\
\text { tests (a) } \\
* * \text { Value used in reference case analyses to represent the final state of ET } \\
\text { surface barriers after design life }{ }^{(\mathrm{a})}\end{array}$ \\
\hline
\end{tabular}

(a) DOE. October 21, 2005. Technical Guidance Document for Composite Analysis of Low-Level Waste Disposal at the Hanford Site. DOE/RL-2005-66, U.S. Department of Energy, Richland, Washington (unsigned). 
2. No Plants. This condition describes the case in which vegetation was removed and plants were prevented from re-establishing (e.g., weed control). This condition can be applied to the analysis of fire effects, although the duration without plants will be short ( $<1$ year). Table 4.14 shows the recharge estimates for the case without vegetation.

Table 4.14. Estimated Recharge Rates for Disturbed Soil Types Without Vegetation

\begin{tabular}{|c|c|c|}
\hline Soil Type & $\begin{array}{l}\text { Recharge Rate Estimate } \\
(\mathrm{mm} / \mathrm{yr})\end{array}$ & Description \\
\hline $\begin{array}{l}\text { Ephrata stony } \\
\text { loam }\left(E_{b}\right)\end{array}$ & 17 & Simulation estimate for period 1958 to 1992 (Fayer and Walters 1995) \\
\hline $\begin{array}{l}\text { Ephrata sandy } \\
\text { loam }\left(E_{l}\right)\end{array}$ & 17 & Simulation estimate for period 1958 to 1992 (Fayer and Walters 1995) \\
\hline $\begin{array}{l}\text { Burbank loamy } \\
\text { sand }\left(B_{a}\right)\end{array}$ & $\begin{array}{l}52 \\
(53) *\end{array}$ & $\begin{array}{l}\text { Simulation estimate for the period } 1957 \text { to } 2003 \text { (Fayer and Szecsody 2004). } \\
* \text { Estimate in parenthesis is based on a simulation estimate for period } 1957 \text { to } \\
1997 \text { (Fayer et al. 1999). This value is used in reference case analyses } \\
\text { DOE/RL-2005-66). }\end{array}$ \\
\hline Rupert Sand $\left(R_{p}\right)$ & 44 & Simulation estimate for period 1957 to 1997 (Fayer et al. 1999) \\
\hline $\begin{array}{l}\text { Rupert Sand near } \\
\text { the IDF }\left(R_{p i}\right)\end{array}$ & 44 & Assumed to be the same as Rupert Sand above. \\
\hline $\begin{array}{l}\text { Rupert Sand near } \\
\text { US Ecology }\left(R_{p u}\right)\end{array}$ & 30 & Taken from the SEPA EIS (DOH 2004) \\
\hline $\begin{array}{l}\text { Hanford- } \\
\text { formation sand } \\
\left(H_{S}\right)\end{array}$ & $\begin{array}{l}63 \\
(55)^{*}\end{array}$ & $\begin{array}{l}\text { 22-yr (1982-1993, 1995-2004) lysimeter record for Hanford sand in the } \\
300 \text { Area (Gee et al. 2005) } \\
\text { * 8-yr (July } 1984 \text { to June 1993) lysimeter record for Hanford sand (Fayer and } \\
\text { Walters 1995). Used in reference case analyses DOE/RL-2005-66) }\end{array}$ \\
\hline $\begin{array}{l}\text { Graveled surface } \\
(G)\end{array}$ & $\begin{array}{c}92 \\
(100) *\end{array}$ & $\begin{array}{l}\text { Value is based on the average rate derived from two lysimeter records for } \\
\text { gravel surfaces (Fayer and Szecsody } 2004 \text { ). Lysimeters C1 and D1 showed } \\
48 \% \text { and } 58 \% \text { of precipitation received became deep drainage. Scaling the } \\
\text { drainage rate to the long-term precipitation rate of } 173 \mathrm{~mm} / \mathrm{yr} \text { (1946-2004; } \\
\text { Hoitink et al. 2005) yielded an average estimate of } 92 \mathrm{~mm} / \mathrm{yr} \text {. } \\
* \text { Value in parenthesis to be used for reference case } \text { analyses }^{(\mathrm{a})}\end{array}$ \\
\hline (a) DOE. O & ET. & $\begin{array}{l}\text { Document for Composite Analysis of Low-Level Waste Disposal at the } \\
\text { ment of Energy, Richland, Washington (unsigned). }\end{array}$ \\
\hline
\end{tabular}

3. Shallow-Rooted Plants. This condition describes the case in which the existing shrub-steppe vegetation is destroyed (e.g., by fire or Hanford operations) and the plants that re-vegetate the site are strictly shallow-rooted (e.g., cheatgrass). Very few recharge data are available for native soils and backfilled sediments with shallow rooted grasses such as cheatgrass (Fayer and Walters 1995). For the purposes of this analysis, it was estimated that a cheatgrass cover will reduce the recharge rates listed in Table 4.14 by $50 \%$ relative to the rates that would occur in the absence of any vegetation. For example, Ephrata stony loam with cheatgrass will have an expected mean annual recharge of $8.5 \mathrm{~mm} /$ year compared to $17 \mathrm{~mm} /$ year when there is no vegetation.

4. Young Shrub-Steppe Plant Community. This condition describes the case in which a young shrubsteppe plant community is developing in an area that had previously been disturbed by an event such as a fire. It was estimated that recharge in such areas will be double the rates estimated for mature shrub-steppe conditions (Table 4.13). 
Table 4.15 shows the estimated recharge rates for various surface conditions for the 17 geographic areas, along with a brief description of each setting and major soil type that was identified using the Hajek (1966) soil map. If a significant secondary soil type is present, that soil type and its estimated recharge rate are shown in parentheses. Note that only those values to be used in the analyses are presented. The alternate values shown in parentheses in Table 4.14 are not included. Note also that a recharge estimate of $1 \mathrm{~mm} /$ year was assumed for those sites that discharged directly to the river, and an estimate of $0.1 \mathrm{~mm} /$ year was assumed for those sites covered by asphalt, concrete, or building.

Table 4.15. Estimated Recharge Rates by Soil Type/Sediment and Vegetation Condition in Each Hanford Area. Significant secondary soil types and their associated recharge estimates are shown in parentheses.

\begin{tabular}{|c|c|c|c|c|c|c|}
\hline \multirow[b]{2}{*}{$\begin{array}{l}\text { Area } \\
\text { Label }\end{array}$} & \multirow[b]{2}{*}{ Brief Description } & \multirow{2}{*}{$\begin{array}{c}\text { Major } \\
{\text { (Secondary })^{(\mathrm{a})} \text { Soil }} \\
\text { Type(s) } \\
\text { and Sediments } \\
\end{array}$} & \multicolumn{4}{|c|}{ Estimated Recharge Rate $(\mathrm{mm} / \mathrm{yr})^{(\mathrm{b})}$} \\
\hline & & & No Vegetation & Cheatgrass & $\begin{array}{c}\text { Young } \\
\text { Shrub-Steppe }\end{array}$ & Shrub-Steppe \\
\hline $\mathrm{C}$ & Reactor along river & $E_{b}\left(B_{a}\right)$ & $17(52)$ & $8.5(26.5)$ & $3.0(6.0)$ & $1.5(3.0)$ \\
\hline $\mathrm{K}$ & Reactor along river & $E_{b}\left(E_{l}\right)$ & $17(17)$ & $8.5(8.5)$ & $3.0(3.0)$ & $1.5(1.5)$ \\
\hline $\mathrm{N}$ & Reactor along river & $E_{b}$ & 17 & 8.5 & 3.0 & 1.5 \\
\hline $\mathrm{D}$ & Reactor along river & $E_{l}$ & 17 & 8.5 & 3.0 & 1.5 \\
\hline $\mathrm{H}$ & Reactor along river & $B_{a}$ & 52 & 26 & 6.0 & 3.0 \\
\hline $\mathrm{F}$ & Reactor along river & $R_{p}\left(E_{\nu}\right)$ & $44(17)$ & $22(8.5)$ & $8.0(3.0)$ & $4.0(1.5)$ \\
\hline $\mathrm{R}$ & 300 Area & $R_{p}\left(E_{\nu}\right)$ & $44(17)$ & $22(8.5)$ & $8.0(3.0)$ & $4.0(1.5)$ \\
\hline Q & 400 Area & $R_{p}\left(B_{a}\right)$ & $44(52)$ & $22(26)$ & $8.0(3.0)$ & $4.0(3.0)$ \\
\hline $\mathrm{P}$ & 618-10 Area & $R_{p}\left(B_{a}\right)$ & $44(52)$ & $22(26)$ & $8.0(3.0)$ & $4.0(3.0)$ \\
\hline $\mathrm{M}$ & 618-11 Area & $R_{p}\left(B_{a}\right)$ & $44(52)$ & $22(26)$ & $8.0(3.0)$ & $4.0(3.0)$ \\
\hline $\mathrm{G}$ & Gable Mtn. Pond Area & $E_{l}\left(B_{a}\right)$ & $17(52)$ & $8.5(26)$ & $3.0(6.0)$ & $1.5(3.0)$ \\
\hline $\mathrm{I}$ & 200N Area & $E_{l}\left(B_{a}\right)$ & $17(52)$ & $8.5(26)$ & $3.0(6.0)$ & $1.5(3.0)$ \\
\hline $\mathrm{T}$ & Northern 200W Area & $R_{p}\left(B_{a}\right)$ & $44(52)$ & $22(26)$ & $8.0(3.0)$ & $4.0(3.0)$ \\
\hline $\mathrm{S}$ & $\begin{array}{l}\text { Southern 200W Area } \\
\text { and ERDF }\end{array}$ & $R_{p}$ & 44 & 22 & 8.0 & 4.0 \\
\hline $\mathrm{A}$ & Southern 200E Area & $R_{p}\left(B_{a}, R_{p i}, R_{p w}\right)$ & $44(52,44,30)$ & $22(26,22, \mathrm{na})$ & $8.0(6.0,1.8, \mathrm{na})$ & $4.0(3.0,0.9, \mathrm{na})$ \\
\hline $\mathrm{B}$ & Northwestern 200E Area & $E_{l}$ & 17 & 8.5 & 3.0 & 1.5 \\
\hline $\mathrm{E}$ & Eastern 200E Area & $B_{a}\left(R_{p}\right)$ & $52(44)$ & $26(22)$ & $6.0(1.8)$ & $3.0(0.9)$ \\
\hline-- & $\begin{array}{l}\text { All Areas with soils } \\
\text { disturbed by excavations }\end{array}$ & Hanford sand & 63 & 31.5 & 8.0 & 4.0 \\
\hline-- & $\begin{array}{l}\text { All Areas with an } \\
\text { Evapotranspiration (ET) } \\
\text { surface barrier after } \\
\text { design life } \\
\end{array}$ & $\begin{array}{l}\text { Warden silt loam } \\
\text { (Wa) }\end{array}$ & na & na & 0.08 & 0.04 \\
\hline-- & $\begin{array}{l}\text { All Areas with gravel } \\
\text { surface and no plants }\end{array}$ & gravel & 92 & 46 & na & na \\
\hline \multicolumn{7}{|c|}{$\begin{array}{l}B_{a}=\text { Burbank loamy sand } \\
E_{b}=\text { Ephrata stony loam } \\
E_{l}=\text { Ephrata sandy loam } \\
R_{p}=\text { Rupert sand } \\
R_{p i}=\text { Rupert sand in the IDF in the } 200 \text { East Area. } \\
R_{p u}=\text { Rupert sand at the US Ecology Site, southwest of the } 200 \text { East Area. } \\
\text { na }=\text { not applicable } \\
\text { (a) Only the major soil types were used to represent each aggregate area. } \\
\text { (b) Alternate/reference case values shown in Table } 4.14 \text { are not provided here. } \\
\text { (c) Value to be used in reference case analyses (DOE. October 21, 2005. Technical Guidance Document for Composite } \\
\text { Analysis of Low-Level Waste Disposal at the Hanford Site. DOE/RL-2005-66, U.S. Department of Energy, Richland, } \\
\text { Washington [unsigned]). }\end{array}$} \\
\hline
\end{tabular}




\subsubsection{Surface Barriers}

The Hanford Site Disposition Baseline (HSDB) as described in the Inventory Data Package for Hanford Assessments (Kincaid et al. 2006) represents the most credible end-state of the Hanford Site based on information made available by DOE and its contractors. It is a combination of remedial actions based on interim and final records of decision or proposed by DOE but not yet interim or finally approved by regulatory agencies. The HSDB provides the schedule and type of engineered surface barriers to be applied to each site for a large-scale Hanford assessment.

This section describes the recharge rates to be used for surface barriers during the institutional control period, their design life, and after their design life. A key assumption of these large-scale Hanford assessments is that deep drainage beneath barrier side slopes and the surrounding terrain does not appreciably affect contaminant release and transport. This assumption is consistent with the Composite Analysis (Kincaid et al. 1998) as well as with recent and ongoing assessments. Since this assumption has not been tested, estimates of side slope drainage are provided here for possible use in sensitivity tests.

\subsubsection{Barrier Tops}

DOE conducted a focused feasibility study of engineered surface barriers and identified four designs that met Hanford needs (DOE 1996b). Table 4.15 lists the four designs and the expected design life of each. For large-scale Hanford assessments, two evapotranspiration (ET) surface barriers will be evaluated for sites that require protection: the Hanford barrier and barriers equivalent to the modified RCRA C barrier. Recharge rates for the top portion of the surface barriers were estimated from field studies of surface barrier systems at Hanford and are shown in Table 4.16. Fayer and Szecsody (2004) and Fayer and Gee (2006) described lysimeter tests and numerical modeling that showed recharge rates beneath silt loam soils with capillary breaks were much lower than $0.1 \mathrm{~mm} / \mathrm{year}$ and in many cases were effectively zero (to the limits of measurement technology). Ward et al. (2005) reported drainage rates for four $322-\mathrm{m}^{2}$ plots in a field-scale prototype barrier having $2 \mathrm{~m}$ of silt loam soil above a capillary break. They reported drainage rates ranging from 0.00003 to $0.02 \mathrm{~mm} /$ year during a 10 -year period that included two of the wettest years on record and irrigation (for stress testing) on two of the plots during the first three years when vegetation was just starting to get established. Even without the capillary break, silt loam soils appear to be effective at limiting drainage. For example, recharge estimates for natural silt loam soils at Hanford show rates average about $0.04 \mathrm{~mm} / \mathrm{year}$ (Prych 1998). To some, such low rates do not seem possible despite the evidence. Rather than expend the additional effort necessary to support using very low rates, researchers elected to specify a barrier recharge rate of $0.1 \mathrm{~mm} /$ year.

\subsubsection{Barrier Side Slopes and Surrounding Terrain}

This discussion of recharge through barrier side slopes and surrounding terrain is provided only for completeness and to provide the basis for possible use in sensitivity analyses. Barrier side slopes and/or the surrounding terrain are likely to have recharge rates that are higher than rates through the surface barrier. Once the water from those areas enters the vadose zone, it can move laterally beneath the "shadow" of the surface barrier and effectively increase the transport of contaminants to groundwater. Recharge rates in the surrounding soils are provided in Table 4.15. Estimates of recharge rates beneath potential barrier side slopes are needed. A large number of surface barriers is being considered for use at Hanford and some may be above-grade structures that require stabilizing side slopes. Two side slope designs are currently being tested at the Prototype Surface Barrier (Ward et al. 2005). One design, called 
'Gravel,' is a sandy gravel/gravelly sand mix emplaced at a 10 horizontal (H):1 vertical (V) slope. The second design, called 'Basalt, ' is open-work basalt riprap emplaced at a $2 \mathrm{H}: 1 \mathrm{~V}$ slope. Neither design incorporates any plant-promoting features. Since being constructed in November 1994, some plants have established on the sandy gravel side slope (the quantity is less than the barrier top) and none has established on the basalt side slope. Drainage data have been collected since November 1994. During that period, records show that Hanford received higher-than-normal precipitation (Hoitink et al. 2005). Therefore, the side-slope drainage data were scaled to the long-term precipitation average $(173 \mathrm{~mm} /$ year for the period from 1946 to 2004; Hoitink et al. 2005) to yield long-term estimates of side slope recharge rates. Table 4.17 shows the scaled recharge estimates for the two side slope materials.

Table 4.16. Barrier Design Life and Estimated Recharge Rates for Barrier Tops

\begin{tabular}{|c|c|c|c|}
\hline $\begin{array}{l}\text { FFS Design } \\
\text { (DOE 1996b) }\end{array}$ & $\begin{array}{l}\text { Design Life } \\
\quad(\mathrm{yr})\end{array}$ & $\begin{array}{l}\text { Recharge Rate } \\
(\mathrm{mm} / \mathrm{yr})^{(\mathrm{b})}\end{array}$ & Source \\
\hline Hanford Barrier & 1,000 & $0.1^{(\mathrm{a})}$ & $\begin{array}{l}\text { Based on lysimeter data and simulation results } \\
\text { (Ward et al. 2005; Fayer and Gee 2006) }\end{array}$ \\
\hline $\begin{array}{l}\text { Modified RCRA C (or } \\
\text { equivalent ET barrier) }\end{array}$ & 500 & $0.1^{(\mathrm{a})}$ & $\begin{array}{l}\text { Based on lysimeter data and simulation results } \\
\text { (Fayer and Szecsody 2004; Fayer and Gee 2006) }\end{array}$ \\
\hline $\begin{array}{l}\text { Standard RCRA C } \\
\text { (not explicitly evaluated in } \\
\text { Hanford assessments) }\end{array}$ & 30 & $0.1^{\text {(a) }}$ & $\begin{array}{l}\text { No data; recommendation is based on presence of } \\
\text { Geomembrane and } 0.69-\mathrm{m} \text { thick clay admix layer }\end{array}$ \\
\hline $\begin{array}{l}\text { Modified RCRA D } \\
\text { (not explicitly evaluated in } \\
\text { Hanford assessments) }\end{array}$ & 100 & $0.1^{\text {(a) }}$ & $\begin{array}{l}\text { Based on simulation results using parameters from } \\
\text { Fayer et al. (1999) }\end{array}$ \\
\hline $\begin{array}{l}\text { Geosynthetic Cap used at the } \\
\text { US Ecology Site }\end{array}$ & 500 & 0.5 & Taken from the SEPA-EIS (DOH 2004) \\
\hline \multicolumn{4}{|c|}{$\begin{array}{l}\text { (a) The value of } 0.1 \mathrm{~mm} / \mathrm{yr} \text { was chosen to represent the performance of ET barriers utilizing silt loam because the } \\
\text { rate is more easily defended that the expected value, which is much lower that } 0.1 \mathrm{~mm} / \mathrm{yr} \text {. } \\
\text { (b) Note that the value to be used in reference case analyses is } 0.5 \mathrm{~mm} / \mathrm{yr} \text { (DOE. October 21, 2005. Technical } \\
\text { Guidance Document for Composite Analysis of Low-Level Waste Disposal at the Hanford Site. DOE/RL-2005-66, } \\
\text { U.S. Department of Energy, Richland, Washington [unsigned]). }\end{array}$} \\
\hline
\end{tabular}

Table 4.17. Initial Side Slope Recharge Rates for Hanford Site Climate Conditions

\begin{tabular}{||c|c|c|c||}
\hline Side Slope Type & Slope & $\begin{array}{c}\text { Initial Recharge Rate } \\
(\mathrm{mm} / \mathrm{yr})\end{array}$ & \multicolumn{1}{||}{ Source } \\
\hline \hline $\begin{array}{l}\text { Gravel (mix of sand } \\
\text { and gravel) }\end{array}$ & $10 \mathrm{H}: 1 \mathrm{~V}$ & 33 & $\begin{array}{l}\text { Based on ten years of drainage data from the prototype } \\
\text { surface barrier (Ward et al. 2005) scaled to average } \\
(1946-2004) \text { precipitation of 173 mm/yr. }\end{array}$ \\
\hline $\begin{array}{l}\text { Basalt (open-work } \\
\text { riprap) }\end{array}$ & $2 \mathrm{H}: 1 \mathrm{~V}$ & 26 & $\begin{array}{l}\text { Based on ten years of drainage data from the prototype } \\
\text { surface barrier (Ward et al. 2005) scaled to average } \\
(1946-2004) \text { precipitation of 173 mm/yr. }\end{array}$ \\
\hline
\end{tabular}

The initial recharge rates shown in Table 4.17 are not expected to persist forever. During the 100 years of institutional control, the plant community and soil on the side slopes is expected to slowly develop and mature to the point where recharge rates beneath the side slopes resemble Burbank loamy sand and a shrub-steppe plant community. Therefore, the side-slope recharge rates should be represented in a time-dependent fashion during the period of institutional control. 


\subsubsection{Surface Barriers After Their Design Life}

No guidance is available for specifying barrier performance after their design life. In the CA (Kincaid et al. 1998), barrier performance after the design life was simply assumed to end, after which recharge rates were set equal to those of the original soil type at each location. However, there is no basis for assuming the surface barrier will disappear or evolve to resemble the local soil. Instead, the barrier will continue to experience soil and ecological processes that will alter the nature of the barrier and affect its performance.

Processes that could affect barrier performance after the design life include erosion, deposition, biotic intrusion, fire, drought, plant succession, subsidence, human intrusion, and climate change. Of these, the two key natural processes are erosion of the silt loam layer and deposition of dune sand on the barrier. Fayer et al. (1999) examined both processes; their results suggested that neither process would significantly alter barrier performance. Thus, after the barrier design life, the barrier would continue to function as designed. Eventually, the barrier top would most likely resemble a Warden silt loam and the side slope would most likely resemble the Ephrata stony loam.

For large-scale Hanford assessments, barrier performance after the design life will be described for what is envisioned to be the final state of the barrier and for a transition period between the design life and the final state. For example, the final state of a silt-loam-based modified RCRA C barrier is expected to be equivalent to the silt loam soils found at the Hanford Site. The transition period will be equivalent in duration to the design life, which in this case would be 500 years. During the transition period, barrier performance would be progressively changed from the rate during the design life to the rate appropriate to the final state (e.g., Warden silt loam). For simplicity and ease of implementation, the changes during this transition period will be represented by five equal stepwise changes in the recharge rates.

\subsubsection{Probability Distribution Functions}

After reviewing the possible probability distributions, we chose a three-point triangular distribution to represent recharge at all sites. In this distribution, the low value is equal to the mean recharge rate minus the standard deviation and the high value is equal to twice the mean value. The number of recharge estimates is too small to calculate adequate statistics, so recharge standard deviations were estimated using statistics from winter precipitation, which is considered to be the primary source of recharge water. Data from HMS precipitation records (Hoitink et al. 2005) were used to obtain the mean and standard deviation of the extended-winter (November through March) precipitation for the period from November 1946 to March 2004. The HMS record yielded a mean value of $101 \mathrm{~mm} /$ year and standard deviation of $40 \mathrm{~mm} /$ year, or roughly $40 \%$ of the mean value. Because the available recharge data were limited, we estimated the standard deviation for each surface as equal to half the mean recharge rate. This choice is slightly conservative, based on the statistic for the extended winter precipitation. For sites with very high recharge rates, the triangular distribution results in unreasonably high upper limits. We reasoned that, because winter precipitation was the primary source of recharge, recharge would seldom, if ever, exceed winter precipitation. Therefore, all recharge rate distributions were truncated to the mean extended winter precipitation rate of $101 \mathrm{~mm} /$ year. As more data are collected for various surface conditions, the actual standard deviations in recharge can be substituted. 


\subsubsection{Integrated Drainage Calculations}

A key assumption of large-scale Hanford assessments is that vadose zone waste is only affected by the recharge that occurs beneath the surface barrier tops. The implication of this assumption is that recharge occurring beneath the barrier side slopes (if present) or in the areas immediately surrounding the surface barrier will not affect the mobilization of waste beneath the surface barrier nor the transport of the waste contaminants to the water table. To test the assumption, a method was developed to integrate the drainage rates from the barrier top and side slopes and surrounding terrain into a single composite rate that could be used for sensitivity analyses in the Hanford assessments.

For Hanford assessments, each waste site is characterized by two drainage estimates defined as follows:

Release Model Drainage. This drainage rate directly affects the behavior of the release model. The assumption is that the waste form is directly beneath the intact and functional part of the surface barrier and affected only by recharge through the barrier top. Any recharge through the barrier side slopes or in the areas surrounding the barrier is assumed to have no impact on the waste form.

Vadose Zone Model Drainage. This drainage rate directly impacts the transport of contaminants released by the waste form through the vadose zone and to the water table. In large-scale Hanford assessments, the vadose zone drainage rate is equivalent to the barrier top drainage rate. However, for sensitivity tests of this assumption, the vadose zone drainage rate could be assigned a value that is a composite of recharge through the barrier and recharge through a portion of the barrier side slopes and surrounding terrain.

The impact of higher drainage rates around a surface barrier is a function of individual site characteristics such as barrier geometry and dimensions, distance to the water table, geology, physicalhydraulic-chemical properties, and contaminant depth and characteristics. Given the diversity of site characteristics and the one-dimensional conceptual model used in large-scale Hanford assessments, the sensitivity could be demonstrated without having to represent the unique features of every site. For this purpose, the recharge rates could be integrated by weighting the recharge contributions from the barrier and the contributing portion of the side slope and surrounding terrain based on their respective areas referenced to the total area.

Some of the recharge beneath the side slope can flow beneath the barrier and affect contaminant transport. The quantity of side slope recharge that affects contaminant transport beneath the barrier depends highly on the site-specific conditions noted above. In lieu of site-specific multidimensional data, the sensitivity to side slope recharge can be demonstrated with a one-dimensional analysis by assuming that recharge beneath half the side slope area contributes to contaminant transport. The resulting integrated vadose zone drainage rate $\left(r_{b}\right)$ can be computed as follows:

$$
r_{b}=\left(r_{b t} A_{b t}+r_{b s} 0.5 A_{b s}\right) / A_{b}
$$

where $r_{b t}=$ drainage rate of the barrier top

$r_{b s}=$ drainage rate of the barrier side slope

$A_{b t}=$ area of the barrier top

$A_{b s}=$ area of the barrier side slope

$A_{b}=$ total area of the barrier and contributing side slope; sum of $A_{b t}$ and $0.5^{*} A_{b s}$ 
The following example illustrates how the integrated recharge rate from a modified RCRA C barrier with side slopes might affect the overall vadose zone drainage rate.

\section{Modified RCRA C Barrier}

- $\quad$ shape $=$ square, $316 \mathrm{~m}$ on a side, yielding area $A_{b t}=10$ ha

- height $=5 \mathrm{~m}$ above the surrounding terrain

- surface barrier drainage rate $r_{b t}=0.1 \mathrm{~mm} / \mathrm{year}$

\section{Gravel Side Slope}

- $\quad$ slope $=5 \mathrm{H}: 1 \mathrm{~V}$

- $\quad$ slope length $=25 \mathrm{~m}$

- contributing area, $0.5 * A_{b s}=1.71$ ha (equal to one-half of the side slope area)

- drainage rate $r_{b s}=3.0 \mathrm{~mm} /$ year (assumed mature shrub-steppe plant community)

Using Equation 4.4 and the values provided above, the integrated vadose zone drainage rate is

$$
r_{b}=[0.1 \times 10+3.0 \times 1.71] / 11.7=0.52 \mathrm{~mm} / \text { year }
$$

This calculation reveals that the integrated drainage rate for the 10-ha waste site is 5 times larger than the barrier top drainage rate. In other words, large side slopes have the potential to seriously reduce the performance of the surface barrier. Similar calculations for waste site areas of 1 and 20 ha $(2.5$ and 50 acres) yield integrated vadose zone drainage rates of 1.22 and $0.41 \mathrm{~mm} /$ year, respectively. These values demonstrate that smaller barriers are far more affected by side slope recharge than are larger barriers.

\subsubsection{Recharge Classes}

To facilitate the assignment of recharge rates for individual waste sites, three sets of recharge classes were developed: (1) rates for baseline soil conditions with shrub-steppe plant community; (2) rates for disturbed conditions with various degrees of vegetation (e.g., native soils or backfilled soils; with various types of vegetation or without; asphalt, concrete, or gravel covers); and (3) rates for surface barrier components. Each recharge class was identified with a unique code based on either the primary native soil and vegetation type or the type and size of the surface barrier. Tables 4.18 through 4.21 provide the estimated recharge rates for each class.

\subsection{Pond Evaporation Estimates}

Large volumes of liquid waste disposed to surface and subsurface infiltration facilities created significant groundwater mounds in the unconfined aquifer during site operations. Evaporation and evapotranspiration from surface water bodies can significantly reduce the volumes of waste water that ultimately infiltrate into the soils and recharge the aquifer. Thus, to improve estimates of deep drainage and recharge from the major anthropogenic sources, evaporation from surface ponds has been estimated. These estimates assume maximum possible evaporation by selecting atmospheric properties that promote evaporation. The parameters used for each month include (1) the highest temperature, (2) the lowest pressure, (3) the lowest relative humidity, (4) the highest wind speed, and (5) the highest net solar radiation. 
Table 4.18. Estimated Recharge Rates for Baseline Soil Conditions

\begin{tabular}{|c|c|c|c|c|c|}
\hline $\begin{array}{l}\text { Recharge } \\
\text { Class Code }\end{array}$ & Description & $\begin{array}{c}\text { Best } \\
\text { Estimate } \\
(\mathrm{mm} / \mathrm{yr})\end{array}$ & $\begin{array}{c}\text { Estimated Standard } \\
\text { Deviation } \\
(\mathrm{mm} / \mathrm{yr})\end{array}$ & $\begin{array}{l}\text { Minimum } \\
(\mathrm{mm} / \mathrm{yr})\end{array}$ & $\begin{array}{l}\text { Maximum } \\
(\mathrm{mm} / \mathrm{yr})\end{array}$ \\
\hline$\overline{E E_{b} \text {-S }}$ & $\begin{array}{l}\text { Ephrata stony loam }\left(E_{b}\right) \text { - with shrub- } \\
\text { steppe }(s) \text { plant community }\end{array}$ & 1.5 & 0.75 & 0.75 & 3.0 \\
\hline$E_{l}-\mathrm{S}$ & $\begin{array}{l}\text { Ephrata sandy loam }\left(E_{l}\right) \text { - with shrub- } \\
\text { steppe }(s) \text { plant community }\end{array}$ & 1.5 & 0.75 & 0.75 & 3.0 \\
\hline$B_{a}-\mathrm{S}$ & $\begin{array}{l}\text { Burbank loamy sand }\left(B_{a}\right) \text { - with shrub- } \\
\text { steppe }(s) \text { plant community }\end{array}$ & 3.0 & 1.5 & 1.5 & 6.0 \\
\hline$R_{p}-\mathrm{S}$ & $\begin{array}{l}\text { Rupert sand }\left(R_{p}\right) \text { - with shrub-steppe }(s) \\
\text { plant community }\end{array}$ & 4.0 & 2.0 & 2.0 & 8.0 \\
\hline$R_{p i}-\mathrm{S}$ & $\begin{array}{l}\left.\text { Rupert sand }\left(R_{p}\right) \text { near the IDF }{ }_{i}\right) \text { - with } \\
\text { shrub-steppe }(s) \text { plant community }\end{array}$ & 0.9 & 0.45 & 0.45 & 1.8 \\
\hline$R_{p u^{-\mathrm{S}}}$ & $\begin{array}{l}\text { Rupert sand }\left(R_{p}\right) \text { near US Ecology }\left({ }_{u}\right)- \\
\text { with shrub-steppe }(s) \text { plant community }\end{array}$ & $\begin{array}{c}5.0 \\
(5)^{(a)}\end{array}$ & $\begin{array}{c}2.5 \\
N A^{(a)}\end{array}$ & $\begin{array}{c}2.5 \\
N A^{(a)}\end{array}$ & $\begin{array}{c}10.0 \\
N A^{(a)}\end{array}$ \\
\hline$W_{a}-\mathrm{S}$ & $\begin{array}{l}\text { Warden silt loam }\left(W_{a}\right)-\text { with shrub- } \\
\text { steppe }(s) \text { plant community }\end{array}$ & $\begin{array}{c}0.04 \\
(0.11)^{*} \\
(1.0)^{* *}\end{array}$ & $\begin{array}{c}0.02 \\
(0.06) * \\
(0.5) * *\end{array}$ & $\begin{array}{c}0.02 \\
(0.06) * \\
(0.5) * *\end{array}$ & $\begin{array}{c}0.08 \\
(0.22) * \\
(2.0) * *\end{array}$ \\
\hline River & Columbia River outfall locations & 1 & $N A$ & $N A$ & $N A$ \\
\hline \multicolumn{6}{|c|}{$\begin{array}{l}\text { (a) Value used in reference case analyses. } \\
\text { *Values are based on the highest (rather than the average) of four values estimated from chloride data. These } \\
\text { values maybe used in sensitivity analyses (DOE. October 21, 2005. Technical Guidance Document for Composite } \\
\text { Analysis of Low-Level Waste Disposal at the Hanford Site. DOE/RL-2005-66, U.S. Department of Energy, Richland, } \\
\text { Washington [unsigned]). } \\
\text { **Value used in reference case analyses to represent the final state of ET surface barriers after design life (DOE/RL-2005-66. } \\
\text { NA = Not applicable. }\end{array}$} \\
\hline
\end{tabular}

Evaporation from open water surfaces (i.e., ponds) was calculated, using a combined aerodynamic and energy balance, Penman equation. Calculations were performed in a spreadsheet to produce average maximum monthly estimates over a one-year interval spanning January to December (Table 4.21). Data input to the equations are derived from meteorological measurements collected at the HMS. These include: the mean of the maximum monthly temperature $\left({ }^{\circ} \mathrm{F}\right)$, the average maximum monthly wind speed $(\mathrm{mph})$, the mean of the lowest monthly relative humidity (\%), the mean of the maximum monthly solar radiation (average daily totals in Langley's), and the mean of the lowest monthly atmospheric pressure (ins. of $\mathrm{Hg}$ ). The input data was based on monthly averages spanning 1945 through 1980, where summary statistics had already been generated and were readily available (e.g., Stone et al. 1983). Summary statistics that include meteorological data collected after 1980 have not been published. The expectation is that they would be similar to the statistics based on the 1945-1980 data. Before any calculations could be performed, the HMS data were converted to consistent units of ${ }^{\circ} \mathrm{C}$ for temperature, $\mathrm{W} / \mathrm{m}^{2}$ for solar radiation, $\mathrm{kPa}$ for atmospheric pressure, and $\mathrm{m} / \mathrm{s}$ for wind speed.

The first step in the process is to calculate evaporation by the energy balance method. The equation for evaporation due to radiant energy is

$$
E_{r}=\frac{R_{n}}{l_{v} \rho_{w}}
$$

where $\mathrm{R}_{\mathrm{n}}=$ the net radiation flux

$1_{\mathrm{v}}=$ the latent heat of vaporization

$\rho_{\mathrm{w}}=$ the density of water $\left(977 \mathrm{~kg} / \mathrm{m}^{3}\right)$. 
Table 4.19. Estimated Recharge Rates for Disturbed Conditions and Sensitivity Tests

\begin{tabular}{|c|c|c|c|c|c|}
\hline $\begin{array}{l}\text { Recharge } \\
\text { Class Code }\end{array}$ & Description & $\begin{array}{c}\text { Best } \\
\text { Estimate } \\
(\mathrm{mm} / \mathrm{yr})\end{array}$ & $\begin{array}{c}\text { Estimated Standard } \\
\begin{array}{c}\text { Deviation } \\
(\mathrm{mm} / \mathrm{yr})\end{array} \\
\end{array}$ & $\begin{array}{c}\text { Minimum } \\
(\mathrm{mm} / \mathrm{yr})\end{array}$ & $\begin{array}{l}\text { Maximum } \\
(\mathrm{mm} / \mathrm{yr})^{(\mathrm{a})}\end{array}$ \\
\hline$E_{b}-\mathrm{ds}$ & $\begin{array}{l}\text { Ephrata stony loam }\left(E_{b}\right) \text {, disturbed }(d) \text { - } \\
\text { with young shrub-steppe }(s) \text { vegetation }\end{array}$ & $\begin{array}{c}3.0 \\
(4.0)^{(b)}\end{array}$ & $\begin{array}{c}1.5 \\
(2.0)^{(b)}\end{array}$ & $\begin{array}{c}1.5 \\
(2.0)^{(b)}\end{array}$ & $\begin{array}{c}6.0 \\
(8.0)^{(b)}\end{array}$ \\
\hline$E_{b}-\mathrm{dg}$ & $\begin{array}{l}\text { Ephrata stony loam }\left(E_{b}\right) \text {, disturbed }(d) \text { - } \\
\text { with cheatgrass }(g) \text { vegetation }\end{array}$ & $\begin{array}{c}8.5 \\
(9)^{(b)}\end{array}$ & $\begin{array}{c}4.25 \\
(4.5)^{(b)}\end{array}$ & $\begin{array}{c}4.25 \\
(4.53)^{(b)}\end{array}$ & $\begin{array}{c}17 \\
(18)^{(b)}\end{array}$ \\
\hline$E_{b}-\mathrm{dn}$ & $\begin{array}{l}\text { Ephrata stony loam }\left(E_{b}\right) \text {, disturbed }(d) \text { - } \\
\text { with no }(n) \text { vegetation }\end{array}$ & 17 & 8.5 & 8.5 & 34 \\
\hline$E_{l}$-ds & $\begin{array}{l}\text { Ephrata sandy loam }\left(E_{l}\right) \text {, disturbed }(d) \text { - } \\
\text { with young shrub-steppe }(s) \text { vegetation }\end{array}$ & $\begin{array}{c}3.0 \\
(4.0)^{(b)}\end{array}$ & $\begin{array}{c}1.5 \\
(2.0)^{(b)}\end{array}$ & $\begin{array}{c}1.5 \\
(2.0)^{(b)}\end{array}$ & $\begin{array}{c}6.0 \\
(8.0)^{(b)}\end{array}$ \\
\hline$E_{l}-\mathrm{dg}$ & $\begin{array}{l}\text { Ephrata sandy loam }\left(E_{l}\right) \text {, disturbed }(d) \text { - } \\
\text { with cheatgrass }(g) \text { vegetation }\end{array}$ & $\begin{array}{c}8.5 \\
(9)^{(b)}\end{array}$ & $\begin{array}{c}4.25 \\
(4.5)^{(b)} \\
\end{array}$ & $\begin{array}{c}4.25 \\
(4.5)^{(b)} \\
\end{array}$ & $\begin{array}{c}17 \\
(18)^{(b)}\end{array}$ \\
\hline$E_{l}-\mathrm{dn}$ & $\begin{array}{l}\text { Ephrata sandy loam }\left(E_{l}\right) \text {, disturbed }(d) \text { - } \\
\text { with no }(n) \text { vegetation }\end{array}$ & 17 & 8.5 & 8.5 & 34 \\
\hline$B_{a}-\mathrm{ds}$ & $\begin{array}{l}\text { Burbank loamy sand }\left(B_{a}\right) \text {, disturbed }(d) \text { - } \\
\text { with young shrub-steppe }(s) \text { plant } \\
\text { community }\end{array}$ & $\begin{array}{c}6.0 \\
(4.0)^{(b)}\end{array}$ & $\begin{array}{c}3.0 \\
(2.0)^{(b)}\end{array}$ & $\begin{array}{c}3.0 \\
(2.0)^{(b)}\end{array}$ & $\begin{array}{c}12 \\
(8.0)^{(b)}\end{array}$ \\
\hline$B_{a}-\mathrm{dg}$ & $\begin{array}{l}\text { Burbank loamy sand }\left(B_{a}\right) \text {, disturbed }(d) \text { - } \\
\text { with cheatgrass }(g) \text { plant community }\end{array}$ & 26 & 13.0 & 13.0 & 52 \\
\hline$B_{a}-\mathrm{dn}$ & $\begin{array}{l}\text { Burbank loamy sand }\left(B_{a}\right) \text {, disturbed }(d) \text { - } \\
\text { with no }(n) \text { vegetation }\end{array}$ & $\begin{array}{c}52 \\
(53)^{(b)} \\
\end{array}$ & $\begin{array}{c}26 \\
(26.5)^{(b)}\end{array}$ & $\begin{array}{c}26 \\
(26.5)^{(b)}\end{array}$ & $\begin{array}{c}101 \\
(106)^{(b)}\end{array}$ \\
\hline$R_{p i}$-ds & $\begin{array}{l}\text { Rupert sand }\left(R_{p}\right) \text { near the IDF }\left({ }_{i}\right) \\
\text { disturbed }(d) \text { - with young shrub-steppe } \\
(s) \text { plant community }\end{array}$ & $\begin{array}{c}1.8 \\
(4.0)^{(b)}\end{array}$ & $\begin{array}{c}0.9 \\
(2.0)^{(b)}\end{array}$ & $\begin{array}{c}0.9 \\
(2.0)^{(b)}\end{array}$ & $\begin{array}{c}3.6 \\
(8.0)^{(b)}\end{array}$ \\
\hline$R_{p i}-\mathrm{dg}$ & $\begin{array}{l}\text { Rupert sand }\left(R_{p}\right) \text { near the IDF }\left({ }_{i}\right), \\
\text { disturbed }(d) \text { - with cheatgrass }(g) \text { plant } \\
\text { community }\end{array}$ & 22 & 11 & 11 & 44 \\
\hline$R_{p i}-\mathrm{dn}$ & $\begin{array}{l}\text { Rupert sand }\left(R_{p}\right) \text { near the } \operatorname{IDF}\left({ }_{i}\right) \\
\text { disturbed }(d) \text { - with no }(n) \text { vegetation }\end{array}$ & 44 & 22 & 22 & 88 \\
\hline$R_{p u^{-\mathrm{dn}}}$ & $\begin{array}{l}\text { Rupert sand }\left(R_{p}\right) \text { near US Ecology }(u) \\
\text { disturbed }(d) \text { - with no }(n) \text { vegetation }\end{array}$ & $\begin{array}{c}30 \\
(30)^{(b)}\end{array}$ & $\begin{array}{c}15 \\
N A^{(b)}\end{array}$ & $\begin{array}{c}15 \\
N A^{(b)}\end{array}$ & $\begin{array}{c}60 \\
N A^{(b)}\end{array}$ \\
\hline$R_{p}-\mathrm{ds}$ & $\begin{array}{l}\text { Rupert sand }\left(R_{p}\right), \text { disturbed }(d) \text { - with } \\
\text { young shrub-steppe }(s) \text { plant community }\end{array}$ & $\begin{array}{c}8.0 \\
(4.0)^{(b)} \\
\end{array}$ & $\begin{array}{c}4.0 \\
(2.0)^{(b)} \\
\end{array}$ & $\begin{array}{c}4.0 \\
(2.0)^{(b)} \\
\end{array}$ & $\begin{array}{c}16.0 \\
(8.0)^{(b)}\end{array}$ \\
\hline$R_{p}-\mathrm{dg}$ & $\begin{array}{l}\text { Rupert sand }\left(R_{p}\right) \text {, disturbed }(d) \text { - with } \\
\text { cheatgrass }(g) \text { plant community }\end{array}$ & 22 & 11 & 11 & 44 \\
\hline$R_{p}-\mathrm{dn}$ & $\begin{array}{l}\text { Rupert sand }\left(R_{p}\right) \text {, disturbed }(d) \text { - with no } \\
(n) \text { vegetation }\end{array}$ & 44 & 22 & 22 & 88 \\
\hline$H_{s}-\mathrm{dn}$ & $\begin{array}{l}\text { Hanford Sand }\left(H_{s}\right) \text {, disturbed }(d) \text { - with } \\
\text { no }(n) \text { vegetation }\end{array}$ & $\begin{array}{c}63 \\
(55)^{(b)}\end{array}$ & $\begin{array}{c}31.5 \\
(27.5)^{(b)}\end{array}$ & $\begin{array}{c}31.5 \\
(27.5)^{(b)}\end{array}$ & $\begin{array}{c}101 \\
(107.5)^{(b)}\end{array}$ \\
\hline$G$-dn & $\begin{array}{l}\text { Gravel surface }(G), \text { disturbed - with no } \\
(n) \text { vegetation }\end{array}$ & $\begin{array}{c}92 \\
(100)^{(b)}\end{array}$ & $\begin{array}{c}46 \\
N A^{(b)}\end{array}$ & $\begin{array}{c}46 \\
N A^{(b)}\end{array}$ & $\begin{array}{c}101 \\
N A^{(b)}\end{array}$ \\
\hline $\mathrm{ABC}$ & $\begin{array}{l}\text { Soil Surface covered by Asphalt, } \\
\text { Building, or Concrete }\end{array}$ & 0.1 & 0.05 & 0.05 & 0.2 \\
\hline \multicolumn{6}{|c|}{$\begin{array}{l}\text { Note: the maximum recharge was truncated at the mean extended winter precipitation value of } 101 \mathrm{~mm} / \mathrm{yr} \text {. } \\
\text { Value to be used in reference case analyses (DOE. October 21, 2005. Technical Guidance Document for Composite } \\
\text { Analysis of Low-Level Waste Disposal at the Hanford Site. DOE/RL-2005-66, U.S. Department of Energy, Richland, } \\
\text { Washington [unsigned]). } \\
\text { = Not applicable. }\end{array}$} \\
\hline
\end{tabular}


Table 4.20. Estimated Recharge Rates for Surface Barrier Components

\begin{tabular}{|c|c|c|c|c|c|}
\hline $\begin{array}{l}\text { Recharge } \\
\text { Class Code }\end{array}$ & Description & $\begin{array}{l}\text { Best } \\
\text { Estimate } \\
(\mathrm{mm} / \mathrm{yr})\end{array}$ & $\begin{array}{c}\text { Estimated Standard } \\
\begin{array}{c}\text { Deviation } \\
(\mathrm{mm} / \mathrm{yr})\end{array} \\
\end{array}$ & $\begin{array}{c}\text { Minimum } \\
(\mathrm{mm} / \mathrm{yr})\end{array}$ & $\begin{array}{c}\text { Maximum } \\
(\mathrm{mm} / \mathrm{yr})\end{array}$ \\
\hline $\begin{array}{l}\text { RCRA C (or } \\
\text { equivalent } \\
\text { ET barrier) }\end{array}$ & $\begin{array}{l}\text { Modified RCRA C (or equivalent) - } \\
\text { barrier top during design life }\end{array}$ & $\begin{array}{c}0.1 \\
(0.5)^{(a)}\end{array}$ & $\begin{array}{c}0.05 \\
(0.25)^{(a)}\end{array}$ & $\begin{array}{c}0.05 \\
(0.25)^{(a)}\end{array}$ & $\begin{array}{l}0.20 \\
(1.0)^{(a)}\end{array}$ \\
\hline GS-Cap & $\begin{array}{l}\text { Geosynthetic Cap used at the US } \\
\text { Ecology Site }\end{array}$ & $\begin{array}{c}0.5 \\
(0.5)^{(a)}\end{array}$ & $\begin{array}{l}0.25 \\
N A^{(a)}\end{array}$ & $\begin{array}{l}0.25 \\
N A^{(a)}\end{array}$ & $\begin{array}{c}1.0 \\
N A^{(a)}\end{array}$ \\
\hline Hanford & $\begin{array}{l}\text { Hanford Barrier- barrier top during } \\
\text { design life }\end{array}$ & $\begin{array}{c}0.1 \\
(0.5)^{(a)}\end{array}$ & $\begin{array}{c}0.05 \\
(0.25)^{(a)} \\
\end{array}$ & $\begin{array}{c}0.05 \\
(0.25)^{(a)}\end{array}$ & $\begin{array}{c}0.20 \\
(1.0)^{(a)}\end{array}$ \\
\hline$W_{a}$-S & $\begin{array}{l}\text { Warden Silt Loam }\left(W_{a}\right) \text { - with shrub- } \\
\text { steppe }(s) \text { plant community (Could be } \\
\text { used to represent state of barrier top } \\
\text { after design life) }\end{array}$ & $\begin{array}{l}0.04 \\
(1)^{(a)}\end{array}$ & $\begin{array}{c}0.02 \\
(0.5)^{(a)}\end{array}$ & $\begin{array}{l}0.02 \\
(0.5)^{(a)}\end{array}$ & $\begin{array}{l}0.08 \\
(2)^{(a)}\end{array}$ \\
\hline$G_{r}$-S & $\begin{array}{l}\text { Gravel side slope - with shrub-steppe }(s) \\
\text { plant community (assumed final state of } \\
\text { a sandy gravel side slope) }\end{array}$ & 3.0 & 1.5 & 1.5 & 6.0 \\
\hline$G_{r}-\mathrm{n}$ & $\begin{array}{l}\text { Gravel side slope }- \text { no vegetation }(n) \\
\text { (data source had sparse vegetation on the } \\
\text { surface) }\end{array}$ & 33 & 16.5 & 16.5 & 66 \\
\hline \multicolumn{6}{|c|}{$\begin{array}{l}\text { (a) Value to be used in reference case analyses (DOE. October 21, 2005. Technical Guidance Document for } \\
\text { Composite Analysis of Low-Level Waste Disposal at the Hanford Site. DOE/RL-2005-66, U.S. Department of Energy, } \\
\text { Richland, Washington [unsigned]). } \\
\text { NA = Not anplicable. }\end{array}$} \\
\hline
\end{tabular}

The radiation flux is solar radiation derived from the 1945 to 1980 HMS data set and the latent heat of vaporization is derived from the measured temperature $(\mathrm{T})$ using the equation

$$
l_{v}=2.5 E+6-2370 \times T\left({ }^{\circ} \mathrm{C}\right)
$$

and has units of $\mathrm{J} / \mathrm{kg}$.

After the energy evaporation term is calculated, the aerodynamic evaporation component is calculated using the equation

$$
E_{a}=B\left(e_{s}-e_{a}\right)
$$

Where B is the vapor transfer coefficient, which is derived from the equation

$$
B=\frac{0.622 k^{2} \rho_{a} u_{2}}{p \rho_{w}\left[\ln \left(z_{2} / z_{0}\right)^{2}\right]}
$$


Table 4.21. Average Maximum Monthly and Yearly Total Evaporation $\left(\mathrm{m}^{3}\right)$ from Hanford Surface Ponds

\begin{tabular}{|c|c|c|c|c|c|c|c|c|c|c|c|c|}
\hline Month & 216-B-3 & 216-B-3A & 216-B-3B & 216-B-3C & 216-A-25 & 216-T-4 & 216-T-4-2 & 216-S-16 & 216-S-11 & 216-S-19 & 216-S-10 & 216-U-10 \\
\hline Jan & $14,881.09$ & $3,720.23$ & $3,720.23$ & $15,253.14$ & $31,941.67$ & $9,223.16$ & 560.77 & $11,532.82$ & 854.03 & 1,302.10 & $1,860.11$ & $11,160.87$ \\
\hline Feb & $21,125.85$ & $5,281.40$ & $5,281.40$ & $21,654.02$ & $45,345.79$ & 13,093.61 & 796.10 & $16,372.49$ & $1,212.42$ & $1,848.52$ & $2,640.70$ & $15,844.45$ \\
\hline March & $36,644.92$ & 9,161.12 & 9,161.12 & $37,561.08$ & $78,656.85$ & 22,712.18 & 1,380.91 & 28,399.74 & 2,103.06 & $3,206.44$ & $4,580.56$ & $27,483.81$ \\
\hline April & $51,527.04$ & $12,881.60$ & $12,881.60$ & $52,815.27$ & $110,600.71$ & $31,935.98$ & $1,941.73$ & 39,933.35 & 2,957.15 & 4,508.62 & $6,440.80$ & $38,645.44$ \\
\hline May & $66,307.80$ & $16,576.75$ & $16,576.75$ & $67,965.56$ & $142,327.01$ & $41,096.96$ & 2,498.72 & $51,388.40$ & $3,805.43$ & $5,801.94$ & 8,288.37 & $49,731.06$ \\
\hline June & $72,537.22$ & $18,134.08$ & $18,134.08$ & $74,350.72$ & $155,698.21$ & $44,957.89$ & 2,733.47 & $56,216.19$ & 4,162.93 & $6,347.02$ & $9,067.04$ & $54,403.14$ \\
\hline July & $80,518.76$ & $20,129.44$ & $20,129.44$ & $82,531.80$ & $172,830.25$ & $49,904.78$ & $3,034.24$ & $62,401.86$ & $4,621.00$ & $7,045.40$ & $10,064.72$ & $60,389.32$ \\
\hline Aug & $70,992.55$ & $17,747.92$ & $17,747.92$ & $72,767.43$ & $152,382.63$ & $44,000.52$ & $2,675.26$ & $55,019.07$ & $4,074.28$ & $6,211.86$ & 8,873.96 & $53,244.63$ \\
\hline Sept & $51,207.68$ & $12,801.76$ & $12,801.76$ & $52,487.92$ & $109,915.22$ & $31,738.04$ & 1,929.69 & $39,685.84$ & 2,938.82 & $4,480.68$ & $6,400.88$ & $38,405.92$ \\
\hline Oct & $34,116.53$ & 8,529.03 & 8,529.03 & $34,969.47$ & $73,229.75$ & $21,145.11$ & $1,285.63$ & $26,440.24$ & 1,957.96 & 2,985.20 & $4,264.51$ & $25,587.50$ \\
\hline Nov & $15,157.78$ & 3,789.40 & 3,789.40 & $15,536.74$ & $32,535.57$ & $9,394.65$ & 571.20 & $11,747.25$ & 869.91 & 1,326.31 & $1,894.70$ & $11,368.38$ \\
\hline Dec & $10,079.90$ & 2,519.94 & 2,519.94 & $10,331.91$ & $21,636.10$ & $6,247.43$ & 379.85 & $7,811.90$ & 578.49 & 881.99 & $1,259.97$ & 7,559.96 \\
\hline Yearly & $5.25 \mathrm{E}+05$ & $1.31 \mathrm{E}+05$ & $1.31 \mathrm{E}+05$ & $5.38 \mathrm{E}+05$ & $1.13 \mathrm{E}+06$ & $3.25 \mathrm{E}+05$ & $1.98 \mathrm{E}+04$ & $4.07 \mathrm{E}+05$ & $3.01 \mathrm{E}+04$ & $4.59 \mathrm{E}+04$ & $6.56 \mathrm{E}+04$ & $3.94 \mathrm{E}+05$ \\
\hline
\end{tabular}


where $\mathrm{k}$ is von Karmans constant $(0.4), \rho_{\mathrm{a}}$ is the air density $\left(1.19 \mathrm{~kg} / \mathrm{m}^{3} @ 25^{\circ} \mathrm{C}\right), \mathrm{u}_{2}$ is the wind speed, $\mathrm{p}$ is atmospheric pressure, $z_{2}$ is the height above the water where measurements were taken (chosen as $1 \mathrm{~m}$ ), and $z_{0}$ is the roughness height of water $(0.03 \mathrm{~cm})$. The saturation vapor pressure, $e_{s}$, is calculated by

$$
e_{s}=611 \exp \left(\frac{17.27 T}{237.3+T}\right)
$$

and the actual vapor pressure, $\mathrm{e}_{\mathrm{a}}$, is calculated from

$$
e_{a}=R H e_{s}
$$

Where RH is the relative humidity, derived from the 1945 to 1980 HMS data set.

Now that the energy balance and aerodynamic components are calculated, a weighted estimate of evaporation is derived from the two calculated evaporation rates. The equation used to calculate the final evaporation is

$$
E=\frac{\Delta}{\Delta+\gamma} E_{r}+\frac{\gamma}{\Delta+\gamma} E_{a}
$$

where $\Delta$ is the gradient of the saturated vapor pressure curve at air temperature and $\gamma$ is the psychometric constant. The equations for $\Delta$ and $\gamma$ are,

$$
\Delta=\frac{4098 e_{s}}{(237.3+T)^{2}}
$$

and

$$
\gamma=\frac{C_{p} k_{h} p}{0.622 l_{v} k_{w}}
$$

where $\mathrm{k}_{\mathrm{h}} / \mathrm{k}_{\mathrm{w}}$ are the heat and vapor diffusivities, the ratio of which is $1, \mathrm{C}_{\mathrm{p}}$ is the specific heat of air $(1005 \mathrm{~J} / \mathrm{kg})$, and $p$ is the atmospheric pressure in kilopascals.

After the daily evaporation rate is calculated, the net, total monthly evaporation is calculated by multiplying the daily evaporation rate by the number of days in the month and the surface area of the pond (as taken from the Waste Information Data System). The total yearly evaporation from each pond is simply, the sum of the monthly evaporation for each pond (Table 4.22). Average maximum monthly and yearly evaporation from Hanford ponds are listed in Table 4.21.

Evaporation estimates are applied in the SAC model as a sink term in the STOMP model. Because the evaporation estimate can occasionally exceed the actual liquid disposal at a site, a pre-conditioner utility is used in SAC to truncate the evaporation sink term so that it cannot exceed the liquid discharge rate in any period. 
Table 4.22. Hanford Pond Identification, Surface Area, and Operational Life Taken from the Waste Information Data System

\begin{tabular}{||l|c|c|c|c||}
\hline \multicolumn{1}{|c|}{ Description } & Site Name & Area $\left(\mathrm{m}^{2}\right)$ & Start Year & End Year \\
\hline \hline B-pond main lobe & 216-B-3 & 161,874 & 1945 & 1994 \\
\hline B-pond A lobe & 216-B-3A & 40,468 & 1983 & 1995 \\
\hline B-pond B lobe & 216-B-3B & 40,468 & 1983 & 1995 \\
\hline B-pond C lobe & $216-\mathrm{B}-3 C$ & 165,921 & 1985 & 1997 \\
\hline Gable Mtn pond & 216-A-25 & 347,456 & 1957 & 1987 \\
\hline T-pond & 216-T-4 & 100,328 & 1944 & 1972 \\
\hline T-pond & $216-T-4-2$ & 6,100 & 1972 & 1995 \\
\hline S pond & $216-S-16$ & 125,452 & 1957 & 1975 \\
\hline S pond & $216-S-11$ & 9,290 & 1954 & 1965 \\
\hline S pond & $216-S-10$ & 20,234 & 1952 & 1984 \\
\hline S pond & $216-S-19$ & 14,164 & 1952 & 1984 \\
\hline U pond & $216-U-10$ & 121,406 & 1944 & 1985 \\
\hline
\end{tabular}




\subsection{Conclusions and Recommendations}

Kincaid et al. (2004) identified 1,052 waste sites from the 2,730 Waste Information Data System (WIDS) sites and several existing and future storage sites for inclusion in a large-scale Hanford assessment. ${ }^{14}$ Large-scale assessments will include one-dimensional stochastic simulations of flow and transport through the vadose zone. Data and interpreted information needed to define the input parameters for the vadose zone simulations have been extracted from existing documents and databases.

This report describes the assumptions and rationale for vadose zone modeling in large-scale assessments conducted using SAC. This includes (1) defining the hydrostratigraphy, hydraulic properties, and distribution coefficients for each site to be simulated; and (2) defining the recharge estimates for each site. To simplify the preparation of input files for the large number of sites, and to improve the computational efficiencies, the Hanford Site was subdivided into 17 geographically similar areas that could each be represented by a single generalized hydrostratigraphic column. The hydrostratigraphic columns for each of the 17 geographic areas were further modified to account for differences in the depth of waste releases, and differences in solid/liquid distribution coefficients ( $K_{d}$ values) affected by different waste chemistries. This resulted in 72 base templates, each with their own unique hydrogeologic stratigraphy, hydraulic parameter distributions, and $K_{d}$ distributions. Flow and transport parameters are to be stochastically sampled for each hydrogeologic unit for each realization. Thus, each model node within a given hydrogeologic unit has the same set of parameters for a given realization.

Recharge estimates are provided for four different conditions: pre-Hanford, operations, postremediation, and post-Hanford. The conditions during these periods include natural soil with shrubsteppe plant communities, disturbed soil with or without various types of vegetation, surface barriers, and the final surface conditions as surface barriers exceed their design life and the waste sites stabilize and return to natural conditions. Probability distributions have been provided for each of these recharge estimates, to facilitate Monte Carlo analysis in estimating the uncertainty in transport rates given the expected range of recharge rates.

There are many issues and sources of uncertainty that can affect the ability to predict the behavior of contaminants in the vadose zone. These include scale effects, spatial resolution of data, preferential flow, funneled flow, colloid transport, density effects, and thermal effects. Fogwell et al. (2003) has identified a number of data gaps related to key technical issues and parameter uncertainties. This includes a number of site characterization and laboratory study needs related to interpreting observations from past tank leaks, spills, and deliberate discharges. Adequate site characterization is important to reduce uncertainties in existing inventory estimates, initial conditions, and also to demonstrate the validity of our understanding and the predictive ability of the models used for flow and transport. Estimating inventories and contaminant distributions is difficult because much of the history and character of the leaks, spills, and water losses is difficult to characterize with a reasonable level of uncertainty. This level of uncertainty will always hamper the ability of models to predict observed distributions of contaminants in the vadose zone, even if those contaminant distributions are well known.

\footnotetext{
${ }^{14}$ Originally 974 of 2,730 Waste Information Data System (WIDS) sites were identified for inclusion in a large scale Hanford assessment. Further work identified 48 more waste sites bringing the total to 1,022. Subsequent reviews identified an additional 30 sites that have been included, many of which account for offsite transfers of waste and nuclear material. This brings the total to 1,052 .
} 
Recommendations to reduce uncertainty and improve the site-wide data sets presented in this document include the following:

- Increase the number of hydrostratigraphic profiles to better represent the site-specific conditions beneath the waste sites. Efforts are underway to refine the Hanford Site geologic model to provide detail on the distribution of facies associations within the vadose zone and to enable sampling of this model to generate the site-specific hydrostratigraphic profiles. Detailed facies-based, site-specific, two or three dimensional representations should also be developed for those sites found to be high risk drivers with correspondingly high uncertainty.

- Improve our quantitative representation (i.e., through geostatistics) of the geologic structure and heterogeneities associated with the various hydrogeologic facies.

- Improve defensibility and traceability of assigning physical, hydrologic, and geochemical properties to the hydrostratigraphic units. Efforts are underway to develop facies- and location-specific pedotransfer functions to improve our understanding and quantification between geologic facies and hydraulic and geochemical property distributions.

- Continue to improve the hydraulic property database and to develop scaling relationships. These data include measured values of unsaturated conductivity, parameter estimates from resulting outflow experiments, and data and parameters resulting from field-scale tests.

- Continue to improve our ability to quantify of the impacts of gravel on hydraulic and sorption behavior of the various hydrogeologic facies, in a systematic and defensible manner.

- Improve the physical and hydraulic property distribution estimates. This would entail addition of unsaturated hydraulic conductivity data to improve curve fitting at the dry-end, improving the number of sample analyses we have for each of the hydraulic property classes, improving these data via pedotransfer functions tied to particle-size data, using Bayesian updating to improve site-specific property distributions, and incorporating concepts for scaling up sample analytical data to the field and model cell scale.

- Improve contaminant distribution coefficient estimates by correcting for gravel content based on particle-size data of the geologic facies and addressing scale-up issues from sample derived $K_{d}$ values to field and model cell scales.

- Improve our recharge estimates, particularly for coarse surface soil and side slope material.

- Improve our technical basis and modeling parameters to investigate the effect of side-slope design on deep infiltration rates.

- Improve the technical basis and modeling parameters for barrier performance after the design life.

- Improve estimates of pond/surface water evaporation based on the median monthly averages using the complete record of meteorological data, rather than the maximum monthly averages for a more limited date range. 


\subsection{References}

Agnew SF, J Boyer, RA Corbin, TB Duran, JR Fitzpatrick, KA Jurgensen, TP Ortiz, and BL Young. 1996. Hanford Tank Chemical and Radionuclide Inventories: HDW Model Rev. 3. LA-UR-96-858, Los Alamos National Laboratory, Los Alamos, New Mexico.

Allard B. 1982. Actinides in Perspective. NM Edenlstein (ed.), pp. 553-580, Pergamon Press, Oxford.

Bacon DH and BP McGrail. 2005. Waste Form Release Calculation for the 2005 Integrated Disposal Facility Performance Assessment. PNNL-15198, Pacific Northwest National Laboratory, Richland, Washington.

Bailey LEF and DE Billington. 1998. Overview of the FEP Analysis Approach to Model Development. NIREX Science Report S/98/009, United Kingdom Nirex Limited, Oxfordshire, United Kingdom.

Baker SM, RF Lorang, RP Elmore, AJ Rossi, and MD Freshley. 1988. U1/U2 Uranium Plume Characterization, Remedial Action Review and Recommendation for Future Action. WHC-EP-0133, Westinghouse Hanford Company, Richland, Washington.

Barnett DB, RM Smith, and CJ Chou. 2000. Groundwater Monitoring Plan for the Hanford Site 216-B-3 Pond RCRA Facility. PNNL-13367, Pacific Northwest National Laboratory, Richland, Washington.

BHI. 1998. Hanford Site Atlas. BHI-01119, Rev. 2, Bechtel Hanford Inc., Richland, Washington.

Bjornstad BN. 1990. Geohydrology of the 218-W-5 Burial Ground, 200-West Area, Hanford Site. PNL-7336, Pacific Northwest Laboratory, Richland, Washington.

Brown CF, RJ Serne, KM Krupka, EM Pierce, and MJ Lindberg. 2005. "Uranium Contamination at the 300 Area of the Hanford Site" In Third International Conference of Remediation of Contaminated Sediments. Battelle Press, Columbus, Ohio.

Bryce RW, CT Kincaid, PW Eslinger, and LF Morasch (eds.). 2002. An Initial Assessment of Hanford Impact Performed with the System Assessment Capability. PNNL-14027, Pacific Northwest National Laboratory, Richland, Washington.

Caggiano JA. 1996. Assessment Groundwater Monitoring Plan for Single-Shell Tank Waste Management Area S-SX. WHC-SD-EN-AP-191, Westinghouse Hanford Company, Richland, Washington.

Campbell JA, SA Clauss, KE Grant, V Hoopes, GM Mong, R Steele, D Bellofatto, and A Sharma. 1998a. Organic Analysis Progress Report FY1997. PNNL-11738, Pacific Northwest National Laboratory, Richland, Washington. 
Campbell JA, AK Sharma, SA Clauss, GM Mong, and D Bellofatto. 1998b. Organic Speciation of $A X-102$, BX-104, C-104, C-201, and C-202 Tank Wastes. PNNL-11955, Pacific Northwest National Laboratory, Richland, Washington.

Cantrell KJ, RJ Serne, and GV Last. 2002. Hanford Contaminant Distribution Coefficient Database and Users Guide. PNNL-13895, Pacific Northwest National Laboratory, Richland, Washington.

Cantrell KJ, RJ Serne, and GV Last. 2003a. Hanford Contaminant Distribution Coefficient Database and Users Guide. PNNL-13895, Rev. 1, Pacific Northwest National Laboratory, Richland, Washington.

Cantrell KJ, RJ Serne, and GV Last. 2003b. Applicability of the Linear Sorption Isotherm Model to Represent Contaminant Transport Processes in Site-Wide Performance Assessments - A White Paper. CP-17089, Fluor Hanford, Inc., Richland, Washington.

Cantrell KJ. 1988. “Actinide(III) Carbonate Complexation.” Polyhedron 7(7):573-574.

Carsel RF and RS Parrish. 1988. "Developing Joint Probability Distributions of Soil Water Retention Characteristics." Water Resour. Res. 24(5):755-769.

Cearlock CS, KM Singleton, ME Todd, and DB Barnett. 2000. 200-CW-1 Operable Unit Borehole/Test Pit Summary Report. BHI-01367, Bechtel Hanford, Inc., Richland Washington.

CH2M HILL Hanford Group, Inc. 2002. Field Investigation Report for Waste Management Area S-SX; Volume 1, Main Text and Appendices A-C, Volume 2, Appendices D - I. RPP-7884, Rev. 0, CH2M HILL Hanford Group, Inc., Richland, Washington.

Chamness, M. A., and J. K. Merz. 2003. Hanford Wells. PNL-8800. Pacific Northwest National Laboratory, Richland, Washington.

Cherrey KD, M Flury, and JB Harsh. 2003. "Nitrate and Colloid Transport through Coarse Hanford Sediments under Steady-State, Variably-Saturated Flow.” Water Resour. Res. 39, 1165, doi:10.1029/2002WR001944.

Comprehensive Environmental Response, Compensation, and Liability Act (CERCLA). 1980. Public Law 96-150, as amended, 94 Stat. 2767, 42 USC 9601 et seq.

Connelly MP, JD Davis, and PD Rittman. 1991. Numerical Simulation of Strontium-90 Transport from the 100-N Area Liquid Waste Disposal Facility. WHC-SD-ER-TA-001, Rev. 0, Westinghouse Hanford Company, Richland, Washington.

Connelly MP, BH Ford, and JV Borghese. 1992a. Hydrogeologic Model for the 200 West Area Groundwater Aggregate Area. WHC-SD-EN-TI-014, Westinghouse Hanford Company, Richland, Washington.

Connelly MP, JV Borghese, CD Delaney, BH Ford, JW Lindberg, and SJ Trent. 1992b. Hydrogeologic Model for the 200 East Groundwater Aggregate Area. WHC-SD-EN-TI-019, Westinghouse Hanford Company, Richland, Washington. 
Crews WS and DD Tillson. 1969. Analysis of Travel Time of I-131 from the 1301-N Crib to the Columbia River During July 1969. BNWL-CC-2326, Pacific Northwest Laboratory, Richland, Washington.

Cushing CE and BE Vaughan. 1988. "Springs and Streams' in Shrub-Steppe Balance and Change in a Semi-Arid Terrestrial Ecosystem." WH Rickard et al. (ed.), Developments in Agricultural and ManagedForest Ecology 20, Elsevier Science Publishers, New York.

Delaney CD, KA Lindsey, and SP Reidel. 1991. Geology and Hydrology of the Hanford Site: A Standardized Text for Use in Westinghouse Hanford Company Documents and Reports.

WHC-SD-ER-TI-003, Westinghouse Hanford Company, Richland, Washington.

DOE. 1987. Final Environmental Impact Statement, Disposal of Hanford Defense High-Level,

Transuranic and Tank Wastes, Hanford Site, Richland, Washington. DOE/EIS-0113, Volumes 1-5. U. S. Department of Energy, Washington, D.C.

DOE. 1988. Consultation Draft Site Characterization Plan. Reference Repository Location, Hanford Site, Washington. DOE/RW-0164, U.S. Department of Energy, Richland Operations Office, Richland, Washington.

DOE. 1992. Z-Plant Source Aggregate Area Management Study. DOE/RL-91-58, U.S. Department of Energy, Richland Operations Office, Richland, Washington.

DOE. 1993a. 200 East Groundwater Aggregate Area Management Study Report. DOE/RL-92-19, Rev. 0, U.S. Department of Energy, Richland Operations Office, Richland, Washington.

DOE. 1993b. Limited Field Investigation Report for the 100-HR-3 Operable Unit. DOE/RL-93-34, U.S. Department of Energy, Richland Operations Office, Richland, Washington.

DOE. 1993c. B Plant Source Aggregate Area Management Study Report. DOE/RL-92-05, U.S. Department of Energy, Richland Operations, Richland, Washington.

DOE. 1993d. 200 North Aggregate Area Source AAMS Report. DOE/RL-92-17, U.S. Department of Energy, Richland Operations, Richland, Washington.

DOE. 1993e. PUREX Source Aggregate Area Management Study Report. DOE/RL-92-04, U.S. Department of Energy, Richland Operations, Richland, Washington.

DOE. 1994. Remedial Investigation and Feasibility Study Report for the Environmental Restoration Disposal Facility. DOE/RL-93-99, Rev. 1, U.S. Department of Energy, Richland Operations Offices, Richland, Washington.

DOE. 1996a. 1301-N and 1325-N Liquid Waste Disposal Facilities Limited Field Investigation Report. DOE/RL-96-11, Rev. 0, U.S. Department of Energy, Richland Operations Office, Richland, Washington.

DOE. 1996b. Focused Feasibility Study of Engineered Barriers for Waste Management Units in the 200 Areas. DOE/RL-93-33, Rev. 0, U.S. Department of Energy, Richland, Washington. 
DOE. 1997. TWRS Vadose Zone Contamination Issue, Expert Panel Status Report. DOE/RL-97-49, Rev. 0, U.S. Department of Energy, Richland, Washington.

DOE. 1998. Groundwater/Vadose Zone Integration Project Specification. DOE/RL-98-48, Draft C, U.S. Department of Energy, Richland Operations Office, Richland, Washington.

DOE. 1999. Groundwater/Vadose Zone Integration Project Background Information and State of Knowledge. DOE/RL-98-48, Vol. II, Rev. 0, U.S. Department of Energy, Richland Operations Office, Richland, Washington.

DOE. 2000a. Groundwater/Vadose Zone Integration Project Science and Technology Summary Description. DOE/RL-98-48, Vol. III, Rev. 1, U.S. Department of Energy, Richland Operations Office, Richland, Washington.

DOE. 2000b. Phase I RCRA Facility Investigation/Corrective Measures Study Work Plan for SingleShell Tank Waste Management Areas. DOE/RL-99-36, Rev. 1, U.S. Department of Energy, Richland Operations Office, Richland, Washington.

DOE. 2002. Standardized Stratigraphic Nomenclature for Post-Ringold-Formation Sediments within the Central Pasco Basin. DOE/RL-2002-39, Rev. 0, U.S. Department of Energy, Richland Operations Office, Richland, Washington.

DOE. 2003. Hanford Site Waste Management Units Report. DOE/RL-88-30, Rev. 12, U.S. Department of Energy, Richland Operations Office, Richland, Washington.

DOE. 2005. 2004 Annual Status Report for the Composite Analysis of Low-Level Disposal in the Central Plateau at the Hanford Site. DOE/RL-2005-58. U.S. Department of Energy, Richland Operations Office, Richland, Washington.

DOE M 435.1-1. 1999. Radioactive Waste Management Manual. U.S. Department of Energy, Washington, D.C. Available on the Internet at http://www.directives.doe.gov/pdfs/doe/doetext/neword/435/m4351-1c1.html

DOE Order 435.1. 1999. Radioactive Waste Management. U.S. Department of Energy, Washington, D.C. Available on the Internet at http://www.hanford.gov/wastemgt/doe/psg/pdf/doeo435.1.pdf

DOH (Washington State Department of Health and Washington State Department of Ecology). 2004. Final Environmental Impact Statement: Commercial Low-Level Radioactive Waste Disposal Site, Richland, Washington. DOH Publication 320-031. Washington State Department of Health, Olympia, Washington.

Domenico PA and FW Schwartz. 1990. Physical and Chemical Hydrogeology. Wiley and Sons, New York, New York.

Durner W. 1992. "Predicting the Unsaturated Hydraulic Conductivity using Multi-Porosity Water Retention Curves." Proceedings of the International Workshop on Indirect Methods for Estimating the Hydraulic Properties of Unsaturated Soils, Riverside, California, October 11-13, 1989, MTh van Genuchten, FJ Leij, and LJ Lund (eds.), University of California, Riverside, California, p. 185-202. 
Enfield CG, JJC Hsieh, and AW Warrick. 1973. "Evaluation of Water Flux above a Deep Water Table Using Thermocouple Psychrometers" in Soil Sci. Soc. Amer. Proc. 37:968-970.

Eslinger PW, DW Engel, LH Gerhardstein, CA Lo Presti, WE Nichols, and DL Strenge. 2002a. "User Instructions for the Systems Assessment Capability, Rev. 0," in Computer Codes, Volume 1: Inventory, Release, and Transport Modules. PNNL-13932, Volume 1, Pacific Northwest National Laboratory, Richland, Washington.

Eslinger PW, C Arimescu, DW Engel, BA Kanyid, and TB Miley. 2002b. "User Instructions for the Systems Assessment Capability, Rev. 0," in Computer Codes, Volume 2: Impacts Modules. PNNL13932, Volume 2, Pacific Northwest National Laboratory, Richland, Washington.

Fayer MJ and TB Walters. 1995. Estimated Recharge Rates at the Hanford Site. PNL-10285, Pacific Northwest Laboratory, Richland, Washington.

Fayer MJ, EM Murphy, JL Downs, FO Khan, CW Lindenmeier, and BN Bjornstad. 1999. Recharge Data Package for the Immobilized Low-Activity Waste 2001 Performance Assessment. PNNL-13033, Pacific Northwest National Laboratory, Richland, Washington.

Fayer MJ, and JE Szecsody. 2004. Recharge Data Package for the 2005 Integrated Disposal Facility Performance Assessment. PNNL-14744, Pacific Northwest National Laboratory, Richland, Washington.

Fayer MJ and GW Gee. 2006. "Multiple-Year Water Balance of Soil Covers in a Semiarid Setting” J. Environ. Qual. 35:366-377.

Fecht KR, GV Last, and KR Price. 1977. Evaluation of Scintillation Probe Profiles from 200 Area Crib Monitoring Wells, Volumes II and III. ARH-ST-156, Atlantic Richfield Hanford Company, Richland, Washington.

Fecht KR and DC Weekes. 1996. Geologic Field Investigation of the Sedimentary Sequence at the

Environmental Restoration Disposal Facility. BHI-00230, Bechtel Hanford, Inc., Richland, Washington.

Fecht KR, KA Lindsey, DG Horton, GV Last, and SP Reidel. 1999. An Atlas of Clastic Injection Dikes of the Pasco Basin and Vicinity. BHI-01103, Rev. 0, Bechtel Hanford, Inc., Richland, Washington.

Fogwell TW, GV Last, AL Bunn, KJ Cantrell, FM Coony, JL Downs, MJ Fayer, EJ Freeman, GW Gee, DG Horton, CT Kincaid, CJ Murray, BA Napier, GW Patton, VV Rawhalf, RG Riley, and PD Thorne. 2003. Characterization of Systems Task Fiscal Year 2003 Status Report. WMP-18045, Fluor Hanford, Inc., Richland, Washington.

Freeman EJ and GV Last. 2003. Vadose Zone Hydraulic Property Letter Reports. WMP-17524, Rev. 0, Fluor Hanford, Richland, Washington.

Freeman EJ, R Khaleel, and PR Heller. 2001. A Catalog of Vadose Zone Hydraulic Properties for the Hanford Site. PNNL-13672, Pacific Northwest National Laboratory, Richland, Washington.

Freeman EJ, R Khaleel, and PR Heller. 2002. A Catalog of Vadose Zone Hydraulic Properties for the Hanford Site. PNNL-13672, Rev. 1, Pacific Northwest National Laboratory, Richland, Washington. 
Frind EO, RW Gillham, and J Pickens. 1977. “Application of Unsaturated Flow Properties in the Design of Geologic Environments for Radioactive Waste Storage Facilities" in Finite Elements in Water Resources, pp. 3.144-3.163. WG Gray, GF Pinder, and CA Brebbia (eds.), Pantech, London.

Garnier JM. 1985. "Retardation of Dissolved Radiocarbon through a Carbonated Matrix." Geochim. Cosmochim. Acta 49:683-693.

Gaylord DR and EP Poeter. 1991. Geology and Hydrology of the 300 Area and Vicinity, Hanford Site, South Central Washington. WHC-EP-0500, Westinghouse Hanford Company, Richland, Washington.

Gee GW and D Hillel. 1988. "Groundwater Recharge in Arid Regions: Review and Critique of Estimation Methods" in Journal of Hydrological Processes 2:255-266.

Gee GW, MJ Fayer, ML Rockhold, and MD Campbell. 1992. "Variations in Recharge at the Hanford Site" in Northwest Science 66:237-250.

Gee GW, JM Keller, and AL Ward. 2005. "Measurement and Prediction of Deep Drainage from Bare Sediments at a Semiarid Site ." Vadose Zone Journal 4(1):32-40

Gelhar LW. 1993. Stochastic Subsurface Hydrology. Prentice Hall, New York.

Gelhar LW and CL Axness. 1983. "Three-Dimensional Analysis of Macrodispersion in a Stratified Aquifer" in Water Resources Research 19:161-180.

Gelhar LW, C Welty, and KR Rehfeldt. 1992. "A Critical Review of Data on Field-Scale Dispersion in Aquifers," in Water Resources Research 28:1955-1974.

Gelhar LW, A Mantoglou, C Welty, and KR Rehfeldt. 1985. A Review of Field-Scale Physical Solute Transport Processes in Saturated and Unsaturated Porous Media. EPRI Report EA-4190, Research Project 2485-5, Electrical Power Research Institute, Palo Alto, California.

Geomatrix. 1996. Probabilistic Seismic Hazard Analysis for DOE Hanford Site, Washington. WHCSD-W236SA-TI-002, Rev. 1. Westinghouse Hanford Company, Richland, Washington.

Hajek BF. 1966. Soil Survey Hanford Project in Benton County, Washington. BNWL-243, Pacific Northwest Laboratory, Richland, Washington.

Hartman MJ (ed.). 2000. Hanford Site Groundwater Monitoring: Setting, Sources, and Methods. PNNL-13080, Pacific Northwest National Laboratory, Richland, Washington.

Hartman MJ and KA Lindsey. 1993. Hydrogeology of the 100-N Area, Hanford Site, Washington. WHC-SD-EN-EV-027, Westinghouse Hanford Company, Richland, Washington.

Hartman MJ and RE Peterson. 1992. Hydrologic Information Summary for the Northern Portion of the Hanford Site. WHC-SD-EN-TI-023, Westinghouse Hanford Company, Richland, Washington.

Hartman MJ and P Dresel. 1998. Hanford Site Groundwater Monitoring for Fiscal Year 1997. PNNL11793. Pacific Northwest National Laboratory, Richland, Washington. 
Hartman MJ. 1999. Hanford Site Groundwater Monitoring for Fiscal Year 1998. PNNL-12086. Pacific Northwest National Laboratory, Richland, Washington.

Hartman MJ, LF Morasch, and WD Webber, eds. 2005. Hanford Site Groundwater Monitoring for Fiscal Year 2004. PNNL-15070. Pacific Northwest National Laboratory, Richland, Washington.

HEDL (Hanford Engineering Development Laboratory). 1975. Site Investigation Report for the Fast Flux Test Facility, Richland, Washington. BCL-1701, prepared by Hanford Engineering Development Laboratory, Westinghouse Hanford Company, Richland, Washington, for the United States Atomic Energy Commission.

Higgo JJW. 1988. Review of Sorption Data Applicable to the Geologic Environment of Interest for Deep Disposal of ILW and LLW in the UK. NSS/R-162, British Geological Survey, Keyworth, Nottingham, UK.

Ho CK, RG Baca, SH Conrad, GA Smith, L Shyr, and TA Wheeler. 1999. Stochastic Parameter Development for PORFLOW Simulations of the Hanford AX Tank Farm. SAND98-2880, Sandia National Laboratories, Albuquerque, New Mexico.

Hoitink DJ, JV Ramsdell, Jr, KW Burk, and WJ Shaw. 2005. Hanford Site Climatological Summary 2004 with Historical Data. PNNL-15160, Pacific Northwest National Laboratory, Richland, WA.

Jacobs Engineering Group, Inc. 1999. Retrieval Performance Evaluation Methodology for the AX Tank Farm. DOE/RL-98-72, prepared by Jacobs Engineering Group Inc. for U.S. Department of Energy, Richland Operations Office, Richland, Washington.

Johnson VG and CJ Chou. 1998. Results of Phase I Groundwater Quality Assessment for Single-Shell Tank Waste Management Areas S-SX at the Hanford Site. PNNL-11810, Pacific Northwest National Laboratory, Richland, Washington.

Jones TL. 1989. Simulating the Water Balance of an Arid Site. PNL-SA-17633, Pacific Northwest Laboratory, Richland, Washington.

Kaplan DI and RJ Serne. 1995. Distribution Coefficient Values Describing Iodine, Neptunium, Selenium, Technetium, and Uranium Sorption to Hanford Sediments. PNL-10379, SUP. 1, Pacific Northwest Laboratory, Richland, Washington.

Kaplan DI and RJ Serne. 2000. Geochemical Data Package for the Hanford Immobilized Low-Activity Tank Waste Performance Assessment (ILAW PA). PNNL-13037, Rev. 1, Pacific Northwest National Laboratory, Richland, Washington.

Kaplan DI, KE Parker, and JC Ritter. 1998. Effects of Aging a Hanford Sediment and Quartz Sand with Sodium Hydroxide on Radionuclide Sorption Coefficients and Sediment Physical and Hydrological Properties: Final Report for Subtask 2a. PNNL-11965, Pacific Northwest National Laboratory, Richland, Washington.

Kaplan DI, RJ Serne, AT Owen, JA Conca, TW Wietsma, and TL Gervais. 1996. Radionuclide Adsorption Distribution Coefficients Measured in Hanford Sediments for the Low Level Waste Performance Assessment Project. PNNL-11385, Pacific Northwest National Laboratory, Richland, Washington. 
Kephart JL, GV Last, and SK Wurstner. 2005. "Enhancement of Stratigraphic Representations for Site Specific Tank Locations within the 200 West and 200 East Areas for the Hanford Site." Journal of Undergraduate Research, Volume V, 2005. Office of Science, U.S. Department of Energy, Washington, D.C.

Khaleel R. 1999. Far-Field Hydrology Data Package for Immobilized Low-Activity Tank Waste Performance Assessment. HNF-4769, Rev. 1, Fluor Daniel Northwest, Inc., Richland, Washington.

Khaleel R and EJ Freeman. 1995. Variability and Scaling of Hydraulic Properties for 200 Area Soils, Hanford Site. WHC-EP-0883, Westinghouse Hanford Company, Richland, Washington.

Khaleel R and PR Heller. 2003. "On the Hydraulic Properties of Coarse-Textured Sediments at Intermediate Water Contents.” Water Resour. Res. 39(9):1233.

Khaleel R and JF Relyea. 1997. "Correcting Laboratory-Measured Moisture Retention Data for Gravel" in Water Resources Research 33(8):1875-1878.

Khaleel R, JF Relyea, and JL Conca. 1995. "Evaluation of van Genuchten-Mualem Relationships to Estimate Unsaturated Hydraulic Conductivity at Low Water Contents." Water Resources Research 31(11):2659-2668.

Khaleel R, T-CJ Yeh, and Z Lu. 2002. "Upscaled Flow and Transport Properties for Heterogeneous Unsaturated Media." Water Resources Research 38(5).

Khaleel R, TE Jones, AJ Knepp, FM Mann, DA Myers, PM Rogers, RJ Serne, and MI Wood. 2001. Modeling Data Package for S-SX Field Investigation Report (FIR). RPP-6296, Rev. 0, CH2M HILL Hanford Group, Inc., Richland, Washington.

Kincaid CT, PW Eslinger, RL Aaberg, TB Miley, IC Nelson, DL Strenge, and JC Evans. 2006. Inventory Data Package for Hanford Assessments. PNNL -15829, Rev. 0. Pacific Northwest National Laboratory, Richland, Washington.

Kincaid CT, RW Bryce, and JW Buck. 2004. Technical Scope and Approach for the 2004 Composite Analysis of Low-Level Waste Disposal at the Hanford Site. PNNL-14372, Pacific Northwest National Laboratory, Richland, Washington.

Kincaid CT, PW Eslinger, WE Nichols, AL Bunn, RW Bryce, TB Miley, MC Richmond, SF Snyder, and RL Aaberg. 2000. Groundwater/Vadose Zone Integration Project, System Assessment Capability (Revision 0), Assessment Description, Requirements, Software Design, and Test Plan. BHI-01365, Draft A, Bechtel Hanford, Inc., Richland, Washington.

Kincaid CT, MP Bergeron, CR Cole, MD Freshley, NL Hassig, VG Johnson, DI Kaplan, RJ Serne, GP Streile, DL Strenge, PD Thorne, LW Vail, GA Whyatt, and SK Wurstner. 1998. Composite Analysis for Low-Level Waste Disposal in the 200 Area Plateau of the Hanford Site. PNNL-11800, Pacific Northwest National Laboratory, Richland, Washington.

Kipp KL and RD Mudd. 1974. Selected Water Table Contour Maps and Well Hydrographs for the Hanford Reservation, 1944-1973. BNWL-B-360, Pacific Northwest Laboratory, Richland, Washington. 
Klute A. 1986. Methods of Soil Analysis, Part 1. 2nd ed., American Society of Agronomy, Madison, Wisconsin.

Knepp AJ. 2002. Field Investigation Report for Waste Management Area B-BX-BY; Volume 1, Main Text and Appendices A - C, Volume 2, Appendices D - I. RPP-10098, Rev. 0. CH2M HILL Hanford Group, Inc., Richland, Washington.

Kosugi K, JW Hopmans, and JH Dane. 2002. "3.3.4 Parameteric Models" in Methods of Soil Analysis" Part 4-Physical Methods. Soil Science Society of America, Madison, Wisconsin, p. 739-757.

Krupka KM and RJ Serne. 1996. Performance Assessment of Low-Level Radioactive Waste Disposal Facilities: Effects on Radionuclide Concentrations by Cement/Ground-Water Interactions. NUREG/CR-6377, U.S. Nuclear, Regulatory Commission, Washington, D.C.

Krupka KM, RJ Serne, and DI Kaplan. 2004. Geochemical Data Package for the 2005 Hanford Integrated Disposal Facility Performance Assessment. PNNL-13037, Rev. 2. Pacific Northwest National Laboratory, Richland, Washington.

Last GV and VJ Rohay. 1993. Refined Conceptual Model for the Volatile Organic Compounds-Arid Integrated Demonstration and 200 West Area Carbon Tetrachloride Expedited Response Action. PNL-8597, Pacific Northwest Laboratory, Richland, Washington.

Last GV, BN Bjornstad, MP Bergeron, DW Wallace, DR Newcomer, JA Schramke, MA Chamness, CS Cline, SP Airhart, and JS Wilbur. 1989. Hydrogeology of the 200 Areas Low-Level Burial Grounds - An Interim Report. PNL-6820, Vol. 1 and 2, Pacific Northwest Laboratory, Richland, Washington.

Last GV, VJ Rohay, FJ Schelling, and L Soler. 2001. Use of Process Relationship Diagrams in Development of Conceptual Models. PNNL-SA-34515, Pacific Northwest National Laboratory, Richland, Washington.

Last GV, VJ Rohay, FJ Schelling, AL Bunn, MA Delamare, RL Dirkes, RD Hildebrand, JG Morse, BA Napier, RG Riley, L Soler, PD Thorne. 2004a. "A Comprehensive and Systematic Approach to Developing and Documenting Conceptual Models of Contaminant Release and Migration at the Hanford Site." Journal of Stochastic Environmental Research and Risk Assessment 18(2):190-116.

Last GV, EJ Freeman, KJ Cantrell, MJ Fayer, GW Gee, WE Nichols, BN Bjornstad, and DG Horton. 2004b. Vadose Zone Hydrogeology Data Package for the 2004 Composite Analysis. PNNL-14702, Rev. 0. Pacific Northwest National Laboratory, Richland, Washington.

Last GV, WE Nichols, and CT Kincaid. 2006. Geographic and Operational Site Parameters List (GOSPL) for Hanford Assessments. PNNL-14725, Rev. 1, Pacific Northwest National Laboratory, Richland, Washington.

Liikala TL, RL Aaberg, NJ Aimo, DJ Bates, TJ Gilmore, EJ Jensen, GV Last, PL Oberlander, KB Olsen, KR Oster, LR Roome, JC Simpson, SS Teel, and EJ Westergard. 1988. Geohydrologic Characterization of the Area Surrounding the 183-H Solar Evaporation Basin. PNL-6728, Pacific Northwest Laboratory, Richland, Washington. 
Lindberg JW and FW Bond. 1979. Geohydrology and Ground-Water Quality Beneath the 300 Area, Hanford Site, Washington. PNL-2949, Pacific Northwest Laboratory, Richland, Washington.

Lindberg JW. 1993a. Geology of the 100-B/C Area, Hanford Site, South-Central Washington. WHCSD-EN-TI-133, Westinghouse Hanford Company, Richland, Washington.

Lindberg JW. 1993b. Geology of the 100-K Area, Hanford Site, South-Central Washington.

WHC-SD-EN-TI-155, Westinghouse Hanford Company, Richland, Washington.

Lindberg JW. 1995. Hydrogeology of the 100-K Area, Hanford Site, South-Central Washington. WHC-SD-EN-TI-294, Westinghouse Hanford Company, Richland, Washington.

Lindsey KA. 1991. Revised Stratigraphy for the Ringold Formation, Hanford Site, South-Central Washington. WHC-SD-EN-EE-004. Westinghouse Hanford Company, Richland, Washington.

Lindsey KA. 1992. Geology of the Northern Part of the Hanford Site: An Outline of Data Sources and Geologic Setting of the 100 Areas. WHC-SD-EN-TI-011, Westinghouse Hanford Company, Richland, Washington.

Lindsey KA. 1995. Miocene- to Pliocene-Aged Suprabasalt Sediments of the Hanford Site, SouthCentral Washington. BHI-00184, Rev. 00, Bechtel Hanford, Inc., Richland, Washington.

Lindsey KA. 1996. Miocene to Pliocene Ringold Formation and Associated Deposits of the Ancestral Columbia River System, South-Central Washington and North Central Oregon. Open File Report 96-8, Washington State Department of Natural Resources, Olympia, Washington.

Lindsey KA and GK Jaeger. 1993. Geologic Setting of the 100-HR-3 Operable Unit, Hanford Site, South-Central Washington. WHC-SD-EN-TI-132, Westinghouse Hanford Company, Richland, Washington.

Lindsey KA and DR Gaylord. 1999. "Lithofacies and Sedimentology of the Miocene-Pliocene Ringold Formation, South-Central Washington.” In Northwest Science. Vol. 64, No. 3, pp. 165-180, May 1990.

Lindsey KA, MP Connelly, and BN Bjornstad. 1992a. Geologic Setting of the 200 West Area: An Update. WHC-SD-EN-TI-008, Westinghouse Hanford Company, Richland, Washington.

Lindsey KA, BN Bjornstad, JW Lindberg, and KM Hoffmann. 1992b. Geologic Setting of the 200 East Area: An Update. WHC-SD-EN-TI-012, Rev. 0, Westinghouse Hanford Company, Richland, Washington.

LMHC. 1999. Statements of Work for FY 2000 to FY 2005 for the Hanford Low-Activity Tank Waste Performance Assessment Program. HNF-SD-WM-PAP-062, Rev. 4, Lockheed Martin Hanford Company, Richland, Washington.

Looney BB and RW Falta (eds.). 2000. Vadose Zone, Science and Technology Solutions. Two Volumes, Battelle Press, Columbus, Ohio. 
Maxfield HL. 1979. Handbook - 200 Areas Waste Sites. RHO-CD-673, Volumes I, II, and III. Rockwell Hanford Operations, Richland, Washington.

Meyer PD, KP Saripalli, and VL Freedman. 2004. Near-Field Hydrology Data Package for the Integrated Disposal Facility 2005 Performance Assessment. PNNL-14700, Pacific Northwest National Laboratory, Richland, Washington.

Millington RJ and JP Quirk. 1959. "Permeability of Poros Media.” Nature 183:387-388.

Mualem Y. 1976. "A New Model for Predicting the Hydraulic Conductivity of Unsaturated Porous Media" in Water Resources Research 12:513.

Murphy EM, TR Ginn, and JL Phillips. 1996. "Geochemical Estimates of Paleorecharge in the Pasco Basin: Evaluation of the Chloride Mass-Balance Technique." Water Resources Research 32(9):2853-2868.

Murray CJ, AL Ward, and JL Wilson. 2003. Influence of Clastic Dikes on Vertical Migration of Contaminants in the Vadose Zone at Hanford. PNNL-14224, Pacific Northwest National Laboratory, Richland, Washington.

Murray CJ, Y Chien, and PD Thorne. 2004. A Geostatistical Analysis of Historical Field Data on Tritium, Technetium-99, Iodine-129, and Uranium. PNNL-14618, Rev. 0, Pacific Northwest National Laboratory, Richland, Washington.

Murray CJ, DG Horton, AL Ward, and GW Gee. 2002. "Hydrogeologic Influence of Clastic Dikes on Vadose Zone Transport," Section 7.3.3 pp. 7.26-7.27, in Hanford Site Environmental Report for Calendar Year 2001. PNNL-13910, Pacific Northwest National Laboratory, Richland, Washington.

NEA (Nuclear Energy Agency). 2000. Features, Events and Processes (FEPs) for Geologic Disposal of Radioactive Waste, An International Database. Organization For Economic Co-Operation and Development (OECD) Publications, France.

Neitzel DA, AL Bunn, SD Cannon, JP Duncan, RA Fowler, BG Fritz, DW Harvey, PL Hendrickson, DJ Hoitink, DG Horton, GV Last, TM Poston, EL Prendergast-Kennedy, SP Reidel, AC Rohay, MJ Scott, and PD Thorne. 2005. Hanford Site National Environmental Policy Act (NEPA) Characterization, Revision 17. PNNL-6415, Rev. 17, Pacific Northwest National Laboratory, Richland, Washington.

Oostrom. M, ML Rockhold, PD Thorne, GV Last, and MJ Truex. 2004. Three-Dimensional Modeling of DNAPL in the Subsurface of the 216-Z-9 Trench at the Hanford Site. PNNL-14895. Pacific Northwest National Laboratory, Richland, Washington.

Pearce GG, RE Brown, and TP O'Farrell. 1969. The Arid Lands Ecology Reserve at Pacific Northwest Laboratory, Richland, Washington. BNWL-SA-2574, Pacific Northwest Laboratory, Richland, Washington.

Peterson RE, RF Raidl, and CW Denslow. 1996. Conceptual Site Models for Groundwater Contamination at the 100-BC-5, 100-KR-4, 100-HR-3, and 100-FR-3 Operable Units. BHI-00917, Bechtel Hanford Company, Richland, Washington. 
Peterson RE and MP Connelly. 2001. Zone of Interaction Between Hanford Site Groundwater and Adjacent Columbia River. PNNL-13674, Pacific Northwest National Laboratory, Richland, Washington.

Price WH and KR Fecht. 1976a. Geology of the 241-U Tank Farm. ARH-LD-138, Informal Report, Atlantic Richfield Hanford Company, Richland, Washington.

Price WH and KR Fecht. 1976b. Geology of the 241-B Tank Farm. ARH-LD-129, Atlantic Richfield Hanford Company, Richland, Washington.

Price WH and KR Fecht. 1976c. Geology of the 241-BX Tank Farm. ARH-LD-130, Atlantic Richfield Hanford Company, Richland, Washington.

Price WH and KR Fecht. 1976d. Geology of the 241-BY Tank Farm. ARH-LD-131, Atlantic Richfield Hanford Company, Richland, Washington.

Pruess K., S Yabusaki, C Steefel, and P Lichtner. 2002. Fluid Flow, Heat Transfer, and Solute Transport at Nuclear Waste Storage Tanks in the Hanford Vadose Zone. Vadose Zone Journal, 1:68-88. Soil Science Society of America, Madison, Wisconsin.

Prych EA. 1998. Using Chloride and Chlorine-36 as Soil-Water Tracers to Estimate Deep Percolation at Selected Locations on the U.S. Department of Energy Hanford Site, Washington. Water-Supply Paper 2481, U.S. Geological Survey, Tacoma, Washington.

Raidl RF. 1994. Geology of the 100-FR-3 Operable Unit, Hanford Site, South-Central Washington. WHC-SD-EN-TI-221, Westinghouse Hanford Company, Richland, Washington.

Reidel SP. 2004. Geologic Data Package for 2005 Integrated Disposal Facility Waste Performance Assessment. PNNL-14586. Pacific Northwest National Laboratory, Richland, Washington.

Reidel SP and AM Ho. 2002. Geologic and Wireline Summaries from Fiscal Year 2002 ILAW Boreholes. PNNL-14029, Pacific Northwest National Laboratory, Richland, Washington.

Reidel SP and DG Horton. 1999. Geologic Data Package for 2001 Immobilized Low-Activity Waste Performance Assessment. PNNL-12257, Rev. 1, Pacific Northwest National Laboratory, Richland, Washington.

Reidel SP, DG Horton, and MM Valenta. 2001. Geologic and Wireline Borehole Summary from the Second ILAW Borehole (299-E24-21). PNNL-13652, Pacific Northwest National Laboratory, Richland, Washington.

Reidel SP, DG Horton, Y Chien, DB Barnett, and K Singleton. 2006. Geology, Hydrogeology, Geochemistry, and Mineralogy Data Package for the Single-Shell Tank Waste Management Areas at the Hanford Site. RPP-23748, Rev. 0. CH2M HILL Hanford Group, Inc. Richland, Washington.

Riley RG and C LoPresti. 2004. Release Model Data Package for the 2004 Composite Analysis. PNNL-14760, Rev. 0, Pacific Northwest National Laboratory, Richland, Washington. 
Rohay VJ, KJ Swett, and GV Last. 1994. 1994 Conceptual Model of the Carbon Tetrachloride Contamination in the 200 West Area at the Hanford Site. WHC-SD-EN-TI-248, Westinghouse Hanford Company, Richland, Washington.

Scanlon BR, SW Tyler, and PJ Wierenga. November 1997. "Hydrologic Issues in Arid, Unsaturated Systems and Implications for Contaminant Transport" in Reviews of Geophysics, 35, 4, pages 461-490. American Geophysical Union.

Schalla R, RW Wallace, RL Aaberg, SP Airhart, DJ Bastes, JVM Carlile, CS Cline, DI Dennison, MD Freshley, PR Heller, EJ Jensen, KB Olsen, RG Parkhurst, JT Rieger, and EJ Westergard. 1988. Interim Characterization Report for the 300 Area Process Trenches. PNL-6716, Pacific Northwest Laboratory, Richland, Washington.

Scott, WE, R. Iverson, M Vallance, W James, and W Hildreth. 1995. Volcano Hazards in the Mount Adams Region, Washington. Open-File Report 95-492. U.S. Geological Survey, Washington, D.C.

Serne RJ and MI Wood. 1990. Hanford Waste-Form Release and Sediment Interaction: A Status Report with Rationale and Recommendations for Additional Studies. PNL-7297, Pacific Northwest Laboratory, Richland, Washington.

Serne RJ and VL LeGore. 1996. Strontium-90 Adsorption-Desorption Properties and Sediment Characterization at the 100-N Area. PNNL-10899, Pacific Northwest National Laboratory, Richland, Washington.

Serne RJ, JL Conca, VL LeGore, KJ Cantrell, CW Lindenmeier, JA Campbell, JE Amonette, and MI Wood. 1993. Solid-Waste Leach Characteristics and Contaminant-Sediment Interactions, Volume 1: Batch Leach and Adsorption Tests and Sediment Characterization. PNL-8889, Vol. 1, Pacific Northwest Laboratory, Richland, Washington.

Serne RJ, RO Lokken, and LJ Criscenti. 1992. "Characterization of Grouted LLW to Support Performance Assessment” in Waste Management 12:271-287.

Skaggs RL and WH Walters. 1981. Flood Risk Analysis of Cold Creek Near the Hanford Site. RHO-BWI-C-120, Rockwell Hanford Operations, Richland, Washington.

Slate JL. 1996. "Buried Carbonate Paleosols Developed in Plio-Pleistocene Deposits of the Pasco Basin, South-Central Washington" in Quaternary International 34-36:191-196.

Slate JL. 2000. Nature and Variability of the Plio-Pleistocene Unit in the 200 West Area of the Hanford Site. BHI-01203, Bechtel Hanford, Inc., Richland, Washington.

Soler L, GV Last, BA Napier, VJ Rohay, and FJ Schelling. 2001. The Application of Features, Events, and Process Methodology at the Hanford Site. BHI-01573, Rev. 0, Bechtel Hanford, Inc., Richland, Washington.

Stenhouse MJ. 1995. Sorption Databases for Crystalline, Marl and Bentonite for Performance Assessment. NTB 93-06, Nagra, Wettingen, Switzerland. 
Stephens DB. 1992. "A Comparison of Calculated and Measured Unsaturated Hydraulic Conductivity of Two Uniform Soils in New Mexico." Proceedings of the International Workshop on Indirect Methods for Estimating the Hydraulic Properties of Unsaturated Soils, Riverside, California, October 11-13, 1989, MTh van Genuchten, FJ Leij, and LJ Lund (eds.), University of California, Riverside, California, p. 249-261.

Stone, WA, JM Thorp, OP Gifford and DJ Hoitink. 1983. Climatological Summary for the Hanford Area. PNL-4622. Pacific Northwest National Laboratory, Richland, Washington.

Stumm W and JJ Morgan. 1996. “Aquatic Chemistry,” Chemical Equilibria and Rates in Natural Waters, $3^{\text {rd }}$ ed., John Wiley and Sons, Inc., New York.

Swanson LC, GG Kelty, KA Lindsey, KR Simpson, RK Price, and SD Consort. 1992. Phase I Hydrogeologic Summary of the 300-FF-5 Operable Unit, 300 Area. WHC-SD-EN-TI-052, Rev. 0, Westinghouse Hanford Company, Richland, Washington.

Swanson LD, VJ Rohay, and JM Faurote. 1999. Hydrogeologic Conceptual Model for the Carbon Tetrachloride and Uranium/Technetium Plumes in the 200 West Area: 1994 through 1999 Update. BHI01311, Bechtel Hanford, Inc., Richland, Washington.

Tallman AM, KR Fecht, MC Marratt, and GV Last. 1979. Geology of the Separation Areas, Hanford Site, South-Central Washington. RHO-ST-23, Rockwell Hanford Operations, Richland, Washington.

Thorne PD, MA Chamness, FA Spane, Jr., VR Vermeul, and WD Webber. 1993. Three-Dimensional Conceptual Model for the Hanford Site Unconfined Aquifer System, FY93 Status Report. PNL-8971, Pacific Northwest Laboratory, Richland, Washington.

Thorne PD, MA Chamness, VR Vermeul, QC MacDonald, and SE Schubert. 1994. Three-Dimensional Conceptual Model for the Hanford Site Unconfined Aquifer System, FY 1994 Status Report. PNL-10195, Pacific Northwest Laboratory, Richland, Washington.

Valenta MM, MB Martin, JR Moreno, RM Ferri, DG Horton, and SP Reidel. 2000. Particle Size Distribution Data From Existing Boreholes at the Immobilized Low-Activity Waste Site. PNNL-13328, Pacific Northwest National Laboratory, Richland, Washington.

van Genuchten MTh. 1980. "A Closed-Form Solution for Predicting the Conductivity of Unsaturated Soils.” Soil Sci. Soc. Am. J. 44:892-898.

Vermeul VR, SS Teel, JE Amonette, CR Cole, JS Fruchter, YA Gorby, FA Spane, JE Szecsody, MD Williams, and SB Yabusaki. 1995. Geologic, Geochemical, Microbiologic, and Hydrologic Characterization at the In Situ Redox Manipulation Test Site. PNL-10633, Pacific Northwest Laboratory, Richland, Washington.

Ward AL, GW Gee, and MD White. 1997. A Comprehensive Analysis of Contaminant Transport in the Vadose Zone Beneath Tank SX-109. PNNL-11463, Pacific Northwest National Laboratory, Richland, Washington. 
Ward AL, JK Linville, JM Keller, GH Seedahmed. 2005. 200-BP-1 Prototype Hanford Barrier Annual Monitoring Report for Fiscal Year 2004. PNNL-14960. Pacific Northwest National Laboratory, Richland, Washington

Warrick A, DE Myers, and D Nelson. 1986. "Geostatistical Methods Applied to Soil Science, in Methods of Soil Analysis,” Part I, Soil Science Society Amer. 53-82.

Webster GD and JW Crosby. 1982. "Appendix 2R - Stratigraphic Investigation of the Skagit/Hanford Nuclear Project” In Skagit/Hanford Nuclear Project, Preliminary Safety Analysis Report. Volume 5. Pudget Power, Pudget Sound Power and Light Company, Bellevue, Washington.

Weekes, DC, BH Ford, and GK Jaeger. 1996. Preoperational Baseline and Site Characterization Report for the Environmental Restoration Disposal Facility. BHI-00270, Rev. 1. Bechtel Hanford, Inc., Richland, Washington.

White MD and M Oostrom. 2000. STOMP Subsurface Transport Over Multiple Phases Version 2.0 Theory Guide. PNNL-12030, Pacific Northwest National Laboratory, Richland, Washington.

Williams BA, BN Bjornstad, R Schalla, and WD Webber. 2000. Revised Hydrogeology for the Suprabasalt Aquifer System, 200-East Area and Vicinity, Hanford Site, Washington. PNNL-12261, Pacific Northwest National Laboratory, Richland, Washington.

Williams BA, BN Bjornstad, R Schalla, and WD Webber. 2002. Revised Hydrogeology for the Suprabasalt Aquifer System, 200-West Area and Vicinity, Hanford Site, Washington. PNNL-13858, Pacific Northwest National Laboratory, Richland, Washington.

Wilson LG, LG Everett, and SJ Cullen. 1995. Handbook of Vadose Zone Characterization and Monitoring. CRC Press, Inc., Lewis Publishers, Raton, Florida.

Wittreich CD, JK Linville, GW Gee, and AL Ward. 2003. 200-OP-1 Prototype Hanford Barrier Annual Monitoring Report for Fiscal Year 2002. CP-14873, Rev. 0, Fluor Hanford, Inc., Richland, Washington.

Wood MI, R Khaleel, PD Rittman, AH Lu, SH Finfrock, RJ Serne, KJ Cantrell, and TH DeLorenzo. 1995. Performance Assessment for the Disposal of Low-Level Waste in the 200-West Area Burial Grounds. WHC-D-0645, Westinghouse Hanford Company, Richland, Washington.

Wood MI, R Khaleel, PD Rittman, SH Finfrock, TH DeLorenzo, and DY Gorbrick. 1996. Performance Assessment for the Disposal of Low-Level Waste in the 200-East Area Burial Grounds.

WHC-SD-WM-TI-730, Westinghouse Hanford Company, Richland, Washington.

Wood MI, R Schalla, BN Bjornstad, and SM Narbutovskih. 2000. Subsurface Conditions Description of the B-BX-BY Waste Management Area. HNF-5507, Rev. 0, CH2M HILL Hanford Group, Inc., Richland, Washington.

Wood MI, TE Jones, BN Bjornstad, and F. N. Hodges. 2001. Subsurface Conditions Description of the T and TX-TY Waste Management Areas. HNF-7123, Rev. 0. CH2M Hill Hanford Group, Inc., Richland, Washington. 
Wood MI, TE Jones, BN Bjornstad, D. G. Horton, SM Narbutovskih, and R Schalla. 2003. Subsurface Conditions Description of the $C$ and A-AX Waste Management Areas. RPP-14430, Rev. 0. CH2M Hill Hanford Group, Inc., Richland, Washington.

Wood MI, and TE Jones. 2003. Subsurface Conditions Description of the U Waste Management Areas. RPP-15808, Rev. 0. CH2M Hill Hanford Group, Inc., Richland, Washington.

Wurstner SK, PD Thorne, MA Chamness, MD Freshly, and MD Williams. 1995. Development of a Three-Dimensional Ground-Water Model of the Hanford Site Unconfined Aquifer System: FY 1995 Status Report. PNL-10886, Pacific Northwest Laboratory, Richland, Washington.

Xie Y, CJ Murray, GV Last, and R Mackley. 2003. Mineralogical and Bulk-Rock Geochemical Signatures of Ringold and Hanford Formation Sediments. PNNL-14202, Pacific Northwest National Laboratory, Richland, Washington.

Yao T-M and JMH Hendricks. 1996. "Stability of Wetting Forests in Dry Homogeneous Soils Under Low Infiltration Ratios." Soil Science Society of America Journal, 60, 20-28, Madison, Wisconsin: Soil Science Society of America TIC 286692.

Zhang ZF, AL Ward, and GW Gee. 2002. Estimating Field-Scale Hydraulic Parameters Using a Combination of Parameter Scaling and Inverse Methods. PNNL-14109, Pacific Northwest National Laboratory, Richland, Washington.

Zhang ZF, AL Ward, and GW Gee. 2003. "Estimating Soil Hydraulic Parameters of a Field Drainage Experiment Using Inverse Techniques.” Vadose Zone J. 2:201-211.

Zhuang J, M Flury, and Y Jin. 2003. "Colloid-Facilitated Cs Transport through Water-Saturated Hanford Sediment and Ottawa Sand.” Environ. Sci. Technol. 37:4905-4911.

Zhuang J, Y Jin, and M Flury. 2004. "Comparison of Hanford Colloids and Kaolinite Transport in Porous Media" Vadose Zone Journal 3:395-402. Soil Science Society of America, Madison, Wisconsin. 


\section{Appendix A}

\section{Hydrostratigraphic Templates}


VZ Base Templates A

South 200 East Area (A Plant, C Plant, U. S. Ecology) Stratigraphic Columns

Notes/Assumptions:

1) Topography ranges from $735 \mathrm{ft}$ MSL in southwest corner of 200 East Area to $645 \mathrm{ft} \mathrm{MSL}$ in the 241-C area (USGS Gable Butte 7.5 min. Quadrangle Map). Will assume an average elevation of $690 \mathrm{ft} \mathrm{MSL}$.

2) The pre-Hanford Water Table (January 1944) is estimated to range from an elevation of $116 \mathrm{~m}$ (380 ft) in the eastern part of 200 East to $119 \mathrm{~m}$ (390 ft) in the western part (Kipp and Mudd 1974). Will assume an average water table elevation of $117 \mathrm{~m}$ (385 ft) MSL.

3) A thin blanket of eolian sand and silt covers the surface of the site where not disturbed.

However, this material was generally removed during excavation and construction of the waste disposal sites and then incorporated into backfill materials.

4) The depth of the sites and thus, the backfull over these sites range from $0 \mathrm{ft}$ for ponds and unplanned releases, to an average of about $15 \mathrm{ft}$ for cribs and burial grounds, and about $50 \mathrm{ft}$ for tanks. Injection well $216-\mathrm{C}-2$ is screened from 15-40 ft. Well 299-E24-11 is $60 \mathrm{ft}$ deep (Hanford Wells). Assume average depth of

\begin{tabular}{|c|c|c|c|c|c|c|c|c|c|c|}
\hline \multicolumn{9}{|c|}{ Template 200A-x for surface disposal sites (e.g., Ponds) } & \multirow[b]{2}{*}{$\begin{array}{l}200 \mathrm{~A}-2 \\
\mathrm{~K}_{\mathrm{d}} \text { Class } \\
\end{array}$} & \multirow{2}{*}{$\begin{array}{l}200 \mathrm{~A}-4 \\
\mathrm{~K}_{\mathrm{d}} \text { Class }\end{array}$} \\
\hline $\begin{array}{c}\text { Average } \\
\text { Thickness } \\
\text { (ft) }\end{array}$ & \begin{tabular}{|c|} 
Adjusted \\
Average \\
Thickness \\
(ft) \\
\end{tabular} & $\begin{array}{c}\text { Depth } \\
\text { (ft) }\end{array}$ & $\begin{array}{c}\text { Elevation } \\
\text { (ft) }\end{array}$ & Geologic Unit & Description & $\begin{array}{c}\text { Hydraulic } \\
\text { Property } \\
\text { Type * }\end{array}$ & $\begin{array}{c}\text { SAC Soil } \\
\text { Type }\end{array}$ & $K_{d} Z_{o n e^{\star \star}}$ & & \\
\hline & & 0 & 690 & Surface & NA & NA & NA & NA & & \\
\hline 15 & 15 & 15 & 675 & Eolian & Sand and Silt & $\mathrm{s}$ & Hss & $\mathrm{HI}$ & $2 \mathrm{H}$ & $4 \mathrm{H}$ \\
\hline 15 & 15 & 30 & 660 & Hanford Gravel & $\begin{array}{l}\text { Slightly Silty pebbly very coarse } \\
\text { to coarse sand }\end{array}$ & SG1 & $\mathrm{Hg}$ & II & 212 & 412 \\
\hline 200 & 203 & 233 & 457 & $\begin{array}{l}\text { South } 200 \text { East } \\
\text { Sand }\end{array}$ & $\begin{array}{l}\text { Slightly silty medium to coarse } \\
\text { sand to coarse to fine sand }\end{array}$ & $\mathrm{s}$ & Hfs & ॥ & 211 & 411 \\
\hline 62 & 62 & 295 & 395 & Hanford Gravel & $\begin{array}{l}\text { Pebbly very coarse to coarse } \\
\text { sand to medium to fine pebble }\end{array}$ & SG1 & $\mathrm{Hg}$ & II & 212 & 412 \\
\hline 10 & 10 & 305 & 385 & Ringold Unit E & $\begin{array}{l}\text { Silty sandy medium to fine } \\
\text { pebble to sandy very coarse to } \\
\text { fine pebble }\end{array}$ & SG2 & $\mathrm{Rg}$ & II & 212 & 412 \\
\hline & & 305 & 385 & Water Table & NA & $\mathrm{NA}$ & NA & $\mathrm{NA}$ & NA & NA \\
\hline
\end{tabular}

\begin{tabular}{|c|c|c|c|c|c|c|c|c|c|c|c|}
\hline \multirow{3}{*}{$\begin{array}{l}\text { Template 216A-x f } \\
\begin{array}{|c|c|}\begin{array}{c}\text { Average } \\
\text { Thickness } \\
\text { (ft) }\end{array} \\
\end{array}\end{array}$} & \multirow[b]{2}{*}{ 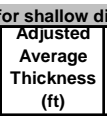 } & \multirow[b]{2}{*}{$\begin{array}{c}\text { Depth } \\
\text { (ft) }\end{array}$} & \multirow[b]{2}{*}{$\begin{array}{c}\text { Elevation } \\
\text { (ft) }\end{array}$} & \multicolumn{2}{|c|}{ Cribs, Burial Grounds) } & \multirow[b]{2}{*}{$\begin{array}{l}\text { Hydraulic } \\
\text { Property } \\
\text { Type * }\end{array}$} & \multirow[b]{2}{*}{$\begin{array}{l}\text { SAC Soil } \\
\text { Type }\end{array}$} & \multirow[b]{2}{*}{$\mathrm{K}_{\mathrm{d}}$ Zone $^{\star \star}$} & \multirow[b]{2}{*}{\begin{tabular}{|l|}
$216 \mathrm{~A}-2$ \\
$\mathrm{~K}_{\mathrm{d}}$ Class \\
\end{tabular}} & \multirow[b]{2}{*}{$\begin{array}{l}216 \mathrm{~A}-3 \\
\mathrm{~K}_{\mathrm{d}} \text { Class }\end{array}$} & \multirow[b]{2}{*}{$\begin{array}{l}216 \mathrm{~A}-4 \\
K_{d} \text { Class }\end{array}$} \\
\hline & & & & Geologic Unit & Description & & & & & & \\
\hline & & & 690 & Surface & NA & NA & NA & NA & NA & NA & NA \\
\hline 15 & 15 & 15 & 675 & Backfill & Backfill & B & $\mathrm{B}$ & $\mathrm{HI}$ & $2 \mathrm{H}$ & $3 \mathrm{H}$ & $4 \mathrm{H}$ \\
\hline 15 & 15 & 30 & 660 & Hanford Gravel & $\begin{array}{l}\text { Slightly Silty pebbly very coarse } \\
\text { to coarse sand }\end{array}$ & SG1 & $\mathrm{Hg}$ & $\mathrm{HI}$ & $2 \mathrm{H}$ & $3 \mathrm{H}$ & $4 \mathrm{H}$ \\
\hline 200 & 203 & 233 & 457 & $\begin{array}{l}\text { South } 200 \text { East } \\
\text { Sand }\end{array}$ & $\begin{array}{l}\text { Slightly silty medium to coarse } \\
\text { sand to coarse to fine sand }\end{array}$ & $\mathrm{s}$ & Hfs & ॥ & 211 & 311 & 411 \\
\hline 62 & 62 & 295 & 395 & Hanford Gravel & $\begin{array}{l}\text { Pebbly very coarse to coarse } \\
\text { sand to medium to fine pebble }\end{array}$ & SG1 & $\mathrm{Hg}$ & II & 212 & 312 & 412 \\
\hline 10 & 10 & 305 & 385 & Ringold Unit E & $\begin{array}{l}\text { Silty sandy medium to fine } \\
\text { pebble to sandy very coarse to } \\
\text { fine pebble }\end{array}$ & SG2 & $\mathrm{Rg}$ & ॥ & 212 & 312 & 412 \\
\hline & & 305 & 385 & Water Table & NA & $\mathrm{NA}$ & $\mathrm{NA}$ & NA & $\mathrm{NA}$ & NA & $\mathrm{NA}$ \\
\hline
\end{tabular}

\begin{tabular}{|c|c|c|c|c|c|c|c|c|c|c|c|}
\hline \multicolumn{9}{|c|}{ Template 241A-x for tanks (modified after Reidel et al. 2006) } & \multirow{2}{*}{\begin{tabular}{|l|}
$241 \mathrm{~A}-2$ \\
$\mathrm{~K}_{\mathrm{d}}$ Class \\
\end{tabular}} & \multirow{2}{*}{$\begin{array}{l}241 \mathrm{~A}-3 \\
\mathrm{~K}_{\mathrm{d}} \text { Class }\end{array}$} & \\
\hline \begin{tabular}{|c|}
$\begin{array}{c}\text { Average } \\
\text { Thickness } \\
\text { (ft) }\end{array}$ \\
\end{tabular} & \begin{tabular}{|c|} 
Adjusted \\
Average \\
Thickness \\
(ft) \\
\end{tabular} & \begin{tabular}{|c|} 
Depth \\
(ft)
\end{tabular} & $\begin{array}{c}\begin{array}{c}\text { Elevation } \\
\text { (ft) }\end{array} \\
\end{array}$ & Geologic Unit & Description & $\begin{array}{c}\text { Hydraulic } \\
\text { Property } \\
\text { Type * }\end{array}$ & $\begin{array}{c}\text { SAC Soil } \\
\text { Type } \\
\end{array}$ & $K_{d} Z_{\text {Zne }}^{* \star}$ & & & \\
\hline & & 0 & 690 & Surface & NA & NA & NA & NA & $\mathrm{NA}$ & NA & \\
\hline 50 & 50 & 50 & 640 & Backfill & $\begin{array}{l}\text { Dominated by gravel consisting } \\
\text { of poorly to moderately sand } \\
\text { with some sand evolved from } \\
\text { coarse grained Hanford } \\
\text { formation }\end{array}$ & B & B & $\mathrm{HI}$ & $2 \mathrm{H}$ & $3 \mathrm{H}$ & \\
\hline 81.5 & 82 & 132 & 558 & $\begin{array}{l}\text { (Gravel dominated } \\
\text { facies association) } \\
\text { H1-b? }\end{array}$ & $\begin{array}{l}\text { Upper gravel dominated unit, } \\
\text { gravelly sand }\end{array}$ & $\mathrm{SG} 1$ & $\mathrm{Hg}$ & $\mathrm{HI}$ & $2 \mathrm{H}$ & $3 \mathrm{H}$ & \\
\hline 162.3 & 162 & 294 & 396 & $\begin{array}{l}\text { (Sand dominated } \\
\text { facies association) } \\
\text { H2? }\end{array}$ & $\begin{array}{l}\text { Upper sand dominated unit, } \\
\text { slightly silty }\end{array}$ & $\mathrm{s}$ & Hfs & $\mathrm{HI}$ & $2 \mathrm{H}$ & $3 \mathrm{H}$ & \\
\hline 5 & 5 & 299 & 391 & Hanford Gravel & $\begin{array}{l}\begin{array}{l}\text { Pebbly very coarse to coarse } \\
\text { sand to medium to fine pebble }\end{array} \\
\end{array}$ & SG1 & $\mathrm{Hg}$ & II & 212 & 312 & \\
\hline 2.6 & 3 & 302 & 388 & \begin{tabular}{|l} 
Cold Creek Upper \\
Sub-unit/Plio- \\
Pleistocene Silt Unit
\end{tabular} & $\begin{array}{l}\text { Locally thick layer of silt overling } \\
\text { the gravelly sediments of lower } \\
\text { subunit }\end{array}$ & ss & PPlz & ॥ & 211 & 311 & \\
\hline 2.5 & 3 & 305 & 385 & $\begin{array}{l}\text { Cold Creek Lower } \\
\text { Sub-unit }\end{array}$ & $\begin{array}{l}\text { Silty sandy medium to fine } \\
\text { pebble to sandy very coarse to } \\
\text { fine pebble }\end{array}$ & SG2 & $\mathrm{Rg}$ & II & 212 & 312 & \\
\hline & & 305 & 385 & Water Table & NA & NA & $\mathrm{NA}$ & $\mathrm{NA}$ & 212 & 312 & \\
\hline
\end{tabular}

\begin{tabular}{|c|c|c|c|c|c|c|c|c|c|c|}
\hline \multirow{2}{*}{\multicolumn{9}{|c|}{ Template 266A-x for deep injection sites (e.g., reverse wells 216-C-2) }} & \multirow{2}{*}{\multicolumn{2}{|c|}{ 266A-4 }} \\
\hline & & & & & & & & & & \\
\hline $\begin{array}{l}\text { Average } \\
\text { Thickness } \\
\text { (ft) }\end{array}$ & $\begin{array}{l}\text { Adjusted } \\
\text { Average } \\
\text { Thickness } \\
\text { (ft) }\end{array}$ & \begin{tabular}{|c|} 
Depth \\
(ft)
\end{tabular} & $\begin{array}{c}\text { Elevation } \\
\text { (ft) }\end{array}$ & Geologic Unit & Description & $\begin{array}{c}\text { Hydraulic } \\
\text { Property } \\
\text { Type * }\end{array}$ & $\begin{array}{l}\text { SAC Soil } \\
\text { Type }\end{array}$ & $K_{d} Z_{\text {Zne }}^{* *}$ & & $K_{d}$ Class \\
\hline & & $\underline{0}$ & 690 & Surface & NA & NA & NA & \begin{tabular}{|l|} 
NA \\
\end{tabular} & & NA \\
\hline 15 & 15 & 15 & 675 & Eolian & Sand and silt & $\mathrm{s}$ & $\mathrm{Hfs}$ & II & & 411 \\
\hline 15 & 35 & 50 & 640 & Hanford Gravel & $\begin{array}{l}\text { Slightly Silty pebbly very coarse } \\
\text { to coarse sand }\end{array}$ & SG1 & $\mathrm{Hg}$ & $\mathrm{HI}$ & & $4 \mathrm{H}$ \\
\hline 200 & 183 & 233 & 457 & $\begin{array}{l}\text { South } 200 \text { East } \\
\text { Sand }\end{array}$ & $\begin{array}{l}\text { Slightly silty medium to coarse } \\
\text { sand to coarse to fine sand }\end{array}$ & $\mathrm{s}$ & Hfs & $\mathrm{HI}$ & & $4 \mathrm{H}$ \\
\hline 62 & 62 & 295 & 395 & Hanford Gravel & $\begin{array}{l}\text { Pebbly very coarse to coarse } \\
\text { sand to medium to fine pebble }\end{array}$ & SG1 & $\mathrm{Hg}$ & II & & 412 \\
\hline 10 & 10 & 305 & 385 & Ringold Unit E & $\begin{array}{l}\text { Silty sandy medium to fine } \\
\text { pebble to sandy very coarse to } \\
\text { fine pebble }\end{array}$ & SG2 & $\mathrm{Rg}$ & II & & 412 \\
\hline & & 305 & 385 & Water Table & NA & $\mathrm{NA}$ & $\mathrm{NA}$ & $\mathrm{NA}$ & & $\mathrm{NA}$ \\
\hline
\end{tabular}

* After Khaleel and Freeman (1995), per white paper by Khaleel (September 2000)

** $\mathrm{HI}=$ high impact, II=Intermediate Impact (After Kincaid et al. 1998).

BLUE = Injection/release point.

(a) Note: Injection well 216-C-2 is screened from 15-40 ft. Well 299-E24-11 is $60 \mathrm{ft}$ deep (Hanford Wells). Assume average depth of $50 \mathrm{ft}$. 


\section{VZ Base Templates - A_BC Cribs}

\section{BC-Cribs (216-B-14 through -19), South 200 East Area Stratigraphic Columns}

Notes/Assumptions:

1) Well head elevations range between 747 and $748 \mathrm{ft}$ (HWIS). Well heads are typically about $3 \mathrm{ft}$ about ground surface.

However, the site was also interim stabilized in 1981 by covering with a minium of $2 \mathrm{ft}(0.61 \mathrm{~m})$ of clean soil and revegetated (WIDS).

Therefore will assume an average elevation of $742 \mathrm{ft}$.

2) The pre-Hanford Water Table (January 1944) is estimated to have been at an elevation of $387 \mathrm{ft}$ (118 m) MSL (based on Kipp and

Mudd 1974)

3) The site depth to the crib bottom is reported to be $13 \mathrm{ft}(4 \mathrm{~m})$ based on Maxfield (1979). Thus, the backfill is assumed to be $13 \mathrm{ft}$ deep.

\begin{tabular}{|c|c|c|c|c|c|c|c|c|c|}
\hline emplate $216 \mathrm{~A}$ & BC_E-X for & e East & n corner & $f$ the $B C$ crib area & ased on 299-E13-1 (N 134404. & 12, E 5736 & 23). & & $\begin{array}{c}216 A \_B C \\
E-3\end{array}$ \\
\hline $\begin{array}{c}\text { Estimated } \\
\text { Thickness } \\
(\mathrm{ft})^{\star \star \star}\end{array}$ & $\begin{array}{c}\text { Adjusted } \\
\text { Thickness } \\
\text { (ft) }\end{array}$ & $\begin{array}{c}\text { Depth } \\
\text { (ft) }\end{array}$ & $\begin{array}{c}\text { Elevation } \\
\text { (ft) }\end{array}$ & Geologic Unit & Description & $\begin{array}{c}\text { Hydraulic } \\
\text { Property } \\
\text { Type * }\end{array}$ & $\begin{array}{l}\text { SAC Soil } \\
\text { Type }\end{array}$ & Kd Zone ${ }^{\star *}$ & Kd Class \\
\hline & & 0 & 742 & Surface & NA & NA & NA & NA & $\mathrm{NA}$ \\
\hline 13 & 13 & 13 & 729 & Backfill & Backfill & $\mathrm{B}$ & $\mathrm{B}$ & $\mathrm{HI}$ & $3 \mathrm{H}$ \\
\hline 9 & 9 & 22 & 720 & $\begin{array}{l}\text { Hanford Sand - } \\
\text { horizontally bedded } \\
\text { coarse sand (Sh[c]) }\end{array}$ & $\begin{array}{l}\text { Pebbly very coarse to medium } \\
\text { sand to coarse to medium sand }\end{array}$ & S & Hcs_BC & $\mathrm{HI}$ & $3 \mathrm{H}$ \\
\hline 221 & 221 & 243 & 499 & $\begin{array}{l}\text { Handford Sand - } \\
\text { horizontally bedded } \\
\text { fine sand (Sh[f]) }\end{array}$ & $\begin{array}{l}\text { Coarse to fine sand to slightly } \\
\text { silty coarse to fine sand }\end{array}$ & S & Hfs_BC & II & $3 \mid 1$ \\
\hline 83 & 112 & 355 & 387 & Ringold Unit E & $\begin{array}{l}\text { Silty sandy coarse to fine pebble } \\
\text { to slightly silty pebbly very } \\
\text { coarse to medium sand }\end{array}$ & SG2 & $\mathrm{Rg}$ & II & 312 \\
\hline & & 355 & 387 & Water Table & NA & NA & NA & NA & NA \\
\hline
\end{tabular}

\begin{tabular}{|c|c|c|c|c|c|c|c|c|c|}
\hline \multicolumn{9}{|c|}{ Template 216A_BC_W-X for the Western corner of the BC crib area based on 299-E13-6 (N 134341.797, E 573564.077). } & \multirow{2}{*}{\begin{tabular}{|c|}
$\begin{array}{c}216 A \_B C \\
\text { W-3 }\end{array}$ \\
\\
Kd Class \\
\end{tabular}} \\
\hline $\begin{array}{c}\text { Estimated } \\
\text { Thickness } \\
(\mathrm{ft})^{\star \star \star}\end{array}$ & $\begin{array}{c}\text { Adjusted } \\
\text { Thickness } \\
\text { (ft) }\end{array}$ & $\begin{array}{c}\text { Depth } \\
\text { (ft) }\end{array}$ & $\begin{array}{c}\text { Elevation } \\
\text { (ft) }\end{array}$ & Geologic Unit & Description & $\begin{array}{c}\text { Hydraulic } \\
\text { Property } \\
\text { Type * }\end{array}$ & $\begin{array}{c}\text { SAC Soil } \\
\text { Type }\end{array}$ & & \\
\hline & & 0 & 742 & Surface & NA & $\mathrm{NA}$ & $\mathrm{NA}$ & $\mathrm{NA}$ & $\mathrm{NA}$ \\
\hline 13 & 13 & 13 & 729 & Backfill & Backfill & $\mathrm{B}$ & $\mathrm{B}$ & $\mathrm{HI}$ & $3 \mathrm{H}$ \\
\hline 10 & 10 & 23 & 719 & $\begin{array}{l}\text { Hanford Sand - } \\
\text { horizontally bedded } \\
\text { coarse sand (Sh[c]) }\end{array}$ & $\begin{array}{l}\text { Pebbly very coarse to medium } \\
\text { sand to coarse to medium sand }\end{array}$ & $\mathrm{s}$ & Hcs_BC & $\mathrm{HI}$ & $3 \mathrm{H}$ \\
\hline 215 & 215 & 238 & 504 & $\begin{array}{l}\text { Handford Sand - } \\
\text { horizontally bedded } \\
\text { fine sand (Sh[f]) }\end{array}$ & $\begin{array}{l}\text { Coarse to fine sand to slightly } \\
\text { silty coarse to fine sand }\end{array}$ & $\mathrm{s}$ & Hfs_BC & II & 311 \\
\hline 98 & 117 & 355 & 387 & Ringold Unit E & $\begin{array}{l}\text { Silty sandy coarse to fine pebble } \\
\text { to slightly silty pebbly very } \\
\text { coarse to medium sand }\end{array}$ & SG2 & $\mathrm{Rg}$ & II & 312 \\
\hline & & 355 & 387 & Water Table & NA & NA & NA & NA & NA \\
\hline
\end{tabular}

* After Khaleel and Freeman (1995), per white paper by Khaleel (September 2000).

${ }^{* *} \mathrm{HI}=$ high impact, II=Intermediate Impact (after Kincaid et al. 1998).

BLUE = Injection/release point. 
VZ Base Templates - A_BC Trenches

BC-Trenches (216-B-20 through -31, -52 through -54, and -58), South 200 East Area Stratigraphic Columns

1) Topography ranges from $228.5 \mathrm{~m}$ (750 ft) MSL near the 216-B-58 trench to $225 \mathrm{~m}(738) \mathrm{ft}$ MSL south of the 216-B-28 trench (as taken from the Hanford Site Atlas)
(a)

Note however, that the site was interim stabilized in 1981 by covering with a minium of $2 \mathrm{ft}(0.61 \mathrm{~m})$ of clean soil and revegetated (WIDS). Ground surface

elevations based on top of casing elevations in Hanford Wells (Chamness and Merz 1993).

2) The pre-Hanford Water Table (January 1944) is estimated to have been at an elevation of $387 \mathrm{ft}(118 \mathrm{~m}$ ) MSL (based on Kipp and Mudd 1974).

The site depth to the trench bottom is reported to be 8 to $10 \mathrm{ft}-\mathrm{min}$. $(2.4-3 \mathrm{~m})$ based on Maxfield (1979). Thus, the backill is assumed to be

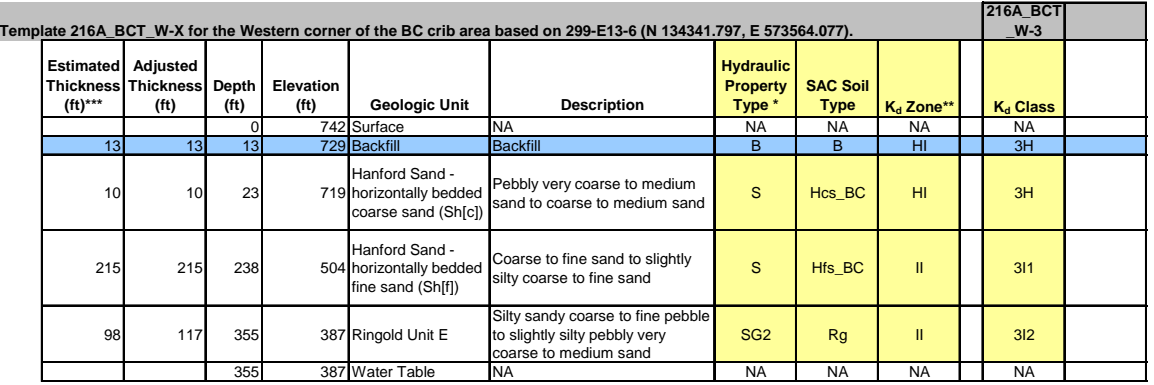

\begin{tabular}{|c|c|c|c|c|c|c|c|c|c|c|}
\hline \begin{tabular}{|c|} 
Estimated \\
Thickness \\
(ft)
\end{tabular} & \begin{tabular}{|c|}
$\begin{array}{c}\text { Adjusted } \\
\text { Thickness } \\
\text { (tt) }\end{array}$ \\
\end{tabular} & $\begin{array}{c}\text { Depth } \\
\text { (ft) }\end{array}$ & \begin{tabular}{|c} 
Elevation \\
$(\mathrm{ft})$
\end{tabular} & Geologic Unit & Description & $\begin{array}{c}\text { Hydraulic } \\
\text { Property } \\
\text { Type * }\end{array}$ & $\begin{array}{c}\text { SAC Soil } \\
\text { Type }\end{array}$ & $K_{d} Z_{o n e}{ }^{* \star}$ & $K_{d}$ Class & $K_{d}$ Class \\
\hline & & & 745 & Surface & NA & NA & NA & NA & NA & NA \\
\hline 10 & 10 & 10 & 735 & Backfill & Backfill & $\mathrm{B}$ & $B$ & $\mathrm{HI}$ & $3 \mathrm{H}$ & $4 \mathrm{H}$ \\
\hline 17 & 17 & 27 & 718 & $\begin{array}{l}\text { Hanford Sand - } \\
\text { horizontally bedded } \\
\text { coarse sand (Sh[c]) }\end{array}$ & $\begin{array}{l}\text { Pebbly very coarse to medium } \\
\text { sand to coarse to medium sand }\end{array}$ & $\mathrm{s}$ & Hcs_BC & $\mathrm{HI}$ & $3 \mathrm{H}$ & $4 \mathrm{H}$ \\
\hline 188 & 188 & 215 & 530 & $\begin{array}{l}\text { Hanford Sand - } \\
\text { horizontally bedded } \\
\text { fine sand (Sh[f]) }\end{array}$ & $\begin{array}{l}\text { Coarse to fine sand to slightly } \\
\text { silty coarse to fine sand }\end{array}$ & $\mathrm{s}$ & Hfs_BC & ॥ & 311 & 411 \\
\hline 58 & 58 & 273 & 472 & $\begin{array}{l}\text { Hanford Sand - } \\
\text { horizontally bedded } \\
\text { coarse sand (Sh[c]) }\end{array}$ & $\begin{array}{l}\text { Slightly pebbly very coarse to } \\
\text { medium sandy coarse to fine } \\
\text { pebble }\end{array}$ & $\mathrm{s}$ & Hcs_BC & ॥ & 311 & 411 \\
\hline 22 & 22 & 295 & 450 & $\left\{\begin{array}{l}\text { Hanford Sand - } \\
\text { horizontally bedded } \\
\text { fine sand (Sh[f]) }\end{array}\right.$ & $\begin{array}{l}\text { Coarse to fine sand to slightly } \\
\text { sitty coarse to fine sand }\end{array}$ & $\mathrm{s}$ & Hfs_BC & ॥ & 311 & 411 \\
\hline 43 & 63 & 358 & 387 & 7 Ringold Unit E & $\begin{array}{l}\text { Silty sandy coarse to fine pebble } \\
\text { to slightly silty pebbly very } \\
\text { coarse to medium sand }\end{array}$ & SG2 & $\mathrm{Rg}$ & ॥ & 412 & 412 \\
\hline & & 358 & 387 & Thater Table & NA & NA & $\mathrm{NA}$ & NA & NA & NA \\
\hline
\end{tabular}

\begin{tabular}{|c|c|c|c|c|c|c|c|c|c|c|}
\hline \multicolumn{9}{|c|}{ Template 216A BCT_S-X for the southwestern portion of the BC trench area based on 299-E13-12 (N 134146.593, E 573188.669). } & \multicolumn{2}{|c|}{ 216A_BCT 216A_BCT } \\
\hline $\begin{array}{c}\text { Estimated } \\
\text { Thickness } \\
(\mathrm{ft})^{\text {thk }}\end{array}$ & $\begin{array}{c}\text { Adjusted } \\
\text { Thickness } \\
\text { (ft) }\end{array}$ & $\begin{array}{c}\text { Depth } \\
\text { (ft) }\end{array}$ & $\begin{array}{c}\text { Elevation } \\
\text { (ft) }\end{array}$ & Geologic Unit & Description & $\begin{array}{c}\text { Hydraulic } \\
\text { Property } \\
\text { Type * }\end{array}$ & $\begin{array}{l}\text { SAC Soil } \\
\text { Type }\end{array}$ & K. Zone*t & $K$ Class & $K$. Class \\
\hline & & & 731 & 1 Surface & NA & \begin{tabular}{|l|} 
NA \\
\end{tabular} & NA & \begin{tabular}{|l|}
$\mathrm{Nd} Z \mathrm{NA}$ \\
\end{tabular} & \begin{tabular}{|l|} 
Nd \\
NA
\end{tabular} & \begin{tabular}{|l} 
NA \\
NA
\end{tabular} \\
\hline 10 & 10 & 10 & 721 & \begin{tabular}{l|l} 
Backfill \\
\end{tabular} & Backfill & $B$ & $B$ & $\mathrm{HI}$ & $3 \mathrm{H}$ & $4 \mathrm{H}$ \\
\hline 187 & 187 & 197 & 534 & $4 \begin{array}{l}\text { Hanford Sand - } \\
\text { horizontally bedded } \\
\text { fine sand (Sh[f]) }\end{array}$ & $\begin{array}{l}\text { Coarse to fine sand to slightly } \\
\text { sitty coarse to fine sand }\end{array}$ & $\mathrm{s}$ & Hfs_BC & $\mathrm{HI}$ & $3 \mathrm{H}$ & $4 \mathrm{H}$ \\
\hline 87 & 87 & 284 & 447 & $7 \begin{array}{l}\text { Hanford Sand - } \\
\text { horizontally bedded } \\
\text { coarse sand (Sh[c]) }\end{array}$ & $\begin{array}{l}\text { Slightly pebbly very coarse to } \\
\text { medium sandy coarse to fine } \\
\text { pebble }\end{array}$ & $\mathrm{s}$ & Hcs_BC & $\|$ & 311 & 411 \\
\hline 5 & 5 & 289 & 442 & \begin{tabular}{|l|} 
Hanford Sand - \\
horizontally bedded \\
fine sand $(\operatorname{Sh}[\mathrm{f})$
\end{tabular} & $\begin{array}{l}\text { Coarse to fine sand to slightly } \\
\text { sitty coarse to fine sand }\end{array}$ & $\mathrm{s}$ & Hfs_BC & ॥ & 311 & 411 \\
\hline 35 & 55 & 344 & 387 & 7 Ringold Unit E & $\begin{array}{l}\text { Silty sandy coarse to fine pebble } \\
\text { to slightly silty pebbly very } \\
\text { coarse to medium sand }\end{array}$ & SG2 & $\mathrm{Rg}$ & ॥ & 312 & 412 \\
\hline & & 344 & 387 & 7 Water Table & NA & NA & NA & NA & NA & NA \\
\hline
\end{tabular}

\begin{tabular}{|c|c|c|c|c|c|c|c|c|c|c|}
\hline & & & & & & & & & $216 \mathrm{~A}$ BCT & 216A_BC \\
\hline Alternate Templat & te 216A_BC & ET_A-X fo & or the $\mathrm{BC}$ cr & ribs and trenches an & nd US Ecology areas based on & 3orehole C4 & & & $A-3$ & \\
\hline \begin{tabular}{|c|} 
Estimated \\
Thickness \\
$(\mathrm{ft})^{\star n+k}$
\end{tabular} & $\begin{array}{c}\text { Adjusted } \\
\text { Thickness } \\
\text { (ft) }\end{array}$ & $\begin{array}{c}\text { Depth } \\
\text { (ft) }\end{array}$ & $\begin{array}{c}\text { Elevation } \\
\text { (ft) }\end{array}$ & Geologic Unit & Description & $\begin{array}{c}\text { Hydraulic } \\
\text { Property } \\
\text { Type * }^{*}\end{array}$ & $\begin{array}{c}\text { SAC Soil } \\
\text { Type }\end{array}$ & $K_{d} Z_{0 n e * t}$ & $K_{d}$ Class & $K_{d}$ Class \\
\hline & & & 731 & Surface & NA & NA & NA & NA & NA & NA \\
\hline 10 & 10 & 10 & 721 & Backfill & Sand, silt, and gravel & $\mathrm{B}$ & $B$ & $\mathrm{HI}$ & $3 \mathrm{H}$ & $4 \mathrm{H}$ \\
\hline 75 & 75 & 85 & 646 & $\left\{\begin{array}{l}\text { Hanford Sand - } \\
\text { horizontally bedded } \\
\text { fine sand (Sh[f]) }\end{array}\right.$ & $\begin{array}{l}\text { Coarse to very fine sand to sity } \\
\text { fine to very fine sand and some } \\
\text { silt lenses }\end{array}$ & $\mathrm{s}$ & Hfs_BC & $\mathrm{HI}$ & $3 \mathrm{H}$ & $4 \mathrm{H}$ \\
\hline 10 & 10 & 95 & 636 & \begin{tabular}{|l} 
Hanford Sand - \\
Laminated Silt to \\
Fine Sand (FI)
\end{tabular} & Compact, dense silt to sandy silt & sS & Hss & $\|$ & 311 & 411 \\
\hline 55 & 55 & 150 & 581 & $\begin{array}{l}\text { Hanford Sand - } \\
\text { horizontally bedded } \\
\text { fine sand }(\mathrm{Sh}[\mathrm{f}])\end{array}$ & $\begin{array}{l}\text { Very coarse to very fine sand } \\
\text { with some sit lenses }\end{array}$ & $\mathrm{s}$ & Hfs_BC & II & 311 & 411 \\
\hline 70 & 70 & 220 & 511 & \begin{tabular}{|l} 
Hanford Sand- \\
Laminated Silt to \\
Fine Sand (FI)
\end{tabular} & $\begin{array}{l}\begin{array}{l}\text { Sandy silt to sitt with some sitty } \\
\text { to slightly silty coarse to medium } \\
\text { sand lenses }\end{array} \\
\end{array}$ & ss & Hss & "I & 311 & 411 \\
\hline 65 & 65 & 285 & 446 & $\begin{array}{l}\text { Hanford Sand - } \\
\text { horizontally bedded } \\
\text { coarse sand (Sh[c]) }\end{array}$ & $\begin{array}{l}\text { Slightly silty gravelly very coarse } \\
\text { to medium sand to silty fine to } \\
\text { very fine sand }\end{array}$ & $\mathrm{s}$ & Hcs_BC & "I & 311 & 411 \\
\hline$<60$ & 59 & 344 & 387 & Ringold Unit E & $\begin{array}{l}\text { Silty sandy coarse to fine pebble } \\
\text { to slightly sitty pebbly very } \\
\text { coarse to medium sand }\end{array}$ & SG2 & $\mathrm{Rg}$ & "I & 312 & 412 \\
\hline & & 344 & 387 & Water Table & NA & NA & NA & NA & NA & NA \\
\hline
\end{tabular}

** HIIIhigh impact, IIIIItermediate Impact (after Kincaid et al. 1998)
BLUE $=$ Injection/release point. 


\section{VZ Base Templates A_C Tanks}

\section{South 200 East Area (C Tank Farm) Stratigraphic Columns}

Notes/Assumptions:

1) Topography is about $645 \mathrm{ft}$ MSL in the 241-C area (USGS Gable Butte $7.5 \mathrm{~min}$. Quadrangle Map).

Will assume an average elevation of $645 \mathrm{ft} \mathrm{MSL}$.

2) The pre-Hanford Water Table (January 1944) is estimated to range from an elevation of $116 \mathrm{~m}(380 \mathrm{ft})$ in the eastern part of

200 East to $119 \mathrm{~m}$ (390 ft) in the western part (Kipp and Mudd 1974).

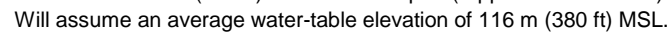

3) A thin blanket of eolian sand and silt covers the surface of the site where not disturbed. However, this material was generally removed during excavation and construction of the waste disposal sites and then incorporated into backfill materials.

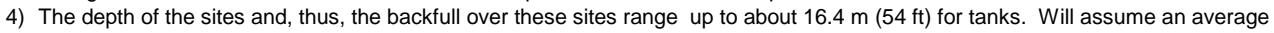
thickness of backfill to be $50 \mathrm{ft}$.

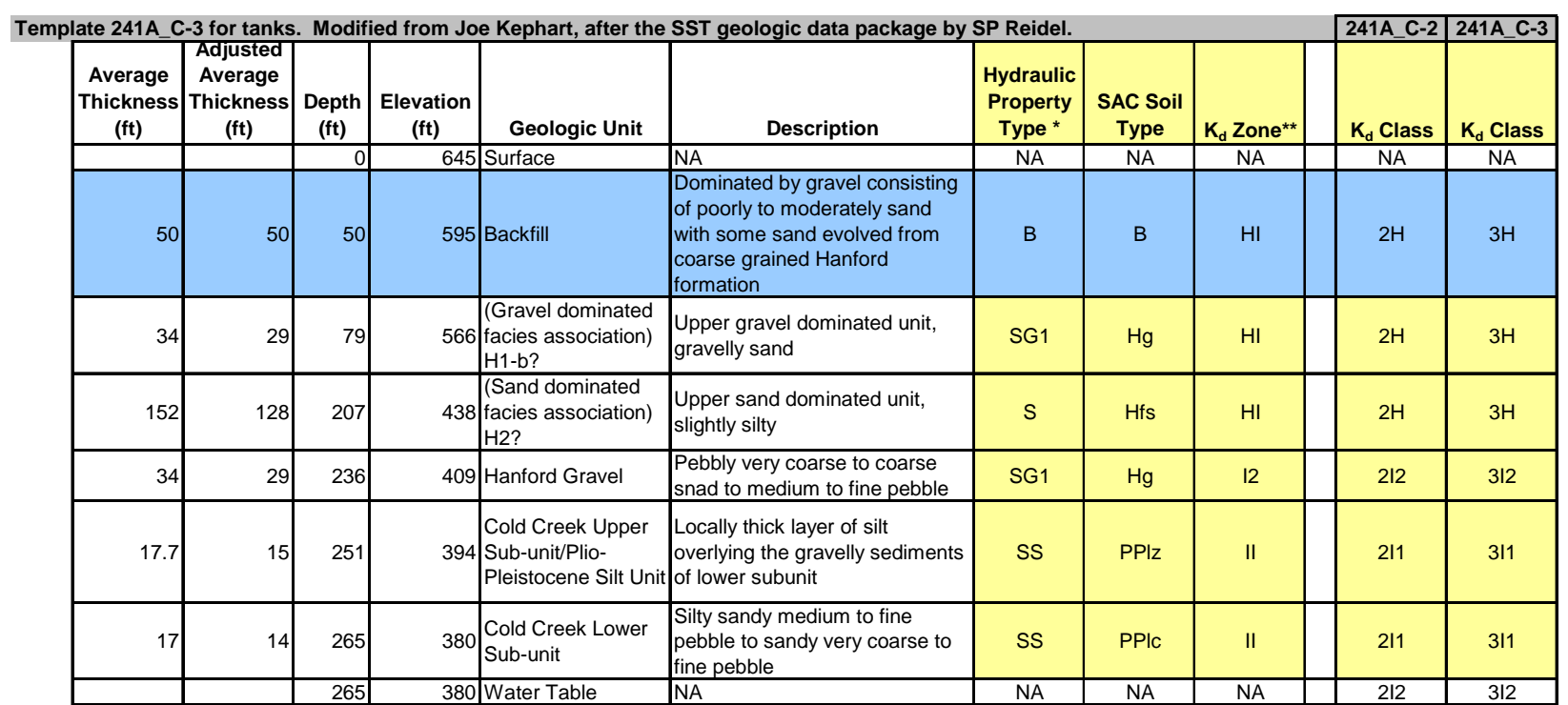

* After Khaleel and Freeman (1995), per white paper by Khaleel (September 2000).

** $\mathrm{HI}=$ high impact, II=Intermediate Impact (after Kincaid et al. 1998).

BLUE = Injection/release point. 
VZ Base Templates - A_ILAW

\section{South 200 East Area (ILAW) Stratigraphic Columns}

Notes/Assumptions:

1) Thicknesses, elevation, and water table are averages from wells 299-W17-21, 299-E17-23, and 199-E17-25 for the south template, averages from wells 299-E17 22, 299-E24-7, and 299-W4-21 for the central template, and taken from well 299-E24-21 for the north template.

2) A thin blanket of eolian sand and silt covers the surface of the site where not disturbed. This is ignored because ILAW activities will remove this unit prior to excavation.

3) All data from Reidel et al. (1998, 2001), Reidel and Ho (2002), and Reidel (2004).

\begin{tabular}{|c|c|c|c|c|c|c|c|c|c|c|}
\hline \multicolumn{9}{|c|}{ Template 216A ILAW_S-X for the southern portion of the ILAW sitebased on 299-E17-21 (N 134893, E 574107) } & \multirow{2}{*}{$\begin{array}{c}\text { 200A_ILA } \\
\text { W_S-5 } \\
\\
\mathrm{K}_{\mathrm{d}} \text { Class } \\
\end{array}$} & \multirow{2}{*}{$\begin{array}{c}\begin{array}{c}200 A \_I L A \\
\text { W_S-6 }\end{array} \\
K_{d} \text { Class }\end{array}$} \\
\hline $\begin{array}{l}\text { Average } \\
\text { Thickness } \\
\text { (ft) }\end{array}$ & \begin{tabular}{|c} 
Adjusted \\
Average \\
Thickness \\
(ft)
\end{tabular} & $\begin{array}{c}\text { Depth } \\
\text { (ft) }\end{array}$ & \begin{tabular}{|c|c|c|}
$\begin{array}{c}\text { Elevation } \\
(\mathrm{ft})\end{array}$ \\
\end{tabular} & Geologic Unit & Description & $\begin{array}{c}\text { Hydraulic } \\
\text { Property } \\
\text { Type * }^{*}\end{array}$ & $\begin{array}{l}\text { SAC Soil } \\
\text { Type }\end{array}$ & $\mathrm{K}_{\mathrm{d}}$ Zone $^{\star *}$ & & \\
\hline & & 0 & 736 & Surface & NA & NA & NA & NA & NA & NA \\
\hline 50 & 50 & 50 & 686 & Backfill & Sand and gravel & B & B & $\mathrm{HI}$ & $5 \mathrm{H}$ & $6 \mathrm{H}$ \\
\hline 187 & 187 & 237 & 499 & $\begin{array}{l}\text { Hanford formation, } \\
\text { sand-dominated }\end{array}$ & Sand (S2) & $\mathrm{s}$ & Hfs & $\mathrm{HI}$ & $5 \mathrm{H}$ & $6 \mathrm{H}$ \\
\hline 11 & 11 & 248 & 488 & $\begin{array}{l}\text { Hanford formation, } \\
\text { gravel-dominated }\end{array}$ & $\begin{array}{l}\text { Gravelly sand to sandy gravel } \\
\text { (G3) }\end{array}$ & SG1 & $\mathrm{Hg}$ & II & 512 & 612 \\
\hline 11 & 11 & 259 & 477 & $\begin{array}{l}\text { Hanford formation, } \\
\text { sand-dominated }\end{array}$ & Sand (S3) & $\mathrm{s}$ & $\mathrm{Hfs}$ & II & 511 & $6 I 1$ \\
\hline 75 & 75 & 334 & 402 & $\begin{array}{l}\text { Hanford formation, } \\
\text { gravel-dominated }\end{array}$ & Gravel to sandy gravel (G4) & SG2 & $\mathrm{Hrg}$ & II & 512 & 612 \\
\hline & & 334 & 402 & Water Table & NA & NA & NA & NA & NA & NA \\
\hline
\end{tabular}

\begin{tabular}{|c|c|c|c|c|c|c|c|c|c|c|}
\hline \multirow{3}{*}{$\begin{array}{l}\text { Template 216A-IL } \\
\qquad \begin{array}{c}\text { Average } \\
\text { Thickness } \\
\text { (ft) }\end{array} \\
\end{array}$} & LAW_C-X fol & $r$ the cer & ntral portion & $n$ of the ILAW site & \multirow[b]{2}{*}{ Description } & \multirow[b]{2}{*}{\begin{tabular}{|l|}
$574407)$. \\
Hydraulic \\
Property \\
Type *
\end{tabular}} & \multirow[b]{2}{*}{\begin{tabular}{|c} 
Hydraulic \\
Property \\
Type *
\end{tabular}} & \multirow[b]{2}{*}{$\mathrm{K}_{\mathrm{d}}$ Zone $^{\star \star}$} & \multirow{2}{*}{\begin{tabular}{|c|}
$\begin{array}{c}200 A \_I L A \\
\text { W_C-5 }\end{array}$ \\
\\
K Class \\
\end{tabular}} & \multirow{2}{*}{\begin{tabular}{|c}
$\begin{array}{c}200 A \_ \text {ILA } \\
\text { W_C-6 }\end{array}$ \\
\\
$\mathrm{K}_{\mathrm{d}}$ Class
\end{tabular}} \\
\hline & \begin{tabular}{|c} 
Adjusted \\
Average \\
Thickness \\
(ft)
\end{tabular} & $\begin{array}{c}\text { Depth } \\
\text { (ft) }\end{array}$ & $\begin{array}{c}\text { Elevation } \\
(\mathrm{ft})\end{array}$ & Geologic Unit & & & & & & \\
\hline & & 0 & 718 & Surface & NA & NA & NA & NA & NA & NA \\
\hline 50 & 50 & 50 & 686 & Backfill & Sand and Gravel & B & B & HI & $5 \mathrm{H}$ & $6 \mathrm{H}$ \\
\hline 164 & 164 & 214 & 522 & $\begin{array}{l}\text { Hanford formation, } \\
\text { sand dominated }\end{array}$ & Sand (S2) & $\mathrm{s}$ & Hfs & $\mathrm{HI}$ & $5 \mathrm{H}$ & $6 \mathrm{H}$ \\
\hline 20 & 20 & 234 & 502 & $\begin{array}{l}\text { Hanford formation, } \\
\text { gravel dominated }\end{array}$ & $\begin{array}{l}\text { Gravelly sand to sandy gravel } \\
\text { (G3) }\end{array}$ & SG1 & $\mathrm{Hg}$ & II & 512 & 612 \\
\hline 33 & 33 & 267 & 469 & $\begin{array}{l}\text { Hanford formation, } \\
\text { sand dominated }\end{array}$ & Sand (S3) & $\mathrm{s}$ & $\mathrm{Hfs}$ & II & $5 I 1$ & $6 I 1$ \\
\hline 51 & 51 & 318 & 418 & $\begin{array}{l}\text { Hanford formation, } \\
\text { gravel dominated }\end{array}$ & Gravel to sandy gravel (G4) & SG2 & $\mathrm{Hrg}$ & II & 512 & 612 \\
\hline & & 318 & 400 & Water Table & NA & NA & NA & NA & NA & NA \\
\hline
\end{tabular}

\begin{tabular}{|c|c|c|c|c|c|c|c|c|c|c|}
\hline \multicolumn{9}{|c|}{ Template 216A-ILAW N-X, for the northern portion of the ILAW Site based on 299-E24-21 (N 135698, E 574636) } & \multirow{2}{*}{$\begin{array}{c}\text { 200A_ILA } \\
\text { W_N-5 } \\
\\
\mathrm{K}_{\mathrm{d}} \text { Class }\end{array}$} & \multirow{2}{*}{$\begin{array}{c}\begin{array}{c}200 A \_ \text {ILA } \\
\text { W_N-6 }\end{array} \\
\mathrm{K}_{\mathrm{d}} \text { Class }\end{array}$} \\
\hline $\begin{array}{c}\text { Average } \\
\text { Thickness } \\
\text { (ft) }\end{array}$ & $\begin{array}{c}\text { Adjusted } \\
\text { Average } \\
\text { Thickness } \\
\text { (ft) }\end{array}$ & $\begin{array}{c}\text { Depth } \\
\text { (ft) }\end{array}$ & $\begin{array}{c}\text { Elevation } \\
\text { (ft) }\end{array}$ & (2) & ( 2 & $\begin{array}{l}\text { Hydraulic } \\
\text { Property } \\
\text { Type * }\end{array}$ & $\begin{array}{l}\text { Hydraulic } \\
\text { Property } \\
\text { Type* }\end{array}$ & $\mathrm{K}_{\mathrm{d}}$ Zone $^{\star \star}$ & & \\
\hline & & 0 & 714 & Surface & NA & NA & NA & NA & NA & NA \\
\hline 50 & 50 & 50 & 686 & Backfill & Sand and Gravel & B & B & HI & $5 \mathrm{H}$ & $6 \mathrm{H}$ \\
\hline 168 & 168 & 218 & 518 & $\begin{array}{l}\text { Hanford formation, } \\
\text { sand dominated }\end{array}$ & Sand (S2) & $\mathrm{s}$ & Hfs & $\mathrm{HI}$ & $5 \mathrm{H}$ & $6 \mathrm{H}$ \\
\hline 14 & 14 & 232 & 504 & $\begin{array}{l}\text { Hanford formation, } \\
\text { gravel dominated }\end{array}$ & $\begin{array}{l}\text { Gravelly sand to sandy gravel } \\
\text { (G3) }\end{array}$ & SG1 & $\mathrm{Hg}$ & II & 512 & 612 \\
\hline 38 & 38 & 270 & 466 & $\begin{array}{l}\text { Hanford formation, } \\
\text { sand dominated }\end{array}$ & Sand (S3) & $\mathrm{s}$ & Hfs & II & 511 & 611 \\
\hline 48 & 48 & 318 & 418 & $\begin{array}{l}\text { Hanford formation, } \\
\text { gravel dominated }\end{array}$ & Gravel to sandy gravel (G4) & SG2 & $\mathrm{Hrg}$ & II & 512 & 612 \\
\hline & & 318 & 396 & Water Table & NA & NA & NA & NA & NA & NA \\
\hline
\end{tabular}

* After Khaleel and Freeman (1995), per white paper by Khaleel (September 2000).

** HI=high impact, II=Intermediate Impact (after Kincaid et al. 1998).

BLUE = Injection/release point 
VZ Base Templates B

North 200 East Area (B Plant facilities and burial grounds) Stratigraphic Columns

Topography ranges from $700 \mathrm{ft}$ MSL east of B Plant to $590 \mathrm{ft}$ MSL in the northeast corner of 200 East Area (USGS Gable Butte 7.5 min. Quadrangle Map).

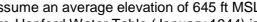

) is estimated to range from an elevation of $116 \mathrm{~m}(380 \mathrm{ft})$ in the eastern part of 200 East to $119 \mathrm{~m}(390 \mathrm{ft})$ in the

Will assume an average water-table elevation of $117 \mathrm{~m}(385 \mathrm{ft}) \mathrm{MSL}$.

3) A thin blanket of eolian sand and silt covers the surface of the site where not disturbed.

However, this material was generally removed during excavation and construction of the waste disposal sites and then incorporated into backfill materials.

burial grounds, and up to $16.4 \mathrm{~m}(54 \mathrm{ft}$ ) for tanks.

4) Five reverse wells are located in this area ranging in depth from $15-92 \mathrm{~m}$. Assume average depth of $50 \mathrm{~m}(164 \mathrm{ft})$, with an average perforated interval of
$11.5 \mathrm{~m}(38 \mathrm{ft})$.

\begin{tabular}{|c|c|c|c|c|c|c|c|c|c|c|c|}
\hline e 200B-x & for surface & isposa & al sites (e.g & 1., Buildings, Ponds & Ditches, Unplanned Releases) & & & & \begin{tabular}{|l|}
$200 \mathrm{~B}-2$ \\
\end{tabular} & 200B-3 & 200B-4 \\
\hline \begin{tabular}{|c|} 
Average \\
Thickness \\
(ft) \\
\end{tabular} & $\begin{array}{c}\text { Average } \\
\text { Average } \\
\text { Thickness } \\
\text { (ft) }\end{array}$ & $\begin{array}{c}\text { Depth } \\
\text { (ft) }\end{array}$ & \begin{tabular}{|c} 
Elevation \\
(ft)
\end{tabular} & Geologic Unit & Description & \begin{tabular}{|c} 
Hydraulic \\
Property \\
Type **
\end{tabular} & $\begin{array}{c}\text { SAC Soil } \\
\text { Type }\end{array}$ & $K_{d} Z_{o n e} e^{* \star}$ & $K_{d}$ Class & $K_{d}$ Class & $K_{d}$ Class \\
\hline & & & & Surface & NA & NA & NA & NA & NA & NA & NA \\
\hline & 2 & & 643 & Eolian & Sand and silt & $\mathrm{S}$ & Hss & $\mathrm{HI}$ & $2 \mathrm{H}$ & $\overline{3 H}$ & $4 \mathrm{H}$ \\
\hline 60 & 64 & 66 & 579 & Hanford Gravel & $\begin{array}{l}\text { Silty sandy medium to fine } \\
\text { pebble to slightly sity pebbly } \\
\text { very coarse to coarse sand }\end{array}$ & SG1 & $\mathrm{Hg}$ & $\mathrm{HI}$ & $2 \mathrm{H}$ & $3 \mathrm{H}$ & $4 \mathrm{H}$ \\
\hline 173 & 183 & 249 & 396 & $\begin{array}{l}\text { North } 200 \text { East } \\
\text { Hanford Sand }\end{array}$ & $\begin{array}{l}\text { Coarse to medium sand to } \\
\text { slightly pebbly slightly sitty } \\
\text { coarse to medium sand }\end{array}$ & $\mathrm{s}$ & Hos & II & 211 & 311 & 411 \\
\hline 10 & 11 & 260 & 38 & $\begin{array}{l}\text { Undifferenciated } \\
\text { Hanford/Plio- } \\
\text { Pleistocene }\end{array}$ & $\begin{array}{l}\begin{array}{l}\text { Pebbly very coarse to coarse } \\
\text { sand to sandy medium to fine } \\
\text { pebble }\end{array} \\
\end{array}$ & SG1 & $\mathrm{Hg}$ & II & 212 & 312 & 412 \\
\hline
\end{tabular}

\begin{tabular}{|c|c|c|c|c|c|c|c|c|c|c|c|}
\hline \multicolumn{9}{|c|}{ Template 216B-X for shallow disposal sites (e.g., Cribs, Burial Grounds) } & \multirow{2}{*}{$\begin{array}{l}216 \mathrm{~B}-2 \\
\mathrm{~K}_{\mathrm{d}} \text { Class }\end{array}$} & \multirow{2}{*}{$\begin{array}{l}216 \mathrm{~B}-3 \\
\mathrm{~K}_{\mathrm{d}} \text { Class } \\
\end{array}$} & \multirow{2}{*}{$\begin{array}{l}216 \mathrm{~B}-4 \\
\mathrm{~K}_{\mathrm{d}} \text { Class } \\
\end{array}$} \\
\hline \begin{tabular}{|c|} 
Average \\
Thickness \\
(ft) \\
\end{tabular} & $\begin{array}{l}\text { Adjusted } \\
\text { Average } \\
\text { Thickness } \\
\text { (ft) }\end{array}$ & $\begin{array}{c}\text { Depth } \\
\text { (ft) }\end{array}$ & $\begin{array}{c}\text { Elevation } \\
\text { (tt) }\end{array}$ & Geologic Unit & Description & $\begin{array}{c}\text { Hydraulic } \\
\text { Property } \\
\text { Type * } \\
\end{array}$ & $\begin{array}{c}\text { SAC Soil } \\
\text { Type }\end{array}$ & $K_{d}$ Zone** & & & \\
\hline & & & & 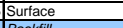 & NA & NA & NA & NA & NA & NA & $\mathrm{NA}$ \\
\hline 15 & 15 & 15 & 630 & Backill & Backfill & B & $\mathrm{B}_{\mathrm{B}}$ & $\mathrm{HI}$ & $2 \mathrm{H}$ & $3 \mathrm{H}$ & $4 \mathrm{H}$ \\
\hline 47 & 51 & 66 & 579 & Hanford Gravel & $\begin{array}{l}\text { Silty sandy medium to fine } \\
\text { pebble to slightly silty pebbly } \\
\text { very coarse to coarse sand }\end{array}$ & sG1 & $\mathrm{Hg}$ & $\mathrm{HI}$ & $2 \mathrm{H}$ & $3 \mathrm{H}$ & $4 \mathrm{H}$ \\
\hline 173 & 183 & 249 & 396 & $\begin{array}{l}\text { North } 200 \text { East } \\
\text { Hanford Sand }\end{array}$ & $\begin{array}{l}\text { Coarse to medium sand to } \\
\text { slightly pebbly slighly silty coarse } \\
\text { to medium sand }\end{array}$ & s & Hcs & $\|$ & 211 & 311 & 411 \\
\hline 10 & 11 & 260 & 385 & \begin{tabular}{|l|} 
Undifferenciated \\
Hanford/Plio- \\
Pleistocene
\end{tabular} & $\begin{array}{l}\text { Pebbly very coarse to coarse } \\
\text { sand to sandy medium to fine } \\
\text { pebble }\end{array}$ & SG1 & $\mathrm{Hg}$ & $\|$ & 212 & 312 & 412 \\
\hline & & & 385 & Th & - & NA & $\mathrm{NA}$ & $\sqrt{ } A$ & NA & NA & \\
\hline
\end{tabular}

\begin{tabular}{|c|c|c|c|c|c|c|c|c|c|c|c|}
\hline Template 241B-X & for tanks (b & jased on & on Reidel et & al. 2006). & & & & & 241B-2 & & \\
\hline \begin{tabular}{|c|}
$\begin{array}{c}\text { Average } \\
\text { Thickness } \\
\text { (ft) }\end{array}$ \\
\end{tabular} & \begin{tabular}{|c|}
$\begin{array}{c}\text { Adjusted } \\
\text { Average } \\
\text { Thickness } \\
(\mathrm{ft})\end{array}$ \\
\end{tabular} & $\begin{array}{c}\text { Depth } \\
\text { (ft) }\end{array}$ & $\begin{array}{c}\begin{array}{c}\text { Elevation } \\
(\mathrm{ft})\end{array} \\
\end{array}$ & Geologic Unit & Description & $\begin{array}{c}\text { Hydraulic } \\
\text { Property } \\
\text { Type * } \\
\end{array}$ & $\begin{array}{c}\text { SAC Soil } \\
\text { Type }\end{array}$ & $\mathrm{K}_{\mathrm{d}}$ Zone $^{* *}$ & $K_{d}$ Class & & \\
\hline & & & 645 & 5 Surface & NA & NA & NA & NA & NA & & \\
\hline 50 & 50 & 50 & 595 & 5 Backfill & $\begin{array}{l}\text { Dominated by gravel consisiting } \\
\text { of poorly to moderately sand } \\
\text { with some sand evolved from } \\
\text { coarse grained Hanford } \\
\text { formation }\end{array}$ & B & B & $\mathrm{HI}$ & $2 \mathrm{H}$ & & \\
\hline 35 & 35 & 85 & 564 & $\begin{array}{l}4 \begin{array}{l}\text { Gravel dominated } \\
\text { facies association) } \\
\text { H1.b? }\end{array} \\
\end{array}$ & $\begin{array}{l}\text { Upper gravel dominated unit, } \\
\text { gravelly sand }\end{array}$ & $\mathrm{sG} 1$ & $\mathrm{Hg}$ & $\mathrm{HI}$ & $2 \mathrm{H}$ & & \\
\hline 105 & 105 & 190 & 455 & $\begin{array}{l}\text { (Sand dominated } \\
\text { facies association) } \\
\text { H2? }\end{array}$ & $\begin{array}{l}\text { Upper sand dominated unit, } \\
\text { slightly sitty }\end{array}$ & $\mathrm{s}$ & Hfs & $\mathrm{HI}$ & $2 \mathrm{H}$ & & \\
\hline 35 & 35 & 225 & 420 & 0 Hanford Gravel & $\begin{array}{l}\begin{array}{l}\text { Pebbly very coarse to coarse } \\
\text { sand to sandy medium to fine } \\
\text { pebble }\end{array} \\
\end{array}$ & SG1 & $\mathrm{Hg}$ & $\|$ & 212 & & \\
\hline 11.7 & 12 & 237 & 40 & $\begin{array}{l}{ }_{8} \begin{array}{l}\text { Cold Creek Upper } \\
\text { Sub-unityPlio- } \\
\text { Pleistocene Silt Unit }\end{array} \\
\end{array}$ & $\begin{array}{l}\text { Locally thick layer of silt } \\
\text { overlying the gravelly sediments } \\
\text { it of lower subunit }\end{array}$ & ss & PPlz & ॥ & 211 & & \\
\hline 23.3 & 23 & 260 & 38 & $5 \begin{array}{l}\begin{array}{l}\text { Cold Creek Lower } \\
\text { Sub-unit }\end{array} \\
\text { lat }\end{array}$ & \begin{tabular}{|l}
$\begin{array}{l}\text { Silty sandy medium to fine } \\
\text { pebble to sandy very coarse to } \\
\text { fine pebble }\end{array}$ \\
\end{tabular} & SG2 & PPlc & ॥ & 211 & & \\
\hline
\end{tabular}

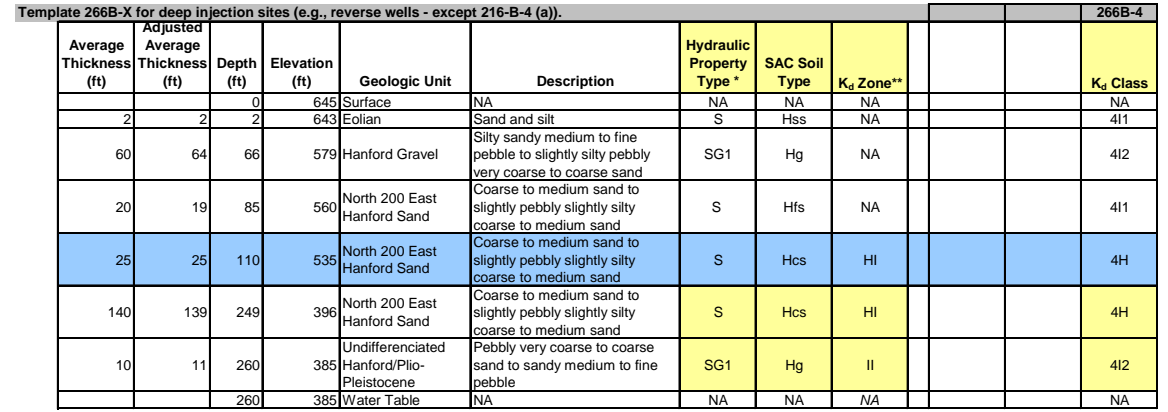

\begin{tabular}{|c|c|c|c|c|c|c|c|c|c|c|c|}
\hline Template 267B-X & for very de & ep inject & tion sites (i. & e., the $216-\mathrm{B}-5$ re & erse well (a)) & & & & \begin{tabular}{|l|} 
267B-2 \\
\end{tabular} & & \\
\hline $\begin{array}{c}\text { Average } \\
\text { Thickness } \\
\text { (tt) }\end{array}$ & $\begin{array}{l}\text { Average } \\
\text { Thickness } \\
\text { (ft) }\end{array}$ & $\begin{array}{c}\text { Depth } \\
\text { (ft) }\end{array}$ & $\begin{array}{c}\text { Elevation } \\
\text { (ft) }\end{array}$ & Geologic Unit & Description & $\begin{array}{c}\text { Hydraulic } \\
\text { Property } \\
\text { Type* }\end{array}$ & $\begin{array}{c}\text { SAC Soil } \\
\text { Type }\end{array}$ & $\mathrm{K}_{\mathrm{d}}$ Zone $^{* *}$ & $K_{d}$ Class & & \\
\hline & & & 645 & Surface & NA & NA & NA & NA & $\mathrm{NA}$ & & \\
\hline & & 2 & 643 & Eolian & Sand and silt & $\mathrm{S}$ & Hss & NA & 211 & & \\
\hline 60 & 64 & 66 & 579 & Hanford Gravel & $\begin{array}{l}\text { Silty sandy medium to fine } \\
\text { pebble to slightly sity pebbly } \\
\text { very coarse to coarse sand }\end{array}$ & SG1 & $\mathrm{Hg}$ & NA & 212 & & \\
\hline & 183 & 249 & 396 & $\begin{array}{l}\text { North } 200 \text { East } \\
\text { Hanford Sand }\end{array}$ & $\begin{array}{l}\text { Coarse to medium sand to } \\
\text { slightly pebbly slightly silty } \\
\text { coarse to medium sand }\end{array}$ & $\mathrm{s}$ & Hfs & NA & 211 & & \\
\hline 10 & 3 & 252 & 35 & $\begin{array}{l}\text { Undifferenciated } \\
\text { Hanford/Plio- } \\
\text { Pleistocene }\end{array}$ & $\begin{array}{l}\text { Pebbly very coarse to coarse } \\
\text { sand to sandy medium to fine } \\
\text { pebble }\end{array}$ & $\mathrm{s}$ & Hcs & $\mathrm{HI}$ & $2 \mathrm{H}$ & & \\
\hline & & 260 & 385 & Water Table & 10 & SG1 & $\mathrm{Hg}$ & $\mathrm{HI}$ & $2 \mathrm{H}$ & & \\
\hline
\end{tabular}

*After Khaleel and Freeman (1995).

"Hl=high impact, IIIIntermediate Impact (after Kincaid et al. 1989).

(a) Injection well 216-B-4 is 108' deep; 216-B-5 is perfed 252-302'; 216-B-6 is perfed 73-75' 


\section{VZ Base Templates C}

\section{0-B/C Stratigraphic Columns}

Notes/Assumptions:

1) Elevation ranges from $500 \mathrm{ft}$ AMSL in the south to about $400 \mathrm{ft}$ AMSL to the north along the rivers edge (USGS Vernita Bridge and

Riverland 7.5 min. Quad Maps).

Average elevation near retention basins is $\sim 440 \mathrm{ft}$ and increases to the south (up to $460 \mathrm{ft}$ ) away from the river.

2) The water table ranges from an elevation of $122 \mathrm{~m}(400.3 \mathrm{ft}$ ) to $123 \mathrm{~m}$ (403.5 ft) (Hartman and Dresel 1998).

Assume an average water-table elevation of $122.5 \mathrm{~m}$ (402 ft) AMSL.

3) A thin $(\leq 1 \mathrm{~m})$ blanket of eolian or fluvial sand or silt may cover the surface of the site where not disturbed.

\begin{tabular}{|c|c|c|c|c|c|c|c|c|c|}
\hline \multicolumn{9}{|c|}{ Template $100 \mathrm{C}-\mathrm{X}$ - For surface disposal sites (i.e., reactors) } & \multirow{2}{*}{$\begin{array}{c}100 \mathrm{C}-4 \\
\mathrm{~K}_{\mathrm{d}} \text { Class }\end{array}$} \\
\hline $\begin{array}{c}\text { Average } \\
\text { Thickness } \\
\text { (ft) }\end{array}$ & \begin{tabular}{|c|} 
Adjusted \\
Average \\
Thickness \\
(ft)
\end{tabular} & $\begin{array}{c}\text { Depth } \\
\text { (ft) }\end{array}$ & $\begin{array}{c}\text { Elevation } \\
\text { (ft) }\end{array}$ & Geologic Unit & Description & $\begin{array}{l}\text { Hydraulic } \\
\text { Property } \\
\text { Type * }\end{array}$ & $\begin{array}{c}\text { SAC Soil } \\
\text { Type }\end{array}$ & $\mathrm{K}_{\mathrm{d}}$ Zone $\mathrm{e}^{\star *}$ & \\
\hline & & 0 & 460 & Surface & NA & $\mathrm{NA}$ & NA & $\mathrm{HI}$ & $4 \mathrm{H}$ \\
\hline & 30 & 30 & 430 & Hanford fm gravel & $\begin{array}{l}\text { Silty sandy pebble to boulder } \\
\text { gravel with lenses of gravelly } \\
\text { medium to coarse sand. (DOE } \\
\text { 1993) }\end{array}$ & SG1 & $\mathrm{Hg}$ & $\mathrm{HI}$ & $4 \mathrm{H}$ \\
\hline & 28 & 58 & 402 & Hanford fm gravel & $\begin{array}{l}\text { Silty sandy pebble to boulder } \\
\text { gravel with lenses of gravelly } \\
\text { medium to coarse sand. (DOE } \\
\text { 1993) }\end{array}$ & SG1 & $\mathrm{Hg}$ & II & 412 \\
\hline & & 58 & 402 & Water Table & NA & $\mathrm{NA}$ & NA & $\mathrm{NA}$ & $\mathrm{NA}$ \\
\hline
\end{tabular}

\begin{tabular}{|c|c|c|c|c|c|c|c|c|c|}
\hline \multicolumn{9}{|c|}{ Template 116C-X - For shallow disposal sites (i.e., cribs, trenches, burial grounds, sand filter) } & \multirow{2}{*}{$\begin{array}{c}116 \mathrm{C}-4 \\
\mathrm{~K}_{\mathrm{d}} \text { Class } \\
\end{array}$} \\
\hline $\begin{array}{c}\text { Average } \\
\text { Thickness } \\
\text { (ft) }\end{array}$ & \begin{tabular}{|c|} 
Adjusted \\
Average \\
Thickness \\
(ft)
\end{tabular} & $\begin{array}{c}\text { Depth } \\
\text { (ft) }\end{array}$ & $\begin{array}{c}\text { Elevation } \\
\text { (ft) }\end{array}$ & Geologic Unit & Description & $\begin{array}{c}\text { Hydraulic } \\
\text { Property } \\
\text { Type * }\end{array}$ & $\begin{array}{c}\text { SAC Soil } \\
\text { Type }\end{array}$ & $\mathrm{K}_{\mathrm{d}}$ Zone $^{\star *}$ & \\
\hline & & 0 & 460 & Surface & NA & $\mathrm{NA}$ & NA & NA & NA \\
\hline & 15 & 15 & 445 & Backfill & & $\mathrm{B}$ & $\mathrm{B}$ & $\mathrm{HI}$ & $4 \mathrm{H}$ \\
\hline & 30 & 45 & 415 & Hanford fm gravel & $\begin{array}{l}\text { Silty sandy pebble to boulder } \\
\text { gravel with lenses of gravelly } \\
\text { medium to coarse sand. (DOE } \\
1993 \text { ) }\end{array}$ & SG1 & $\mathrm{Hg}$ & $\mathrm{HI}$ & $4 \mathrm{H}$ \\
\hline & 13 & 58 & 402 & Hanford fm gravel & $\begin{array}{l}\text { Silty sandy pebble to boulder } \\
\text { gravel with lenses of gravelly } \\
\text { medium to coarse sand. (DOE }\end{array}$ & SG1 & $\mathrm{Hg}$ & II & 412 \\
\hline & & 58 & 402 & Water Table & NA & NA & NA & NA & NA \\
\hline
\end{tabular}

* After Khaleel and Freeman (1995), per white paper by Khaleel (September 2000).

** $\mathrm{HI}=$ high impact, II=Intermediate Impact (after Kincaid et al. 1989).

Blue = injection/release point. 


\section{VZ Base Templates D}

\section{0-D/DR Stratigraphic Columns}

Notes/Assumptions:

1) Surface elevation ranges from $470 \mathrm{ft}$ MSL along the southern boundary to about $390 \mathrm{ft}$ MSL to the northwest along rivers edge (USGS

Coyote Rapids 7.5 min. Quad Map).

Will assume an average elevation of $460 \mathrm{ft} \mathrm{MSL}$

2) Water table ranges from an elevation of $116.5 \mathrm{~m}$ (382 ft) along the eastern boundary to $119 \mathrm{~m}$ (390.5 ft) to the northwest (DOE 1993 ; Hartman and Dresel 1998).

Will assume an average water table elevation of $118 \mathrm{~m}(387 \mathrm{ft}) \mathrm{MSL}$

3) A thin $(\leq 1 \mathrm{~m})$ blanket of eolian or fluvial sand or silt may cover the surface of the site where not disturbed.

\begin{tabular}{|c|c|c|c|c|c|c|c|c|c|}
\hline \multicolumn{9}{|c|}{ Template 100D-X - For surface disposal sites (i.e., reactors) } & 100D-4 \\
\hline \begin{tabular}{|c|} 
Average \\
Thickness \\
(ft)
\end{tabular} & \begin{tabular}{|c|} 
Adjusted \\
Average \\
Thickness \\
(ft)
\end{tabular} & $\begin{array}{c}\text { Depth } \\
\text { (ft) }\end{array}$ & $\begin{array}{c}\text { Elevation } \\
(\mathrm{ft})\end{array}$ & Geologic Unit & Description & $\begin{array}{c}\text { Hydraulic } \\
\text { Property } \\
\text { Type * } \\
\end{array}$ & $\begin{array}{c}\text { SAC Soil } \\
\text { Type }\end{array}$ & $\mathrm{K}_{\mathrm{d}}$ Zone $^{\star \star}$ & $\mathrm{K}_{\mathrm{d}}$ Class \\
\hline & & 0 & 460 & Surface & NA & NA & NA & NA & NA \\
\hline & 30 & 30 & 430 & Hanford fm gravel & $\begin{array}{l}\text { Sandy gravel and gravelly sand, } \\
\text { with local sandy and silty } \\
\text { interbeds (Peterson et al. 1996) }\end{array}$ & SG1 & $\mathrm{Hg}$ & $\mathrm{HI}$ & $4 \mathrm{H}$ \\
\hline & 23 & 53 & 407 & Hanford fm gravel & $\begin{array}{l}\text { Sandy gravel and gravelly sand, } \\
\text { with local sandy and silty } \\
\text { interbeds (Peterson et al. 1996) }\end{array}$ & SG1 & $\mathrm{Hg}$ & II & 412 \\
\hline & 20 & 73 & 387 & Ringold Unit E & Silty sandy gravel & SG2 & $\mathrm{Rg}$ & II & 412 \\
\hline & & 73 & 387 & Water Table & & NA & NA & NA & NA \\
\hline
\end{tabular}

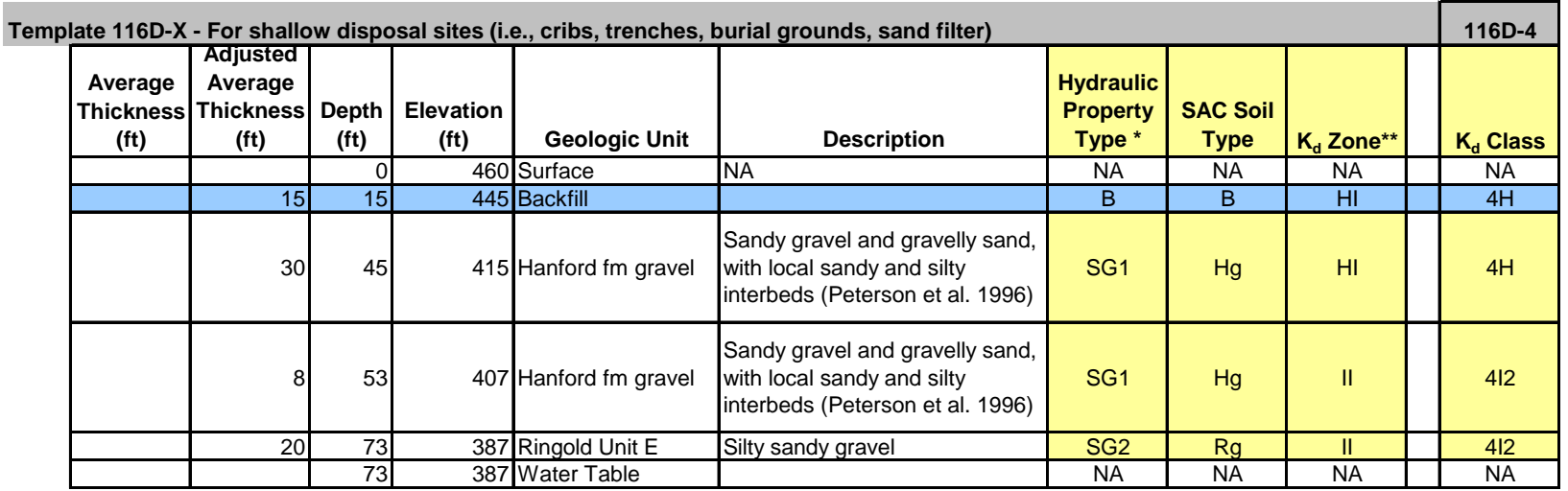

* After Khaleel and Freeman (1995), per white paper by Khaleel (September 2000).

** $\mathrm{HI}=$ high impact, II=Intermediate Impact (after Kincaid et al. 1998).

BLUE = injection/release point. 


\section{VZ Base Templates E}

\section{East 200 East Area (B-Pond) Stratigraphic Columns}

Notes/Assumptions:

1) Topography ranges from 460 to $650 \mathrm{ft}$ (137 to $198 \mathrm{~m}$ ) MSL (USGS Gable Butte $7.5 \mathrm{~min}$. Quadrangle Map).

Will assume an average elevation of $169 \mathrm{~m}(555 \mathrm{ft}) \mathrm{MSL}$.

2) The pre-Hanford Water Table (January 1944) is estimated to range from an elevation of $113 \mathrm{~m}$ (370 ft) to $116 \mathrm{~m}$ (380 ft) MSL (Kipp and Mudd 1974).

Will assume an average water-table elevation of $115 \mathrm{~m}(375 \mathrm{ft}) \mathrm{MSL}$

3) A thin blanket of eolian sand and silt covers the surface of the site where not disturbed.

However, this material was generally removed during excavation and construction of the waste disposal sites and then incorporated into backfill materials.

4) The depth of the sites and, thus, the backfull over these sites range from $0 \mathrm{~m}$ for ponds and unplanned releases, to an average of about

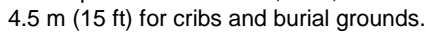

Template 200E-X for surface disposal sites (e.g., Ponds)

\begin{tabular}{|c|c|c|c|c|c|c|c|c|c|}
\hline $\begin{array}{c}\text { Average } \\
\text { Thickness } \\
\text { (ft) }\end{array}$ & \begin{tabular}{|c|} 
Adjusted \\
Average \\
Thickness \\
(ft)
\end{tabular} & $\begin{array}{c}\text { Depth } \\
\text { (ft) }\end{array}$ & $\begin{array}{c}\text { Elevation } \\
\text { (ft) }\end{array}$ & Geologic Unit & Description & $\begin{array}{c}\text { Hydraulic } \\
\text { Property } \\
\text { Type * }\end{array}$ & $\begin{array}{c}\text { SAC Soil } \\
\text { Type }\end{array}$ & $\mathrm{K}_{\mathrm{d}}$ Zone $^{\star *}$ & $\mathrm{~K}_{\mathrm{d}}$ Class \\
\hline & & 0 & 555 & Surface & NA & $\mathrm{NA}$ & NA & $\mathrm{HI}$ & $4 \mathrm{H}$ \\
\hline 3 & 3 & 3 & 552 & Eolian & Sand and silt & $\mathrm{S}$ & $\mathrm{Hss}$ & $\mathrm{HI}$ & $4 \mathrm{H}$ \\
\hline 12 & 11 & 14 & 541 & Hanford Gravel & $\begin{array}{l}\text { Silty sandy gravel to sandy } \\
\text { gravel to gravelly sand }\end{array}$ & SG1 & $\mathrm{Hg}$ & $\mathrm{HI}$ & $4 \mathrm{H}$ \\
\hline 62 & 58 & 72 & 483 & Hanford sand & $\begin{array}{l}\text { Slightly pebbly, slightly silty } \\
\text { coarse to medium sand to } \\
\text { coarse to fine sand }\end{array}$ & $\mathrm{S}$ & Hcs & II & $4 I 1$ \\
\hline 85 & 79 & 151 & 404 & Hanford gravel & $\begin{array}{l}\text { Sandy gravel to silty sandy } \\
\text { gravel }\end{array}$ & SG1 & $\mathrm{Hg}$ & II & 412 \\
\hline 30 & 29 & 180 & 375 & Ringold Lower Mud & silt, sandy silt & SS & PPIz & ॥ & $4 \mid 1$ \\
\hline & & 180 & 375 & Water Table & NA & $\mathrm{NA}$ & NA & NA & NA \\
\hline
\end{tabular}

Template 216E-X for shallow disposal sites (i.e., cribs, trenches, burial grounds, sand filter, septic systems)

\begin{tabular}{|c|c|c|c|c|c|c|c|c|c|}
\hline $\begin{array}{c}\text { Average } \\
\text { Thickness } \\
\text { (ft) }\end{array}$ & \begin{tabular}{|c|} 
Adjusted \\
Average \\
Thickness \\
(ft)
\end{tabular} & $\begin{array}{c}\text { Depth } \\
\text { (ft) }\end{array}$ & $\begin{array}{c}\text { Elevation } \\
\text { (ft) }\end{array}$ & Geologic Unit & Description & $\begin{array}{l}\text { Hydraulic } \\
\text { Property } \\
\text { Type * }\end{array}$ & $\begin{array}{l}\text { SAC Soil } \\
\text { Type }\end{array}$ & $\mathrm{K}_{\mathrm{d}}$ Zone $^{* *}$ & $\mathrm{~K}_{\mathrm{d}}$ Class \\
\hline & & 0 & 555 & Surface & NA & NA & NA & NA & NA \\
\hline 15 & 15 & 15 & 540 & Backfill & & $\mathrm{B}$ & $\mathrm{B}$ & $\mathrm{HI}$ & $4 \mathrm{H}$ \\
\hline 62 & 57 & 72 & 483 & Hanford sand & $\begin{array}{l}\text { Slightly pebbly, slightly silty } \\
\text { coarse to medium sand to } \\
\text { coarse to fine sand }\end{array}$ & S & Hcs & $\mathrm{HI}$ & $4 \mathrm{H}$ \\
\hline 85 & 79 & 151 & 404 & Hanford gravel & $\begin{array}{l}\text { Sandy gravel to silty sandy } \\
\text { gravel }\end{array}$ & SG1 & $\mathrm{Hg}$ & II & 412 \\
\hline 30 & 29 & 180 & 375 & Ringold Lower Mud & silt, sandy silt & SS & PPIz & II & $4 I 1$ \\
\hline & & 180 & 375 & Water Table & NA & NA & NA & NA & NA \\
\hline
\end{tabular}

* After Khaleel and Freeman (1995), per white paper by Khaleel (September 2000).

** $\mathrm{HI}=$ high impact, II=Intermediate Impact (after Kincaid et al. 1998).

BLUE = Injection/release point. 


\section{VZ Base Templates F}

\section{0-F Stratigraphic Columns}

Notes/Assumptions:

1) Surface elevation ranges from $420 \mathrm{ft}$ MSL within the north-central 100-F Area to about $380 \mathrm{ft}$ MSL to the northeast along rivers edge (USGS Locke Island $7.5 \mathrm{~min}$. Quad Map).

Will assume an average elevation of $410 \mathrm{ft}$ MSL.

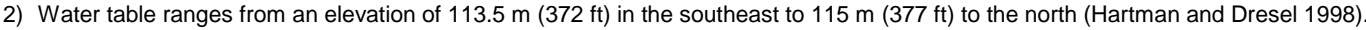

Will assume an average water-table elevation of $114 \mathrm{~m}(374 \mathrm{ft}) \mathrm{MSL}$

3) A thin $(\leq 1 \mathrm{~m})$ blanket of eolian or fluvial sand or silt may cover the surface of the site where not disturbed.

\begin{tabular}{|c|c|c|c|c|c|c|c|c|c|}
\hline \multicolumn{9}{|c|}{ Template 100F-X for surface disposal sites (i.e., reactors) } & \multirow{2}{*}{$\begin{array}{l}100 \mathrm{~F}-4 \\
\mathrm{~K}_{\mathrm{d}} \text { Class }\end{array}$} \\
\hline $\begin{array}{c}\text { Average } \\
\text { Thickness } \\
\text { (ft) }\end{array}$ & $\begin{array}{l}\text { Adjusted } \\
\text { Average } \\
\text { Thickness } \\
\text { (ft) }\end{array}$ & $\begin{array}{c}\text { Depth } \\
\text { (ft) }\end{array}$ & $\begin{array}{l}\text { Elevation } \\
\text { (ft) }\end{array}$ & Geologic Unit & Description & $\begin{array}{c}\text { Hydraulic } \\
\text { Property } \\
\text { Type * }\end{array}$ & $\begin{array}{c}\text { SAC Soil } \\
\text { Type }\end{array}$ & $\mathrm{K}_{\mathrm{d}}$ Zone $^{\star *}$ & \\
\hline & & 0 & 410 & Surface & NA & NA & NA & NA & NA \\
\hline & 30 & 30 & 380 & Hanford Gravel & $\begin{array}{l}\text { Sandy gravel to silty sandy } \\
\text { gravel (Peterson et al. 1996). } \\
\text { Gravel-dominated with } \\
\text { subordinate sand-dominated } \\
\text { facies (Raidl 1994). }\end{array}$ & SG1 & $\mathrm{Hg}$ & $\mathrm{HI}$ & $4 \mathrm{H}$ \\
\hline & 6 & 36 & 374 & Hanford Gravel & $\begin{array}{l}\text { Sandy gravel to silty sandy } \\
\text { gravel (Peterson et al. 1996). } \\
\text { Gravel-dominated with } \\
\text { subordinate sand-dominated } \\
\text { facies (Raidl 1994). }\end{array}$ & SG1 & $\mathrm{Hg}$ & II & 412 \\
\hline & & 36 & 374 & Water Table & NA & NA & NA & NA & NA \\
\hline
\end{tabular}

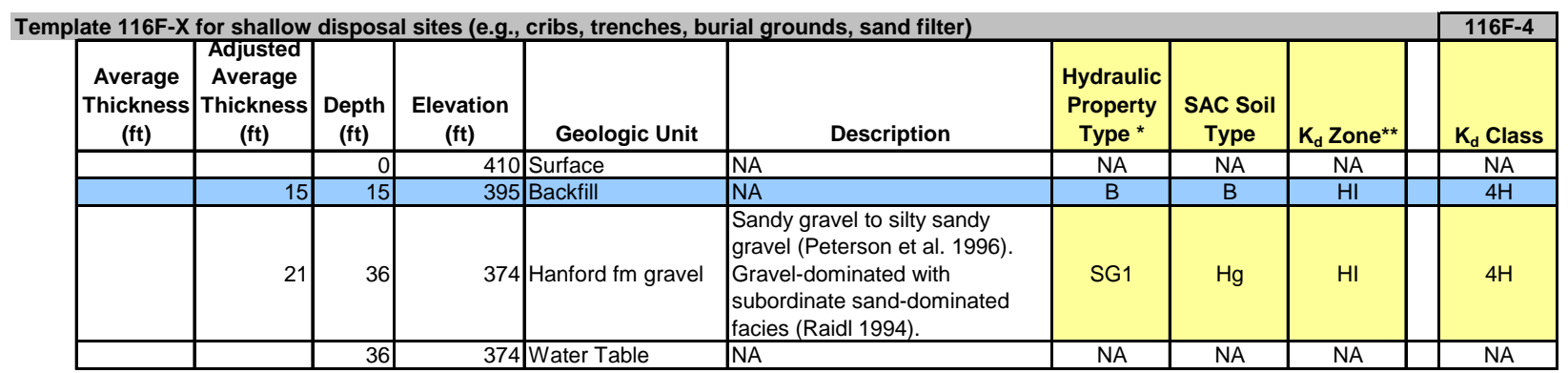

*After Khaleel and Freeman (1995), per white paper by Khaleel (September 2000)

** $\mathrm{HI}=$ high impact, II=Intermediate Impact (after Kincaid et al. 1998).

BLUE = Injection/release point. 


\section{VZ Base Templates G}

\section{Gable Mountain Pond (Aggregate Area G) Stratigraphic Columns}

Notes/Assumptions:

1) Topography ranges from $435 \mathrm{ft}$ MSL at Gable Mountain Pond to $410 \mathrm{ft} \mathrm{MSL}$ at West Lake (Gable Butte Quadrangle, 7.5 Minute Series, 1986).

Will assume an average elevation of $430 \mathrm{ft} \mathrm{MSL}$.

2) The pre-Hanford water table (January 1944) is estimated at elevation of $119 \mathrm{~m}$ (390 ft) (Kipp and Mudd 1974). Will assume an average water-table elevation of $119 \mathrm{~m}(390 \mathrm{ft}) \mathrm{MSL}$.

3) Stratigraphy interpreted from as-built drawings of wells 699-53-50, -54-49, -56-53, - 59-55, and 51-46. Undifferentiate Hanford formation materials range from a thickness of 12 to over $149 \mathrm{ft}$. Laying directly on basalt.

Will assume an average thickness of the Hanford formation of $48 \mathrm{ft}$.

4) The depth of the sites and, thus, the backfull over these sites range from $0 \mathrm{~m}$ for ponds and unplanned releases to an average of about

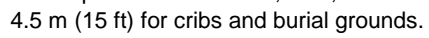

\begin{tabular}{|c|c|c|c|c|c|c|c|c|c|}
\hline \multicolumn{9}{|c|}{ Template 200G-X for surface disposal sites (e.g., Ponds, trenches, buildings) } & \multirow[b]{2}{*}{\begin{tabular}{|c}
$200 G-4$ \\
$K_{d}$ Class \\
\end{tabular}} \\
\hline \begin{tabular}{|c|} 
Average \\
Thickness \\
(ft) \\
\end{tabular} & \begin{tabular}{|c} 
Adjusted \\
Average \\
Thickness \\
(ft) \\
\end{tabular} & $\begin{array}{c}\text { Depth } \\
\text { (ft) }\end{array}$ & $\begin{array}{c}\text { Elevation } \\
\text { (ft) }\end{array}$ & Geologic Unit & Description & $\begin{array}{c}\text { Hydraulic } \\
\text { Property } \\
\text { Type * }\end{array}$ & $\begin{array}{l}\text { SAC Soil } \\
\text { Type }\end{array}$ & $\mathrm{K}_{\mathrm{d}}$ Zone $^{\star *}$ & \\
\hline & & 0 & 430 & Surface & NA & $\mathrm{NA}$ & $\mathrm{NA}$ & $\mathrm{NA}$ & NA \\
\hline 48 & 40 & 40 & 390 & $\begin{array}{l}\text { Undifferenciated } \\
\text { Hanford formation }\end{array}$ & $\begin{array}{l}\text { coarse sand to gravel, cobbles, } \\
\text { and boulders (up to } 95 \% \text { cobble } \\
\text { and boulders) }\end{array}$ & SG1 & $\mathrm{Hg}$ & $\mathrm{HI}$ & $4 \mathrm{H}$ \\
\hline & & 40 & 390 & Water Table & NA & NA & NA & NA & NA \\
\hline
\end{tabular}

\begin{tabular}{|c|c|c|c|c|c|c|c|c|c|}
\hline \multicolumn{9}{|c|}{ Template 216G-X for shallow disposal sites (e.g., Cribs) } & \multirow[b]{2}{*}{\begin{tabular}{|c|}
$216 \mathrm{G}-4$ \\
$\mathrm{~K}_{\mathrm{d}}$ Class \\
\end{tabular}} \\
\hline \begin{tabular}{|c} 
Average \\
Thickness \\
(ft)
\end{tabular} & \begin{tabular}{|c|} 
Adjusted \\
Average \\
Thickness \\
(ft)
\end{tabular} & $\begin{array}{c}\text { Depth } \\
\text { (ft) }\end{array}$ & $\begin{array}{c}\text { Elevation } \\
\text { (ft) }\end{array}$ & Geologic Unit & Description & $\begin{array}{c}\text { Hydraulic } \\
\text { Property } \\
\text { Type * }\end{array}$ & $\begin{array}{l}\text { SAC Soil } \\
\text { Type }\end{array}$ & $\mathrm{K}_{\mathrm{d}}$ Zone $^{\star *}$ & \\
\hline & & 0 & 430 & Surface & NA & NA & NA & NA & NA \\
\hline 15 & 15 & 15 & 415 & Backfill & Backfill & $\mathrm{B}$ & $\mathrm{B}$ & $\mathrm{HI}$ & $4 \mathrm{H}$ \\
\hline 33 & 25 & 40 & 390 & $\begin{array}{l}\text { Undifferenciated } \\
\text { Hanford formation }\end{array}$ & $\begin{array}{l}\text { Coarse gravel and sand to silty } \\
\text { sandy gravel }\end{array}$ & SG1 & $\mathrm{Hg}$ & $\mathrm{HI}$ & $4 \mathrm{H}$ \\
\hline & & 40 & 390 & Water Table & NA & NA & NA & NA & NA \\
\hline
\end{tabular}

* After Khaleel and Freeman (1995), per white paper by Khaleel (September 2000).

** $\mathrm{HI}=$ high impact, II=Intermediate Impact (after Kincaid et al. 1998).

BLUE = Injection/release point 


\section{VZ Base Templates $\mathrm{H}$}

\section{0-H Stratigraphic Columns}

Notes/Assumptions:

1) Surface elevation ranges from $425 \mathrm{ft} \mathrm{MSL}$ in the center of the $100-\mathrm{H}$ Area to about $380 \mathrm{ft} \mathrm{MSL}$ along rivers edge to the northeast

(USDOE, Hanford Site Topography - Locke Island, Bechtel Job \#22192; USGS Locke Island 7.5 min. Quad Map).

Will assume an average elevation of $415 \mathrm{ft} \mathrm{MSL}$.

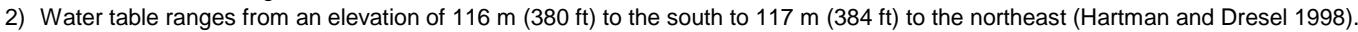

Will assume an average water-table elevation of $116.5 \mathrm{~m}(382 \mathrm{ft}) \mathrm{MSL}$

3) A thin $(\leq 1 \mathrm{~m})$ blanket of eolian or fluvial sand or silt may cover the surface of the site where not disturbed.

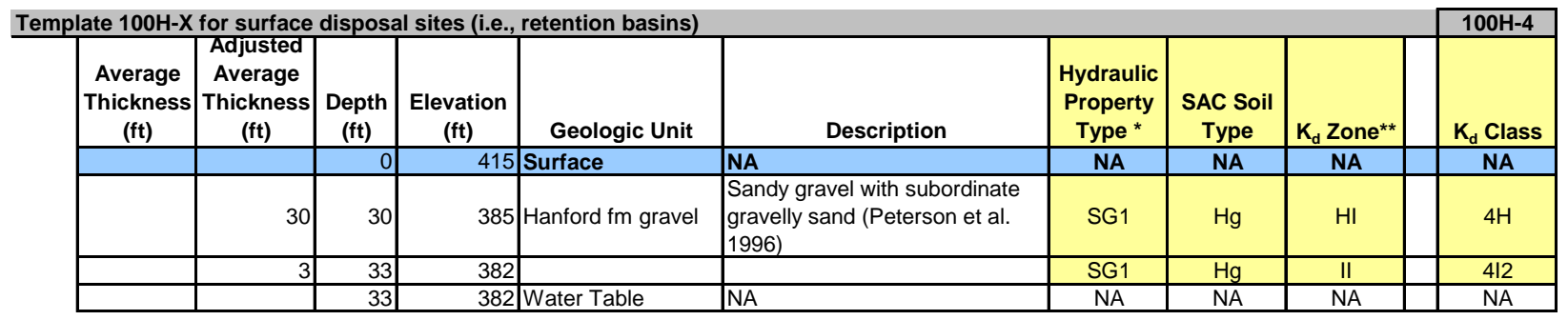

\begin{tabular}{|c|c|c|c|c|c|c|c|c|c|}
\hline \multirow{5}{*}{\begin{tabular}{|c|}
$\begin{array}{c}\text { Average } \\
\text { Thickness } \\
(\mathrm{ft})\end{array}$ \\
\end{tabular}} & & & & & & & & & $116 \mathrm{H}-4$ \\
\hline & $\begin{array}{c}\text { Adjusted } \\
\text { Average } \\
\text { Thickness } \\
\text { (ft) } \\
\end{array}$ & $\begin{array}{c}\text { Depth } \\
\text { (ft) }\end{array}$ & $\begin{array}{c}\text { Elevation } \\
(\mathrm{ft})\end{array}$ & Geologic Unit & Description & $\begin{array}{c}\text { Hydraulic } \\
\text { Property } \\
\text { Type * }\end{array}$ & $\begin{array}{c}\text { SAC Soil } \\
\text { Type }\end{array}$ & $\mathrm{K}_{\mathrm{d}}$ Zone & $\mathrm{K}_{\mathrm{d}}$ Class \\
\hline & & 0 & 415 & Surface & $\mathrm{NA}$ & $\mathrm{NA}$ & $\mathrm{NA}$ & $\mathrm{NA}$ & NA \\
\hline & 15 & 15 & 400 & Backfill & & $\mathrm{B}$ & $\mathrm{B}$ & $\mathrm{HI}$ & $4 \mathrm{H}$ \\
\hline & 18 & 33 & 382 & Hanford fm gravel & $\begin{array}{l}\text { Sandy gravel with subordinate } \\
\text { gravelly sand (Peterson et al. } \\
1996)\end{array}$ & SG1 & $\mathrm{Hg}$ & $\mathrm{HI}$ & $4 \mathrm{H}$ \\
\hline & & 33 & 382 & Water Table & NA & NA & $\mathrm{NA}$ & $\mathrm{NA}$ & NA \\
\hline
\end{tabular}

* After Khaleel and Freeman (1995), per white paper by Khaleel (September 2000).

** $\mathrm{HI}=$ high impact, II=Intermediate Impact (after Kincaid et al. 1998).

BLUE = Injection/release point. 


\section{VZ Base Templates I}

\section{North Area Stratigraphic Columns}

Notes/Assumptions:

1) Topography ranges from $580 \mathrm{ft}$ MSL near $216-\mathrm{N}-3$ in the NW portion of this geographic area to $540 \mathrm{ft}$ MSL beneath the old 216-N-6 Pond in the SE portion of the area (Gable Butte Quadrangle, 7.5 Minute Series, 1986).

Will assume an average elevation of $565 \mathrm{ft} \mathrm{MSL}$.

2) The pre-Hanford water table (January 1944) is estimated at an elevation of $395 \mathrm{ft}$ (Kipp and Mudd 1974).

Will assume an average water-table elevation of $395 \mathrm{ft} \mathrm{MSL}$.

3) Stratigraphy based on as-built drawings of 699-55-60A,B, and -51-63 (see HWIS).

A thin blanket of top soil (eolian sand and silt) covers the surface of the site where not disturbed. However, this material was generally removed during excavation and construction of the waste disposal sites and then incorporated into backfill materials.

4) The depth of the sites and, thus, the backfull over these sites range from $0 \mathrm{~m}$ for ponds and unplanned releases to an average of about $4.5 \mathrm{~m}(15 \mathrm{ft})$ for cribs and burial grounds.

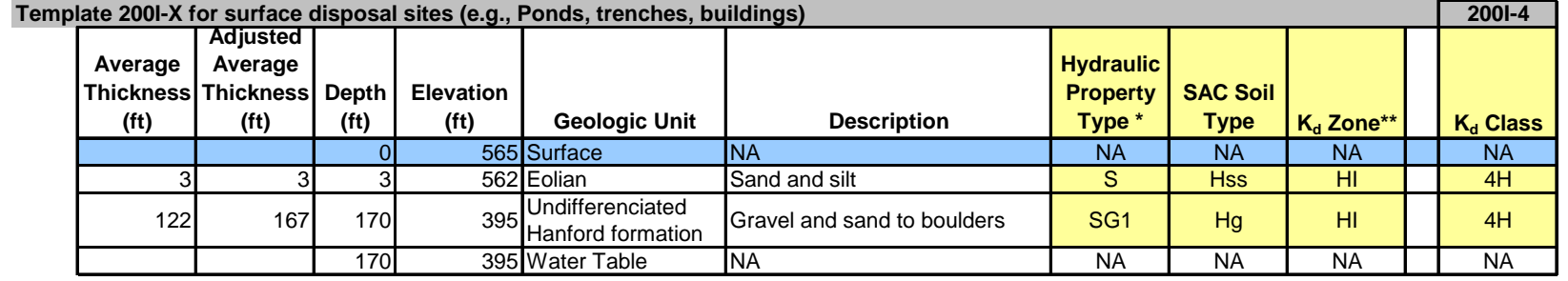

\begin{tabular}{|c|c|c|c|c|c|c|c|c|c|}
\hline \multicolumn{9}{|c|}{ Template $216 \mathrm{I}-\mathrm{X}$ for shallow disposal sites (e.g., Cribs) } & \multirow{2}{*}{$\begin{array}{c}216 \mathrm{I}-4 \\
\mathrm{~K}_{\mathrm{d}} \text { Class }\end{array}$} \\
\hline \begin{tabular}{|c|} 
Average \\
Thickness \\
(ft) \\
\end{tabular} & \begin{tabular}{|c} 
Adjusted \\
Average \\
Thickness \\
(ft)
\end{tabular} & $\begin{array}{c}\text { Depth } \\
(\mathrm{ft})\end{array}$ & $\begin{array}{c}\text { Elevation } \\
\text { (ft) }\end{array}$ & Geologic Unit & Description & $\begin{array}{c}\text { Hydraulic } \\
\text { Property } \\
\text { Type * }\end{array}$ & $\begin{array}{c}\text { SAC Soil } \\
\text { Type }\end{array}$ & $\mathrm{K}_{\mathrm{d}}$ Zone** & \\
\hline & & 0 & 565 & Surface & NA & $\mathrm{NA}$ & NA & NA & NA \\
\hline 15 & 15 & 15 & 550 & Backfill & Backfill & $\mathrm{B}$ & $\mathrm{B}$ & $\mathrm{HI}$ & $4 \mathrm{H}$ \\
\hline 110 & 155 & 170 & 395 & $\begin{array}{l}\text { Undifferenciated } \\
\text { Hanford formation }\end{array}$ & Gravel and sand to boulders & SG1 & $\mathrm{Hg}$ & $\mathrm{HI}$ & $4 \mathrm{H}$ \\
\hline & & 170 & 395 & Water Table & NA & $\mathrm{NA}$ & NA & $\mathrm{NA}$ & NA \\
\hline
\end{tabular}

* After Khaleel and Freeman (1995), per white paper by Khaleel (September 2000).

${ }^{\star *} \mathrm{HI}=$ high impact, II=Intermediate Impact (after Kincaid et al. 1998).

BLUE = Injection/release point. 
VZ Base Templates K

\section{0-K Stratigraphic Columns}

Notes/Assumptions:

1) Surface elevation ranges from $515 \mathrm{ft}$ MSL in adjacent waste sites south of $\mathrm{K}$ Area to about $390 \mathrm{ft}$ MSL to the northwest along rivers edge (USGS Coyote Rapids 7.5 min. Quad Map).

Will assume an average elevation of $480 \mathrm{ft}$ MSL, except injection wells which have projected surface elevation of $465 \mathrm{ft} \mathrm{MSL}$.

2) Water table ranges from an elevation of $121 \mathrm{~m}(397 \mathrm{ft})$ to the northeast to $121.5 \mathrm{~m}(399 \mathrm{ft})$ to the south (Hartman and Dresel 1998). Will assume an average water-table elevation of $121.5 \mathrm{~m}(399 \mathrm{ft}) \mathrm{MSL}$.

3) A thin (<1 m) layer of eolian or fluvial sand or silt may cover the surface of the site where not disturbed (Lindberg 1995).

4) Two injection wells (116-KE-3 and 116-KE-2) extend $10 \mathrm{ft}$ into water table, and approximately $10 \mathrm{ft}$ of the perforated casings extend above the water table (i.e., open to the vadose zone) within Ringold Unit E.

\begin{tabular}{|c|c|c|c|c|c|c|c|c|c|}
\hline Template $100 \mathrm{~K}-\mathrm{X}$ for & surface disp & sal sites (i. & e., ponds an & id reactors) & & & & & $100 \mathrm{~K}-4$ \\
\hline $\begin{array}{c}\text { Average } \\
\text { Thickness } \\
\text { (ft) }\end{array}$ & $\begin{array}{l}\text { Adjusted } \\
\text { Average } \\
\text { Thickness } \\
\text { (ft) }\end{array}$ & Depth (ft) & $\begin{array}{c}\text { Elevation } \\
\text { (ft) }\end{array}$ & Geologic Unit & Description & $\begin{array}{c}\text { Hydraulic } \\
\text { Property } \\
\text { Type * }\end{array}$ & $\begin{array}{c}\text { SAC Soil } \\
\text { Type }\end{array}$ & $\mathrm{K}_{\mathrm{d}}$ Zone $^{* *}$ & $\mathrm{~K}_{\mathrm{d}}$ Class \\
\hline & & 0 & 480 & Surface & NA & NA & NA & NA & NA \\
\hline & 30 & 30 & 450 & $\begin{array}{l}\text { Hanford fm } \\
\text { gravel }\end{array}$ & $\begin{array}{l}\text { Sandy gravel to silty } \\
\text { sandy gravel intercalated } \\
\text { with gravelly sand to } \\
\text { sand (Lindberg 1995; } \\
\text { Peterson et al. 1996) }\end{array}$ & SG1 & $\mathrm{Hg}$ & $\mathrm{HI}$ & $4 \mathrm{H}$ \\
\hline & 15 & 45 & 435 & $\begin{array}{l}\text { Hanford fm } \\
\text { gravel }\end{array}$ & $\begin{array}{l}\text { Sandy gravel to silty } \\
\text { sandy gravel intercalated } \\
\text { with gravelly sand to } \\
\text { sand (Lindberg 1995; } \\
\text { Peterson et al. 1996) }\end{array}$ & SG1 & $\mathrm{Hg}$ & II & 412 \\
\hline & 36 & 81 & 399 & Ringold Unit E & $\begin{array}{l}\text { Fluvial sandy gravel to } \\
\text { silty sandy gravel } \\
\text { (Lindberg 1995) }\end{array}$ & SG2 & $\mathrm{Rg}$ & II & 412 \\
\hline & & 81 & 399 & Water Table & NA & NA & NA & NA & NA \\
\hline
\end{tabular}

Template 116K-X for shallow disposal sites (e.g. cribs, trenches, burial grounds)

\begin{tabular}{|c|c|c|c|c|c|c|c|c|c|}
\hline $\begin{array}{c}\text { Average } \\
\text { Thickness } \\
\text { (ft) }\end{array}$ & $\begin{array}{l}\text { Adjusted } \\
\text { Average } \\
\text { Thickness } \\
\text { (ft) }\end{array}$ & Depth (ft) & $\begin{array}{c}\text { Elevation } \\
\text { (ft) }\end{array}$ & Geologic Unit & Description & $\begin{array}{c}\text { Hydraulic } \\
\text { Property } \\
\text { Type * }\end{array}$ & $\begin{array}{l}\text { SAC Soil } \\
\text { Type }\end{array}$ & $\mathrm{K}_{\mathrm{d}}$ Zone $^{* *}$ & $\mathrm{~K}_{\mathrm{d}}$ Class \\
\hline & & 0 & 480 & Surface & $\mathrm{NA}$ & NA & $\mathrm{NA}$ & NA & NA \\
\hline & 15 & 15 & 465 & Backfill & $\begin{array}{l}\text { Loose sandy gravel to } \\
\text { silty sandy gravel }\end{array}$ & B & B & $\mathrm{HI}$ & $4 \mathrm{H}$ \\
\hline & 30 & 45 & 435 & $\begin{array}{l}\text { Hanford fm } \\
\text { gravel }\end{array}$ & $\begin{array}{l}\text { Sandy gravel to silty } \\
\text { sandy gravel intercalated } \\
\text { with gravelly sand to } \\
\text { sand (Lindberg 1995; } \\
\text { Peterson et al. 1996) }\end{array}$ & SG1 & $\mathrm{Hg}$ & $\mathrm{HI}$ & $4 \mathrm{H}$ \\
\hline & 36 & 81 & 399 & Ringold Unit E & $\begin{array}{l}\text { Fluvial sandy gravel to } \\
\text { silty sandy gravel } \\
\text { (Lindberg 1995) }\end{array}$ & SG2 & $\mathrm{Rg}$ & II & 412 \\
\hline & & 81 & 399 & Water Table & INA & NA & NA & NA & NA \\
\hline
\end{tabular}

\begin{tabular}{|c|c|c|c|c|c|c|c|c|c|}
\hline \multicolumn{9}{|c|}{ Template $166 \mathrm{~K}-\mathrm{X}$ for deep disposal sites (e.g. reverse wells) } & \multirow{2}{*}{\begin{tabular}{|r|}
$166 \mathrm{~K}-4$ \\
$\mathrm{~K}_{\mathrm{d}}$ Class \\
\end{tabular}} \\
\hline $\begin{array}{c}\text { Average } \\
\text { Thickness } \\
\text { (ft) }\end{array}$ & $\begin{array}{c}\text { Adjusted } \\
\text { Average } \\
\text { Thickness } \\
\text { (ft) }\end{array}$ & Depth (ft) & $\begin{array}{c}\text { Elevation } \\
\text { (ft) }\end{array}$ & Geologic Unit & Description & $\begin{array}{c}\text { Hydraulic } \\
\text { Property } \\
\text { Type * } \\
\end{array}$ & $\begin{array}{l}\text { SAC Soil } \\
\text { Type }\end{array}$ & $\mathrm{K}_{\mathrm{d}}$ Zone $\mathrm{Z}^{* *}$ & \\
\hline & & 0 & 465 & Surface & NA & NA & NA & NA & NA \\
\hline & 20 & 20 & 445 & Backfill & $\begin{array}{l}\text { Loose sandy gravel to } \\
\text { silty sandy gravel }\end{array}$ & B & B & II & 412 \\
\hline & 20 & 40 & 425 & $\begin{array}{l}\text { Hanford fm } \\
\text { gravel }\end{array}$ & $\begin{array}{l}\text { Sandy gravel to silty } \\
\text { sandy gravel intercalated } \\
\text { with gravelly sand to } \\
\text { sand (Lindberg 1995; } \\
\text { Peterson et al. 1996) }\end{array}$ & SG1 & $\mathrm{Hg}$ & II & 412 \\
\hline & 16 & 56 & 409 & Ringold Unit E & $\begin{array}{l}\text { Fluvial sandy gravel to } \\
\text { silty sandy gravel } \\
\text { (Lindberg 1995) }\end{array}$ & SG2 & $\mathrm{Rg}$ & II & 412 \\
\hline & 10 & 66 & 399 & Ringold Unit E & $\begin{array}{l}\text { Fluvial sandy gravel to } \\
\text { silty sandy gravel } \\
\text { (Lindberg 1995) }\end{array}$ & SG2 & $\mathrm{Rg}$ & $\mathrm{HI}$ & $4 \mathrm{H}$ \\
\hline & & 66 & 399 & Water Table & NA & $\mathrm{NA}$ & $\mathrm{NA}$ & $\mathrm{NA}$ & NA \\
\hline
\end{tabular}

* After Khaleel and Freeman (1995), per white paper by Khaleel (September 2000).

** $\mathrm{HI}=$ high impact, II=Intermediate Impact (after Kincaid et al. 1998).

BLUE = Injection/release point. 


\section{VZ Base Templates M}

\section{South Central 600 Area (e.g. 618-11) Stratigraphic Columns}

Notes/Assumptions:

1) Assume an average elevation of $450 \mathrm{ft}$ (137.2 m) MSL (USGS Topo - Richland, Washington, 15 min. Quad. 1951)

2) Assume an average water-table elevation of $365 \mathrm{ft}$ (111.3 m) MSL (Kipp and Mudd 1974).

3) Lithofacies taken from well logs (699-13-3A) found in the Hanford Well Log Library, Sigma V Building.

\begin{tabular}{|c|c|c|c|c|c|c|c|c|c|}
\hline \multicolumn{9}{|c|}{ Template $600 \mathrm{M}-\mathrm{X}$ for surface disposal sites (e.g., Trenches, ponds, unplanned releases) } & \multirow[b]{2}{*}{$\begin{array}{r}600 \mathrm{M}-4 \\
\text { Kd Class }\end{array}$} \\
\hline \begin{tabular}{|c} 
Average \\
Thickness \\
(ft)
\end{tabular} & $\begin{array}{c}\text { Adjusted } \\
\text { Average } \\
\text { Thickness } \\
\text { (ft) }\end{array}$ & $\begin{array}{c}\text { Depth } \\
\text { (ft) }\end{array}$ & $\begin{array}{c}\text { Elevation } \\
\text { (ft) }\end{array}$ & Geologic Unit & Description & $\begin{array}{c}\text { Hydraulic } \\
\text { Property } \\
\text { Type * }\end{array}$ & $\begin{array}{c}\text { SAC Soil } \\
\text { Type }\end{array}$ & Kd Zone ${ }^{\star *}$ & \\
\hline & & 0 & 450 & Surface & NA & NA & NA & NA & NA \\
\hline & 6 & 6 & 444 & Hanford Hfs & Silty Silty Sand & $\mathrm{S}$ & $\mathrm{HcS}$ & $\mathrm{HI}$ & $4 \mathrm{H}$ \\
\hline & 12 & 18 & 432 & Hanford $\mathrm{Hg}$ & Sandy Gravel & SG1 & $\mathrm{Hg}$ & $\mathrm{HI}$ & $4 \mathrm{H}$ \\
\hline & 22 & 40 & 410 & Hanford Hgs & Gravelly Sand & GS & $\mathrm{Hgs}$ & II & $4 I 1$ \\
\hline & 10 & 50 & 400 & Hanford $\mathrm{Hg}$ & Gravel & SG1 & $\mathrm{Hg}$ & II & 412 \\
\hline & 35 & 85 & 365 & Ringold Rg & $\begin{array}{l}\text { Gravelly Sand (Ringold } \\
\text { Formation) }\end{array}$ & SG2 & $\mathrm{Rg}$ & II & 412 \\
\hline & & 85 & 365 & Water Table & NA & $\mathrm{NA}$ & NA & NA & NA \\
\hline
\end{tabular}

Template 616M-X for shallow disposal (e.g., cribs, burial grounds)

\begin{tabular}{|c|c|c|c|c|c|c|c|c|c|}
\hline te $616 \mathrm{M}-$ & r shallov & sng & $\mathrm{eq}_{\mathrm{c}} \mathrm{cru}$ & burıal grounc & & & & & $616 \mathrm{M}-4$ \\
\hline $\begin{array}{c}\text { Average } \\
\text { Thickness } \\
\text { (ft) }\end{array}$ & \begin{tabular}{|c|} 
Adjusted \\
Average \\
Thickness \\
(ft)
\end{tabular} & $\begin{array}{c}\text { Depth } \\
\text { (ft) }\end{array}$ & $\begin{array}{c}\text { Elevation } \\
\text { (ft) }\end{array}$ & Geologic Unit & Description & $\begin{array}{c}\text { Hydraulic } \\
\text { Property } \\
\text { Type * }\end{array}$ & $\begin{array}{l}\text { SAC Soil } \\
\text { Type }\end{array}$ & Kd Zone ${ }^{\star *}$ & Kd Class \\
\hline & & 0 & 450 & Surface & NA & NA & NA & NA & NA \\
\hline & 15 & 15 & 435 & Backfill & & B & $\mathrm{B}$ & $\mathrm{HI}$ & $4 \mathrm{H}$ \\
\hline & 3 & 18 & 432 & Hanford $\mathrm{Hg}$ & Sandy Gravel & SG1 & $\mathrm{Hg}$ & $\mathrm{HI}$ & $4 \mathrm{H}$ \\
\hline & 22 & 40 & 410 & Hanford Hgs & Gravelly Sand & GS & $\mathrm{Hgs}$ & $\mathrm{HI}$ & $4 \mathrm{H}$ \\
\hline & 10 & 50 & 400 & Hanford $\mathrm{Hg}$ & Gravel & SG1 & $\mathrm{Hg}$ & II & 412 \\
\hline & 35 & 85 & 365 & Ringold $\mathrm{Rg}$ & $\begin{array}{l}\text { Gravelly Sand (Ringold } \\
\text { Formation) }\end{array}$ & SG2 & $\mathrm{Rg}$ & II & $4 I 2$ \\
\hline & & 85 & 365 & Water Table & NA & NA & NA & $\mathrm{NA}$ & NA \\
\hline
\end{tabular}

* After Khaleel and Freeman (1995), per white paper by Khaleel (September 2000).

** HI=high impact, II=Intermediate Impact (after Kincaid et al. 1998).

BLUE = Injection/release point. 


\section{VZ Base Templates $\mathrm{N}$}

\section{0-N Stratigraphic Columns}

Notes/Assumptions:

1) Surface elevation ranges from $460 \mathrm{ft}$ MSL in the center of the $100-\mathrm{N}$ Area to about $390 \mathrm{ft} \mathrm{MSL}$ along the rivers edge to the northwest

(USGS Coyote Rapids 7.5 min. Quad Map).

Will assume an average elevation of $455 \mathrm{ft}$ MSL.

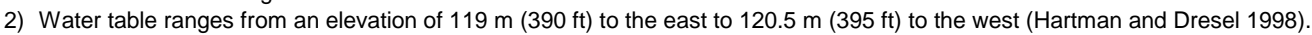

Will assume an average water-table elevation of $119.5 \mathrm{~m}(392 \mathrm{ft}) \mathrm{MSL}$.

3) A thin $(\leq 1 \mathrm{~m})$ blanket of eolian or fluvial sand or silt may cover the surface of the site where not disturbed.

\begin{tabular}{|c|c|c|c|c|c|c|c|c|c|}
\hline Template $100 \mathrm{~N}-\mathrm{X}$ & for surface & disposa & sites (i.e., & ponds and reactor & & & & & $100 N-4$ \\
\hline $\begin{array}{c}\text { Average } \\
\text { Thickness } \\
\text { (ft) } \\
\end{array}$ & \begin{tabular}{|c|} 
Adjusted \\
Average \\
Thickness \\
(ft)
\end{tabular} & $\begin{array}{c}\text { Depth } \\
\text { (ft) }\end{array}$ & $\begin{array}{c}\text { Elevation } \\
\text { (ft) }\end{array}$ & Geologic Unit & Description & $\begin{array}{c}\text { Hydraulic } \\
\text { Property } \\
\text { Type * }\end{array}$ & $\begin{array}{c}\text { SAC Soil } \\
\text { Type }\end{array}$ & $\mathrm{K}_{\mathrm{d}}$ Zone $^{\star *}$ & $\mathrm{~K}_{\mathrm{d}}$ Class \\
\hline & & 0 & 455 & Surface & NA & NA & $\mathrm{NA}$ & NA & NA \\
\hline & 30 & 30 & 425 & Hanford fm gravel & $\begin{array}{l}\text { Glaciofluvial sandy pebble to } \\
\text { boulder gravel (Hartman and } \\
\text { Lindsey 1993) }\end{array}$ & SG1 & $\mathrm{Hg}$ & $\mathrm{HI}$ & $4 \mathrm{H}$ \\
\hline & 10 & 40 & 415 & Hanford fm gravel & $\begin{array}{l}\text { Glaciofluvial sandy pebble to } \\
\text { boulder gravel (Hartman and } \\
\text { Lindsey 1993) }\end{array}$ & SG1 & $\mathrm{Hg}$ & II & 412 \\
\hline & 23 & 63 & 392 & Ringold Unit E & $\begin{array}{l}\text { Fluvial, sandy pebble to cobble } \\
\text { gravel (Hartman and Lindsey } \\
\text { 1993) }\end{array}$ & SG2 & $\mathrm{Rg}$ & II & 412 \\
\hline & & 63 & 392 & Water Table & NA & $\mathrm{NA}$ & $\mathrm{NA}$ & $\mathrm{NA}$ & $\mathrm{NA}$ \\
\hline
\end{tabular}

\begin{tabular}{|c|c|c|c|c|c|c|c|c|c|}
\hline \multicolumn{9}{|c|}{ Template $116 \mathrm{~N}-\mathrm{X}$ for shallow disposal sites (e.g., cribs and trenches) } & \multirow[b]{2}{*}{$\begin{array}{l}116 \mathrm{~N}-4 \\
\mathrm{~K}_{\mathrm{d}} \text { Class }\end{array}$} \\
\hline $\begin{array}{c}\text { Average } \\
\text { Thickness } \\
\text { (ft) }\end{array}$ & $\begin{array}{c}\text { Adjusted } \\
\text { Average } \\
\text { Thickness } \\
\text { (ft) }\end{array}$ & $\begin{array}{c}\text { Depth } \\
\text { (ft) }\end{array}$ & $\begin{array}{c}\text { Elevation } \\
(\mathrm{ft})\end{array}$ & Geologic Unit & Description & $\begin{array}{l}\text { Hydraulic } \\
\text { Property } \\
\text { Type * }\end{array}$ & $\begin{array}{l}\text { Hydraulic } \\
\text { Property } \\
\text { Type * }\end{array}$ & $\mathrm{K}_{\mathrm{d}}$ Zone** & \\
\hline & & 0 & 455 & Surface & NA & NA & NA & NA & NA \\
\hline & 15 & 15 & 440 & Backfill & & $\mathrm{B}$ & $\mathrm{B}$ & $\mathrm{HI}$ & $4 \mathrm{H}$ \\
\hline & 25 & 40 & 415 & Hanford fm gravel & $\begin{array}{l}\text { Glaciofluvial sandy pebble to } \\
\text { boulder gravel (Hartman and } \\
\text { Lindsey 1993) }\end{array}$ & SG1 & $\mathrm{Hg}$ & $\mathrm{HI}$ & $4 \mathrm{H}$ \\
\hline & 23 & 63 & 392 & Ringold Unit E & $\begin{array}{l}\text { Fluvial, sandy pebble to cobble } \\
\text { gravel (Hartman and Lindsey } \\
\text { 1993) }\end{array}$ & SG2 & $\mathrm{Rg}$ & II & 412 \\
\hline & & 63 & 392 & Water Table & NA & NA & NA & NA & NA \\
\hline
\end{tabular}

* After Khaleel and Freeman (1995), per white paper by Khaleel (September 2000)

** $\mathrm{HI}=$ high impact, II=Intermediate Impact (after Kincaid et al. 1998).

BLUE = Injection/release point. 


\section{VZ Base Templates $P$}

\section{Southern 600 Area (e.g. 316-4, 618-10) Stratigraphic Columns}

Notes/Assumptions:

1) Assume an average elevation of $440 \mathrm{ft}$ (134.1 m) MSL (USGS Topo - Richland, Washington, 15 min. Quad. 1951).

2) Assume an average water-table elevation of $358 \mathrm{ft}(109.1 \mathrm{~m}) \mathrm{MSL}$ (based on well S6-4D in Kipp and Mudd 1974).

3) Lithofacies taken from well logs (699-S6-E4A and D) found in the Hanford Well Log Library in the Sigma V Building.

\begin{tabular}{|c|c|c|c|c|c|c|c|c|c|}
\hline \multicolumn{9}{|c|}{ Template 600P-X for surface disposal sites (e.g., Trenches, ponds, unplanned releases) } & \multirow{2}{*}{\begin{tabular}{|c|}
$600 \mathrm{P}-4$ \\
$\mathrm{~K}_{\mathrm{d}}$ Class \\
\end{tabular}} \\
\hline $\begin{array}{c}\text { Average } \\
\text { Thickness } \\
\text { (ft) }\end{array}$ & $\begin{array}{l}\text { Adjusted } \\
\text { Average } \\
\text { Thickness } \\
\text { (ft) }\end{array}$ & $\begin{array}{l}\text { Depth } \\
\text { (ft) }\end{array}$ & $\begin{array}{l}\text { Elevation } \\
\text { (ft) }\end{array}$ & Geologic Unit & Description & $\begin{array}{c}\text { Hydraulic } \\
\text { Property } \\
\text { Type * }\end{array}$ & $\begin{array}{l}\text { SAC Soil } \\
\text { Type }\end{array}$ & $\mathrm{K}_{\mathrm{d}}$ Zone $^{\star *}$ & \\
\hline & & 0 & 440 & Surface & NA & NA & NA & NA & NA \\
\hline & 35 & 35 & 405 & Hanford HcS & Grey to Black Basaltic Sand & $\mathrm{S}$ & $\mathrm{HcS}$ & $\mathrm{HI}$ & $4 \mathrm{H}$ \\
\hline & 45 & 80 & 360 & Hanford Hg & $\begin{array}{l}\text { Gravel with sand and small } \\
\text { amount of clay }\end{array}$ & SG1 & $\mathrm{Hg}$ & II & 412 \\
\hline & 2 & 82 & 358 & Ringold Unit E & $\begin{array}{l}\text { Cemented gravel and pure } \\
\text { gravel, drills hard, all colors }\end{array}$ & SG2 & $\mathrm{Rg}$ & II & 412 \\
\hline & & 82 & 358 & Water Table & NA & $\mathrm{NA}$ & NA & NA & NA \\
\hline
\end{tabular}

Template 616P-X for shallow disposal (e.g., cribs, burial grounds)

\begin{tabular}{|c|c|c|c|c|c|c|c|c|c|}
\hline $\begin{array}{l}\text { Average } \\
\text { Thickness } \\
\text { (ft) }\end{array}$ & \begin{tabular}{|c|} 
Adjusted \\
Average \\
Thickness \\
(ft) \\
\end{tabular} & $\begin{array}{c}\text { Depth } \\
\text { (ft) }\end{array}$ & $\begin{array}{c}\text { Elevation } \\
(\mathrm{ft})\end{array}$ & Geologic Unit & Description & $\begin{array}{c}\text { Hydraulic } \\
\text { Property } \\
\text { Type * }\end{array}$ & $\begin{array}{l}\text { SAC Soil } \\
\text { Type }\end{array}$ & $\mathrm{K}_{\mathrm{d}}$ Zone $^{\star *}$ & $\mathrm{~K}_{\mathrm{d}}$ Class \\
\hline & & 0 & 440 & Surface & NA & NA & $\mathrm{NA}$ & $\mathrm{NA}$ & $\mathrm{NA}$ \\
\hline & 15 & 15 & 425 & Backfill & & $\mathrm{B}$ & $B$ & $\mathrm{HI}$ & $4 \mathrm{H}$ \\
\hline & 20 & 35 & 405 & Hanford Hcs & Grey to Black Basaltic Sand & $\mathrm{S}$ & $\mathrm{HCS}$ & $\mathrm{HI}$ & $4 \mathrm{H}$ \\
\hline & 45 & 80 & 360 & Hanford Hg & $\begin{array}{l}\text { Gravel with sand and small } \\
\text { amount of clay }\end{array}$ & SG1 & $\mathrm{Hg}$ & II & 412 \\
\hline & 2 & 82 & 358 & Ringold Unit E & $\begin{array}{l}\text { Cemented gravel and pure } \\
\text { gravel, drills hard, all colors }\end{array}$ & SG2 & $\mathrm{Rg}$ & II & 412 \\
\hline & & 82 & 358 & Water Table & NA & $\mathrm{NA}$ & NA & NA & NA \\
\hline
\end{tabular}

* After Khaleel and Freeman (1995), per white paper by Khaleel (September 2000).

** $\mathrm{HI}=$ high impact, II=Intermediate Impact (after Kincaid et al. 1998).

BLUE = Injection/release point. 


\section{VZ Base Templates Q}

\section{Area (FFTF) Stratigraphic Columns}

Notes/Assumptions:

1) Assume an average elevation of $540 \mathrm{ft}$ (164.6 m) MSL (USGS Topo - Richland, Washington, $15 \mathrm{~min}$. Quad. 1951).

2) Assume an average water-table elevation of $370 \mathrm{ft}$ (112.8 m) MSL (based on well 2-3 in Kipp and Mudd 1974).

3) Lithofacies taken from Summary Report, FFTF Well No. 4 (499-S1-8J) in Project Inspection Log Book Project V-749, Meier Associates, Inc., Kennewick, Washington, and well logs for 499-S1-7B from the Hanford Well Log Library in the Sigma $\vee$ Building.

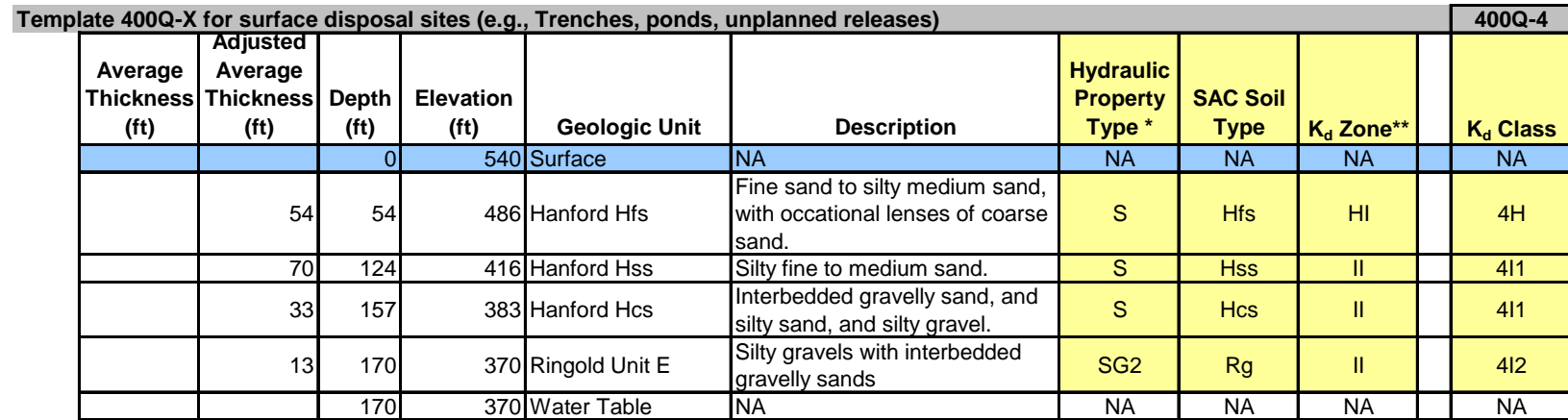

\begin{tabular}{|c|c|c|c|c|c|c|c|c|c|}
\hline \multicolumn{9}{|c|}{ Template 416Q-X for shallow disposal (e.g., cribs, burial grounds) } & \multirow[b]{2}{*}{$\begin{array}{l}416 Q-4 \\
\mathrm{~K}_{\mathrm{d}} \text { Class }\end{array}$} \\
\hline \begin{tabular}{|c} 
Average \\
Thickness \\
(ft)
\end{tabular} & $\begin{array}{c}\text { Adjusted } \\
\text { Average } \\
\text { Thickness } \\
\text { (ft) }\end{array}$ & $\begin{array}{c}\text { Depth } \\
\text { (ft) }\end{array}$ & $\begin{array}{c}\text { Elevation } \\
(\mathrm{ft})\end{array}$ & Geologic Unit & Description & $\begin{array}{c}\text { Hydraulic } \\
\text { Property } \\
\text { Type * }\end{array}$ & $\begin{array}{l}\text { SAC Soil } \\
\text { Type }\end{array}$ & $\mathrm{K}_{\mathrm{d}}$ Zone $^{\star *}$ & \\
\hline & & 0 & 540 & Surface & NA & NA & NA & NA & NA \\
\hline & 15 & 15 & 525 & Backfill & & B & B & $\mathrm{HI}$ & $4 \mathrm{H}$ \\
\hline & 39 & 54 & 486 & Hanford Hfs & $\begin{array}{l}\text { Fine sand to silty medium sand, } \\
\text { with occational lenses of coarse } \\
\text { sand. }\end{array}$ & S & Hfs & $\mathrm{HI}$ & $4 \mathrm{H}$ \\
\hline & 70 & 124 & 416 & Hanford Hss & Silty fine to medium sand. & $\mathrm{S}$ & Hss & II & $4 \mid 1$ \\
\hline & 33 & 157 & 383 & Hanford Hcs & $\begin{array}{l}\text { Interbedded gravelly sand, and } \\
\text { silty sand, and silty gravel. }\end{array}$ & $\mathrm{S}$ & Hcs & II & $4 I 1$ \\
\hline & 13 & 170 & 370 & Ringold Unit E & $\begin{array}{l}\text { Silty gravels with interbedded } \\
\text { gravelly sands }\end{array}$ & SG2 & $\mathrm{Rg}$ & II & $4 \mid 2$ \\
\hline & & 170 & 370 & Water Table & NA & $\mathrm{NA}$ & NA & $\mathrm{NA}$ & NA \\
\hline
\end{tabular}

* After Khaleel and Freeman (1995), per white paper by Khaleel (September 2000).

** $\mathrm{HI}=$ high impact, II=Intermediate Impact (after Kincaid et al. 1998)

BLUE = Injection/release point. 


\section{VZ Base Templates R}

\section{Area Stratigraphic Columns}

Notes/Assumptions:

1) Assume an average elevation of $380 \mathrm{ft}(115.8 \mathrm{~m}) \mathrm{MSL}$ (Schalla et al. 1988)

2) Assume an average water-table elevation of $347 \mathrm{ft}$ (106 m) MSL (Hartman et al. 2000).

Water levels fluctuate daily, weekly, and seasonally up to a meter depending on postion relative to the river.

Water levels have been increasing recently due to irrigation west of 300 Area.

3) Lithofacies are based on Lindsey (1991) and Gaylord Lindsey (1990). Lithofacies are highly varible in thickness and extent because of the fluvial nature of depostion.

\begin{tabular}{|c|c|c|c|c|c|c|c|c|c|}
\hline \multicolumn{9}{|c|}{ Template 300R-X for surface disposal sites (e.g., Trenches, ponds, unplanned releases) } & \multirow[b]{2}{*}{\begin{tabular}{|l}
$300 R-4$ \\
$K_{d}$ Class \\
\end{tabular}} \\
\hline \begin{tabular}{|c|}
$\begin{array}{c}\text { Average } \\
\text { Thickness } \\
\text { (ft) }\end{array}$ \\
\end{tabular} & \begin{tabular}{|c|} 
Adjusted \\
Average \\
Thickness \\
(ft) \\
\end{tabular} & \begin{tabular}{|c} 
Depth \\
(ft)
\end{tabular} & $\begin{array}{c}\text { Elevation } \\
\text { (ft) }\end{array}$ & Geologic Unit & Description & $\begin{array}{c}\text { Hydraulic } \\
\text { Property } \\
\text { Type * }\end{array}$ & $\begin{array}{c}\text { SAC Soil } \\
\text { Type }\end{array}$ & $\mathrm{K}_{\mathrm{d}}$ Zone $^{\star *}$ & \\
\hline & & 0 & 380 & Surface & NA & $\mathrm{NA}$ & NA & NA & NA \\
\hline 2 & 2 & 2 & 378 & Eolian & $\begin{array}{l}\text { Sand and silt (absent for } \\
\text { trenches and ponds) }\end{array}$ & S & Hss & $\mathrm{HI}$ & $4 \mathrm{H}$ \\
\hline 37 & 31 & 33 & 347 & Hanford $\mathrm{Hg}$ & $\begin{array}{l}\text { Gravel (Cobble/boulder to } \\
\text { gravel/pebble lithofacies after } \\
\text { Lindsey [1989, 1991] and } \\
\text { Gaylord Lindsey [1990]). }\end{array}$ & SG1 & $\mathrm{Hg}$ & $\mathrm{HI}$ & $4 \mathrm{H}$ \\
\hline & & 33 & 347 & Water Table & NA & $\mathrm{NA}$ & $\mathrm{NA}$ & $\mathrm{NA}$ & NA \\
\hline
\end{tabular}

\begin{tabular}{|c|c|c|c|c|c|c|c|c|c|}
\hline Template 316R-X & for surface & dispose & I sites (e.g., & Trenches, ponds & unplanned releases) & & & & 316R-4 \\
\hline $\begin{array}{c}\text { Average } \\
\text { Thickness } \\
\text { (ft) }\end{array}$ & \begin{tabular}{|c|} 
Adjusted \\
Average \\
Thickness \\
(ft) \\
\end{tabular} & $\begin{array}{c}\text { Depth } \\
\text { (ft) }\end{array}$ & $\begin{array}{c}\text { Elevation } \\
\text { (ft) }\end{array}$ & Geologic Unit & Description & $\begin{array}{c}\text { Hydraulic } \\
\text { Property } \\
\text { Type * }\end{array}$ & $\begin{array}{c}\text { SAC Soil } \\
\text { Type }\end{array}$ & $\mathrm{K}_{\mathrm{d}}$ Zone $\mathrm{Z}^{\star *}$ & $\mathrm{~K}_{\mathrm{d}}$ Class \\
\hline & & 0 & 380 & Surface & $\mathrm{NA}$ & $\mathrm{NA}$ & $\mathrm{NA}$ & $\mathrm{NA}$ & $\mathrm{NA}$ \\
\hline 15 & 15 & 15 & 365 & Backfill & & $\mathrm{B}$ & $\mathrm{B}$ & $\mathrm{HI}$ & $4 \mathrm{H}$ \\
\hline 37 & 18 & 33 & 347 & Hanford $\mathrm{Hg}$ & $\begin{array}{l}\text { Gravel (Cobble/boulder to } \\
\text { gravel/pebble lithofacies after } \\
\text { Lindsey [1989, 1991] and } \\
\text { Gaylord Lindsey [1990]). }\end{array}$ & SG1 & $\mathrm{Hg}$ & $\mathrm{HI}$ & $4 \mathrm{H}$ \\
\hline & & 33 & 347 & Water Table & NA & $\mathrm{NA}$ & $\mathrm{NA}$ & $\mathrm{NA}$ & $\mathrm{NA}$ \\
\hline
\end{tabular}

* After Khaleel and Freeman (1995), per white paper by Khaleel (September 2000).

** $\mathrm{HI}=$ high impact, II=Intermediate Impact (after Kincaid et al. 1998).

BLUE = Injection/release point. 


\section{VZ Base Templates - S_ERDF_E}

\section{Template for east half of ERDF and US Ecology}

Notes/Assumptions:

1) Template applies only to east half of ERDF and the US Ecology Site. The west half of ERDF includes the Plio-Pleistocene and upper Ringold units, which are missing under the east half of ERDF.

2) Based on 1:24,000-scale USGS topographic maps, topography ranges from $720 \mathrm{ft}$ AMSL along southeastern margin of ERDF to $750 \mathrm{ft}$ AMSL along northeastern boundary.

Will assume an average elevation of $735 \mathrm{ft}$ AMSL.

3) Pre-Hanford water-table elevation is $\sim 390 \mathrm{ft}$ AMSL at east end of ERDF, based on Kipp and Mudd (1974).

Will assume an average water-table elevation of $390 \mathrm{ft}$ AMSL.

4) Depth of the ERDF excavation is $\sim 60 \mathrm{ft}$ bgs based on measured sections at west end reported in Fecht and Weekes (1996)

5) Depths to strata beneath ERDF are based on cross sections presented in Weekes et al. (1996).

6) Assumes bottom of excavation is not level, but an even $60 \mathrm{ft}$ depth that parallels the land surface.

\begin{tabular}{|c|c|c|c|c|c|c|c|c|c|}
\hline \multicolumn{9}{|c|}{ Template 216S_ERDF_E-X. } & \begin{tabular}{|c|} 
216S_ERD \\
F_E-4 \\
\end{tabular} \\
\hline \begin{tabular}{|c|} 
Estimated \\
Thickness \\
(ft)
\end{tabular} & $\begin{array}{c}\text { Adjusted } \\
\text { Thickness } \\
\text { (ft) }\end{array}$ & $\begin{array}{c}\text { Depth } \\
\text { (ft) }\end{array}$ & $\begin{array}{l}\text { Elevation } \\
\text { (ft) }\end{array}$ & Geologic Unit & Description & $\begin{array}{c}\text { Hydraulic } \\
\text { Property } \\
\text { Type * }\end{array}$ & $\begin{array}{l}\text { SAC Soil } \\
\text { Type }\end{array}$ & $\mathrm{K}_{\mathrm{d}}$ Zone $^{\star \star}$ & $\mathrm{K}_{\mathrm{d}}$ Class \\
\hline & & 0 & 735 & Surface & NA & $\mathrm{NA}$ & NA & NA & NA \\
\hline 60 & 60 & 60 & 675 & Backfill & Backfill & $\mathrm{B}$ & $\mathrm{B}$ & $\mathrm{HI}$ & $4 \mathrm{H}$ \\
\hline 220 & 220 & 280 & 455 & Hanford Sand & $\begin{array}{l}\text { Slightly silty coarse to very fine } \\
\text { sand }\end{array}$ & $\mathrm{S}$ & Hfs_BC & $\mathrm{HI}$ & $4 \mathrm{H}$ \\
\hline 65 & 65 & 345 & 390 & Ringold Unit E & $\begin{array}{l}\text { Silty Sandy Medium to fine } \\
\text { pebble to sandy very coarse to } \\
\text { fine pebble (semi-indurated) }\end{array}$ & SG2 & $\mathrm{Rg}$ & II & 412 \\
\hline & & 345 & 390 & Water Table & NA & $\mathrm{NA}$ & NA & NA & NA \\
\hline
\end{tabular}

* After Khaleel and Freeman (1995), per white paper by Khaleel (September 2000)

** $\mathrm{HI}=$ high impact, II=Intermediate Impact (after Kincaid et al. 1998).

BLUE = Injection/release point. 


\section{VZ Base Templates S - ERDF}

\section{South 200 West Area - ERDF_W Stratigraphic Columns}

Notes/Assumptions:

1) Template applies only to west half of ERDF. East half of ERDF is missing Plio-Pleistocene and upper Ringold units.

2) Based on 1:24,000-scale USGS topographic maps, topography ranges from $675 \mathrm{ft}$ AMSL at southwest corner of ERDF to $750 \mathrm{ft}$ AMSL along northern boundary. Average elevation at west end is $\sim 720 \mathrm{ft}$ AMSL.

Will assume an average elevation of $720 \mathrm{ft}$ AMSL.

3) Pre-Hanford water-table elevation at west end of ERDF is $\sim 400 \mathrm{ft}$ AMSL based on Kipp and Mudd (1974).

Will assume an average water-table elevation of $400 \mathrm{ft}$ AMSL.

4) Depth of the ERDF excavation is $\sim 60 \mathrm{ft}$ bgs based on measured sections at west end reported in Fecht and Weekes (1996).

5) Depths to strata beneath ERDF are based on cross sections presented in Weekes et al. (1996).

\begin{tabular}{|c|c|c|c|c|c|c|c|c|c|}
\hline \multicolumn{9}{|c|}{ Template 216S_ERDF_W-X for the western portion of the ERDF Site } & \multirow{2}{*}{\begin{tabular}{|c|}
$\begin{array}{c}216 S \_E R D \\
\text { F_W-4 }\end{array}$ \\
\\
$\mathrm{K}_{\mathrm{d}}$ Class \\
\end{tabular}} \\
\hline \begin{tabular}{|c|} 
Average \\
Thickness \\
(ft)
\end{tabular} & \begin{tabular}{|c|} 
Adjusted \\
Average \\
Thickness \\
(ft) \\
\end{tabular} & $\begin{array}{c}\text { Depth } \\
\text { (ft) }\end{array}$ & $\begin{array}{c}\text { Elevation } \\
\text { (ft) }\end{array}$ & 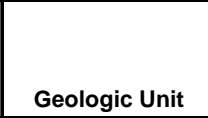 & Description & $\begin{array}{c}\text { Hydraulic } \\
\text { Property } \\
\text { Type * }\end{array}$ & $\begin{array}{l}\text { SAC Soil } \\
\text { Type }\end{array}$ & $\mathrm{K}_{\mathrm{d}}$ Zone $^{* *}$ & \\
\hline & & 0 & 720 & Surface & NA & NA & NA & NA & NA \\
\hline 60 & 60 & 60 & 660 & Backfill & Backfill & $\mathrm{B}$ & $\mathrm{B}$ & $\mathrm{HI}$ & $4 \mathrm{H}$ \\
\hline 180 & 180 & 240 & 480 & Hanford Sand & $\begin{array}{l}\text { Slightly silty coarse to very fine } \\
\text { sand }\end{array}$ & $\mathrm{S}$ & Hfs_2W & $\mathrm{HI}$ & $4 \mathrm{H}$ \\
\hline 10 & 10 & 250 & 470 & $\begin{array}{l}\text { Old Hanford/Cold } \\
\text { Creek Silt ("Early } \\
\text { Palouse") } \\
\end{array}$ & Silty fine to very fine sand & SS & PPIz & II & 411 \\
\hline 15 & 15 & 265 & 455 & $\begin{array}{l}\text { Cold Creek } \\
\text { Carbonate }\end{array}$ & $\begin{array}{l}\text { Pebbly silty coarse to very fine } \\
\text { sand to silty medium to very fine } \\
\text { sand }\end{array}$ & SS & PPlc & II & $4 I 1$ \\
\hline 15 & 15 & 280 & 440 & Upper Ringold Unit & $\begin{array}{l}\text { Felsic fine to medium sand with } \\
\text { minor silt }\end{array}$ & $\mathrm{S}$ & $\mathrm{PPlz}$ & II & $4 I 1$ \\
\hline 40 & 40 & 320 & 400 & Ringold (Unit E) & $\begin{array}{l}\text { Silty Sandy Medium to fine } \\
\text { pebble to sandy very coarse to } \\
\text { fine pebble (semi-indurated) }\end{array}$ & SG2 & Rg_2W & II & 412 \\
\hline & & 320 & 400 & Water Table & NA & $\mathrm{NA}$ & NA & NA & NA \\
\hline
\end{tabular}

* After Khaleel and Freeman (1995), per white paper by Khaleel (September 2000).

** $\mathrm{HI}=$ high impact, II=Intermediate Impact (after Kincaid et al. 1998).

BLUE = Injection/release point. 
VZ Base Templates S

South 200 West Area (S, U [except U-1\&2], Z Areas [except 216-Z-9]) Stratigraphic Columns

Notes/Assumptions:

1) Topography ranges from $730 \mathrm{ft}$ MSL east of ERDF to $625 \mathrm{ft}$ MSL southwest of the S-16 Pond (USGS Gable Butte and Riverland 7.5 min. Quad Maps).

Will assume an average elevation of $680 \mathrm{ft}$ MSL.

2) The pre-Hanford water table (January 1944) is estimated to range from an elevation of $122 \mathrm{~m}$ (400 ft) east of $200 \mathrm{~W}$ Area to $127 \mathrm{~m}$ (417 ft) west of the S-16 Pond (DOE 1987, page 4.21).

3) A thin blanket of eolian sand and silt covers the surface of the site where not disturbed. However, this material was generally removed

A thin blanket of eolian sand and silt covers the surface of the site where not disturbed. However, this mateid
during excavation and construction of the waste disposal sites and then incorporated into backfill materials.

4) The depth of the sites and, thus, the backfull over these sites range from $0 \mathrm{~m}$ for ponds and unplanned releases to an average of about

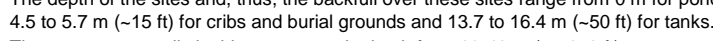

5) The two reverse wells in this area range in depth from $23-46 \mathrm{~m}(75-150 \mathrm{ft})$

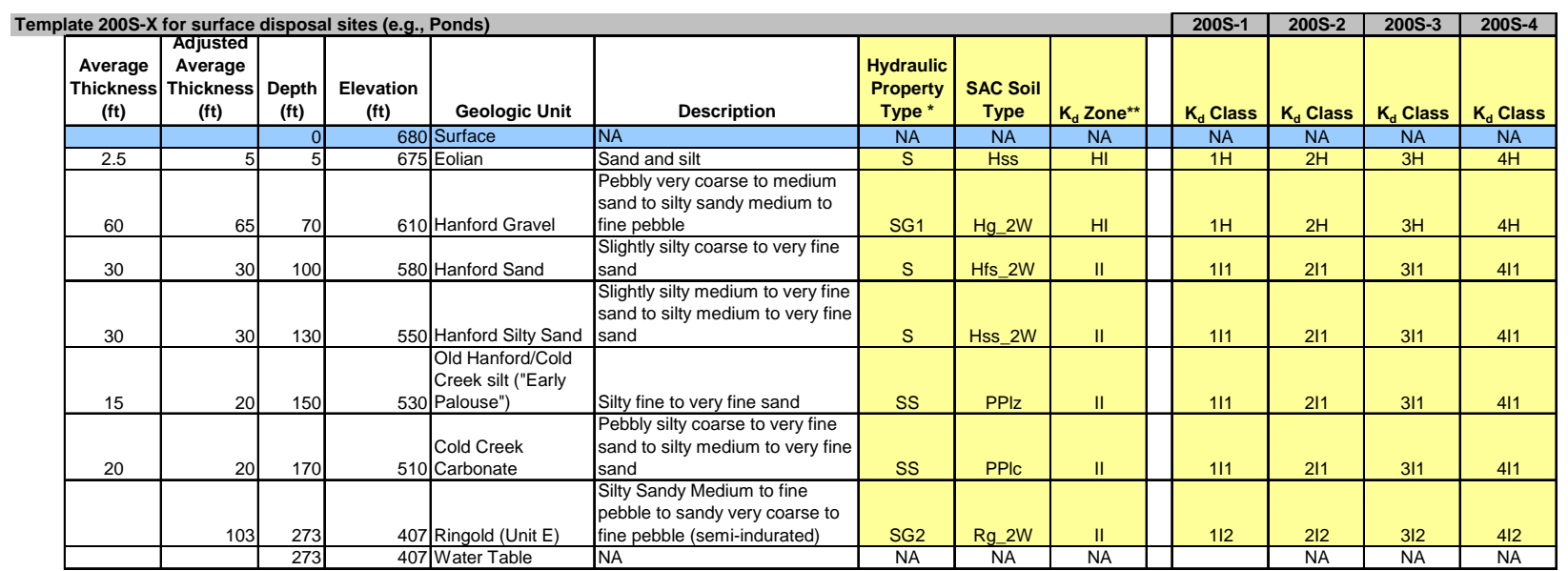

\begin{tabular}{|c|c|c|c|c|c|c|c|c|c|c|c|c|}
\hline \multirow{2}{*}{$\begin{array}{l}\text { Template 216S-X } \\
\qquad \begin{array}{c}\begin{array}{c}\text { Average } \\
\text { Thickness } \\
\text { (ft) }\end{array} \\
\end{array} \\
\end{array}$} & for shallow & disposa & al sites (e.g., & Cribs, Burial Grou & nds) & & & & $216 \mathrm{~S}-1$ & $216 \mathrm{~S}-2$ & $216 \mathrm{~S}-3$ & $216 \mathrm{~S}-4$ \\
\hline & \begin{tabular}{|c|} 
Adjusted \\
Average \\
Thickness \\
(ft)
\end{tabular} & $\begin{array}{c}\text { Depth } \\
\text { (ft) }\end{array}$ & $\begin{array}{c}\text { Elevation } \\
(\mathrm{ft})\end{array}$ & Geologic Unit & Description & $\begin{array}{c}\text { Hydraulic } \\
\text { Property } \\
\text { Type * } \\
\end{array}$ & $\begin{array}{c}\text { SAC Soil } \\
\text { Type }\end{array}$ & $\mathrm{K}_{\mathrm{d}}$ Zone & $\mathrm{K}_{\mathrm{d}}$ Class & $\mathrm{K}_{\mathrm{d}}$ Class & $\mathrm{K}_{\mathrm{d}}$ Class & $\mathrm{K}_{\mathrm{d}}$ Class \\
\hline & & 0 & 680 & Surface & NA & NA & NA & NA & $\mathrm{NA}$ & $\mathrm{NA}$ & NA & NA \\
\hline 15 & 15 & 15 & 665 & Backfill & Backfill & $\mathrm{B}$ & $\mathrm{B}$ & $\mathrm{HI}$ & $1 \mathrm{H}$ & $2 \mathrm{H}$ & $3 \mathrm{H}$ & $4 \mathrm{H}$ \\
\hline 50 & 55 & 70 & 610 & Hanford Gravel & $\begin{array}{l}\text { Pebbly very coarse to medium } \\
\text { sand to silty sandy medium to } \\
\text { fine pebble }\end{array}$ & SG1 & $\mathrm{Hg} 2 \mathrm{~W}$ & $\mathrm{HI}$ & $1 \mathrm{H}$ & $2 \mathrm{H}$ & $3 \mathrm{H}$ & $4 \mathrm{H}$ \\
\hline 30 & 30 & 100 & 580 & Hanford Sand & $\begin{array}{l}\text { Slightly silty coarse to very fine } \\
\text { sand }\end{array}$ & $\mathrm{s}$ & Hfs_2W & II & 111 & 211 & 311 & 411 \\
\hline 30 & 30 & 130 & 550 & Hanford Silty Sand & $\begin{array}{l}\text { Slightly silty medium to very fine } \\
\text { sand to silty medium to very fine } \\
\text { sand }\end{array}$ & $\mathrm{s}$ & Hss_2W & II & 111 & 211 & 311 & $4 \mid 1$ \\
\hline 15 & 20 & 150 & 530 & $\begin{array}{l}\text { Old Hanford/Cold } \\
\text { Creek silt ("Early } \\
\text { Palouse") }\end{array}$ & Silty fine to very fine sand & SS & $\mathrm{PPIz}$ & II & 111 & 211 & 311 & $4 \mid 1$ \\
\hline 20 & 20 & 170 & 510 & $\begin{array}{l}\text { Cold Creek } \\
\text { Carbonate }\end{array}$ & $\begin{array}{l}\text { Pebbly silty coarse to very fine } \\
\text { sand to silty medium to very fine } \\
\text { sand }\end{array}$ & SS & PPIc & II & 111 & 211 & 311 & 411 \\
\hline & 103 & 273 & 407 & Ringold (Unit E) & \begin{tabular}{|l} 
Silty Sandy Medium to fine \\
pebble to sandy very coarse to \\
fine pebble (semi-indurated)
\end{tabular} & SG2 & $\mathrm{Rg} \_2 \mathrm{~W}$ & II & 112 & 212 & 312 & 412 \\
\hline & & 273 & 407 & Water Table & NA & NA & NA & NA & NA & NA & NA & NA \\
\hline
\end{tabular}

\begin{tabular}{|c|c|c|c|c|c|c|c|c|c|c|c|c|}
\hline Template 217S-x & for shallow & disposa & I sites (e.g., & Cribs, Tilefields) re & ceiving NAPL CCl4 & & & & 217S-1 & & & \\
\hline $\begin{array}{c}\text { Average } \\
\text { Thickness } \\
\text { (ft) }\end{array}$ & $\begin{array}{c}\text { Adjusted } \\
\text { Average } \\
\text { Thickness } \\
\text { (ft) }\end{array}$ & $\begin{array}{c}\text { Depth } \\
\text { (ft) }\end{array}$ & $\begin{array}{c}\text { Elevation } \\
\text { (ft) }\end{array}$ & Geologic Unit & Description & $\begin{array}{c}\text { Hydraulic } \\
\text { Property } \\
\text { Type * }\end{array}$ & $\begin{array}{l}\text { SAC Soil } \\
\text { Type }\end{array}$ & $\mathrm{K}_{\mathrm{d}}$ Zone $\mathrm{e}^{* *}$ & $K_{d}$ Class & & & \\
\hline & & 0 & 680 & Surface & NA & NA & NA & NA & NA & & & \\
\hline 15 & 15 & 15 & 665 & Backfill & Backfill & $\mathrm{B}$ & $\mathrm{B}$ & $\mathrm{HI}$ & $1 \mathrm{H}$ & & & \\
\hline 50 & 55 & 70 & 610 & Hanford Gravel & $\begin{array}{l}\text { Pebbly very coarse to medium } \\
\text { sand to silty sandy medium to } \\
\text { fine pebble }\end{array}$ & SG1 & $\mathrm{Hg} 2 \mathrm{~W}$ & $\mathrm{HI}$ & $1 \mathrm{H}$ & & & \\
\hline 30 & 30 & 100 & 580 & Hanford Sand & $\begin{array}{l}\text { Slightly silty coarse to very fine } \\
\text { sand }\end{array}$ & $\mathrm{s}$ & Hfs_2W & II & 111 & & & \\
\hline 30 & 30 & 130 & 550 & Hanford Silty Sand & $\begin{array}{l}\text { Slightly silty medium to very fine } \\
\text { sand to silty medium to very fine } \\
\text { sand }\end{array}$ & $\mathrm{s}$ & Hss_2W & II & 111 & & & \\
\hline 15 & 20 & 150 & 530 & $\begin{array}{l}\text { Old Hanford/Cold } \\
\text { Creek silt ("Early } \\
\text { Palouse") }\end{array}$ & Silty fine to very fine sand & SS & $\mathrm{PPlz}$ & II & 111 & & & \\
\hline 20 & 20 & 170 & 510 & $\begin{array}{l}\text { Cold Creek } \\
\text { Carbonate }\end{array}$ & $\begin{array}{l}\text { Pebbly silty coarse to very fine } \\
\text { sand to silty medium to very fine } \\
\text { sand }\end{array}$ & SS & PPlc & II & 111 & & & \\
\hline & 103 & 273 & 407 & Ringold (Unit E) & $\begin{array}{l}\text { Silty Sandy Medium to fine } \\
\text { pebble to sandy very coarse to } \\
\text { fine pebble (semi-indurated) }\end{array}$ & $\mathrm{SG} 2$ & $\mathrm{Rg}_{2} 2 \mathrm{~W}$ & II & 112 & & & \\
\hline & & 273 & 407 & Water Table & NA & NA & NA & NA & NA & & & \\
\hline
\end{tabular}


VZ Base Templates S

South 200 West Area (S, U [except U-1\&2], Z Areas [except 216-Z-9]) Stratigraphic Columns

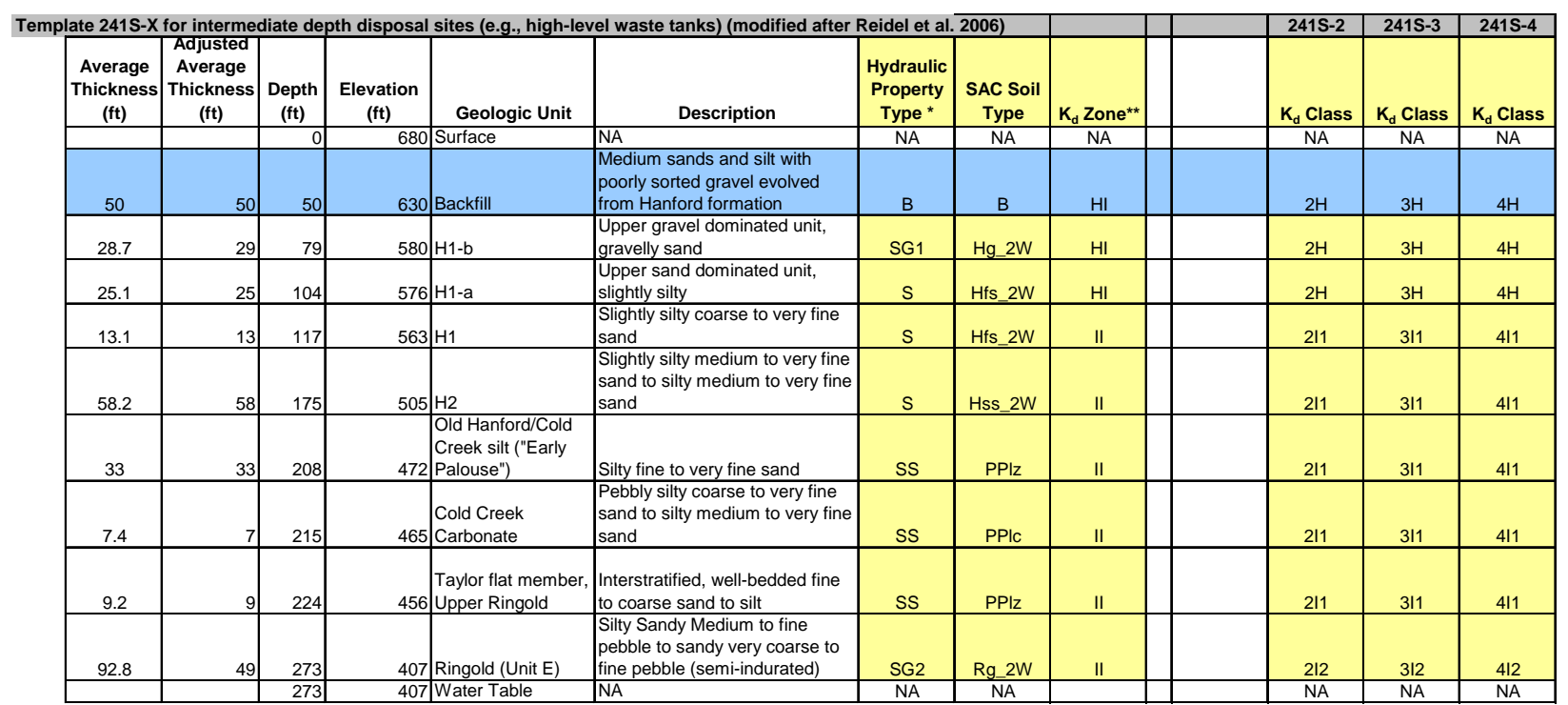

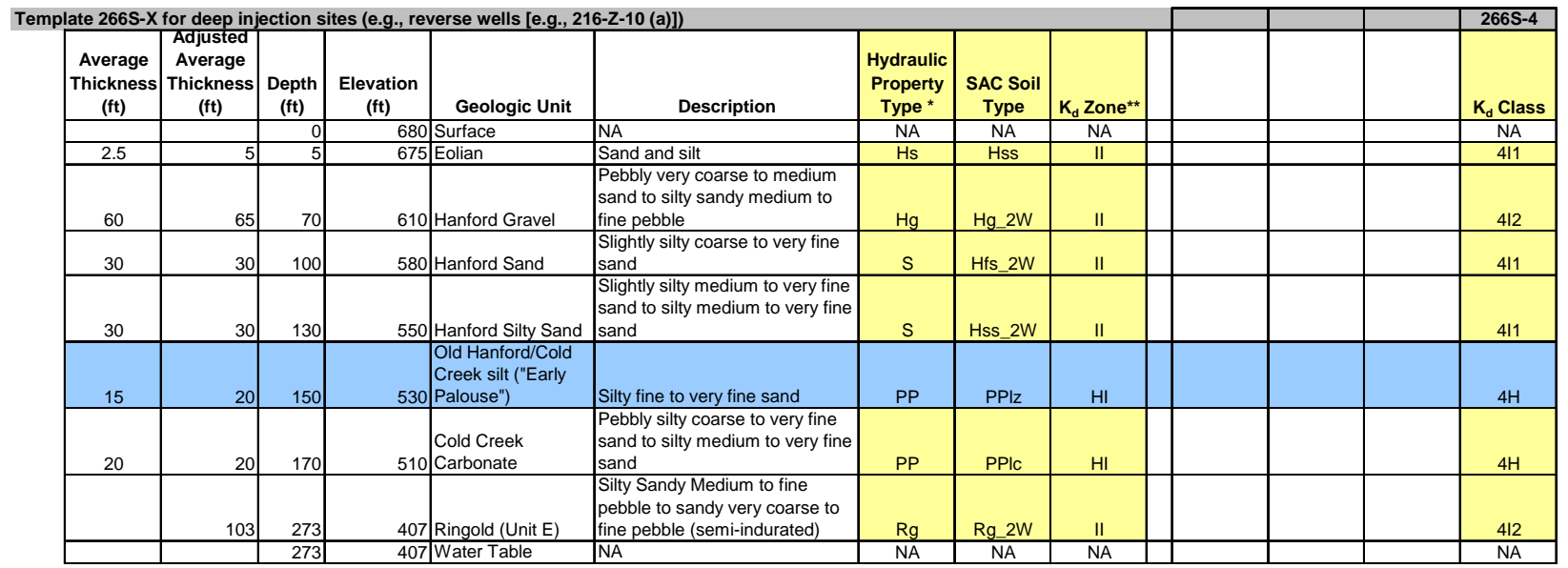

* After Khaleel and Freeman (1995), per white paper by Khaleel (September 2000).

** HI=high impact, II=Intermediate Impact (after Kincaid et al. 1998).

BLUE = Injection/release point.

(a) Note: Injection well $216-Z-10$ is screened from $118-150 \mathrm{ft}$. Well $216-\mathrm{U}-4$ is screened from $50-75 \mathrm{ft}$. 


\section{VZ Base Templates - U Cribs}

\section{$U$ Cribs (216-U-1, -2 and -16) \\ Notes/Assumptions:}

1) Surface elevation ranges from $211.0 \mathrm{~m}$ (692.3 ft) near 216-U-16 to $212.5 \mathrm{~m}$ (697.2 ft) MSL near the $216-\mathrm{U}-1$ and -2 Cribs as taken from the Hanford Site Atlas (BHI 1998).

2) Ground surface and water-table elevations from the HYDRODAT database managed by the Pacific Northwest National Laboratory.

3) The pre-Hanford water table (January 1944) is estimated to have been at an elevation of 405 MSL (based on Kipp and Mudd 1974).

4) The site depth to bottom of the $216-\mathrm{U}-1$ and -2 Cribs is reported to be $24 \mathrm{ft} / \mathrm{min}$ (7.3 m) based on Maxfield (1979). No bottom is reported for the $216-\mathrm{U}-16$ Crib. Thus, the backfill is assumed to be $24 \mathrm{ft}$ deep for all three cribs.

Template 216S_U_N-x for the area N-NE of the 216-U-1\&2 Cribs, based on well 299-W19-16 (N 135029.21, E 567270.68) located $24 \mathrm{~m}(80 \mathrm{ft})$ north of $216-\mathrm{U}-1$ Crib.

\begin{tabular}{|c|c|c|c|c|c|c|c|c|c|}
\hline $\begin{array}{c}\text { Estimated } \\
\text { Thickness } \\
(\mathrm{ft})^{\star \star \star}\end{array}$ & $\begin{array}{c}\text { Adjusted } \\
\text { Thickness } \\
\text { (ft) }\end{array}$ & $\begin{array}{c}\text { Bottom } \\
\text { Depth (ft) }\end{array}$ & $\begin{array}{c}\text { Bottom } \\
\text { Elevation } \\
\text { (ft) }\end{array}$ & Geologic Unit & Description & $\begin{array}{c}\text { Hydraulic } \\
\text { Property } \\
\text { Type * }\end{array}$ & $\begin{array}{c}\text { SAC Soil } \\
\text { Type }\end{array}$ & $\mathrm{K}_{\mathrm{d}}$ Zone $^{\star \star}$ & $\mathrm{K}_{\mathrm{d}}$ Class \\
\hline & & 0 & 695.157 & Surface & NA & NA & NA & NA & NA \\
\hline 24 & 24 & 24 & 671 & Backfill & Backfill & $\mathrm{B}$ & $\mathrm{B}$ & $\mathrm{HI}$ & $4 \mathrm{H}$ \\
\hline 67 & 67 & 91 & 604 & Hanford H1 & $\begin{array}{l}\text { Interbedded layers of fine to } \\
\text { coarse sand and sandy gravel }\end{array}$ & S & Hcs_2W & $\mathrm{HI}$ & $4 \mathrm{H}$ \\
\hline 55 & 55 & 146 & 549 & Hanford H2 & $\begin{array}{l}\text { Interbedded layers of silty to } \\
\text { fine, medium, and coarse sand }\end{array}$ & $\mathrm{s}$ & Hfs_U & II & $4 I 1$ \\
\hline 19 & 19 & 165 & 530 & CCU-upper & Silt and fine sand & SS & PPlz_U & II & 411 \\
\hline 2 & 2 & 167 & 528 & CCU-lower & $\begin{array}{l}\text { Calcium-carbonate cemented } \\
\text { sand, silt and clay (caliche) }\end{array}$ & SS & PPIc & II & $4 I 1$ \\
\hline 83 & 83 & 250 & 445 & Ringold Unit E & Sandy gravel & SG2 & $\mathrm{Rg} \_\mathrm{U}$ & II & 412 \\
\hline & & 250.59 & 444.57 & Water Table & NA & NA & NA & NA & NA \\
\hline
\end{tabular}

\begin{tabular}{|c|c|c|c|c|c|c|c|c|c|}
\hline \multicolumn{9}{|c|}{$\begin{array}{l}\text { Template } 216 \mathrm{~S} \text { U_S-x for the southern portion of the } 216-\mathrm{U}-1 \& 2 \mathrm{crib} \text { area, based on well 299-W19-14 (N 134831.14, E } \\
567267.99) \text {, located } 9 \mathrm{~m} \text { ( } 30 \mathrm{ft}) \text { from SE edge of } 216-\mathrm{U}-16 \text { Crib. }\end{array}$} & \multirow{2}{*}{\begin{tabular}{|c} 
216S_U_S-4 \\
$\mathrm{K}_{\mathrm{d}}$ Class \\
\end{tabular}} \\
\hline $\begin{array}{c}\text { Estimated } \\
\text { Thickness } \\
(\mathrm{ft})^{\star \star \star} \\
\end{array}$ & \begin{tabular}{|c} 
Adjusted \\
Thickness \\
(ft)
\end{tabular} & \begin{tabular}{c|} 
Bottom \\
Depth (ft)
\end{tabular} & $\begin{array}{c}\text { Bottom } \\
\text { Elevation } \\
\text { (ft) }\end{array}$ & Geologic Unit & Description & $\begin{array}{c}\text { Hydraulic } \\
\text { Property } \\
\text { Type * } \\
\end{array}$ & $\begin{array}{l}\text { SAC Soil } \\
\text { Type }\end{array}$ & $\mathrm{K}_{\mathrm{d}}$ Zone $^{\star \star}$ & \\
\hline & & 0 & 693.44 & Surface & NA & NA & NA & NA & NA \\
\hline 24 & 24 & 24 & 669 & Backfill & Backfill & $\mathrm{B}$ & $\mathrm{B}$ & $4 \mathrm{H}$ & $4 \mathrm{H}$ \\
\hline 86 & 86 & 110 & 583 & Hanford H1 & $\begin{array}{l}\text { Interbedded layers of fine to } \\
\text { coarse sand and sandy gravel }\end{array}$ & $\mathrm{S}$ & Hcs_2W & $4 \mathrm{H}$ & $4 \mathrm{H}$ \\
\hline 42 & 42 & 152 & 541 & Hanford $\mathrm{H} 2$ & $\begin{array}{l}\text { Interbedded layers of silty to } \\
\text { fine, medium, and coarse sand }\end{array}$ & $\mathrm{S}$ & Hfs_U & $4 I 1$ & $4 \mid 1$ \\
\hline 14 & 14 & 166 & 527 & CCU-upper & Silt and fine sand & SS & PPlz_U & 411 & 411 \\
\hline 4 & 4 & 170 & 523 & CCU-lower & $\begin{array}{l}\text { Calcium-carbonate cemented } \\
\text { sand, silt and clay (caliche) }\end{array}$ & SS & PPIc & $4 I 1$ & $4 I 1$ \\
\hline 78 & 78 & 248 & 445 & Ringold Unit E & Sandy gravel & SG2 & $\mathrm{Rg} \_\mathrm{U}$ & 412 & 412 \\
\hline & & 248.02 & 445.42 & Water Table & NA & NA & NA & NA & NA \\
\hline
\end{tabular}

* After Khaleel and Freeman (1995), per white paper by Khaleel (September 2000).

** $\mathrm{HI}=$ high impact, II=Intermediate Impact (after Kincaid et al. 1998).

BLUE = Injection/release point. 
VZ Base Templates S_U tanks

\section{South 200 West Area (U-Tanks) Stratigraphic Columns}

Notes/Assumptions:

1) Surface elevation is roughly $665 \mathrm{ft}$ based on well 299-W18-132.

Will assume an average elevation of $665 \mathrm{ft}$ MSL.

2) The pre-Hanford water table (January 1944) is estimated to be about $407 \mathrm{ft}$ (Kipp and Mudd 1974).

Will assume an average water-table elevation of $124 \mathrm{~m}(407 \mathrm{ft}) \mathrm{MSL}$.

3) A thin blanket of eolian sand and silt covers the surface of the site where not disturbed. However, this material was generally

removed during excavation and construction of the waste disposal sites and then incorporated into backfill materials.

4) The depth of the sites and, thus, the backfull over these sites range from about 13.7 to $16.4 \mathrm{~m}(\sim 50 \mathrm{ft})$ for tanks.

\begin{tabular}{|c|c|c|c|c|c|c|c|c|c|c|c|}
\hline Template 241S_U & $-x$ for intern & nediate & depth dis & sposal sites (e.g., h & igh-level waste tanks). Modified & after Reide & l et al. $(200$ & 6). & 241S_U-2 & 241S_U-3 & 241S U-4 \\
\hline $\begin{array}{c}\text { Average } \\
\text { Thickness } \\
\text { (ft) }\end{array}$ & $\begin{array}{c}\text { Adjusted } \\
\text { Average } \\
\text { Thickness } \\
\text { (ft) }\end{array}$ & $\begin{array}{c}\text { Depth } \\
\text { (ft) }\end{array}$ & $\mid \begin{array}{c}\text { Elevatio } \\
\mathrm{n}(\mathrm{ft})\end{array}$ & Geologic Unit & Description & $\begin{array}{l}\text { Hydraulic } \\
\text { Property } \\
\text { Type * }\end{array}$ & $\begin{array}{c}\text { SAC Soil } \\
\text { Type }\end{array}$ & $\mathrm{K}_{\mathrm{d}}$ Zone $^{\star *}$ & $\mathrm{~K}_{\mathrm{d}}$ Class & $\mathrm{K}_{\mathrm{d}}$ Class & $\mathrm{K}_{\mathrm{d}}$ Class \\
\hline & & 0 & 665 & Surface & NA & NA & NA & NA & NA & NA & NA \\
\hline 50 & 50 & 50 & 615 & Backfill & $\begin{array}{l}\text { Medium sands and silt with } \\
\text { poorly sorted gravel evolved } \\
\text { from Hanford formation }\end{array}$ & B & B & $\mathrm{HI}$ & $2 \mathrm{H}$ & $3 \mathrm{H}$ & $4 \mathrm{H}$ \\
\hline $26-36$ & 26 & 76 & 589 & $\mathrm{H} 1$ & $\begin{array}{l}\text { Slightly silty coarse to very fine } \\
\text { sand }\end{array}$ & $\mathrm{s}$ & Hfs_2W & $\mathrm{HI}$ & $2 \mathrm{H}$ & $3 \mathrm{H}$ & $4 \mathrm{H}$ \\
\hline 89 & 89 & 165 & 500 & $\mathrm{H} 2$ & $\begin{array}{l}\text { Slightly silty medium to very fine } \\
\text { sand to silty medium to very fine } \\
\text { sand }\end{array}$ & $\mathrm{s}$ & Hss $2 \mathrm{~W}$ & $\mathrm{HI}$ & $2 \mathrm{H}$ & $3 \mathrm{H}$ & $4 \mathrm{H}$ \\
\hline 32 & 32 & 197 & 468 & $\begin{array}{l}\text { Cold Creek Upper: } \\
\text { Old Hanford/Plio- } \\
\text { Pleistocene ("Early } \\
\text { Palouse") }\end{array}$ & Silty fine to very fine sand & SS & PPIz & II & $2 \mathrm{II}$ & 311 & $4 I 1$ \\
\hline 8 & 8 & 205 & 460 & $\begin{array}{l}\text { Cold Creek Lower: } \\
\text { Plio-Pleistocene } \\
\text { Caliche }\end{array}$ & $\begin{array}{l}\text { Pebbly silty coarse to very fine } \\
\text { sand to silty medium to very fine } \\
\text { sand }\end{array}$ & sS & PPIc & II & 2।1 & $3 І 1$ & $4 \mid 1$ \\
\hline 102 & 53 & 258 & 407 & Ringold (Unit E) & $\begin{array}{l}\text { Silty Sandy Medium to fine } \\
\text { pebble to sandy very coarse to } \\
\text { fine pebble (semi-indurated) }\end{array}$ & SG2 & $\mathrm{Rg} \_2 \mathrm{~W}$ & II & 212 & 312 & 412 \\
\hline & & 258 & 407 & Water Table & NA & NA & NA & & NA & NA & NA \\
\hline
\end{tabular}

* After Khaleel and Freeman (1995), per white paper by Khaleel (September 2000).

** $\mathrm{HI}=$ high impact, II=Intermediate Impact (after Kincaid et al. 1998).

BLUE = Injection/release point. 


\section{VZ Base Templates - S_Z9}

\section{6-Z-9 Trench Stratigraphic Columns}

Notes/Assumptions:

1) Land surface elevations range from $201.1 \mathrm{~m}$ (660 ft) near well 299-W15-39 to $209.4 \mathrm{~m}$ (687 ft) near well 299-W15-18.

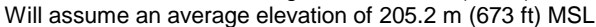

2) The pre-Hanford water table (January 1944) is estimated to range from an elevation of $122 \mathrm{~m}$ (400 ft) east of $200 \mathrm{~W}$ Area to $127 \mathrm{~m}$ (417 ft) west of the S-16 Pond (DOE 1987, page 4.21).

Will assume a minimum water-table elevation of $124 \mathrm{~m}(407 \mathrm{ft}) \mathrm{MSL}$

3) Lithofacies data taken from 9 wells near Z-9 (Wells 299-W15-5, -8, -9, -83, -84, -86, -95, -101, -217)

4) A thin blanket of eolian sand and silt covers the surface of the site where not disturbed. However, this material was generally removed during excavation and construction of the waste disposal sites and then incorporated into backfill materials.

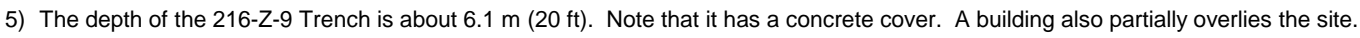

\begin{tabular}{|c|c|c|c|c|c|c|c|c|c|}
\hline \multicolumn{9}{|c|}{ Template 216S_Z9-X for the 216-Z-9 Trench } & \multirow[b]{2}{*}{$\begin{array}{l}216 S \_29-1 \\
K_{d} \text { Class }\end{array}$} \\
\hline \begin{tabular}{|c} 
Average \\
Thickness \\
(ft) \\
\end{tabular} & \begin{tabular}{|c|} 
Adjusted \\
Average \\
Thickness \\
(ft) \\
\end{tabular} & $\begin{array}{c}\text { Depth } \\
\text { (ft) }\end{array}$ & $\begin{array}{c}\text { Elevation } \\
\text { (ft) }\end{array}$ & Geologic Unit & Description & $\begin{array}{c}\text { VZ } \\
\text { Hydraulic } \\
\text { Property } \\
\text { Type * } \\
\end{array}$ & $\begin{array}{c}\text { SAC Soil } \\
\text { Type }\end{array}$ & $\mathrm{K}_{\mathrm{d}}$ Zone $^{\star *}$ & \\
\hline & & 0 & 673 & Surface & Concrete & NA & NA & NA & NA \\
\hline 15.5 & 20 & 20 & 653 & Backfill & Gravelly Medium Sand & $\mathrm{B}$ & $\mathrm{B}$ & $\mathrm{HI}$ & $1 \mathrm{H}$ \\
\hline 29.2 & 24 & 44 & 629 & \begin{tabular}{|l} 
Hanford Gravel \\
$(\mathrm{H} 1)$
\end{tabular} & Sandy Gravel & SG1 & Hg_Z & $\mathrm{HI}$ & $1 \mathrm{H}$ \\
\hline 39.2 & 39 & 83 & 590 & Hanford Sand $(\mathrm{H} 2)$ & Coarse to Medium Sand & $\mathrm{S}$ & Hfs_Z & II & 111 \\
\hline 23.4 & 23 & 106 & 567 & \begin{tabular}{|l} 
Hanford \\
Interbedded sand \\
and mud $(\mathrm{H} 4)$
\end{tabular} & $\begin{array}{l}\text { Slightly Muddy Medium to Fine } \\
\text { Sand to Sandy Mud }\end{array}$ & S & Hss_Z & II & 111 \\
\hline 8.7 & 9 & 115 & 558 & CCU Silt & Sandy Mud & SS & PPlz_Z & II & 111 \\
\hline 4.0 & 4 & 119 & 554 & CCU Carbonate & $\begin{array}{l}\text { Calcareous Gravelly, Muddy, } \\
\text { Sand }\end{array}$ & SS & PPIc_Z & II & 111 \\
\hline 146.1 & 147 & 266 & 407 & Ringold (Unit E) & $\begin{array}{l}\text { Semi-indurated Muddy Sandy } \\
\text { Gravel }\end{array}$ & SG2 & Rg_2W & II & 112 \\
\hline 127.0 & 163 & 429 & 244 & $\begin{array}{l}\text { Ringold (Unit E) - } \\
\text { Saturated }\end{array}$ & $\begin{array}{l}\text { Semi-indurated Muddy Sandy } \\
\text { Gravel }\end{array}$ & NA & NA & GW & NA \\
\hline 54.0 & 54 & 483 & 190 & Ringold Lower Mud & Muddy Medium to Fine Sand & NA & NA & GW & NA \\
\hline 45.0 & 45 & 528 & 145 & Ringold Unit A & Sandy Gravel & NA & NA & GW & NA \\
\hline & & & & $\begin{array}{l}\text { Elephant Mountain } \\
\text { Basalt }\end{array}$ & Basalt & NA & NA & NA & NA \\
\hline
\end{tabular}

* After Khaleel and Freeman (1995), per white paper by Khaleel (September 2000).

** HI=high impact, II=Intermediate Impact (after Kincaid et al. 1998).

BLUE = Injection/release point.

LT. BLUE = Saturated Zone 


\section{VZ Base Templates T}

\section{North 200 West Area (T Areas) Stratigraphic Columns}

Notes/Assumptions:

1) Topography ranges from $790 \mathrm{ft}$ MSL in the NW corner of the $218-\mathrm{W}-5$ burial ground to about $665 \mathrm{ft}$ MSL east of the TX Tank Farm (USGS Gable Butte and Riverland 7.5 min. Quad Maps). Will assume an average elevation of $690 \mathrm{ft}$ MSL.

2) The pre-Hanford water table (January 1944) is estimated to range from an elevation of $122 \mathrm{~m}$ (400 ft) east of $200 \mathrm{~W}$ to $127 \mathrm{~m}$ (417 ft) on the west side of the 218-W-5 Burial Ground (Kipp and Mudd 1974; DOE 1987, page 4.21). Will assume an average water-table elevation of $124 \mathrm{~m}$ (407 ft) MSL.

3) A thin blanket of eolian sand and silt covers the surface of the site where not disturbed. However, this material was generally removed during excavation and construction of the waste disposal sites and then incorporated into backfill materials.

4) The depth of the sites and, thus, the backfull over these sites range from $0 \mathrm{~m}$ for ponds and most unplanned releases to an average of

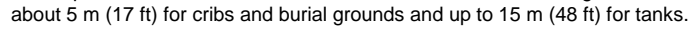

5) Two reverse wells in this area range in depth from 22-62 m (75-206 ft). Will assume an average depth of $180 \mathrm{ft}$.

\begin{tabular}{|c|c|c|c|c|c|c|c|c|c|c|}
\hline \multicolumn{9}{|c|}{ Template 200T-X for surface disposal sites (e.g., Ponds) } & $200 T-2$ & $200 \mathrm{~T}-4$ \\
\hline $\begin{array}{c}\text { Average } \\
\text { Thickness } \\
\text { (ft) }\end{array}$ & \begin{tabular}{|c|} 
Adjusted \\
Average \\
Thickness \\
(ft)
\end{tabular} & $\begin{array}{l}\text { Depth } \\
\text { (ft) }\end{array}$ & $\begin{array}{l}\text { Elevation } \\
\text { (ft) }\end{array}$ & Geologic Unit & Description & $\begin{array}{c}\text { Hydraulic } \\
\text { Property } \\
\text { Type * }\end{array}$ & $\begin{array}{l}\text { SAC Soil } \\
\text { Type }\end{array}$ & $\mathrm{K}_{\mathrm{d}}$ Zone $^{\star \star}$ & $\mathrm{K}_{\mathrm{d}}$ Class & $\mathrm{K}_{\mathrm{d}}$ Class \\
\hline & & 0 & 690 & Surface & NA & NA & NA & NA & NA & NA \\
\hline 2.5 & 2 & 2 & 688 & Eolian & Sand and silt & $\mathrm{s}$ & Hss & $\mathrm{HI}$ & $2 \mathrm{H}$ & $4 \mathrm{H}$ \\
\hline 90 & 90 & 92 & 598 & Hanford Gravel & $\begin{array}{l}\text { Silty sandy medium to fine } \\
\text { pebble to slightly silty pebbly } \\
\text { very coarse to coarse sand. }\end{array}$ & SG1 & $\mathrm{Hg}_{2} 2 \mathrm{~W}$ & $\mathrm{HI}$ & $2 \mathrm{H}$ & $4 \mathrm{H}$ \\
\hline 35 & 35 & 127 & 563 & $\begin{array}{l}\text { Hanford Gravelly } \\
\text { Sand }\end{array}$ & $\begin{array}{l}\text { Pebbly very coarse to medium } \\
\text { sand to slightly silty very coarse } \\
\text { to medium sand }\end{array}$ & GS & Hgs_2W & II & $2 \mid 1$ & $4 \mid 1$ \\
\hline 10 & 10 & 137 & 553 & $\begin{array}{l}\text { Old Hanford/Cold } \\
\text { Creek Silt ("Early } \\
\text { Palouse") }\end{array}$ & $\begin{array}{l}\text { Silty fine to very fine sand to } \\
\text { slightly silty fine to very fine sand }\end{array}$ & SS & $\mathrm{PPlz}$ & II & 211 & 411 \\
\hline 18 & 18 & 155 & 535 & $\begin{array}{l}\text { Cold Creek } \\
\text { Carbonate }\end{array}$ & $\begin{array}{l}\text { Pebbly silty coarse to fine sand } \\
\text { to silty medium to very fine sand } \\
\text { with caliche }\end{array}$ & SS & PPlc & II & $2 \mid 1$ & 411 \\
\hline 25 & 25 & 180 & 510 & Upper Ringold & $\begin{array}{l}\text { silty fine to very fine sand to silty } \\
\text { medium to very fine sand (semi- } \\
\text { indurated) }\end{array}$ & $\mathrm{s}$ & PPlz & II & $2 \mid 1$ & $4 \mid 1$ \\
\hline & 103 & 283 & 407 & Ringold Unit E & $\begin{array}{l}\text { Silty Sandy Medium to fine } \\
\text { pebble to sandy very coarse to } \\
\text { fine pebble (semi-indurated) }\end{array}$ & $\mathrm{SG} 2$ & $\mathrm{Rg} \_2 \mathrm{~W}$ & II & 212 & 412 \\
\hline & & 283 & 407 & Water Table & NA & NA & NA & $\mathrm{NA}$ & NA & NA \\
\hline
\end{tabular}

\begin{tabular}{|c|c|c|c|c|c|c|c|c|c|c|c|}
\hline \multicolumn{9}{|c|}{ Template 216T-X for shallow disposal sites (e.g., Cribs, Burial Grounds) } & $216 \mathrm{~T}-2$ & $216 \mathrm{~T}-3$ & $216 \mathrm{~T}-4$ \\
\hline \begin{tabular}{|c|} 
Average \\
Thickness \\
(ft)
\end{tabular} & \begin{tabular}{|c|} 
Adjusted \\
Average \\
Thickness \\
(ft)
\end{tabular} & $\begin{array}{c}\text { Depth } \\
\text { (ft) }\end{array}$ & $\begin{array}{l}\text { Elevation } \\
\text { (ft) }\end{array}$ & Geologic Unit & Description & $\begin{array}{c}\text { Hydraulic } \\
\text { Property } \\
\text { Type * }\end{array}$ & $\begin{array}{c}\text { SAC Soil } \\
\text { Type }\end{array}$ & $\mathrm{K}_{\mathrm{d}}$ Zone $^{\star \star}$ & $\mathrm{K}_{\mathrm{d}}$ Class & $\mathrm{K}_{\mathrm{d}}$ Class & $\mathrm{K}_{\mathrm{d}}$ Class \\
\hline & & 0 & 690 & Surface & NA & NA & $\mathrm{NA}$ & NA & NA & NA & NA \\
\hline 17 & 17 & 17 & 673 & Backfill & & $\mathrm{B}$ & $\mathrm{B}$ & $\mathrm{HI}$ & $2 \mathrm{H}$ & $3 \mathrm{H}$ & $4 \mathrm{H}$ \\
\hline 90 & 75 & 92 & 598 & Hanford Gravel & $\begin{array}{l}\text { Silty sandy medium to fine } \\
\text { pebble to slightly silty pebbly } \\
\text { very coarse to coarse sand. }\end{array}$ & SG1 & Hg_2W & $\mathrm{HI}$ & $2 \mathrm{H}$ & $3 \mathrm{H}$ & $4 \mathrm{H}$ \\
\hline 35 & 35 & 127 & 563 & $\begin{array}{l}\text { Hanford Gravelly } \\
\text { Sand }\end{array}$ & $\begin{array}{l}\text { Pebbly very coarse to medium } \\
\text { sand to slightly silty very coarse } \\
\text { to medium sand }\end{array}$ & GS & Hgs_2W & II & $2 \mathrm{II}$ & 311 & $4 \mid 1$ \\
\hline 10 & 10 & 137 & 553 & $\begin{array}{l}\text { Old Hanford/Cold } \\
\text { Creek Silt ("Early } \\
\text { Palouse") }\end{array}$ & $\begin{array}{l}\text { Silty fine to very fine sand to } \\
\text { slightly silty fine to very fine sand }\end{array}$ & SS & PPlz & II & $2 \mathrm{II}$ & 311 & $4 \mid 1$ \\
\hline 18 & 18 & 155 & 535 & $\begin{array}{l}\text { Cold Creek } \\
\text { Carbonate }\end{array}$ & $\begin{array}{l}\text { Pebbly silty coarse to fine sand } \\
\text { to silty medium to very fine sand } \\
\text { with caliche }\end{array}$ & SS & PPIc & II & 211 & 311 & $4 \mid 1$ \\
\hline 25 & 25 & 180 & 510 & Upper Ringold & $\begin{array}{l}\text { silty fine to very fine sand to silty } \\
\text { medium to very fine sand (semi- } \\
\text { indurated) }\end{array}$ & $\mathrm{S}$ & PPIz & II & $2 \mathrm{I} 1$ & 311 & $4 \mathrm{I} 1$ \\
\hline & 103 & 283 & 407 & Ringold Unit E & $\begin{array}{l}\text { Silty Sandy Medium to fine } \\
\text { pebble to sandy very coarse to } \\
\text { fine pebble (semi-indurated) }\end{array}$ & SG2 & $\mathrm{Rg} \_2 \mathrm{~W}$ & II & 212 & 312 & 412 \\
\hline & & 283 & 407 & Water Table & NA & NA & NA & $\mathrm{NA}$ & $\mathrm{NA}$ & NA & NA \\
\hline
\end{tabular}


VZ Base Templates T

\section{North 200 West Area (T Areas) Stratigraphic Columns}

\begin{tabular}{|c|c|c|c|c|c|c|c|c|c|c|c|}
\hline Template 241T-X & for tanks (N & hodified & after Reidel & et al. 2006) & & & & & 241T-2 & & \\
\hline \begin{tabular}{|c|} 
Average \\
Thickness \\
(ft)
\end{tabular} & \begin{tabular}{|c|} 
Adjusted \\
Average \\
Thickness \\
(ft)
\end{tabular} & $\begin{array}{c}\text { Depth } \\
\text { (ft) }\end{array}$ & $\begin{array}{c}\text { Elevation } \\
\text { (ft) }\end{array}$ & Geologic Unit & Description & $\begin{array}{c}\text { Hydraulic } \\
\text { Property } \\
\text { Type* * }\end{array}$ & $\begin{array}{c}\text { SAC Soil } \\
\text { Type }\end{array}$ & $\mathrm{K}_{\mathrm{d}}$ Zone $^{\star \star}$ & $K_{d}$ Class & & \\
\hline & & 0 & 690 & Surface & NA & NA & NA & NA & NA & & \\
\hline 48 & 48 & 48 & 642 & Backfill & $\begin{array}{l}\text { Medium sands and silt with } \\
\text { poorly sorted gravel evolved } \\
\text { from Hanford formation }\end{array}$ & B & B & $\mathrm{HI}$ & $2 \mathrm{H}$ & & \\
\hline 35.4 & 35 & 83 & 607 & $\mathrm{H} 1$ & $\begin{array}{l}\text { Slightly silty coarse to very fine } \\
\text { sand }\end{array}$ & $\mathrm{s}$ & Hfs_2W & $\mathrm{HI}$ & $2 \mathrm{H}$ & & \\
\hline 43.4 & 43 & 126 & 564 & $\mathrm{H} 2$ & $\begin{array}{l}\text { Slightly silty medium to very fine } \\
\text { sand to silty medium to very fine } \\
\text { sand }\end{array}$ & $\mathrm{s}$ & Hss_2W & $\mathrm{HI}$ & $2 \mathrm{H}$ & & \\
\hline 13.11 & 13 & 139 & 551 & Cold Creek Upper & Silty fine to very fine sand & SS & $\mathrm{PPlz}$ & II & 211 & & \\
\hline 14.8 & 15 & 154 & 536 & Cold Creek Lower & $\begin{array}{l}\text { Pebbly silty coarse to fine sand } \\
\text { to silty medium to very fine sand } \\
\text { with caliche }\end{array}$ & SS & PPlc & II & $2 \mathrm{I} 1$ & & \\
\hline 35.6 & 36 & 190 & 500 & Upper Ringold & Sand and silt deposits & SS & $\mathrm{PPIz}$ & II & 211 & & \\
\hline 91.8 & 93 & 283 & 407 & Ringold Unit E & $\begin{array}{l}\text { Silty Sandy Medium to fine } \\
\text { pebble to sandy very coarse to } \\
\text { fine pebble (semi-indurated) }\end{array}$ & SG2 & $\mathrm{Rg}_{2} 2 \mathrm{~W}$ & II & 212 & & \\
\hline & & 283 & 407 & Water Table & NA & NA & NA & NA & NA & & \\
\hline
\end{tabular}

\begin{tabular}{|c|c|c|c|c|c|c|c|c|c|c|}
\hline \multirow{3}{*}{$\begin{array}{l}\text { Template 266T-X } \\
\qquad \begin{array}{c}\begin{array}{c}\text { Average } \\
\text { Thickness } \\
\text { (ft) }\end{array} \\
\end{array}\end{array}$} & for deep inj & ection $\mathrm{s}$ & ites (e.g., re & verse wells [e.g., & $6-T-2 \&-3(a)])$ & \multirow[b]{2}{*}{$\begin{array}{l}\text { Hydraulic } \\
\text { Property } \\
\text { Type * }\end{array}$} & \multirow[b]{2}{*}{$\begin{array}{c}\text { SAC Soil } \\
\text { Type }\end{array}$} & \multirow[b]{2}{*}{$\mathrm{K}_{\mathrm{d}}$ Zone $^{\star \star}$} & \multirow{2}{*}{\begin{tabular}{|l}
$266 \mathrm{~T}-2$ \\
$K_{d}$ Class
\end{tabular}} & \multirow{2}{*}{$\begin{array}{l}266 \mathrm{~T}-4 \\
\mathrm{~K}_{\mathrm{d}} \text { Class }\end{array}$} \\
\hline & \begin{tabular}{|c|} 
Adjusted \\
Average \\
Thickness \\
(ft) \\
\end{tabular} & $\begin{array}{c}\begin{array}{c}\text { Depth } \\
\text { (ft) }\end{array} \\
\end{array}$ & $\begin{array}{c}\text { Elevation } \\
\text { (ft) }\end{array}$ & Geologic Unit & Description & & & & & \\
\hline & & 0 & 690 & Surface & NA & NA & NA & NA & NA & NA \\
\hline 2.5 & 2 & 2 & 688 & Eolian & Sand and silt & $\mathrm{s}$ & Hss & II & $2 \mathrm{II}$ & $4 ! 1$ \\
\hline 90 & 90 & 92 & 598 & Hanford Gravel & $\begin{array}{l}\text { Silty sandy medium to fine } \\
\text { pebble to slightly silty pebbly } \\
\text { very coarse to coarse sand. }\end{array}$ & SG1 & Hg_2W & II & 212 & 412 \\
\hline 35 & 35 & 127 & 563 & $\begin{array}{l}\text { Hanford Gravelly } \\
\text { Sand }\end{array}$ & $\begin{array}{l}\text { Pebbly very coarse to medium } \\
\text { sand to slightly silty very coarse } \\
\text { to medium sand }\end{array}$ & GS & Hgs_2W & II & $2 \mid 1$ & $4 I 1$ \\
\hline 10 & 10 & 137 & 553 & $\begin{array}{l}\text { Old Hanford/Cold } \\
\text { Creek Silt ("Early } \\
\text { Palouse") }\end{array}$ & $\begin{array}{l}\text { Silty fine to very fine sand to } \\
\text { slightly silty fine to very fine sand }\end{array}$ & SS & PPlz & II & $2 \mid 1$ & $4 I 1$ \\
\hline 18 & 18 & 155 & 535 & $\begin{array}{l}\text { Cold Creek } \\
\text { Carbonate }\end{array}$ & $\begin{array}{l}\text { Pebbly silty coarse to fine sand } \\
\text { to silty medium to very fine sand } \\
\text { with caliche }\end{array}$ & ss & PPlc & II & $2 \mid 1$ & $4 \mid 1$ \\
\hline 25 & 25 & 180 & 510 & Upper Ringold & $\begin{array}{l}\text { silty fine to very fine sand to silty } \\
\text { medium to very fine sand (semi- } \\
\text { indurated) }\end{array}$ & $\mathrm{S}$ & $\mathrm{PPlz}$ & $\mathrm{HI}$ & $2 \mathrm{H}$ & $4 \mathrm{H}$ \\
\hline & 103 & 283 & 407 & Ringold Unit E & $\begin{array}{l}\text { Silty Sandy Medium to fine } \\
\text { pebble to sandy very coarse to } \\
\text { fine pebble (semi-indurated) }\end{array}$ & $\mathrm{SG} 2$ & $\mathrm{Rg}_{2} 2 \mathrm{~W}$ & $\mathrm{HI}$ & $2 \mathrm{H}$ & $4 \mathrm{H}$ \\
\hline & & 283 & 407 & Water Table & NA & NA & NA & $\mathrm{NA}$ & NA & NA \\
\hline
\end{tabular}

* After Khaleel and Freeman (1995), per white paper by Khaleel (September 2000).

** $\mathrm{HI}=$ high impact, II=Intermediate Impact (after Kincaid et al. 1998).

BLUE = Injection/release point.

(a) Note: Injection well 216-T-2 is $75 \mathrm{ft}$ deep. Well 216-T-3 is reported as $206 \mathrm{ft}$. Screened interval is unknown -- will assume $25 \mathrm{ft}$ screened interval. 


\section{References}

BHI. 1998. Hanford Site Atlas. BHI-01119, Rev. 2, Bechtel Hanford Inc., Richland, Washington.

Chamness MA and JK Merz. 2003. Hanford Wells. PNL-8800, Pacific Northwest National Laboratory, Richland, Washington.

DOE. 1987. Final Environmental Impact Statement, Disposal of Hanford Defense High-Level, Transuranic and Tank Wastes, Hanford Site, Richland, Washington. DOE/EIS-0113, Volumes 1-5, U.S. Department of Energy, Washington, D.C.

DOE. 1993. Limited Field Investigation Report for the 100-HR-3 Operable Unit. DOE/RL-93-34, U.S. Department of Energy, Richland, Washington.

Fecht KR and DC Weekes. 1996. Geologic Field Investigation of the Sedimentary Sequence at the Environmental Restoration Disposal Facility. BHI-00230, Bechtel Hanford, Inc., Richland, Washington.

Hartman MJ. 1999. Hanford Site Groundwater Monitoring for Fiscal Year 1998. PNNL-12086, Pacific Northwest National Laboratory, Richland, Washington.

Hartman MJ and P Dresel. 1998. Hanford Site Groundwater Monitoring for Fiscal Year 1997. PNNL-11793, Pacific Northwest National Laboratory, Richland, Washington.

Hartman MJ and KA Lindsey. 1993. Hydrogeology of the 100-N Area, Hanford Site, Washington. WHC-SD-EN-EV-027, Westinghouse Hanford Company, Richland, Washington.

Hartman MJ, LF Morasch, and WD Webber (eds). 2000. Hanford Site Groundwater Monitoring for Fiscal Year 1999. PNNL-13116, Pacific Northwest National Laboratory, Richland, Washington.

Khaleel R and EJ Freeman. 1995. Variability and Scaling of Hydraulic Properties for 200 Area Soils, Hanford Site. WHC-EP-0883, Westinghouse Hanford Company, Richland, Washington.

Kincaid CT, MP Bergeron, CR Cole, MD Freshley, NL Hassig, VG Johnson, DI Kaplan, RJ Serne, GP Streile, DL Strenge, PD Thorne, LW Vail, GA Whyatt, and SK Wurstner. 1998. Composite Analysis for Low-Level Waste Disposal in the 200 Area Plateau of the Hanford Site. PNNL-11800, Pacific Northwest National Laboratory, Richland, Washington.

Kipp KL and RD Mudd. 1974. Selected Water Table Contour Maps and Well Hydrographs for the Hanford Reservation, 1944-1973. BNWL-B-360, Pacific Northwest Laboratory, Richland, Washington.

Lindberg JW. 1995. Hydrogeology of the 100-K Area, Hanford Site, South-Central Washington. WHC-SD-EN-TI-294, Westinghouse Hanford Company, Richland, Washington.

Lindsey KA and DR Gaylord. 1990. "Lithofacies and Sedimentology of the Miocene-Pliocene Ringold Formation, Hanford Site, South-Central Washington.” Northwest Sci. 4:165-180.

Lindsey KA. 1991. Revised Stratigraphy for the Ringold Formation, Hanford Site, South-Central Washington. WHC-SD-EN-EE-004, Westinghouse Hanford Company, Richland, Washington. 
Maxfield HL. 1979. Handbook - 200 Areas Waste Sites. RHO-CD-673, Volumes I, II, and III, Rockwell Hanford Operations, Richland, Washington.

Peterson RE, RF Raidl, and CW Denslow. 1996. Conceptual Site Models for Groundwater Contamination at the 100-BC-5, 100-KR-4, 100-HR-3, and 100-FR-3 Operable Units. BHI-00917, Bechtel Hanford Company, Richland, Washington.

Raidl RF. 1994. Geology of the 100-FR-3 Operable Unit, Hanford Site, South-Central Washington. WHC-SD-EN-TI-221, Westinghouse Hanford Company, Richland, Washington.

Reidel SP. 2004. Geologic Data Package for 2005 Integrated Disposal Facility Waste Performance Assessment. PNNL-14586, Pacific Northwest National Laboratory, Richland, Washington.

Reidel SP and AM Ho. 2002. Geologic and Wireline Summaries from Fiscal Year 2002 ILAW Boreholes. PNNL-14029, Pacific Northwest National Laboratory, Richland, Washington.

Reidel SP, DG Horton, and MM Valenta. 2001. Geologic and Wireline Borehole Summary from the Second ILAW Borehole (299-E24-21). PNNL-13652, Pacific Northwest National Laboratory, Richland, Washington.

Reidel, SP, KD Reynolds, and DG Horton. 1998. Immobilized Low-Activity Waste Site Borehole 299-E17-21. PNNL-11957, Pacific Northwest National Laboratory, Richland, Washington.

Reidel SP, DG Horton, Y Chien, DB Barnett, and K Singleton. 2006. Geology, Hydrogeology, Geochemistry, and Mineralogy Data Package for the Single-Shell Tank Waste Management Areas at the Hanford Site. RPP-23748, Rev. 0, CH2M HILL Hanford Group, Inc., Richland, Washington.

Schalla R, RW Wallace, RL Aaberg, SP Airhart, DJ Bastes, JVM Carlile, CS Cline, DI Dennison, MD Freshley, PR Heller, EJ Jensen, KB Olsen, RG Parkhurst, JT Rieger, and EJ Westergard. 1988. Interim Characterization Report for the 300 Area Process Trenches. PNL-6716, Pacific Northwest Laboratory, Richland, Washington.

Weekes, DC, BH Ford, and GK Jaeger. 1996. Preoperational Baseline and Site Characterization Report for the Environmental Restoration Disposal Facility. BHI-00270, Rev. 1, Bechtel Hanford, Inc., Richland, Washington. 


\section{Appendix B}

\section{Hydraulic Property Distributions}




\section{Appendix B}

\section{Hydraulic Property Distributions}

Table B.1. Approximation for the Distribution Function for Soil Type "B" (backfill) Based on Khaleel and Freeman (1995) Soil Category SSG (sand and gravel mixed with finer fraction)

\begin{tabular}{|c|c|c|c|c|c|c|c|c|c|c|c|c|}
\hline B & \multirow{2}{*}{$\begin{array}{c}\text { Number } \\
\text { of } \\
\text { Samples }\end{array}$} & \multicolumn{4}{|c|}{ Raw } & \multirow[b]{2}{*}{$\begin{array}{c}\text { Transform } \\
\dagger \\
\end{array}$} & \multicolumn{4}{|c|}{ Transformed (normal distribution) } & \multicolumn{2}{|c|}{$\begin{array}{c}\text { Observed Data } \\
\text { Range Truncation } \\
\text { Limits } \\
\end{array}$} \\
\hline Parameter & & Low & High & Mean & $\begin{array}{l}\text { Standard } \\
\text { Deviation }\end{array}$ & & Upper Limit & Lower Limit & Mean & $\begin{array}{l}\text { Standard } \\
\text { Deviation }\end{array}$ & Lower & Upper \\
\hline qs & 6 & 0.187 & 0.375 & 0.262 & 0.072 & NO & & & & & 0.151 & 0.942 \\
\hline$q_{R}$ & 6 & 0.000 & 0.064 & 0.030 & 0.029 & NO & & & & & 0.146 & 0.879 \\
\hline$s_{r}$ & 6 & 0.000 & 0.213 & 0.103 & 0.098 & NO & & & & & 0.146 & 0.869 \\
\hline $\mathrm{a}(1 / \mathrm{cm})$ & 6 & 0.003 & 0.103 & 0.019 & 0.036 & LN & -2.276 & -5.843 & -3.957 & 1.166 & 0.053 & 0.925 \\
\hline$n$ & 6 & 1.256 & 1.629 & 1.400 & 0.131 & $\mathrm{NO}$ & & & & & 0.134 & 0.960 \\
\hline $\mathrm{K}_{\mathrm{s}}(\mathrm{cm} / \mathrm{s})$ & 6 & 2.76E-05 & 6.80E-02 & 5.98E-04 & 2.73E-02 & LN & -2.688 & -10.498 & -7.421 & 3.359 & 0.180 & 0.921 \\
\hline $\begin{array}{l}\text { Longitudinal } \\
\text { Dispersivity }^{1}(\mathrm{~m})\end{array}$ & NA & 0.0270 & 0.178 & 0.09 & $\mathrm{NA}$ & UN & - & - & - & & & \\
\hline$\%$ Gravel & & & & & & & & & & & & \\
\hline $\begin{array}{l}\text { Bulk Density } \\
\left(\mathrm{g} / \mathrm{cm}^{3}\right)\end{array}$ & NA & - & - & 1.94 & & $\mathrm{CO}$ & - & - & - & & & \\
\hline
\end{tabular}

†NO = Normal (no transformation required); LN = Lognormal; LR = Log ratio; SN = Hyperbolic arcsine; UN = Uniform; CO = Constant; BE = Beta.

${ }^{1}$ Taken from Ho et al. (1999).

Table B.2. Approximation for the Distribution Function for Soil Type "Hss" (Hanford silty fine sand) Modified from Khaleel and Freeman (1995) Soil Category SS (sand mixed with finer fraction)

\begin{tabular}{|c|c|c|c|c|c|c|c|c|c|c|c|c|}
\hline Hss & \multirow{2}{*}{$\begin{array}{c}\text { Number } \\
\text { of } \\
\text { Samples }\end{array}$} & \multicolumn{4}{|c|}{ Raw } & \multirow[b]{2}{*}{$\begin{array}{c}\text { Transform } \\
\dagger\end{array}$} & \multicolumn{4}{|c|}{ Transformed (normal distribution) } & \multicolumn{2}{|c|}{$\begin{array}{c}\text { Observed Data } \\
\text { Range Truncation } \\
\text { Limits }\end{array}$} \\
\hline Parameter & & Low & High & Mean & $\begin{array}{l}\text { Standard } \\
\text { Deviation }\end{array}$ & & Upper Limit L & Lower Limit & Mean & $\begin{array}{l}\text { Standard } \\
\text { Deviation }\end{array}$ & Lower & Upper \\
\hline$q_{s}$ & 38 & 0.321 & 0.587 & 0.445 & 0.060 & NO & & & & & 0.019 & 0.991 \\
\hline$q_{R}$ & 38 & 0.019 & 0.181 & 0.072 & 0.033 & NO & & & & & 0.053 & 1.000 \\
\hline$s_{r}$ & 38 & 0.047 & 0.339 & 0.159 & 0.059 & NO & & & & & 0.030 & 0.999 \\
\hline $\mathrm{a}(1 / \mathrm{cm})$ & 38 & 0.001 & 0.387 & 0.008 & 0.076 & LN & -0.949 & -7.131 & -4.866 & 1.212 & 0.031 & 0.999 \\
\hline$n$ & 38 & 1.262 & 3.265 & 1.915 & 0.461 & NO & & & & & 0.078 & 0.998 \\
\hline $\mathrm{K}_{\mathrm{s}}(\mathrm{cm} / \mathrm{s})$ & 30 & 3.20E-07 & 8.88E-04 & 8.58E-05 & 2.66E-04 & LN & -7.027 & -14.955 & -9.363 & 1.885 & 0.002 & 0.892 \\
\hline $\begin{array}{l}\text { Longitudinal } \\
\text { Dispersivity }^{1}(\mathrm{~m})\end{array}$ & NA & 0.0279 & 0.0341 & 0.031 & NA & UN & - & - & - & & & \\
\hline$\%$ Gravel & 38 & 0 & 2 & 0.18 & 0.51 & & & & & & & \\
\hline $\begin{array}{l}\text { Bulk Density } \\
\left(\mathrm{g} / \mathrm{cm}^{3}\right)\end{array}$ & 35 & 1.28 & 2.13 & 1.61 & 0.17 & NO & - & - & - & & & \\
\hline
\end{tabular}

†NO = Normal (no transformation required); LN = Lognormal; LR = Log ratio; SN = Hyperbolic arcsine; UN = Uniform; CO = Constant; BE = Beta.

${ }^{1}$ Taken from Ho et al. (1999). 
Table B.3. Approximation for the Distribution Function for Soil Type "Hss_2W" (Hanford silty fine sand - 200 West Area) Modified from Khaleel and Freeman (1995) Soil Category SS (sand mixed with finer fraction)

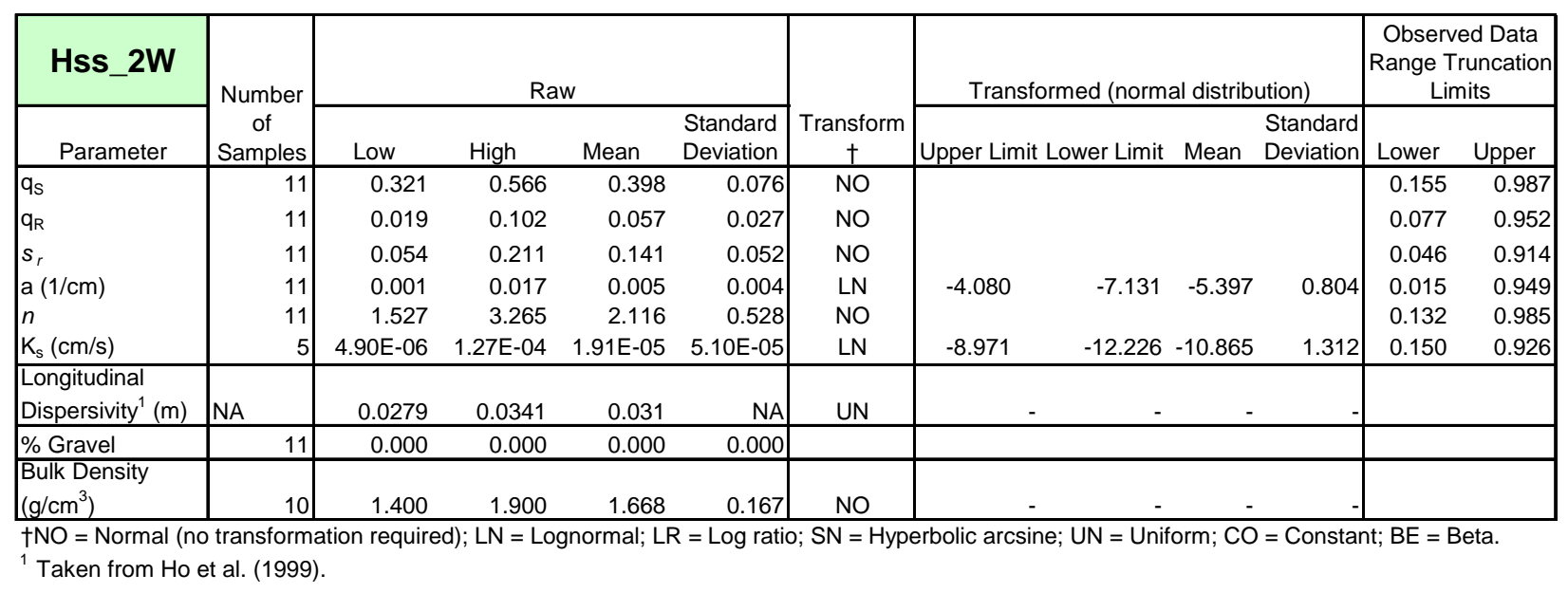

Table B.4. Approximation for the Distribution function for soil type "Hss_U" (Hanford silty fine sand 200-UP-1) Modified from Khaleel and Freeman (1995) Soil Category SS (sand mixed with finer fraction)

\begin{tabular}{|c|c|c|c|c|c|c|c|c|c|c|c|c|}
\hline \multirow{2}{*}{$\begin{array}{l}\text { Hss_U } \\
\text { Parameter }\end{array}$} & \multirow{2}{*}{$\begin{array}{c}\text { Number } \\
\text { of } \\
\text { Samples }\end{array}$} & \multicolumn{4}{|c|}{ Raw } & \multirow[b]{2}{*}{$\begin{array}{c}\text { Transform } \\
\dagger\end{array}$} & \multicolumn{4}{|c|}{ Transformed (normal distribution) } & \multicolumn{2}{|c|}{$\begin{array}{c}\text { Observed Data } \\
\text { Range Truncation } \\
\text { Limits }\end{array}$} \\
\hline & & Low & High & Mean & $\begin{array}{l}\text { Standard } \\
\text { Deviation }\end{array}$ & & Upper Limit L & Lower Limit & Mean & $\begin{array}{l}\text { Standard } \\
\text { Deviation }\end{array}$ & Lower & Upper \\
\hline$q_{s}$ & 6 & 0.353 & 0.566 & 0.437 & 0.078 & NO & & & & & 0.140 & 0.952 \\
\hline$q_{R}$ & 6 & 0.019 & 0.102 & 0.066 & 0.033 & NO & & & & & 0.074 & 0.866 \\
\hline$s_{r}$ & 6 & 0.054 & 0.211 & 0.147 & 0.064 & NO & & & & & 0.071 & 0.841 \\
\hline $\mathrm{a}(1 / \mathrm{cm})$ & 6 & 0.003 & 0.017 & 0.007 & 0.005 & LN & -4.080 & -5.843 & -4.994 & 0.596 & 0.077 & 0.937 \\
\hline$n$ & 6 & 1.527 & 3.265 & 2.347 & 0.597 & NO & & & & & 0.085 & 0.938 \\
\hline $\mathrm{K}_{\mathrm{s}}(\mathrm{cm} / \mathrm{s})$ & 2 & $4.90 \mathrm{E}-06$ & 1.27E-04 & 2.49E-05 & 8.63E-05 & LN & -8.971 & -12.226 & -10.599 & 2.302 & 0.240 & 0.760 \\
\hline \begin{tabular}{|l|} 
Longitudinal \\
Dispersivity $^{1}(\mathrm{~m})$
\end{tabular} & NA & 0.0279 & 0.0341 & 0.031 & $\mathrm{NA}$ & UN & - & - & - & & & \\
\hline \% Gravel & 6 & 0 & 0 & 0 & 0 & & & & & & & \\
\hline \begin{tabular}{|l} 
Bulk Density \\
$\left(\mathrm{g} / \mathrm{cm}^{3}\right)$
\end{tabular} & 6 & 1.4 & 1.72 & 1.58 & 0.13 & NO & - & - & - & & & \\
\hline
\end{tabular}

†NO = Normal (no transformation required); LN = Lognormal; LR = Log ratio; SN = Hyperbolic arcsine; UN = Uniform; CO = Constant; BE = Beta.

${ }^{1}$ Taken from Ho et al. (1999). 
Table B.5. Approximation for the Distribution Function for Soil Type "Hss_Z" (Hanford silty fine sand 200-ZP-1) Modified from Khaleel and Freeman (1995) Soil Category SS (sand mixed with finer fraction)

\begin{tabular}{|c|c|c|c|c|c|c|c|c|c|c|c|}
\hline \multirow{2}{*}{$\begin{array}{l}\text { Hss_Z } \\
\text { Parameter }\end{array}$} & \multirow{2}{*}{$\begin{array}{c}\text { Number } \\
\text { of } \\
\text { Samples }\end{array}$} & \multicolumn{4}{|c|}{ Raw } & \multirow[b]{2}{*}{$\begin{array}{c}\text { Transform } \\
\dagger \\
\end{array}$} & \multicolumn{3}{|c|}{ Transformed (normal distribution) } & \multicolumn{2}{|c|}{$\begin{array}{c}\text { Observed Data } \\
\text { Range Truncation } \\
\text { Limits }\end{array}$} \\
\hline & & Low & High & Mean & $\begin{array}{l}\text { Standard } \\
\text { Deviation }\end{array}$ & & Upper Limit Lower Limit & Mean & $\begin{array}{l}\text { Standard } \\
\text { Deviation }\end{array}$ & Lower & Upper \\
\hline$q_{s}$ & 5 & 0.321 & 0.413 & 0.351 & 0.040 & NO & & & & 0.229 & 0.941 \\
\hline$q_{R}$ & 5 & 0.030 & 0.060 & 0.047 & 0.015 & NO & & & & 0.136 & 0.799 \\
\hline$s_{r}$ & 5 & 0.093 & 0.178 & 0.133 & 0.038 & NO & & & & 0.150 & 0.886 \\
\hline $\mathrm{a}(1 / \mathrm{cm})$ & 5 & 0.001 & 0.006 & 0.003 & 0.002 & LN & -7.131 & -5.880 & 0.797 & 0.058 & 0.851 \\
\hline$n$ & 5 & 1.638 & 2.259 & 1.840 & 0.274 & NO & & & & 0.230 & 0.937 \\
\hline $\mathrm{K}_{\mathrm{s}}(\mathrm{cm} / \mathrm{s})$ & 1 & $6.55 \mathrm{E}-06$ & $6.55 \mathrm{E}-06$ & $6.55 \mathrm{E}-06$ & $0.00 \mathrm{E}+00$ & $\mathrm{CO}$ & & & & & \\
\hline \begin{tabular}{|l} 
Longitudinal \\
Dispersivity $^{1}(\mathrm{~m})$
\end{tabular} & NA & 0.0279 & 0.0341 & 0.031 & NA & UN & - & - & - & & \\
\hline$\%$ Gravel & 5 & 0 & 0 & 0 & 0 & & & & & & \\
\hline $\begin{array}{l}\text { Bulk Density } \\
\left(\mathrm{g} / \mathrm{cm}^{3}\right)\end{array}$ & 4 & 1.61 & 1.9 & 1.8 & 0.130 & NO & - & - & & & \\
\hline $\begin{array}{l}\text { Particle Density } \\
\left(\mathrm{g} / \mathrm{cm}^{3}\right)\end{array}$ & & & & & & $\mathrm{NO}$ & & & & & \\
\hline
\end{tabular}

Table B.6. Approximation for the Distribution Function for Soil Type "Hfs" (Hanford fine sand) Modified from Khaleel and Freeman (1995) Soil Category S (sand)

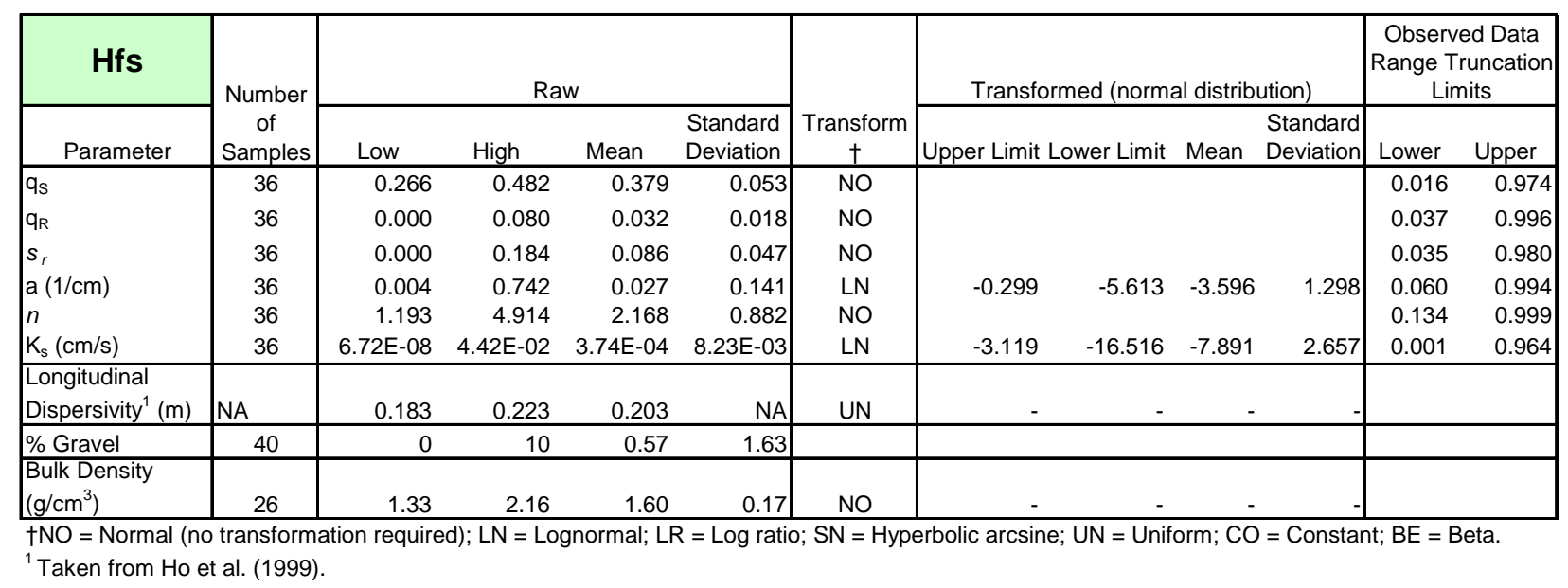


Table B.7. Approximation for the Distribution Function for soil type "Hfs_BC" (Hanford fine sand BC cribs and trenches) Modified from Khaleel and Freeman (1995) Soil Category S (sand)

\begin{tabular}{|c|c|c|c|c|c|c|c|c|c|c|c|c|}
\hline \multirow{2}{*}{$\begin{array}{l}\text { Hfs_BC } \\
\text { Parameter }\end{array}$} & \multirow{2}{*}{$\begin{array}{c}\text { Number } \\
\text { of } \\
\text { Samples }\end{array}$} & \multicolumn{4}{|c|}{ Raw } & \multirow[b]{2}{*}{$\begin{array}{c}\text { Transform } \\
\dagger\end{array}$} & \multicolumn{4}{|c|}{ Transformed (normal distribution) } & \multicolumn{2}{|c|}{\begin{tabular}{|c|} 
Observed Data \\
Range Truncation \\
Limits \\
\end{tabular}} \\
\hline & & Low & High & Mean & $\begin{array}{l}\text { Standard } \\
\text { Deviation } \\
\end{array}$ & & Upper Limit & Lower Limit & Mean & $\begin{array}{l}\text { Standard } \\
\text { Deviation }\end{array}$ & Lower & Upper \\
\hline$q_{s}$ & 18 & 0.323 & 0.444 & 0.380 & 0.040 & NO & & & & & 0.081 & 0.945 \\
\hline$q_{R}$ & 18 & 0.016 & 0.061 & 0.033 & 0.011 & NO & & & & & 0.065 & 0.992 \\
\hline$s_{r}$ & 18 & 0.045 & 0.184 & 0.089 & 0.035 & NO & & & & & 0.102 & 0.997 \\
\hline $\mathrm{a}(1 / \mathrm{cm})$ & 18 & 0.005 & 0.201 & 0.021 & 0.045 & LN & -1.604 & -5.279 & -3.874 & 0.889 & 0.057 & 0.995 \\
\hline$n$ & 18 & 1.542 & 4.914 & 2.507 & 1.036 & NO & & & & & 0.176 & 0.990 \\
\hline $\mathrm{K}_{\mathrm{s}}(\mathrm{cm} / \mathrm{s})$ & 18 & 1.40E-04 & 4.42E-02 & $2.25 \mathrm{E}-03$ & 1.09E-02 & LN & -3.119 & -8.874 & -6.097 & 1.563 & 0.038 & 0.972 \\
\hline $\begin{array}{l}\text { Longitudinal } \\
\text { Dispersivity }^{1}(\mathrm{~m}) \\
\end{array}$ & NA & 0.183 & 0.223 & 0.203 & $\mathrm{NA}$ & UN & - & - & - & & & \\
\hline$\%$ Gravel & 18 & 0 & 2 & 0.38 & 0.57 & & & & & & & \\
\hline $\begin{array}{l}\text { Bulk Density } \\
\left(\mathrm{g} / \mathrm{cm}^{3}\right)\end{array}$ & 8 & 1.52 & 1.79 & 1.65 & 0.10 & NO & - & - & - & & & \\
\hline
\end{tabular}

†NO = Normal (no transformation required); LN = Lognormal; LR = Log ratio; SN = Hyperbolic arcsine; UN = Uniform; CO = Constant; $\mathrm{BE}=$ Beta.

${ }^{1}$ Taken from Ho et al. (1999).

Table B.8. Approximation for the Distribution Function for soil type "Hfs_2W" (Hanford fine sand200 West Area) Modified from Khaleel and Freeman (1995) Soil Category S (sand)

\begin{tabular}{|c|c|c|c|c|c|c|c|c|c|c|c|}
\hline \multirow{2}{*}{$\begin{array}{c}\text { Hfs_2W } \\
\text { Parameter }\end{array}$} & \multirow{2}{*}{$\begin{array}{c}\text { Number } \\
\text { of } \\
\text { Samples }\end{array}$} & \multicolumn{4}{|c|}{ Raw } & \multirow[b]{2}{*}{$\begin{array}{c}\text { Transform } \\
\dagger\end{array}$} & \multicolumn{3}{|c|}{ Transformed (normal distribution) } & \multicolumn{2}{|c|}{\begin{tabular}{|c|} 
Observed Data \\
Range Truncation \\
Limits \\
\end{tabular}} \\
\hline & & Low & High & Mean & $\begin{array}{l}\text { Standard } \\
\text { Deviation } \\
\end{array}$ & & Upper Limit Lower Limit & Mean & $\begin{array}{l}\text { Standard } \\
\text { Deviation }\end{array}$ & Lower & Upper \\
\hline$q_{s}$ & 8 & 0.325 & 0.433 & 0.356 & 0.035 & NO & & & & 0.188 & 0.986 \\
\hline$q_{R}$ & 8 & 0.027 & 0.058 & 0.042 & 0.014 & NO & & & & 0.143 & 0.869 \\
\hline$s_{r}$ & 8 & 0.074 & 0.167 & 0.118 & 0.040 & NO & & & & 0.142 & 0.889 \\
\hline $\mathrm{a}(1 / \mathrm{cm})$ & 8 & 0.004 & 0.026 & 0.010 & 0.008 & LN & -3.646 & -4.584 & 0.704 & 0.072 & 0.909 \\
\hline$n$ & 8 & 1.574 & 3.294 & 2.177 & 0.546 & NO & & & & 0.135 & 0.980 \\
\hline $\mathrm{K}_{\mathrm{s}}(\mathrm{cm} / \mathrm{s})$ & 8 & 6.72E-08 & 4.62E-04 & 3.67E-05 & 1.76E-04 & LN & -16.516 & -10.212 & 2.808 & 0.012 & 0.816 \\
\hline $\begin{array}{l}\text { Longitudinal } \\
\text { Dispersivity }^{1}(\mathrm{~m})\end{array}$ & NA & 0.183 & 0.223 & 0.203 & $\mathrm{NA}$ & UN & - & - & & & \\
\hline$\%$ Gravel & 8 & 0 & 2 & 0.38 & 0.74 & & & & & & \\
\hline $\begin{array}{l}\text { Bulk Density } \\
\left(\mathrm{g} / \mathrm{cm}^{3}\right)\end{array}$ & 7 & 1.58 & 1.82 & 1.70 & 0.10 & NO & - & - & & & \\
\hline $\begin{array}{l}\text { Particle Density } \\
\left(\mathrm{g} / \mathrm{cm}^{3}\right)\end{array}$ & & & & & & NO & & & & & \\
\hline
\end{tabular}


Table B.9. Approximation for the Distribution Function for Soil Type "Hfs_U" (Hanford fine sand 200-UP-1) Modified from Khaleel and Freeman (1995) Soil Category S (sand)

\begin{tabular}{|c|c|c|c|c|c|c|c|c|c|c|c|c|}
\hline \multirow{2}{*}{$\begin{array}{l}\text { Hfs_U } \\
\text { Parameter }\end{array}$} & \multirow{2}{*}{$\begin{array}{c}\text { Number } \\
\text { of } \\
\text { Samples }\end{array}$} & \multicolumn{4}{|c|}{ Raw } & \multirow[b]{2}{*}{$\begin{array}{c}\text { Transform } \\
\dagger \\
\end{array}$} & \multicolumn{4}{|c|}{ Transformed (normal distribution) } & \multicolumn{2}{|c|}{$\begin{array}{c}\text { Observed Data } \\
\text { Range Truncation } \\
\text { Limits }\end{array}$} \\
\hline & & Low & High & Mean & $\begin{array}{l}\text { Standard } \\
\text { Deviation }\end{array}$ & & Upper Limit & Lower Limit & Mean & $\begin{array}{l}\text { Standard } \\
\text { Deviation }\end{array}$ & Lower & Upper \\
\hline$q_{s}$ & 4 & 0.325 & 0.374 & 0.347 & 0.021 & NO & & & & & 0.150 & 0.902 \\
\hline$q_{R}$ & 4 & 0.028 & 0.057 & 0.042 & 0.015 & NO & & & & & 0.173 & 0.837 \\
\hline$S_{r}$ & 4 & 0.074 & 0.163 & 0.122 & 0.047 & NO & & & & & 0.153 & 0.809 \\
\hline $\mathrm{a}(1 / \mathrm{cm})$ & 4 & 0.004 & 0.026 & 0.013 & 0.010 & LN & -3.646 & -5.613 & -4.380 & 0.888 & 0.082 & 0.796 \\
\hline$n$ & 4 & 1.673 & 3.294 & 2.451 & 0.663 & NO & & & & & 0.120 & 0.898 \\
\hline $\mathrm{K}_{\mathrm{s}}(\mathrm{cm} / \mathrm{s})$ & 4 & $6.72 \mathrm{E}-08$ & 4.62E-04 & 1.71E-05 & 2.15E-04 & LN & -7.680 & -16.516 & -10.975 & 3.841 & 0.075 & 0.805 \\
\hline $\begin{array}{l}\text { Longitudinal } \\
\text { Dispersivity }^{1}(\mathrm{~m})\end{array}$ & NA & 0.183 & 0.223 & 0.203 & NA & UN & - & - & - & t & & \\
\hline$\%$ Gravel & 4 & 0 & 0 & 0 & 0 & & & & & & & \\
\hline $\begin{array}{l}\text { Bulk Density } \\
\left(\mathrm{g} / \mathrm{cm}^{3}\right)\end{array}$ & 4 & 1.58 & 1.82 & 1.72 & 0.12 & NO & - & - & - & & & \\
\hline
\end{tabular}

†NO = Normal (no transformation required); LN = Lognormal; LR = Log ratio; SN = Hyperbolic arcsine; UN = Uniform; CO = Constant; BE = Beta.

${ }^{1}$ Taken from Ho et al. (1999).

Table B.10. Approximation for the Distribution Function for Soil Type "Hfs_Z" (Hanford fine sand 200-ZP-1) Modified from Khaleel and Freeman (1995) Soil Category S (sand)

\begin{tabular}{|c|c|c|c|c|c|c|c|c|c|c|c|c|}
\hline \multirow{2}{*}{$\begin{array}{c}\text { Hfs_Z } \\
\text { Parameter } \\
\end{array}$} & \multirow{2}{*}{$\begin{array}{c}\begin{array}{c}\text { Number } \\
\text { of } \\
\text { Samples }\end{array} \\
\end{array}$} & \multicolumn{4}{|c|}{ Raw } & \multirow[b]{2}{*}{$\begin{array}{c}\text { Transform } \\
\dagger \\
\end{array}$} & \multicolumn{4}{|c|}{ Transformed (normal distribution) } & \multicolumn{2}{|c|}{$\begin{array}{c}\text { Observed Data } \\
\text { Range Truncation } \\
\text { Limits }\end{array}$} \\
\hline & & Low & High & Mean & $\begin{array}{l}\text { Standard } \\
\text { Deviation }\end{array}$ & & Upper Limit L & Lower Limit & Mean & $\begin{array}{c}\text { Standard } \\
\text { Deviation }\end{array}$ & Lower & Upper \\
\hline$q_{s}$ & 4 & 0.326 & 0.433 & 0.366 & 0.047 & NO & & & & & 0.199 & 0.925 \\
\hline$q_{R}$ & 4 & 0.027 & 0.058 & 0.042 & 0.015 & NO & & & & & 0.169 & 0.850 \\
\hline$s_{r}$ & 4 & 0.082 & 0.167 & 0.113 & 0.040 & NO & & & & & 0.218 & 0.911 \\
\hline $\mathrm{a}(1 / \mathrm{cm})$ & 4 & 0.004 & 0.013 & 0.008 & 0.004 & LN & -4.358 & -5.521 & -4.788 & 0.508 & 0.074 & 0.802 \\
\hline$n$ & 4 & 1.574 & 2.086 & 1.903 & 0.238 & NO & & & & & 0.083 & 0.779 \\
\hline $\mathrm{K}_{\mathrm{s}}(\mathrm{cm} / \mathrm{s})$ & 4 & 1.38E-05 & 3.70E-04 & 7.88E-05 & $1.61 \mathrm{E}-04$ & LN & -7.902 & -11.191 & -9.449 & 1.446 & 0.114 & 0.858 \\
\hline $\begin{array}{l}\text { Longitudinal } \\
\text { Dispersivity }^{1}(\mathrm{~m})\end{array}$ & NA & 0.183 & 0.223 & 0.203 & NA & UN & - & - & 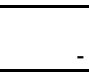 & r & & \\
\hline$\%$ Gravel & 4 & 0 & 2 & 0.75 & 0.96 & $\mathrm{NO}$ & & & & & & \\
\hline $\begin{array}{l}\text { Bulk Density } \\
\left(\mathrm{g} / \mathrm{cm}^{3}\right)\end{array}$ & 4 & 1.59 & 1.76 & 1.68 & 0.09 & NO & - & - & - & - & & \\
\hline
\end{tabular}

†NO = Normal (no transformation required); LN = Lognormal; LR = Log ratio; SN = Hyperbolic arcsine; UN = Uniform; CO = Constant; BE = Beta.

${ }^{1}$ Taken from Ho et al. (1999). 
Table B.11. Approximation for the Distribution Function for Soil Type "Hcs" (Hanford coarse sand) Modified from Khaleel and Freeman (1995) Soil Category S (sand)

\begin{tabular}{|c|c|c|c|c|c|c|c|c|c|c|c|c|}
\hline Hcs & \multirow{2}{*}{$\begin{array}{c}\text { Number } \\
\text { of } \\
\text { Samples }\end{array}$} & \multicolumn{4}{|c|}{ Raw } & \multirow[b]{2}{*}{$\begin{array}{c}\text { Transform } \\
\dagger\end{array}$} & \multicolumn{4}{|c|}{ Transformed (normal distribution) } & \multicolumn{2}{|c|}{$\begin{array}{c}\text { Observed Data } \\
\text { Range Truncation } \\
\text { Limits }\end{array}$} \\
\hline Parameter & & Low & High & Mean & $\begin{array}{l}\text { Standard } \\
\text { Deviation }\end{array}$ & & Upper Limit & Lower Limit & Mean & $\begin{array}{l}\text { Standard } \\
\text { Deviation }\end{array}$ & Lower & Upper \\
\hline$q_{s}$ & 81 & 0.197 & 0.519 & 0.349 & 0.070 & NO & & & & & 0.015 & 0.992 \\
\hline$q_{R}$ & 81 & 0.000 & 0.103 & 0.027 & 0.017 & NO & & & & & 0.056 & 1.000 \\
\hline$s_{r}$ & 81 & 0.000 & 0.246 & 0.080 & 0.047 & NO & & & & & 0.044 & 1.000 \\
\hline $\mathrm{a}(1 / \mathrm{cm})$ & 81 & 0.006 & 0.861 & 0.061 & 0.133 & LN & -0.149 & -5.116 & -2.797 & 0.996 & 0.010 & 0.996 \\
\hline$n$ & 81 & 1.266 & 5.000 & 2.031 & 0.687 & NO & & & & & 0.133 & 1.000 \\
\hline $\mathrm{K}_{\mathrm{s}}(\mathrm{cm} / \mathrm{s})$ & 80 & 2.100E-05 & 5.800E-02 & $2.270 \mathrm{E}-03$ & $1.200 \mathrm{E}-02$ & LN & -2.847 & -10.771 & -6.088 & 1.721 & 0.003 & 0.970 \\
\hline $\begin{array}{l}\text { Longitudinal } \\
\text { Dispersivity }^{1}(\mathrm{~m})\end{array}$ & NA & 0.183 & 0.223 & 0.203 & NA & UN & - & - & - & - & & \\
\hline$\%$ Gravel & 82 & 0.00 & 31.90 & 2.55 & 4.56 & & & & & & & \\
\hline $\begin{array}{l}\text { Bulk Density } \\
\left(\mathrm{g} / \mathrm{cm}^{3}\right)\end{array}$ & 68 & 1.51 & 2.02 & 1.67 & 0.10 & $\mathrm{NO}$ & - & - & - & & & \\
\hline
\end{tabular}

†NO = Normal (no transformation required); LN = Lognormal; LR = Log ratio; SN = Hyperbolic arcsine; UN = Uniform; CO = Constant; BE = Beta.

${ }^{1}$ Taken from Ho et al. (1999).

Table B.12. Approximation for the Distribution Function for Soil Type "Hcs_BC" (Hanford coarse sand - BC crib and trench area) Modified from Khaleel and Freeman (1995) Soil Category S (sand)

\begin{tabular}{|c|c|c|c|c|c|c|c|c|c|c|c|c|}
\hline Hcs_BC & \multirow{2}{*}{$\begin{array}{c}\begin{array}{c}\text { Number } \\
\text { of } \\
\text { Samples }\end{array} \\
\end{array}$} & \multicolumn{4}{|c|}{ Raw } & \multirow[b]{2}{*}{$\begin{array}{c}\text { Transform } \\
\dagger\end{array}$} & \multicolumn{4}{|c|}{ Transformed (normal distribution) } & \multicolumn{2}{|c|}{\begin{tabular}{|c} 
Observed Data \\
Range Truncation \\
Limits
\end{tabular}} \\
\hline Parameter & & Low & High & Mean & $\begin{array}{l}\text { Standard } \\
\text { Deviation }\end{array}$ & & Upper Limit & Lower Limit & Mean & $\begin{array}{l}\text { Standard } \\
\text { Deviation }\end{array}$ & Lower & Upper \\
\hline$q_{s}$ & 46 & 0.245 & 0.453 & 0.357 & 0.052 & NO & & & & & 0.016 & 0.968 \\
\hline$q_{R}$ & 46 & 0.000 & 0.045 & 0.026 & 0.011 & NO & & & & & 0.007 & 0.964 \\
\hline$s_{r}$ & 46 & 0.000 & 0.129 & 0.074 & 0.031 & NO & & & & & 0.009 & 0.964 \\
\hline $\mathrm{a}(1 / \mathrm{cm})$ & 46 & 0.013 & 0.861 & 0.072 & 0.146 & $\mathrm{LN}$ & -0.149 & -4.343 & -2.632 & 0.800 & 0.016 & 0.999 \\
\hline$n$ & 46 & 1.337 & 4.170 & 2.047 & 0.581 & NO & & & & & 0.111 & 1.000 \\
\hline $\mathrm{K}_{\mathrm{s}}(\mathrm{cm} / \mathrm{s})$ & 46 & 5.16E-04 & 4.93E-02 & 5.32E-03 & 1.18E-02 & LN & -3.010 & -7.569 & -5.235 & 1.173 & 0.023 & 0.971 \\
\hline \begin{tabular}{|l|} 
Longitudinal \\
Dispersivity $^{1}(\mathrm{~m})$ \\
\end{tabular} & NA & 0.183 & 0.223 & 0.203 & $\mathrm{NA}$ & UN & - & - & - & - & & \\
\hline$\%$ Gravel & 46 & 0 & 31.9 & 2.68 & 5.34 & & & & & & & \\
\hline $\begin{array}{l}\text { Bulk Density } \\
\left(\mathrm{g} / \mathrm{cm}^{3}\right)\end{array}$ & 37 & 1.51 & 1.92 & 1.67 & 0.10 & $\mathrm{NO}$ & - & - & - & & & \\
\hline
\end{tabular}

†NO = Normal (no transformation required); LN = Lognormal; LR = Log ratio; SN = Hyperbolic arcsine; UN = Uniform; CO = Constant; BE = Beta.

${ }^{1}$ Taken from Ho et al. (1999). 
Table B.13. Approximation for the Distribution Function for Soil Type "Hcs_2W" (Hanford coarse sand - 200 West Area) Modified from Khaleel and Freeman (1995) Soil Category S (sand)

\begin{tabular}{|c|c|c|c|c|c|c|c|c|c|c|c|}
\hline \multirow{2}{*}{$\begin{array}{c}\text { Hcs_2W } \\
\text { Parameter } \\
\end{array}$} & \multirow{2}{*}{$\begin{array}{c}\text { Number } \\
\text { of } \\
\text { Samples }\end{array}$} & \multicolumn{4}{|c|}{ Raw } & \multirow[b]{2}{*}{$\begin{array}{c}\text { Transform } \\
\dagger\end{array}$} & \multicolumn{3}{|c|}{ Transformed (normal distribution) } & \multicolumn{2}{|c|}{$\begin{array}{c}\text { Observed Data } \\
\text { Range Truncation } \\
\text { Limits }\end{array}$} \\
\hline & & Low & High & Mean & $\begin{array}{l}\text { Standard } \\
\text { Deviation }\end{array}$ & & Upper Limit Lower Limit & Mean & $\begin{array}{l}\text { Standard } \\
\text { Deviation }\end{array}$ & Lower & Upper \\
\hline$q_{s}$ & 7 & 0.208 & 0.416 & 0.317 & 0.083 & NO & & & & 0.095 & 0.885 \\
\hline$q_{R}$ & 7 & 0.000 & 0.111 & 0.035 & 0.035 & NO & & & & 0.163 & 0.984 \\
\hline$s_{r}$ & 7 & 0.000 & 0.266 & 0.099 & 0.082 & NO & & & & 0.114 & 0.980 \\
\hline $\mathrm{a}(1 / \mathrm{cm})$ & 7 & 0.004 & 0.131 & 0.038 & 0.043 & LN & -2.034 & -3.275 & 1.178 & 0.023 & 0.854 \\
\hline$n$ & 7 & 1.311 & 3.059 & 1.945 & 0.576 & NO & & & & 0.135 & 0.973 \\
\hline $\mathrm{K}_{\mathrm{s}}(\mathrm{cm} / \mathrm{s})$ & 7 & 1.80E-04 & $5.80 \mathrm{E}-02$ & 1.09E-03 & 2.16E-02 & LN & -2.847 & -6.822 & 2.002 & 0.184 & 0.976 \\
\hline \begin{tabular}{|l} 
Longitudinal \\
Dispersivity $^{1}(\mathrm{~m})$
\end{tabular} & NA & 0.183 & 0.223 & 0.203 & $\mathrm{NA}$ & UN & - & - & & & \\
\hline$\%$ Gravel & 7 & 0.000 & 15.000 & 2.143 & 5.669 & & & & & & \\
\hline $\begin{array}{l}\text { Bulk Density } \\
\left(\mathrm{g} / \mathrm{cm}^{3}\right)\end{array}$ & 5 & 1.490 & 1.860 & 1.650 & 0.143 & NO & - & - & & & \\
\hline
\end{tabular}

Table B.14. Approximation for the Distribution Function for Soil Type "Hcs_Z" (Hanford coarse sand 200-ZP-1) Modified from Khaleel and Freeman (1995) Soil Category S (sand)

\begin{tabular}{|c|c|c|c|c|c|c|c|c|c|c|c|c|}
\hline Hcs_Z & \multirow{2}{*}{$\begin{array}{l}\text { Number } \\
\text { of } \\
\text { Samples }\end{array}$} & \multicolumn{4}{|c|}{ Raw } & \multirow[b]{2}{*}{$\begin{array}{c}\text { Transform } \\
\dagger\end{array}$} & \multicolumn{4}{|c|}{ Transformed (normal distribution) } & \multicolumn{2}{|c|}{$\begin{array}{c}\text { Observed Data } \\
\text { Range Truncation } \\
\text { Limits }\end{array}$} \\
\hline Parameter & & Low & High & Mean & $\begin{array}{l}\text { Standard } \\
\text { Deviation } \\
\end{array}$ & & Upper Limit & Lower Limit & Mean & $\begin{array}{l}\text { Standard } \\
\text { Deviation }\end{array}$ & Lower & Upper \\
\hline$q_{s}$ & 5 & 0.208 & 0.392 & 0.292 & 0.083 & NO & & & & & 0.157 & 0.886 \\
\hline$q_{R}$ & 5 & 0.000 & 0.040 & 0.021 & 0.014 & NO & & & & & 0.065 & 0.903 \\
\hline$s_{r}$ & 5 & 0.000 & 0.110 & 0.069 & 0.043 & NO & & & & & 0.054 & 0.824 \\
\hline $\mathrm{a}(1 / \mathrm{cm})$ & 5 & 0.041 & 0.131 & 0.067 & 0.037 & LN & -2.034 & -3.199 & -2.710 & 0.496 & 0.162 & 0.914 \\
\hline$n$ & 5 & 1.311 & 2.067 & 1.692 & 0.319 & NO & & & & & 0.116 & 0.880 \\
\hline $\mathrm{K}_{\mathrm{s}}(\mathrm{cm} / \mathrm{s})$ & 5 & $1.80 \mathrm{E}-04$ & $5.80 \mathrm{E}-02$ & $1.49 \mathrm{E}-03$ & $2.55 \mathrm{E}-02$ & LN & -2.847 & -8.623 & -6.512 & 2.361 & 0.186 & 0.940 \\
\hline Longitudinal & & & & & & & & & & & & \\
\hline Dispersivity $^{1}(\mathrm{~m})$ & NA & 0.183 & 0.223 & 0.203 & NA & UN & - & - & - & & & \\
\hline$\%$ Gravel & 5 & 0 & 0 & 0 & 0 & & & & & & & \\
\hline $\begin{array}{l}\text { Bulk Density } \\
\left(\mathrm{g} / \mathrm{cm}^{3}\right)\end{array}$ & 3 & 1.49 & 1.65 & 1.56 & 0.08 & NO & - & - & & & & \\
\hline
\end{tabular}

†NO = Normal (no transformation required); LN = Lognormal; LR = Log ratio; SN = Hyperbolic arcsine; UN = Uniform; CO = Constant; BE = Beta.

${ }^{1}$ Taken from Ho et al. (1999). 
Table B.15. Approximation for the Distribution Function for Soil Type "Hgs" (Hanford gravelly sand) Based on Khaleel and Freeman (1995) Soil Category GS

\begin{tabular}{|c|c|c|c|c|c|c|c|c|c|c|c|c|}
\hline Hgs & \multirow{2}{*}{$\begin{array}{c}\text { Number } \\
\text { of } \\
\text { Samples }\end{array}$} & \multicolumn{4}{|c|}{ Raw } & \multirow[b]{2}{*}{$\begin{array}{c}\text { Transform } \\
\dagger\end{array}$} & \multicolumn{4}{|c|}{ Transformed (normal distribution) } & \multicolumn{2}{|c|}{$\begin{array}{c}\text { Observed Data } \\
\text { Range Truncation } \\
\text { Limits }\end{array}$} \\
\hline Parameter & & Low & High & Mean & $\begin{array}{l}\text { Standard } \\
\text { Deviation }\end{array}$ & & Upper Limit & Lower Limit & Mean & $\begin{array}{l}\text { Standard } \\
\text { Deviation }\end{array}$ & Lower & Upper \\
\hline$q_{s}$ & 16 & 0.180 & 0.337 & 0.238 & 0.054 & NO & - & - & - & & 0.143 & 0.966 \\
\hline$q_{R}$ & 16 & 0.010 & 0.074 & 0.033 & 0.019 & NO & - & - & - & 1 & 0.107 & 0.986 \\
\hline$s_{r}$ & 16 & 0.030 & 0.244 & 0.140 & 0.066 & NO & & & & & 0.047 & 0.942 \\
\hline $\mathrm{a}(1 / \mathrm{cm})$ & 16 & 0.004 & 0.090 & 0.014 & 0.023 & LN & -2.411 & -5.655 & -4.250 & 1.032 & 0.087 & 0.963 \\
\hline$n$ & 16 & 1.529 & 4.148 & 2.120 & 0.703 & NO & & & & & 0.200 & 0.998 \\
\hline $\mathrm{K}_{\mathrm{s}}(\mathrm{cm} / \mathrm{s})$ & 16 & 2.60E-05 & 9.00E-02 & 6.65E-04 & 2.22E-02 & LR & -2.408 & -10.557 & -7.315 & 2.290 & & \\
\hline Longitudinal & & & & & & & & & & & & \\
\hline Dispersivity $^{1}(\mathrm{~m})$ & NA & 0.0468 & 0.134 & 0.088 & $\mathrm{NA}$ & UN & - & - & - & 1 & & \\
\hline$\%$ Gravel & 17 & 10 & 40.00 & 25.78 & 9.65 & $\mathrm{NO}$ & & & & & & \\
\hline $\begin{array}{l}\text { Bulk Density } \\
\left(\mathrm{g} / \mathrm{cm}^{3}\right)\end{array}$ & 14 & 1.73 & 2.16 & 1.94 & 0.15 & NO & - & - & - & & & \\
\hline
\end{tabular}

†NO = Normal (no transformation required); LN = Lognormal; LR = Log ratio; SN = Hyperbolic arcsine; UN = Uniform; CO = Constant; BE = Beta.

${ }^{1}$ Taken from Ho et al. (1999).

Table B.16. Approximation for the Distribution Function for Soil Type "Hgs_2W" (Hanford gravelly sand - 200 West Area) Based on Khaleel and Freeman (1995) Soil Category GS

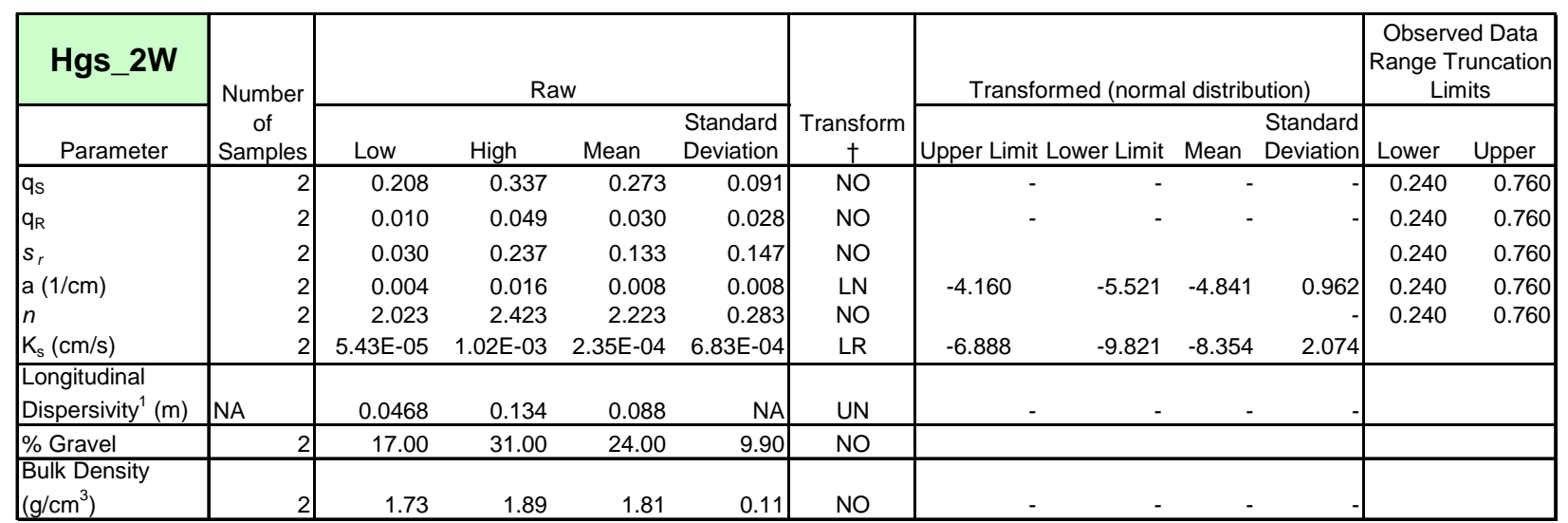

†NO = Normal (no transformation required); LN = Lognormal; LR = Log ratio; SN = Hyperbolic arcsine; UN = Uniform; CO = Constant; BE = Beta.

${ }^{1}$ Taken from Ho et al. (1999). 
Table B.17. Approximation for the Distribution Function for Soil Type "Hsg" (Hanford sandy gravel) Based on Khaleel and Freeman (1995) Soil Category SG1 (sandy gravel with gravel fraction < 60\%) (formerly called "Hg" Hanford gravel)

\begin{tabular}{|c|c|c|c|c|c|c|c|c|c|c|c|c|}
\hline $\mathrm{Hg}$ & \multirow{2}{*}{$\begin{array}{c}\text { Number } \\
\text { of } \\
\text { Samples }\end{array}$} & \multicolumn{4}{|c|}{ Raw } & \multirow[b]{2}{*}{$\begin{array}{c}\text { Transform } \\
\dagger\end{array}$} & \multicolumn{4}{|c|}{ Transformed (normal distribution) } & \multicolumn{2}{|c|}{$\begin{array}{c}\text { Observed Data } \\
\text { Range Truncation } \\
\text { Limits }\end{array}$} \\
\hline Parameter & & Low & High & Mean & $\begin{array}{l}\text { Standard } \\
\text { Deviation }\end{array}$ & & Upper Limit L & Lower Limit & Mean & $\begin{array}{l}\text { Standard } \\
\text { Deviation }\end{array}$ & Lower & Upper \\
\hline$q_{s}$ & 28 & 0.072 & 0.307 & 0.167 & 0.048 & NO & - & - & - & & 0.023 & 0.998 \\
\hline$q_{R}$ & 28 & 0.000 & 0.054 & 0.022 & 0.012 & NO & - & - & - & - & 0.033 & 0.996 \\
\hline$S_{r}$ & 28 & 0.000 & 0.275 & 0.134 & 0.071 & NO & & & & & 0.030 & 0.976 \\
\hline $\mathrm{a}(1 / \mathrm{cm})$ & 28 & 0.002 & 0.919 & 0.017 & 0.193 & LN & -0.084 & -6.075 & -4.072 & 1.487 & 0.089 & 0.996 \\
\hline$n$ & 28 & 1.347 & 2.947 & 1.725 & 0.367 & NO & & & & & 0.151 & 1.000 \\
\hline $\mathrm{K}_{\mathrm{s}}(\mathrm{cm} / \mathrm{s})$ & 27 & $1.90 \mathrm{E}-07$ & 3.70E-02 & 3.30E-04 & 8.88E-03 & $\mathrm{LN}$ & -3.297 & -15.476 & -8.016 & 3.265 & 0.011 & 0.926 \\
\hline $\begin{array}{l}\text { Longitudinal } \\
\text { Dispersivity }^{1}(\mathrm{~m})\end{array}$ & NA & 0.027 & 0.178 & 0.09 & $\mathrm{NA}$ & UN & - & 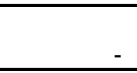 & - & & & \\
\hline$\%$ Gravel & 29 & 22 & 80 & 51.42 & 12.81 & $\mathrm{NO}$ & & & & & & \\
\hline $\begin{array}{l}\text { Bulk Density } \\
\left(\mathrm{g} / \mathrm{cm}^{3}\right)\end{array}$ & 25 & 1.6 & 2.3 & 1.93 & 0.21 & $\mathrm{NO}$ & - & - & - & - & & \\
\hline
\end{tabular}

Table B.18. Approximation for the Distribution Function for Soil Type "Hsg_2W" (Hanford sandy gravel -200 West Area) Based on Khaleel and Freeman (1995) Soil Category SG1 (sandy gravel with gravel fraction < 60\%) (formerly called "Hg" Hanford gravel - 200 West Area)

\begin{tabular}{|c|c|c|c|c|c|c|c|c|c|c|c|c|}
\hline \multirow{2}{*}{$\begin{array}{c}\text { Hg_2W } \\
\text { Parameter }\end{array}$} & \multirow{2}{*}{$\begin{array}{c}\text { Number } \\
\text { of } \\
\text { Samples }\end{array}$} & \multicolumn{4}{|c|}{ Raw } & \multirow[b]{2}{*}{$\begin{array}{c}\text { Transform } \\
\dagger\end{array}$} & \multicolumn{4}{|c|}{ Transformed (normal distribution) } & \multicolumn{2}{|c|}{$\begin{array}{c}\text { Observed Data } \\
\text { Range Truncation } \\
\text { Limits }\end{array}$} \\
\hline & & Low & High & Mean & $\begin{array}{l}\text { Standard } \\
\text { Deviation }\end{array}$ & & Upper Limit & Lower Limit & Mean & $\begin{array}{l}\text { Standard } \\
\text { Deviation }\end{array}$ & Lower & Upper \\
\hline$q_{s}$ & 11 & 0.072 & 0.217 & 0.154 & 0.042 & NO & - & - & - & 1 & 0.026 & 0.932 \\
\hline$q_{R}$ & 11 & 0.000 & 0.045 & 0.024 & 0.013 & NO & - & - & - & & 0.037 & 0.941 \\
\hline$s_{r}$ & 11 & 0.000 & 0.243 & 0.152 & 0.086 & NO & & & & & 0.038 & 0.854 \\
\hline $\mathrm{a}(1 / \mathrm{cm})$ & 11 & 0.002 & 0.276 & 0.014 & 0.080 & LN & -1.288 & -6.075 & -4.234 & 1.301 & 0.079 & 0.988 \\
\hline$n$ & 11 & 1.347 & 2.269 & 1.742 & 0.339 & NO & & & & & 0.122 & 0.940 \\
\hline $\mathrm{K}_{\mathrm{s}}(\mathrm{cm} / \mathrm{s})$ & 11 & 3.30E-06 & 3.70E-02 & 1.40E-03 & $1.26 \mathrm{E}-02$ & LN & -3.297 & -12.622 & -6.569 & 2.960 & 0.020 & 0.866 \\
\hline \begin{tabular}{|l|} 
Longitudinal \\
Dispersivity $^{1}(\mathrm{~m})$ \\
\end{tabular} & NA & 0.027 & 0.178 & 0.09 & $\mathrm{NA}$ & UN & - & - & - & 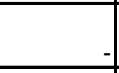 & & \\
\hline$\%$ Gravel & 12 & 39.000 & 80.000 & 54.358 & 12.380 & $\mathrm{NO}$ & & & & & & \\
\hline $\begin{array}{l}\text { Bulk Density } \\
\left(\mathrm{g} / \mathrm{cm}^{3}\right)\end{array}$ & 9 & 1.630 & 2.300 & 1.891 & 0.225 & $\mathrm{NO}$ & - & - & - & & & \\
\hline
\end{tabular}

†NO = Normal (no transformation required); LN = Lognormal; LR = Log ratio; SN = Hyperbolic arcsine; UN = Uniform; CO = Constant; BE = Beta.

${ }^{1}$ Taken from Ho et al. (1999). Same as SSG. 
Table B.19. Approximation for the Distribution Function for Soil Type "Hsg_U" (Hanford sandy gravel - 200-UP-1) Based on Khaleel and Freeman (1995) Soil Category SG1 (sandy gravel with gravel fraction < 60\%) (formerly called "Hg" Hanford gravel - 200-UP-1)

\begin{tabular}{|c|c|c|c|c|c|c|c|c|c|c|c|c|}
\hline \multirow{2}{*}{$\begin{array}{c}\text { Hg_U } \\
\text { Parameter }\end{array}$} & \multirow{2}{*}{$\begin{array}{c}\text { Number } \\
\text { of } \\
\text { Samples }\end{array}$} & \multicolumn{4}{|c|}{ Raw } & \multirow[b]{2}{*}{$\begin{array}{c}\text { Transform } \\
\dagger\end{array}$} & \multicolumn{4}{|c|}{ Transformed (normal distribution) } & \multicolumn{2}{|c|}{$\begin{array}{c}\text { Observed Data } \\
\text { Range Truncation } \\
\text { Limits }\end{array}$} \\
\hline & & Low & High & Mean & $\begin{array}{l}\text { Standard } \\
\text { Deviation }\end{array}$ & & Upper Limit L & Lower Limit & Mean & $\begin{array}{l}\text { Standard } \\
\text { Deviation }\end{array}$ & Lower & Upper \\
\hline$q_{s}$ & 3 & 0.124 & 0.194 & 0.150 & 0.039 & NO & - & - & - & - & 0.249 & 0.875 \\
\hline$q_{R}$ & 3 & 0.028 & 0.030 & 0.029 & 0.001 & NO & - & - & - & - & 0.136 & 0.805 \\
\hline$s_{r}$ & 3 & 0.144 & 0.239 & 0.204 & 0.052 & NO & & & & & 0.125 & 0.746 \\
\hline $\mathrm{a}(1 / \mathrm{cm})$ & 3 & 0.006 & 0.033 & 0.011 & 0.015 & LN & -3.417 & -5.083 & -4.473 & 0.918 & 0.253 & 0.875 \\
\hline$n$ & 3 & 1.660 & 2.205 & 1.845 & 0.312 & NO & & & & & 0.277 & 0.876 \\
\hline $\mathrm{K}_{\mathrm{s}}(\mathrm{cm} / \mathrm{s})$ & 3 & 3.300E-06 & 5.590E-03 & 2.884E-04 & $2.924 \mathrm{E}-03$ & $\mathrm{LN}$ & -5.187 & -12.622 & -8.151 & 3.940 & 0.128 & 0.774 \\
\hline $\begin{array}{l}\text { Longitudinal } \\
\text { Dispersivity }^{1}(\mathrm{~m})\end{array}$ & NA & 0.027 & 0.178 & 0.09 & $\mathrm{NA}$ & UN & - & - & - & & & \\
\hline$\%$ Gravel & 3 & 43.3 & 65 & 57.10 & 11.99 & $\mathrm{NO}$ & & & & & & \\
\hline $\begin{array}{l}\text { Bulk Density } \\
\left(\mathrm{g} / \mathrm{cm}^{3}\right)\end{array}$ & 3 & 1.8 & 2.3 & 2.09 & 0.26 & $\mathrm{NO}$ & - & - & - & - & & \\
\hline
\end{tabular}

Table B.20. Approximation for the Distribution Function for Soil Type "Hsg_Z" (Hanford sandy gravel - 200-ZP-1) Based on Khaleel and Freeman (1995) Soil Category SG1 (sandy gravel with gravel fraction < 60\%) (formerly called "Hg" Hanford gravel - 200-ZP-1)

\begin{tabular}{|c|c|c|c|c|c|c|c|c|c|c|c|c|}
\hline Hg_z & \multirow{2}{*}{$\begin{array}{c}\text { Number } \\
\text { of } \\
\text { Samples }\end{array}$} & \multicolumn{4}{|c|}{ Raw } & \multirow[b]{2}{*}{$\begin{array}{c}\text { Transform } \\
\dagger\end{array}$} & \multicolumn{4}{|c|}{ Transformed (normal distribution) } & \multicolumn{2}{|c|}{\begin{tabular}{|c} 
Observed Data \\
Range Truncation \\
Limits
\end{tabular}} \\
\hline Parameter & & Low & High & Mean & $\begin{array}{l}\text { Standard } \\
\text { Deviation }\end{array}$ & & Upper Limit & Lower Limit & Mean & $\begin{array}{l}\text { Standard } \\
\text { Deviation }\end{array}$ & Lower & Upper \\
\hline$q_{s}$ & 8 & 0.072 & 0.217 & 0.155 & 0.046 & NO & - & - & - & & 0.035 & 0.910 \\
\hline$q_{R}$ & 8 & 0.000 & 0.045 & 0.022 & 0.016 & NO & - & - & - & - & 0.078 & 0.931 \\
\hline$s_{r}$ & 8 & 0.000 & 0.243 & 0.133 & 0.090 & NO & & & & & 0.070 & 0.888 \\
\hline $\mathrm{a}(1 / \mathrm{cm})$ & 8 & 0.002 & 0.276 & 0.016 & 0.093 & LN & -1.288 & -6.075 & -4.145 & 1.464 & 0.094 & 0.974 \\
\hline$n$ & 8 & 1.347 & 2.269 & 1.703 & 0.361 & NO & & & & & 0.162 & 0.942 \\
\hline $\mathrm{K}_{\mathrm{s}}(\mathrm{cm} / \mathrm{s})$ & 7 & 2.83E-05 & 3.70E-02 & 3.65E-03 & $1.42 \mathrm{E}-02$ & LN & -3.297 & -10.473 & -5.613 & 2.546 & 0.028 & 0.819 \\
\hline \begin{tabular}{|l} 
Longitudinal \\
Dispersivity $^{1}(\mathrm{~m})$
\end{tabular} & NA & 0.027 & 0.178 & 0.09 & $\mathrm{NA}$ & UN & - & - & - & & & \\
\hline$\%$ Gravel & 9 & 39 & 80 & 53.44 & 13.08 & NO & & & & & & \\
\hline $\begin{array}{l}\text { Bulk Density } \\
\left(\mathrm{g} / \mathrm{cm}^{3}\right)\end{array}$ & 6 & 1.63 & 1.92 & 1.79 & 0.13 & NO & - & - & - & & & \\
\hline
\end{tabular}

†NO = Normal (no transformation required); LN = Lognormal; LR = Log ratio; SN = Hyperbolic arcsine; UN = Uniform; CO = Constant; BE = Beta.

${ }^{1}$ Taken from Ho et al. (1999). Same as SSG 
Table B.21. Approximation for the Distribution Function for Soil Type "Hcg" (Hanford coarse gravel) Based on Khaleel and Freeman (1995) Soil Category SG2 (sandy gravel with gravel fraction >60\%) (formerly called "Hrg" Hanford river gravel)

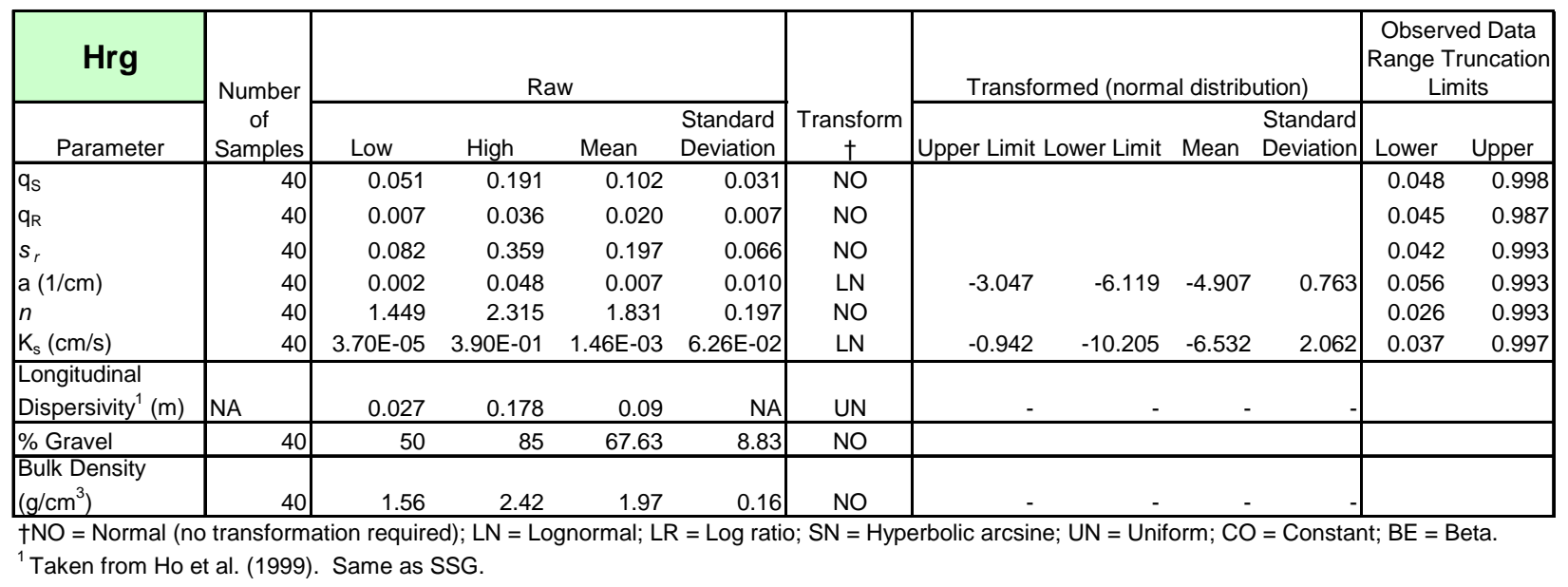

Table B.22. Approximation for the Distribution Function for Soil Type "CCUz" (Cold Creek unit-silt formerly called "PPlz" [Plio-Pleistocene-silt]) Modified from Khaleel and Freeman (1995) Soil Category SS (sand mixed with finer fraction)

\begin{tabular}{|c|c|c|c|c|c|c|c|c|c|c|c|c|}
\hline PPIz & \multirow{2}{*}{$\begin{array}{c}\text { Number } \\
\text { of } \\
\text { Samples }\end{array}$} & \multicolumn{4}{|c|}{ Raw } & \multirow[b]{2}{*}{$\begin{array}{c}\text { Transform } \\
\dagger\end{array}$} & \multicolumn{4}{|c|}{ Transformed (normal distribution) } & \multicolumn{2}{|c|}{$\begin{array}{c}\text { Observed Data } \\
\text { Range Truncation } \\
\text { Limits }\end{array}$} \\
\hline Parameter & & Low & High & Mean & $\begin{array}{l}\text { Standard } \\
\text { Deviation }\end{array}$ & & Upper Limit L & Lower Limit & Mean & $\begin{array}{l}\text { Standard } \\
\text { Deviation }\end{array}$ & Lower & Upper \\
\hline$q_{s}$ & 9 & 0.288 & 0.533 & 0.419 & 0.091 & NO & & & & & 0.075 & 0.895 \\
\hline$q_{R}$ & 9 & 0.010 & 0.087 & 0.040 & 0.023 & NO & & & & & 0.096 & 0.979 \\
\hline$S_{r}$ & 9 & 0.020 & 0.169 & 0.097 & 0.046 & NO & & & & & 0.047 & 0.941 \\
\hline $\mathrm{a}(1 / \mathrm{cm})$ & 9 & 0.001 & 0.014 & 0.005 & 0.004 & LN & -4.269 & -6.522 & -5.298 & 0.645 & 0.029 & 0.945 \\
\hline$n$ & 9 & 1.522 & 2.815 & 2.249 & 0.440 & NO & & & & & 0.049 & 0.901 \\
\hline $\mathrm{K}_{\mathrm{s}}(\mathrm{cm} / \mathrm{s})$ & 9 & 4.12E-07 & 1.36E-01 & 5.57E-05 & 4.53E-02 & LN & -1.995 & -14.702 & -9.795 & 3.805 & 0.099 & 0.980 \\
\hline $\begin{array}{l}\text { Longitudinal } \\
\text { Dispersivity }^{1}(\mathrm{~m})\end{array}$ & NA & 0.0279 & 0.0341 & 0.031 & NA & UN & - & - & - & & & \\
\hline$\%$ Gravel & 9 & 0 & 4 & 0.44 & 1.33 & & & & & & & \\
\hline $\begin{array}{l}\text { Bulk Density } \\
\left(\mathrm{g} / \mathrm{cm}^{3}\right)\end{array}$ & 9 & 1.55 & 1.8 & 1.68 & 0.08 & NO & - & - & - & & & \\
\hline
\end{tabular}

†NO = Normal (no transformation required); LN = Lognormal; LR = Log ratio; SN = Hyperbolic arcsine; UN = Uniform; CO = Constant; BE = Beta.

${ }^{1}$ Taken from Ho et al. (1999). 
Table B.23. Approximation for the Distribution Function for Soil Type "CCUz_U" (Cold Creek unitsit 1 200-UP-1, formerly called "PPlz_U" [Plio-Pleistocene-silt - 200-UP-1]) Modified from Khaleel and Freeman (1995) Soil Category SS (sand mixed with finer fraction)

\begin{tabular}{|c|c|c|c|c|c|c|c|c|c|c|c|}
\hline \multirow{2}{*}{$\begin{array}{l}\text { PPIz_U } \\
\text { Parameter }\end{array}$} & \multirow{2}{*}{$\begin{array}{c}\text { Number } \\
\text { of } \\
\text { Samples }\end{array}$} & \multicolumn{4}{|c|}{ Raw } & \multirow[b]{2}{*}{$\begin{array}{c}\text { Transform } \\
\dagger\end{array}$} & \multicolumn{3}{|c|}{ Transformed (normal distribution) } & \multicolumn{2}{|c|}{$\begin{array}{c}\text { Observed Data } \\
\begin{array}{c}\text { Range Truncation } \\
\text { Limits }\end{array}\end{array}$} \\
\hline & & Low & High & Mean & $\begin{array}{l}\text { Standard } \\
\text { Deviation }\end{array}$ & & Upper Limit Lower Limit & Mean & $\begin{array}{l}\text { Standard } \\
\text { Deviation }\end{array}$ & Lower & Upper \\
\hline$q_{s}$ & 5 & 0.288 & 0.514 & 0.395 & 0.101 & NO & & & & 0.145 & 0.881 \\
\hline$q_{R}$ & 5 & 0.025 & 0.087 & 0.047 & 0.024 & NO & & & & 0.180 & 0.952 \\
\hline$S_{r}$ & 5 & 0.075 & 0.169 & 0.117 & 0.041 & NO & & & & 0.153 & 0.898 \\
\hline $\mathrm{a}(1 / \mathrm{cm})$ & 5 & 0.001 & 0.014 & 0.004 & 0.005 & LN & -6.522 & -5.521 & 0.816 & 0.110 & 0.938 \\
\hline$n$ & 5 & 1.522 & 2.743 & 2.285 & 0.470 & NO & & & & 0.052 & 0.835 \\
\hline $\mathrm{K}_{\mathrm{s}}(\mathrm{cm} / \mathrm{s})$ & 5 & 4.12E-07 & $6.74 \mathrm{E}-04$ & 7.27E-06 & $3.00 \mathrm{E}-04$ & $\mathrm{LN}$ & -14.702 & -11.831 & 2.818 & 0.154 & 0.946 \\
\hline $\begin{array}{l}\text { Longitudinal }^{2} \\
\text { Dispersivity }^{1}(\mathrm{~m})\end{array}$ & NA & 0.0279 & 0.0341 & 0.031 & $\mathrm{NA}$ & UN & - & - & 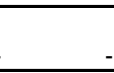 & & \\
\hline$\%$ Gravel & 5 & 0 & 0.4 & 0.08 & 0.18 & & & & & & \\
\hline $\begin{array}{l}\text { Bulk Density } \\
\left(\mathrm{g} / \mathrm{cm}^{3}\right)\end{array}$ & 5 & 1.55 & 1.8 & 1.71 & 0.10 & $\mathrm{NO}$ & - & - & . & & \\
\hline
\end{tabular}

Table B.24. Approximation for the Distribution Function for Soil Type "CCUz-Z (Cold Creek unit-silt 200-ZP-1, formerly called "PPlz_Z" [Plio-Pleistocene-silt - 200-ZP-1]) Modified from Khaleel and Freeman (1995) Soil Category SS (sand mixed with finer fraction)

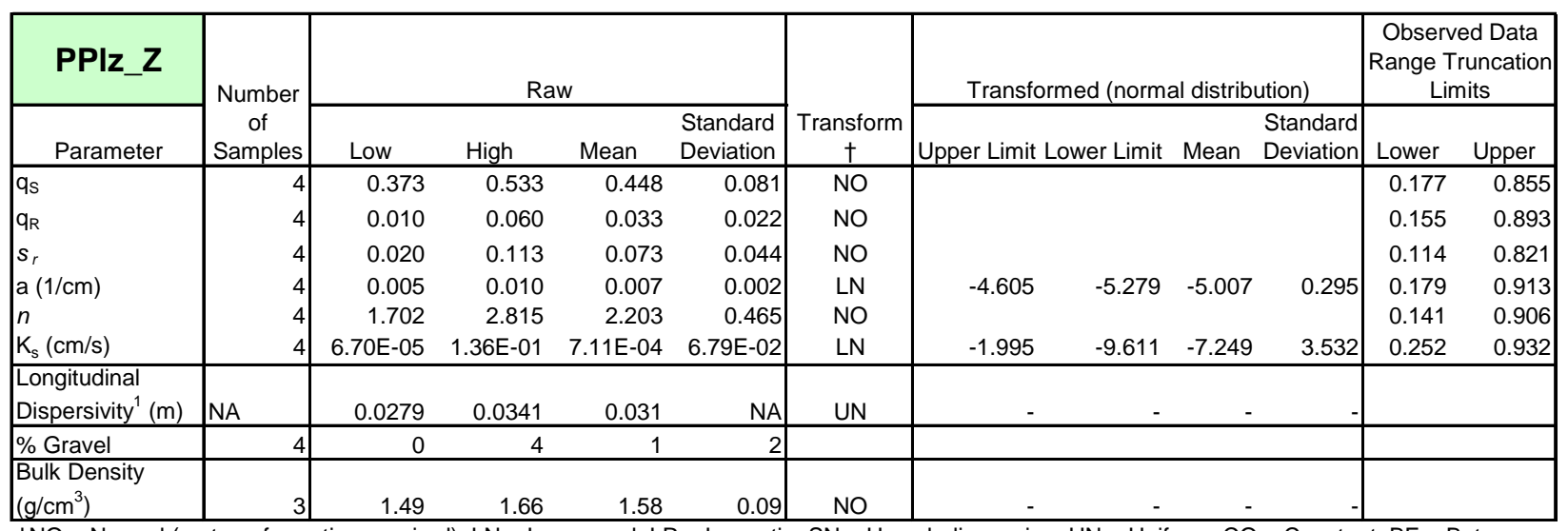

†NO = Normal (no transformation required); LN = Lognormal; LR = Log ratio; SN = Hyperbolic arcsine; UN = Uniform; CO = Constant; BE = Beta.

${ }^{1}$ Taken from Ho et al. (1999). 
Table B.25. Approximation for the Distribution Function for Soil Type "CCUc" (Cold Creek unitcarbonate, formerly called "PPlc" [Plio-Pleistocene-carbonate]) Modified from Khaleel and Freeman (1995) Soil Category SS (sand mixed with finer fraction)

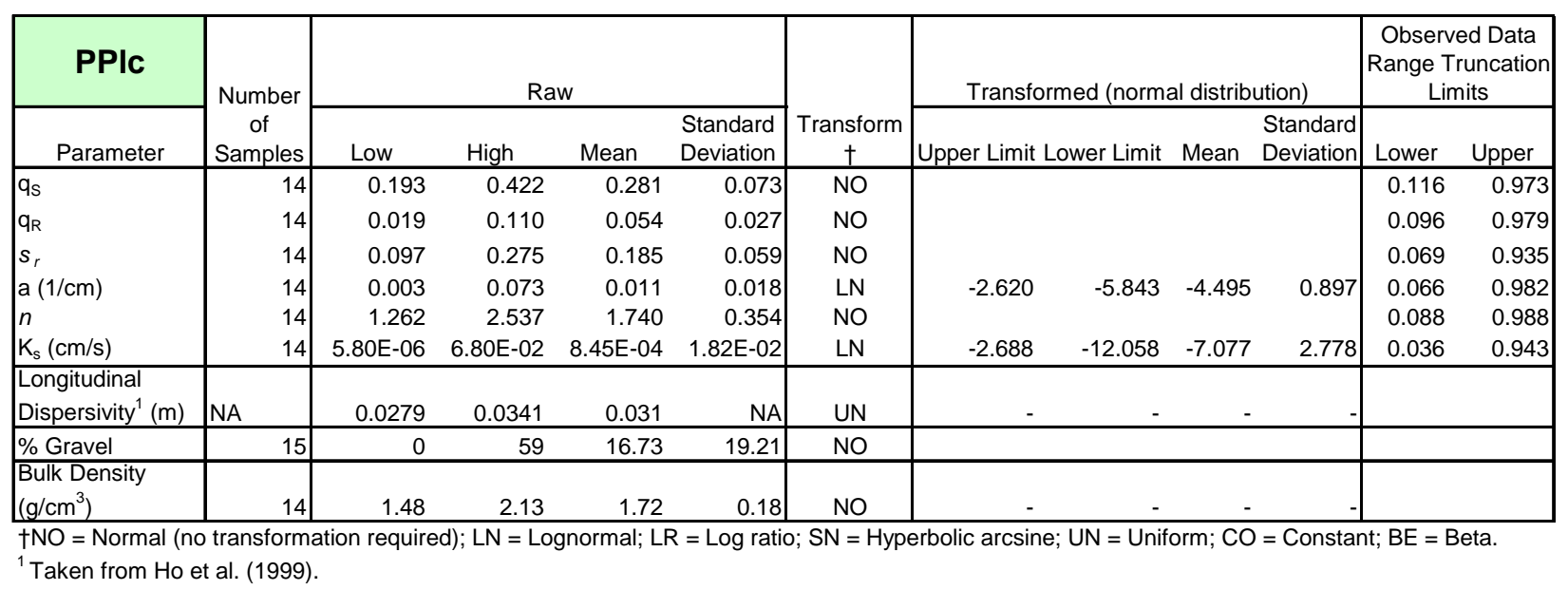

Table B.26. Approximation for the Distribution Function for Soil Type "CCUc-Z" (Cold Creek unitcarbonate - 200-ZP-1, formerlly called "PPlc_Z" [Plio-Pleistocene-carbonate - 200-ZP-1]) Modified from Khaleel and Freeman (1995) Soil Category SS (sand mixed with finer fraction)

\begin{tabular}{|c|c|c|c|c|c|c|c|c|c|c|c|c|}
\hline \multirow{2}{*}{$\begin{array}{c}\text { PPIc_Z } \\
\text { Parameter }\end{array}$} & \multirow{2}{*}{$\begin{array}{c}\text { Number } \\
\text { of } \\
\text { Samples }\end{array}$} & \multicolumn{4}{|c|}{ Raw } & \multirow[b]{2}{*}{$\begin{array}{c}\text { Transform } \\
\dagger\end{array}$} & \multicolumn{4}{|c|}{ Transformed (normal distribution) } & \multicolumn{2}{|c|}{$\begin{array}{c}\text { Observed Data } \\
\text { Range Truncation } \\
\text { Limits }\end{array}$} \\
\hline & & Low & High & Mean & $\begin{array}{l}\text { Standard } \\
\text { Deviation }\end{array}$ & & Upper Limit & Lower Limit & Mean & $\begin{array}{l}\text { Standard } \\
\text { Deviation }\end{array}$ & Lower & Upper \\
\hline$q_{s}$ & 13 & 0.193 & 0.422 & 0.286 & 0.074 & $\mathrm{NO}$ & & & & & 0.107 & 0.967 \\
\hline$q_{R}$ & 13 & 0.019 & 0.110 & 0.056 & 0.027 & NO & & & & & 0.081 & 0.976 \\
\hline$S_{r}$ & 13 & 0.097 & 0.275 & 0.190 & 0.058 & NO & & & & & 0.055 & 0.927 \\
\hline $\mathrm{a}(1 / \mathrm{cm})$ & 13 & 0.003 & 0.073 & 0.011 & 0.019 & LN & -2.620 & -5.843 & -4.484 & 0.933 & 0.073 & 0.977 \\
\hline$n$ & 13 & 1.262 & 2.537 & 1.750 & 0.366 & NO & & & & & 0.091 & 0.984 \\
\hline $\mathrm{K}_{\mathrm{s}}(\mathrm{cm} / \mathrm{s})$ & 13 & 5.80E-06 & 6.80E-02 & 1.03E-03 & 1.88E-02 & LN & -2.688 & -12.058 & -6.878 & 2.786 & 0.031 & 0.934 \\
\hline Longitudinal & & & & & & & & & & & & \\
\hline Dispersivity $^{1}(\mathrm{~m})$ & NA & 0.0279 & 0.0341 & 0.031 & NA & UN & - & - & - & & & \\
\hline$\%$ Gravel & 14 & 0.00 & 59.00 & 15.07 & 18.79 & NO & & & & & & \\
\hline $\begin{array}{l}\text { Bulk Density } \\
\left(\mathrm{g} / \mathrm{cm}^{3}\right)\end{array}$ & 12 & 1.48 & 1.94 & 1.68 & 0.16 & NO & - & - & - & & & \\
\hline
\end{tabular}

†NO = Normal (no transformation required); LN = Lognormal; LR = Log ratio; SN = Hyperbolic arcsine; UN = Uniform; CO = Constant; BE = Beta.

${ }^{1}$ Taken from Ho et al. (1999). 
Table B.27. Approximation for the Distribution Function for Soil Type "Rg" (Ringold sandy gravel) Based on Khaleel and Freeman (1995) Soil Category SG2 (sandy gravel with gravel fraction $>60 \%$ )

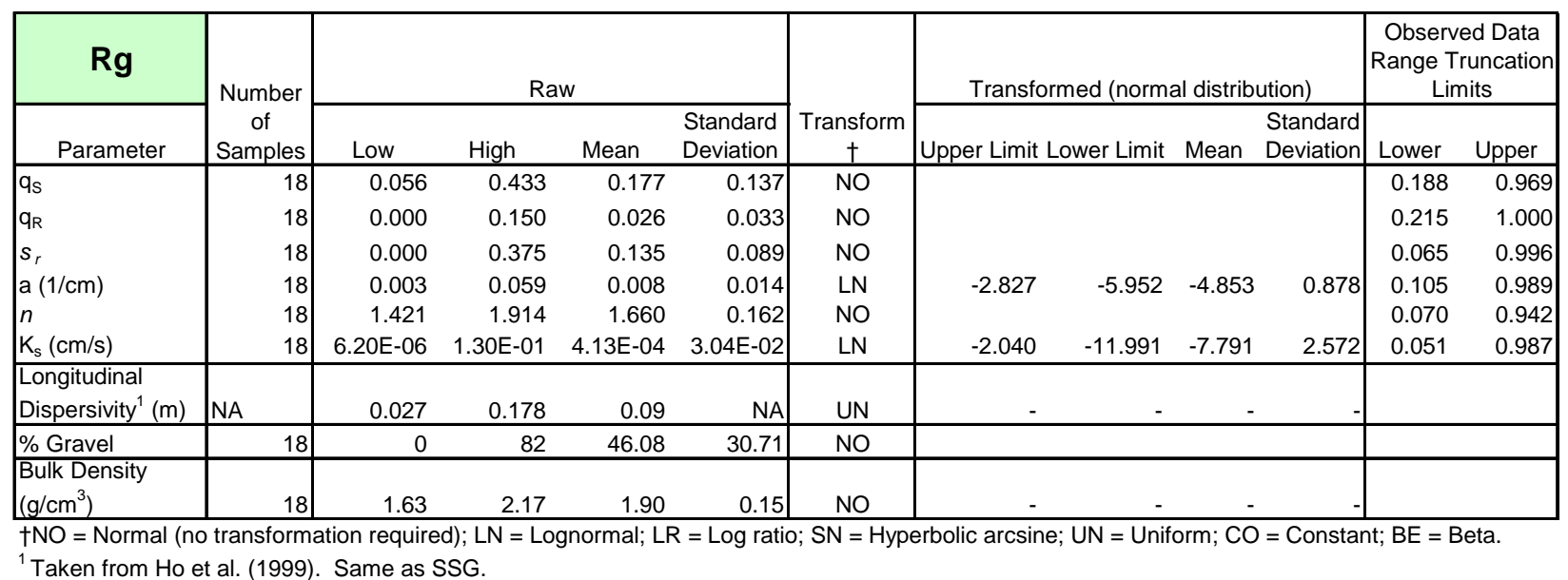

Table B.28. Approximation for the Distribution Function for Soil Type "Rg_2W" (Ringold sandy gravel - 200 West Area) Based on Khaleel and Freeman (1995) Soil Category SG2 (sandy gravel with gravel fraction $>60 \%$ )

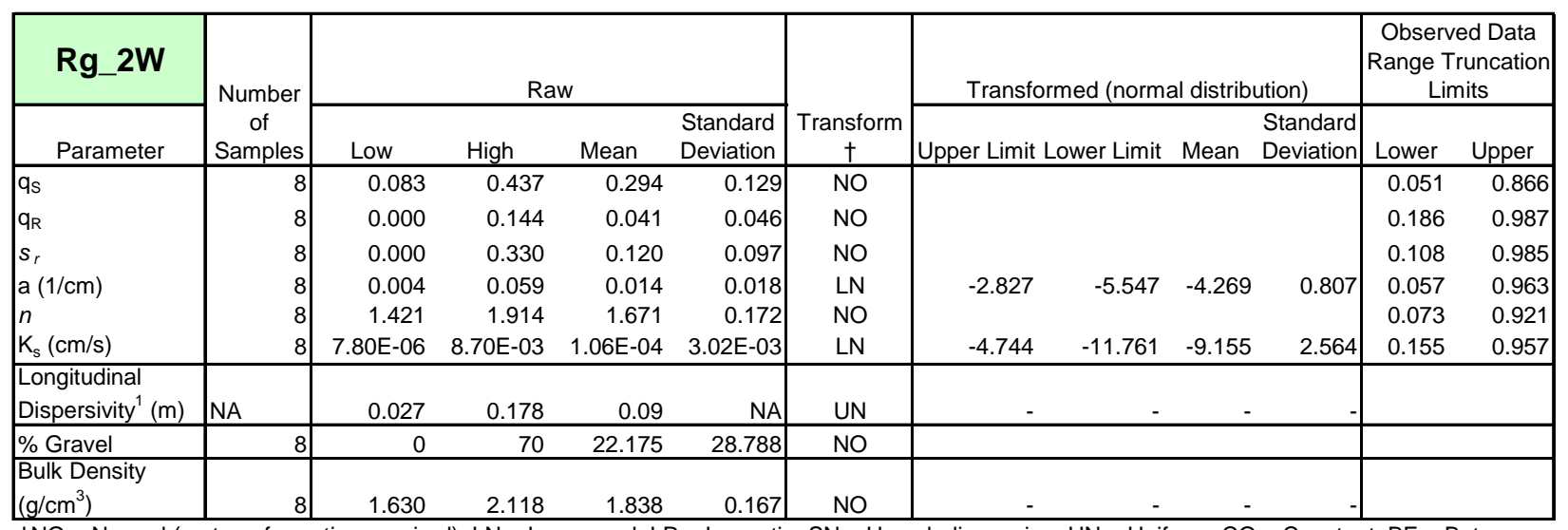

†NO = Normal (no transformation required); LN = Lognormal; LR = Log ratio; SN = Hyperbolic arcsine; UN = Uniform; CO = Constant; BE = Beta.

${ }^{1}$ Taken from Ho et al. (1999). Same as SSG. 
Table B.29. Approximation for the Distribution Function for Soil Type "Rg_U" (Ringold sandy gravel 200-UP-1) Based on Khaleel and Freeman (1995) Soil Category SG2 (sandy gravel with gravel fraction $>60 \%$ )

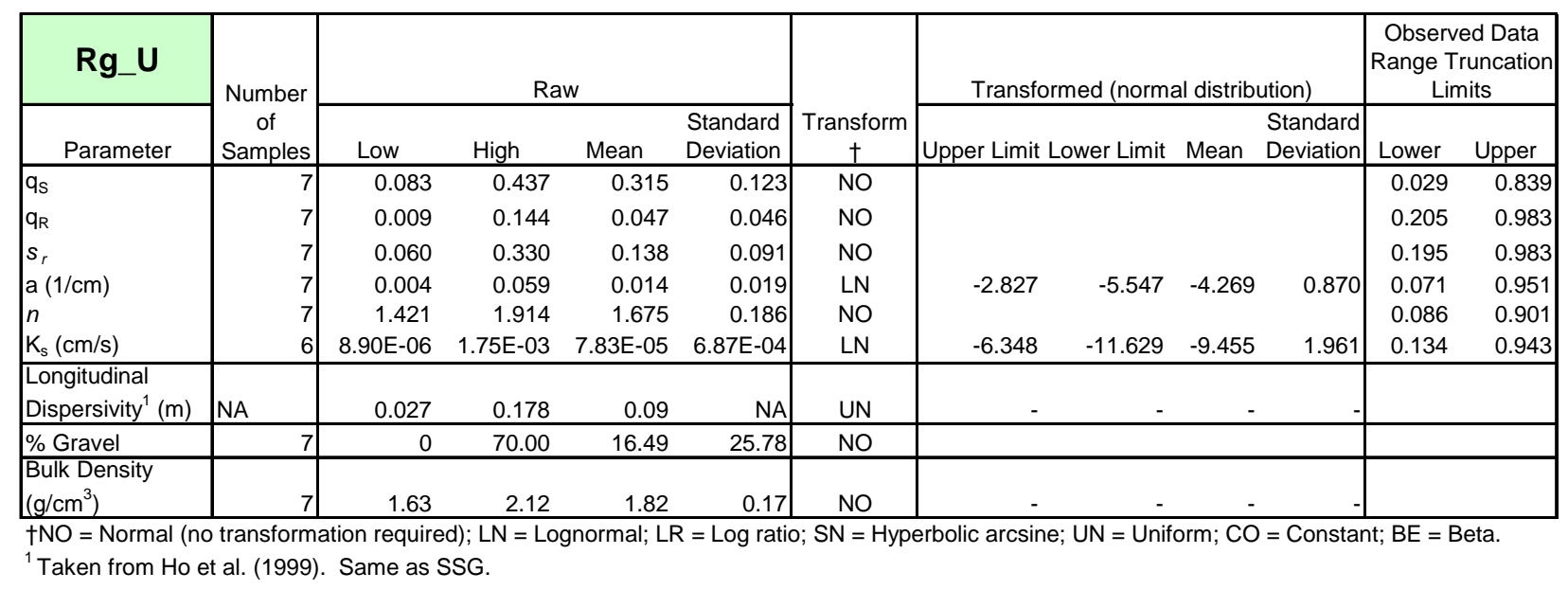

\section{References}

Ho CK, RG Baca, SH Conrad, GA Smith, L Shyr, and TA Wheeler. 1999. Stochastic Parameter Development for PORFLOW Simulations of the Hanford AX Tank Farm. SAND98-2880, Sandia National Laboratories, Albuquerque, New Mexico.

Khaleel R and EJ Freeman. 1995. Variability and Scaling of Hydraulic Properties for 200 Area Soils, Hanford Site. WHC-EP-0883, Westinghouse Hanford Company, Richland, Washington. 


\section{Appendix C}

Resolution of Discrepancies in the System Assessment Capability Vadose Zone Model for the BC Cribs and Trenches 


\title{
Appendix C
}

\section{Resolution of Discrepancies in the System Assessment Capability Vadose Zone Model for the BC Cribs and Trenches}

\author{
W. E. Nichols
}

The System Assessment Capability (SAC) Initial Assessment (Bryce et al. 2002) exhibited large, early releases of technetium-99. In all cases, the releases from the vadose zone to groundwater were nearly instant, following disposal to ground by only a year or two. To date, no groundwater monitoring data show evidence of any technetium-99 plume from the area of these sites consistent with such large releases.

Because of the large predicted impact of technetium-99 from the BC cribs and trenches and inconsistency between predictions and groundwater monitoring data, resolution of the vadose zone model at these sites is required.

\section{C.1 Approach}

The SAC vadose zone modeling uses a one-dimensional approach for computational speed. It is recognized that the multidimensional aspects of the vadose zone are highly important, but multidimensional modeling of the hundreds of waste disposal sites addressed in the SAC in a stochastic framework is computationally untenable. For vadose zone sites with liquid discharges, this is compensated by applying a $\mathrm{K}_{\mathrm{s}}$-dependent wetted area adjustment, wherein the area of the vadose zone area represented in the onedimensional model is scaled so that a unit gradient is attained in the layer with the lowest saturated hydraulic conductivity for the period with the highest liquid discharge rate.

However, for the BC trenches, the $\mathrm{K}_{\mathrm{s}}$-depended wetted area adjustment method does not yield an area larger than the site area, so the SAC model defaults to using the Waste Information Data System (WIDS) area. This is equivalent to declaring there is no lateral movement of liquid associated with the liquid discharges at these sites.

Lateral spreading undoubtedly still occurs for the short-duration (less than one year) discharges that occurred at the BC trenches, and two-dimensional modeling of each crib and trench for median input values can be used to quantify the extent of lateral spreading. Lateral spreading of fluid will tend to delay arrival of technetium-99 at the aquifer. If enough delay occurs, then the disposal inventory could still be consistent with the groundwater monitoring data that does not indicate a substantial technetium-99 plume in the vicinity of the BC cribs and trenches before calendar year 2000.

\section{C.2 Multidimensional Modeling of BC Trenches}

The BC trenches and their respective areas and discharge volumes are listed in Table C.1. The BC trenches are long relative to their width and were, therefore, idealized as a two-dimensional feature 
symmetric about the length axis of the trench. An idealized two-dimensional model was constructed that assumes the trench is infinite in length, and that lateral spreading is strictly perpendicular to the trench length axis.

Table C.1. BC Trenches (data from Maxfield 1979)

\begin{tabular}{||c|c|c||}
\hline WIDS Identification & Area (square meters) & Discharge Volume (liters) \\
\hline \hline $216-B-20$ & $152.4 \times 3.0=457.2$ & $4.68 \times 10^{6}$ \\
\hline $216-B-21$ & $152.4 \times 3.0=457.2$ & $4.67 \times 10^{6}$ \\
\hline $216-B-22$ & $152.4 \times 3.0=457.2$ & $4.74 \times 10^{6}$ \\
\hline $216-B-23$ & $152.4 \times 3.0=457.2$ & $4.52 \times 10^{6}$ \\
\hline $216-B-24$ & $152.4 \times 3.0=457.2$ & $4.7 \times 10^{6}$ \\
\hline $216-B-25$ & $152.4 \times 3.0=457.2$ & $3.76 \times 10^{6}$ \\
\hline $216-B-26$ & $152.4 \times 3.0=457.2$ & $5.88 \times 10^{6}$ \\
\hline $216-B-27$ & $152.4 \times 3.0=457.2$ & $4.42 \times 10^{6}$ \\
\hline $216-B-28$ & $152.4 \times 3.0=457.2$ & $5.05 \times 10^{6}$ \\
\hline $216-B-29$ & $152.4 \times 3.0=457.2$ & $4.84 \times 10^{6}$ \\
\hline $216-B-30$ & $152.4 \times 3.0=457.2$ & $4.78 \times 10^{6}$ \\
\hline $216-B-31$ & $152.4 \times 3.0=457.2$ & $4.74 \times 10^{6}$ \\
\hline $216-B-32$ & $152.4 \times 3.0=457.2$ & $4.77 \times 10^{6}$ \\
\hline $216-B-33$ & $152.4 \times 3.0=457.2$ & $4.74 \times 10^{6}$ \\
\hline $216-B-34$ & $152.4 \times 3.0=457.2$ & $4.87 \times 10^{6}$ \\
\hline $216-B-52$ & $176.8 \times 3.0=530.4$ & $8.53 \times 10^{6}$ \\
\hline $216-B-53 A$ & $18.3 \times 3.0=54.9$ & $5.49 \times 10^{5}$ \\
\hline $216-B-53 B$ & $45.7 \times 3.0=137.2$ & $1.51 \times 10^{4}$ \\
\hline $216-B-54$ & $61.0 \times 3.0=182.9$ & $9.99 \times 10^{5}$ \\
\hline $216-B-58$ & $61.0 \times 3.0=182.9$ & $4.13 \times 10^{5}$ \\
\hline WIDS - Waste Information Data Systemc & \\
\hline & & \\
\hline
\end{tabular}

The SAC one-dimensional model for each BC trench with a substantial inventory of technetium-99 (trenches below 216-B-34 in Table C.1 did not have a large disposal of technetium-99) was expanded into a two-dimensional axial-symmetric model (half the trench represented, with results scalable to represent the whole trench). The vertical resolution (580 0.15-meter grid cells) was retained, and the $\mathrm{x}$-axis was resolve into 96, 0.15-meter grid cells. This yielded a model grid of 55,680 grid nodes. The liquid and analyte discharges were converted to density-type sources and assigned to the topmost nodes in the grid index range from 1 to 10 (inner 1.5 meters), representing half the source term (again, consistent with the axial-symmetric treatment).

Hanford soils are anisotropic, considered about 10 times more conductive in the horizontal dimension than in the vertical. To consider this feature, each trench was modeled twice, once with isotropic properties and once with 10:1 anisotropy in saturated hydraulic conductivity.

Once the release histories for the multidimensional model runs were available, the one-dimensional model was rerun with several 'AreaX' (area scaling parameter) values. By trial-and-error, an 'AreaX' scaling factor that would cause the one-dimensional model to produce releases similar to the twodimensional model (with explicit treatment of lateral flow) was determined. For all BC trenches, the 
value AreaX $=3.0$ provided the best match for isotropic conductivity and AreaX $=6.5$ provided the best match for anisotropic (10:1 ratio) conductivity.

Figures C.1 through C.15 provide the modeling results for the BC trenches with substantial technetium-99 inventory (216-B-20 through 216-B-34, inclusive). Each figure depicts the release from the VADER vadose zone release model (i.e., the "input signal”), the release from the various Subsurface Transport Over Multiple Phases (STOMP) one-dimensional models (with variable AreaX factor values), and from the STOMP two-dimensional models (with isotropic and anisotropic conductivity).

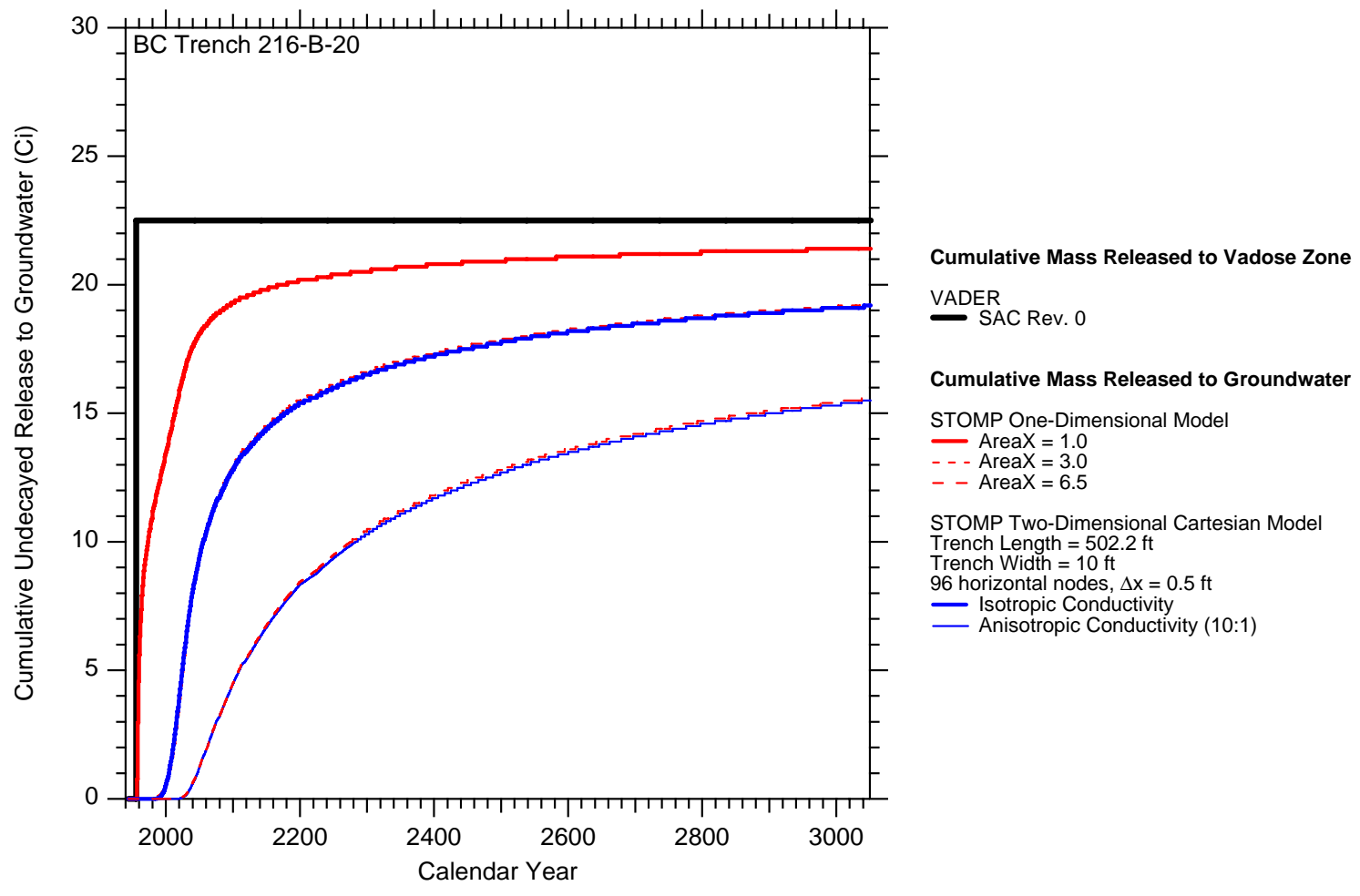

Figure C.1. Vadose Zone Cumulative Release to Groundwater Modeled for Trench 216-B-20 


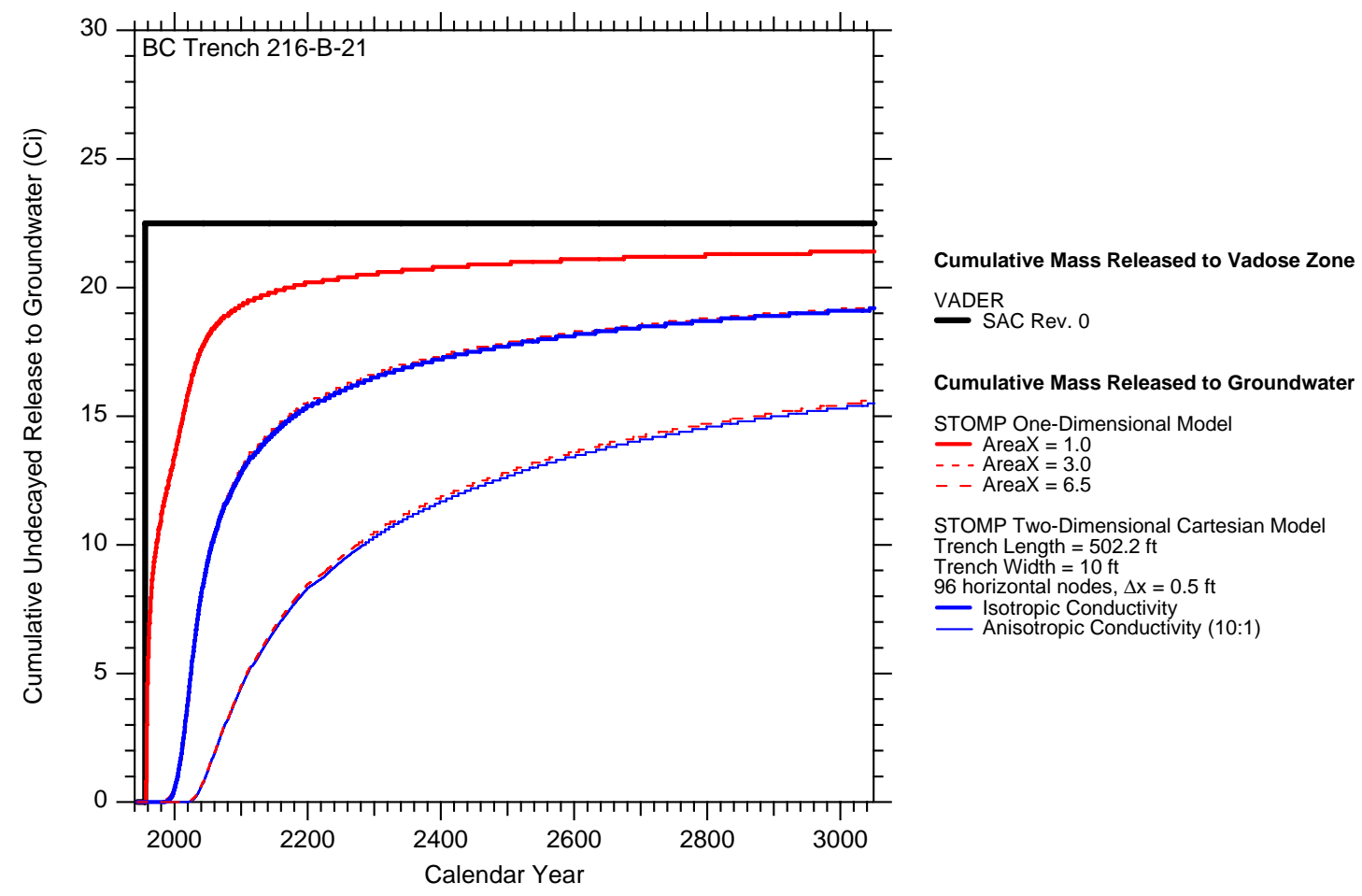

Figure C.2. Vadose Zone Cumulative Release to Groundwater Modeled for Trench 216-B-21

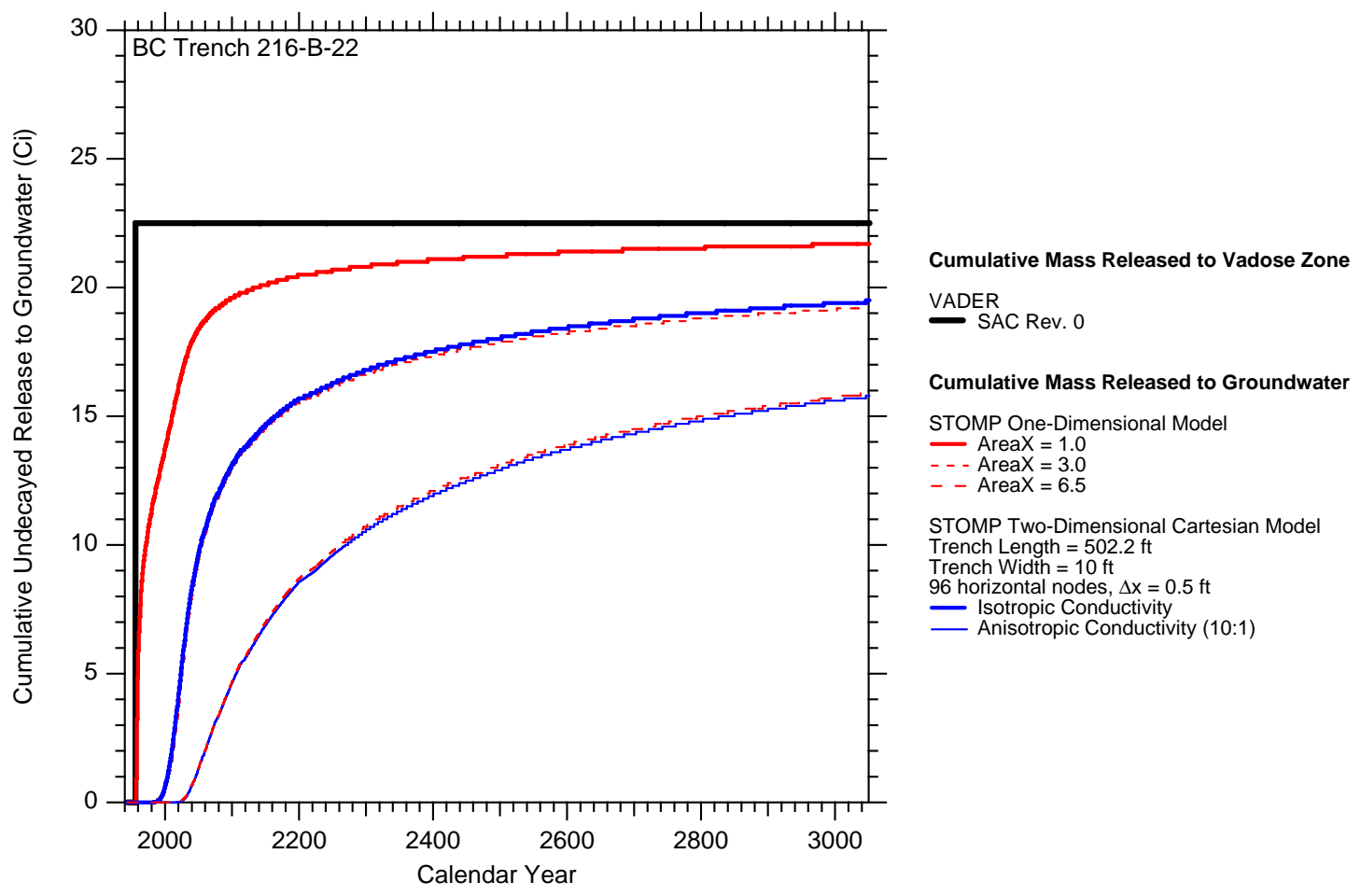

Figure C.3. V Vadose Zone Cumulative Release to Groundwater Modeled for Trench 216-B-22 


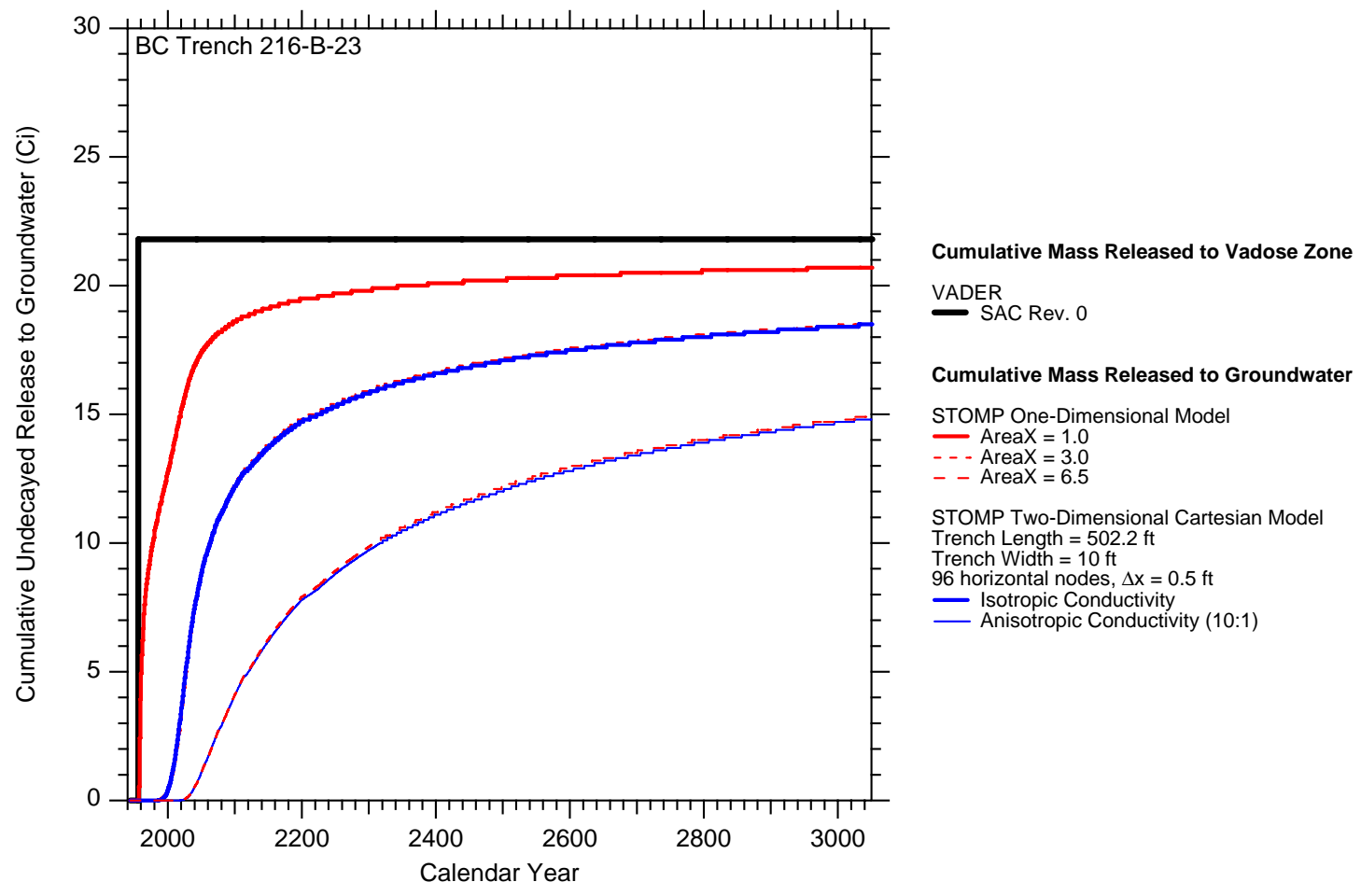

Figure C.4. Vadose Zone Cumulative Release to Groundwater Modeled for Trench 216-B-23

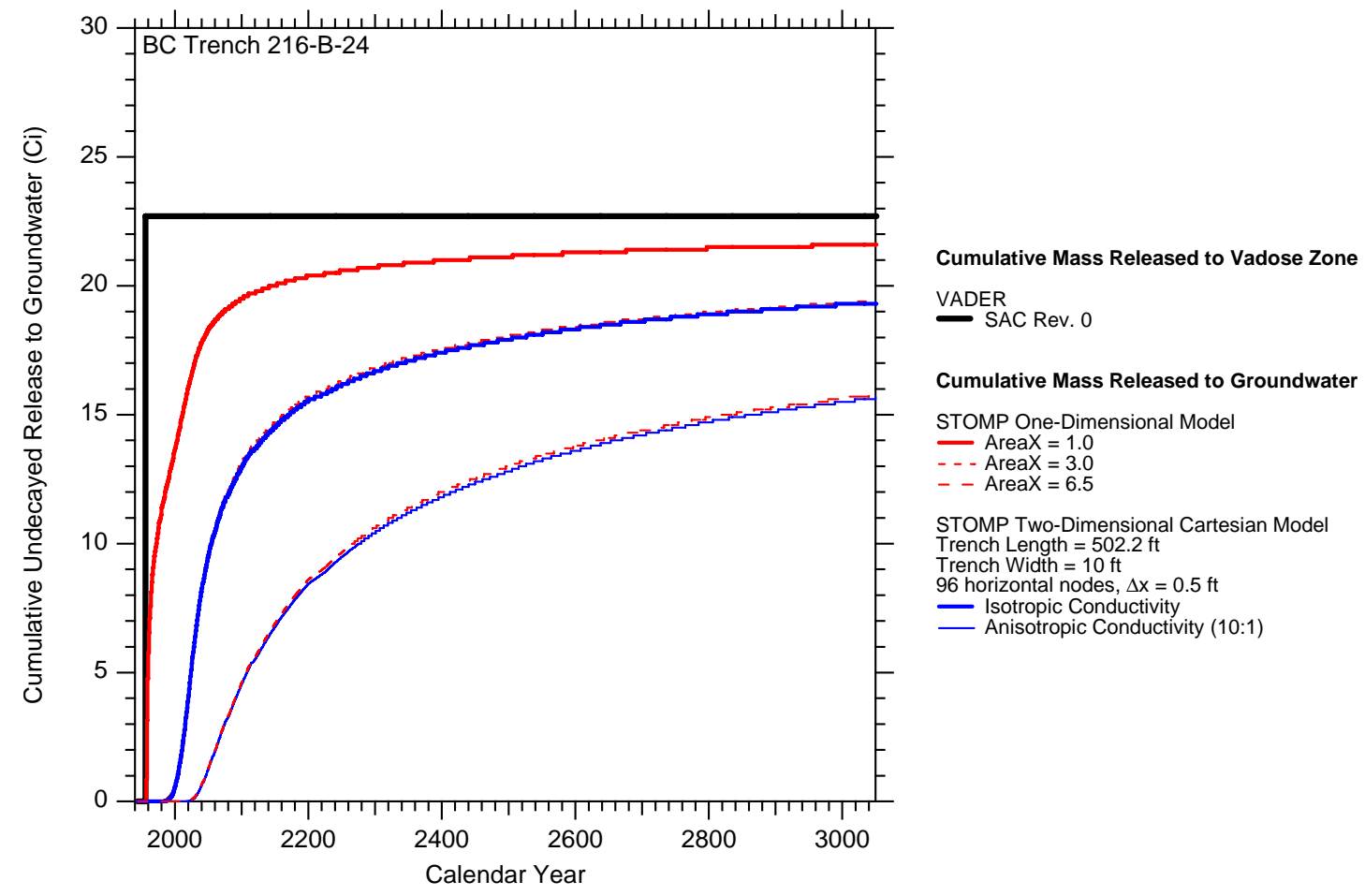

Figure C.5. Vadose Zone Cumulative Release to Groundwater Modeled for Trench 216-B-24 


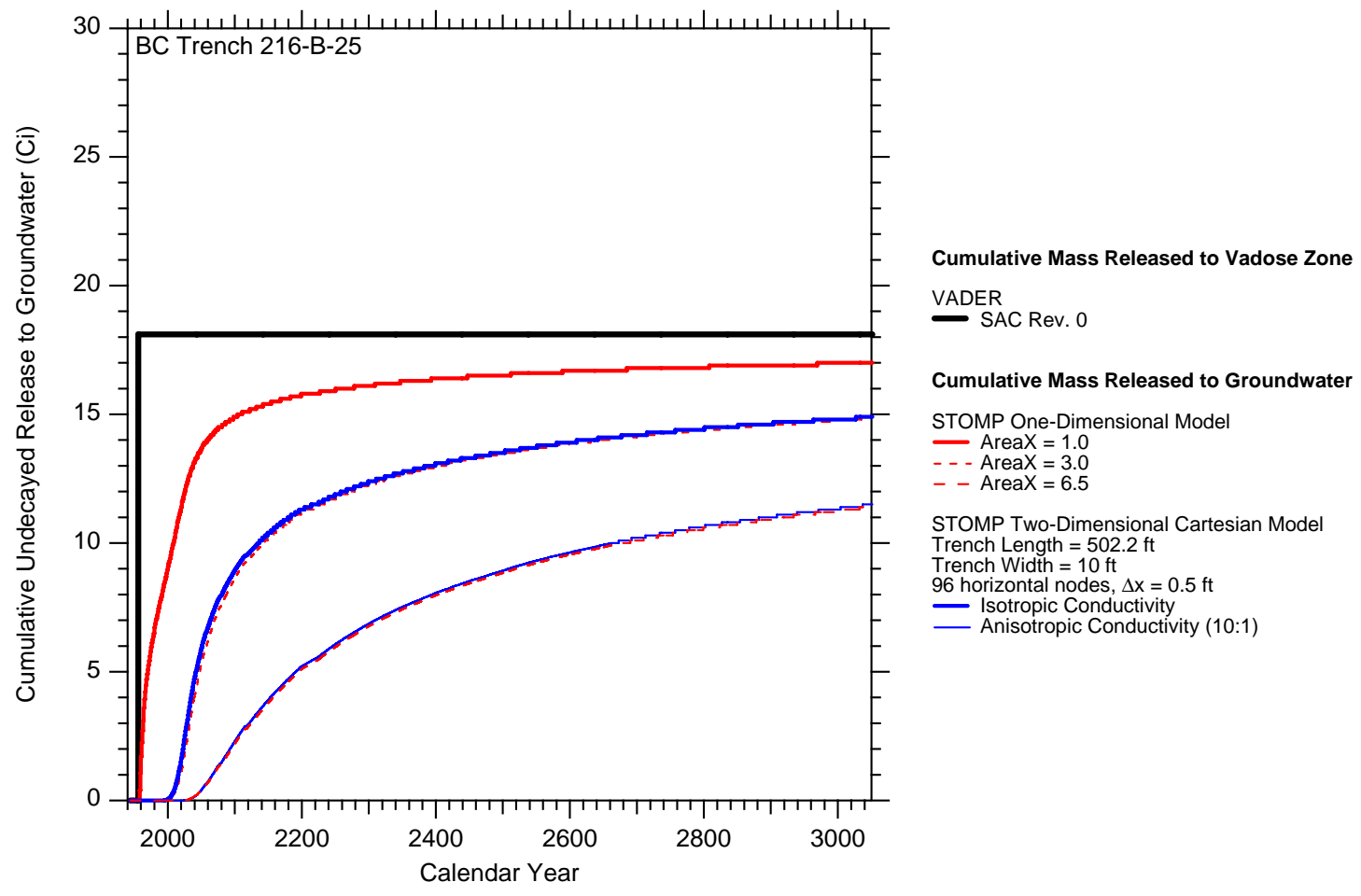

Figure C.6. Vadose Zone Cumulative Release to Groundwater Modeled for Trench 216-B-25

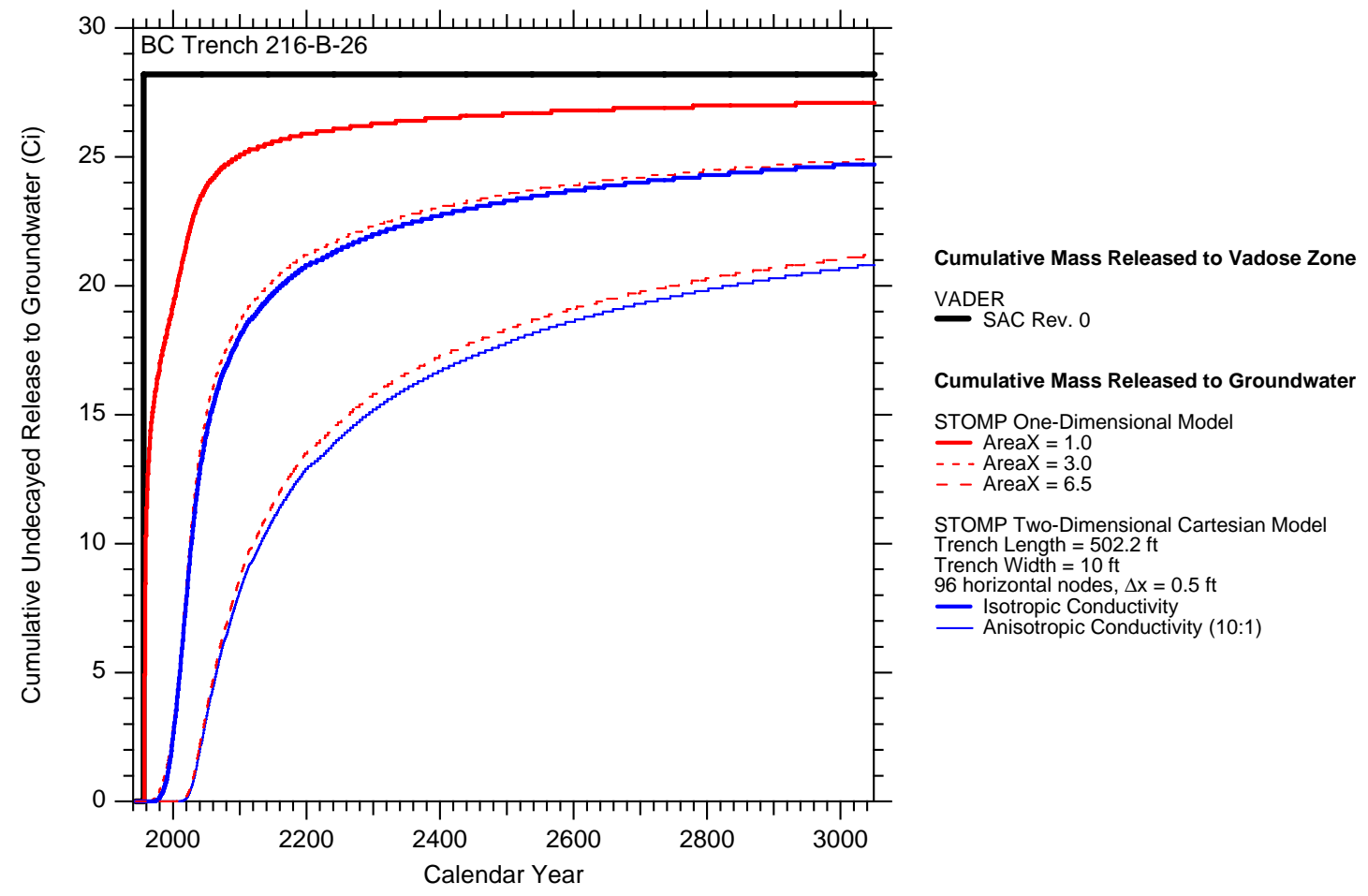

Figure C.7. Vadose Zone Cumulative Release to Groundwater Modeled for Trench 216-B-26 


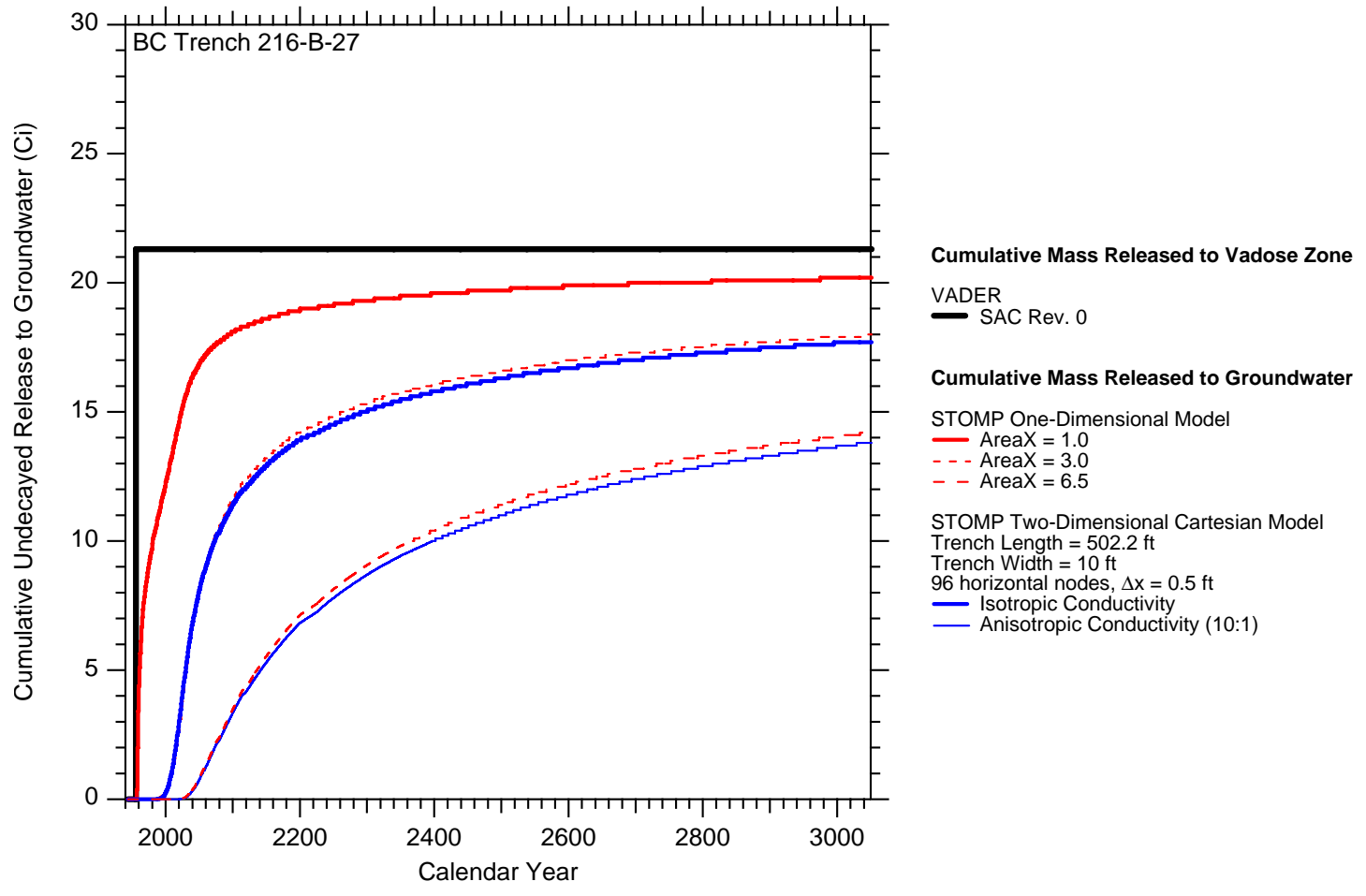

Figure C.8. Vadose Zone Cumulative Release to Groundwater Modeled for Trench 216-B-27

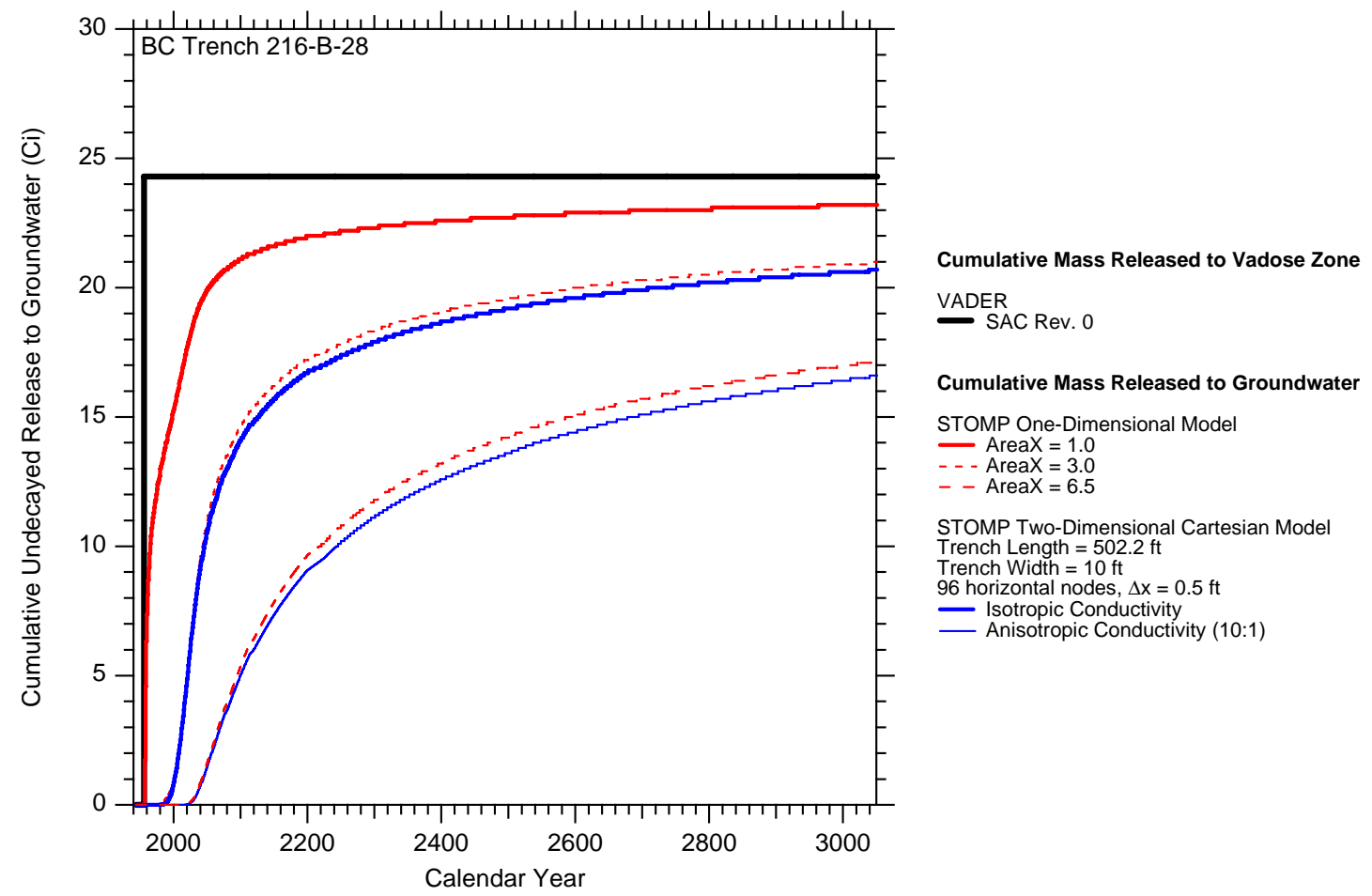

Figure C.9. Vadose Zone Cumulative Release to Groundwater Modeled for Trench 216-B-28 


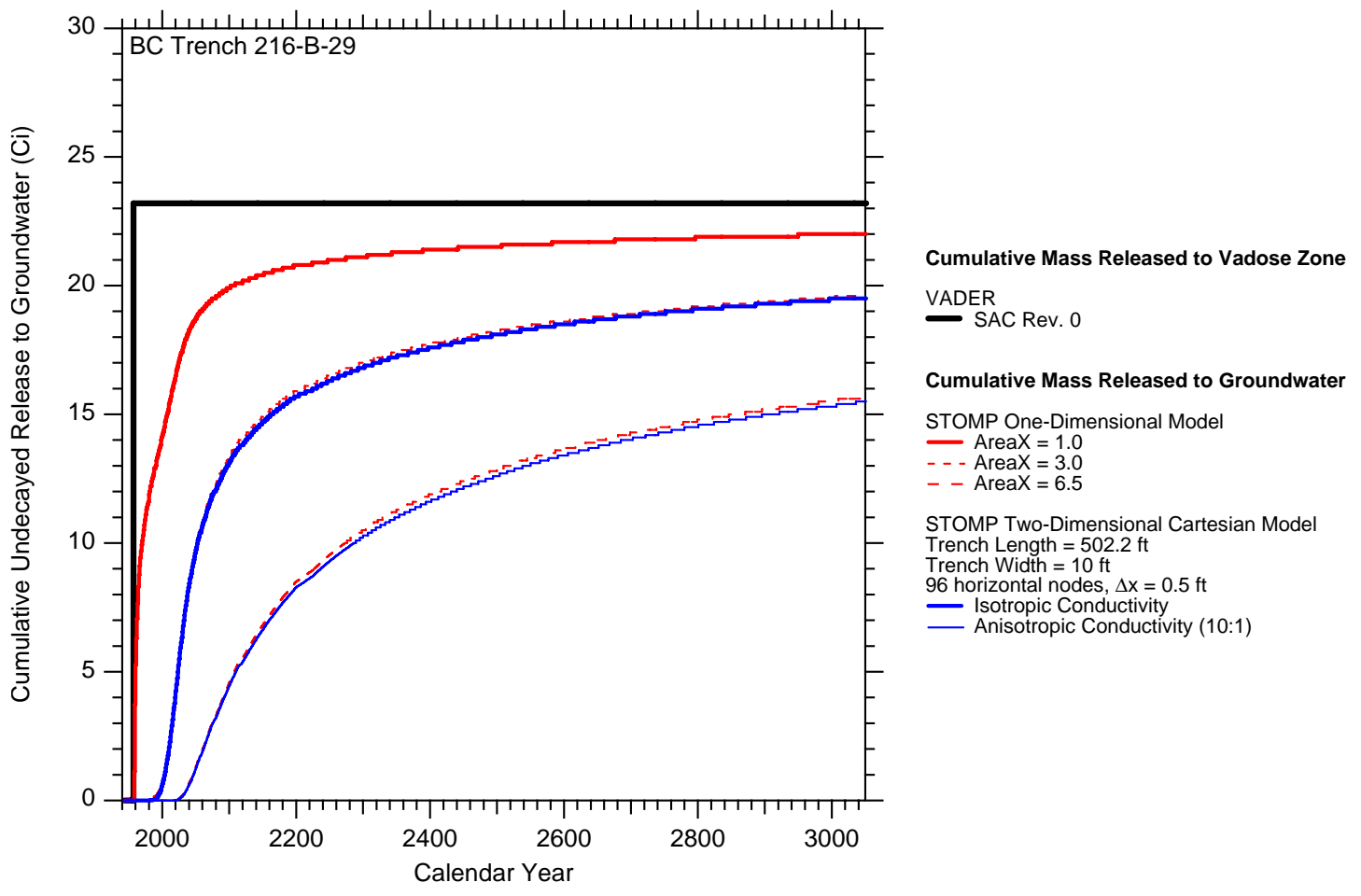

Figure C.10. Vadose Zone Cumulative Release to Groundwater Modeled for Trench 216-B-29

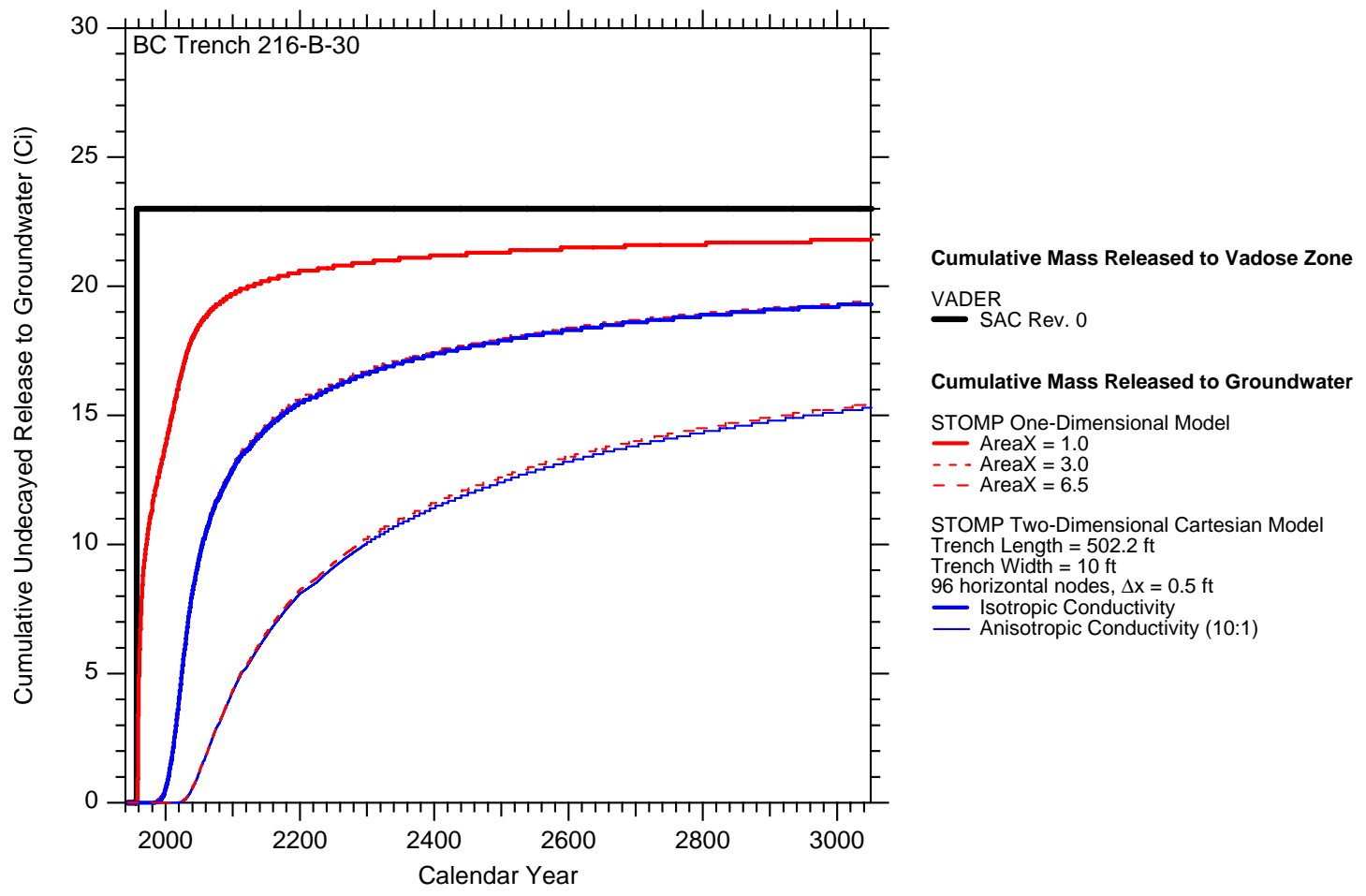

Figure C.11. Vadose Zone Cumulative Release to Groundwater Modeled for Trench 216-B-30 


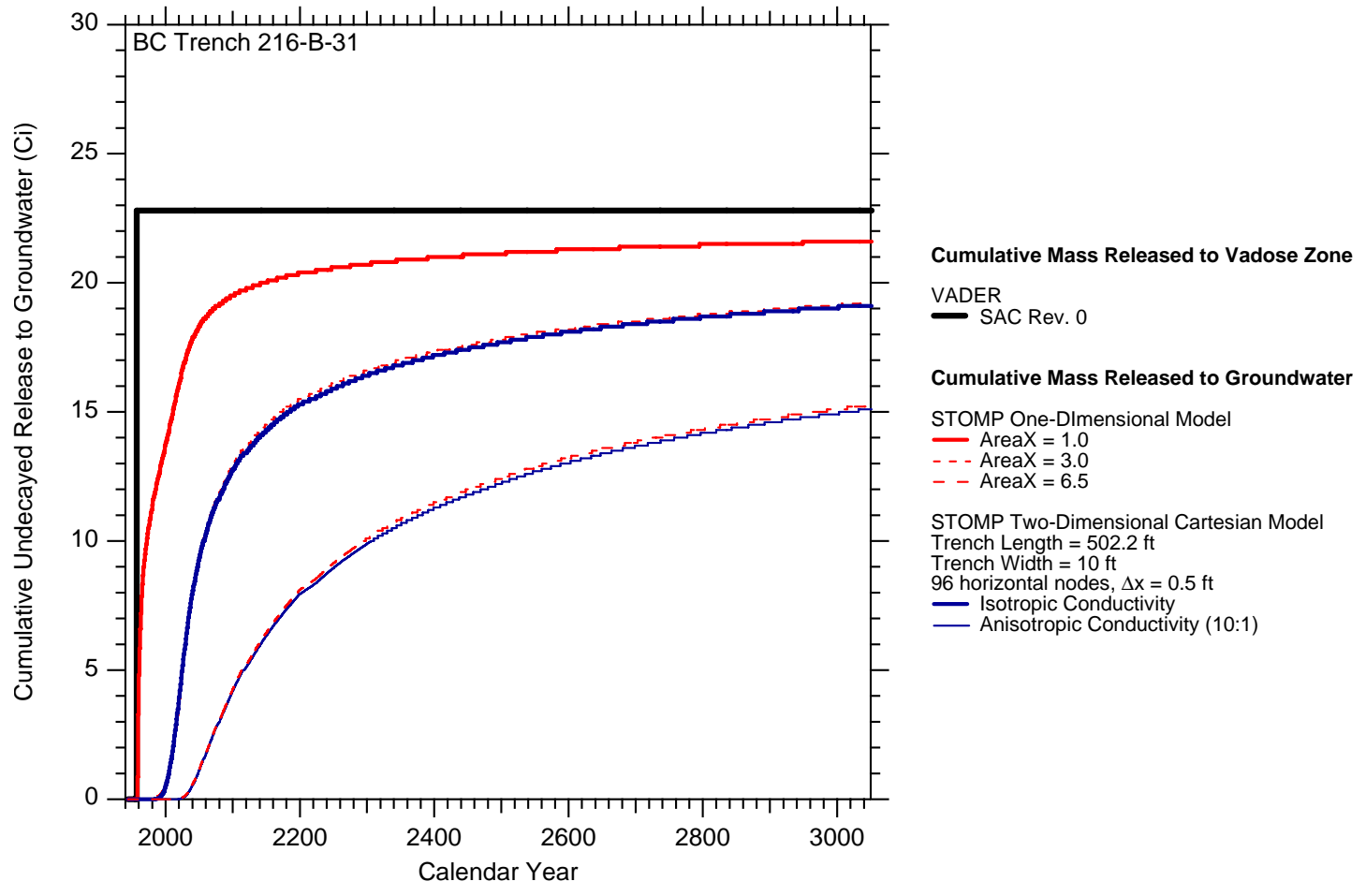

Figure C.12. Vadose Zone Cumulative Release to Groundwater Modeled for Trench 216-B-31

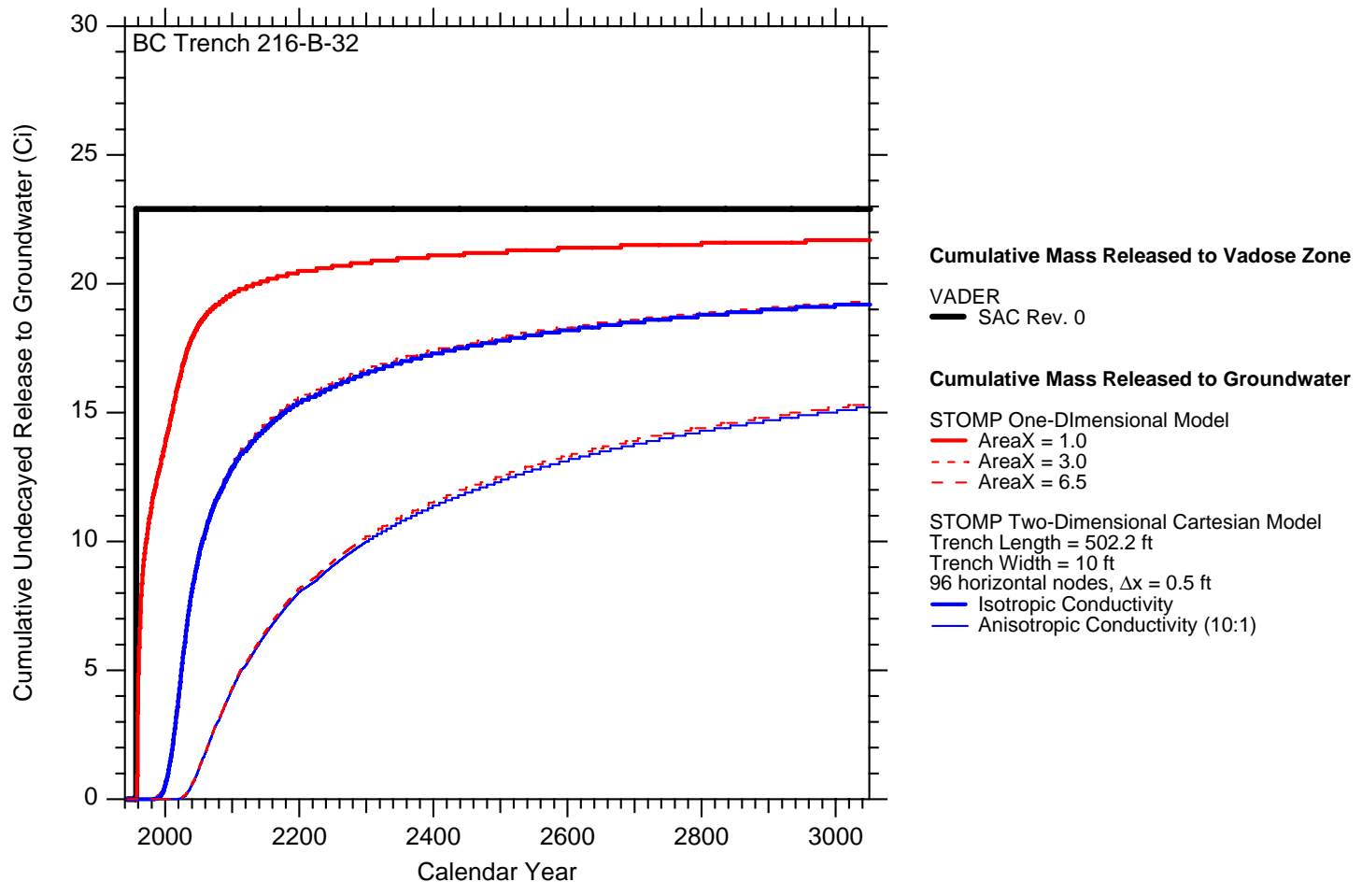

Figure C.13. Vadose Zone Cumulative Release to Groundwater Modeled for Trench 216-B-32 


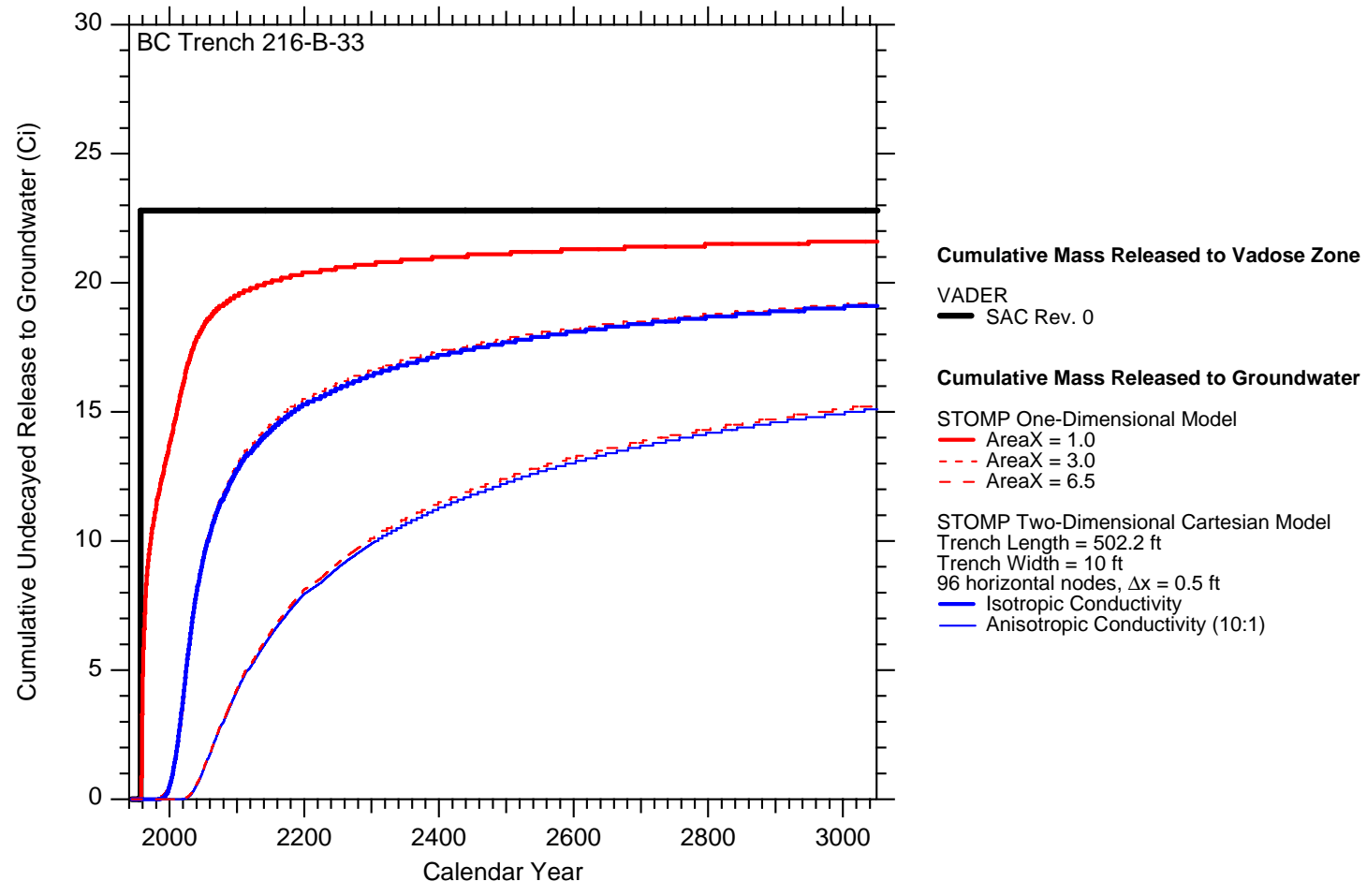

Figure C.14. Vadose Zone Cumulative Release to Groundwater Modeled for Trench 216-B-33

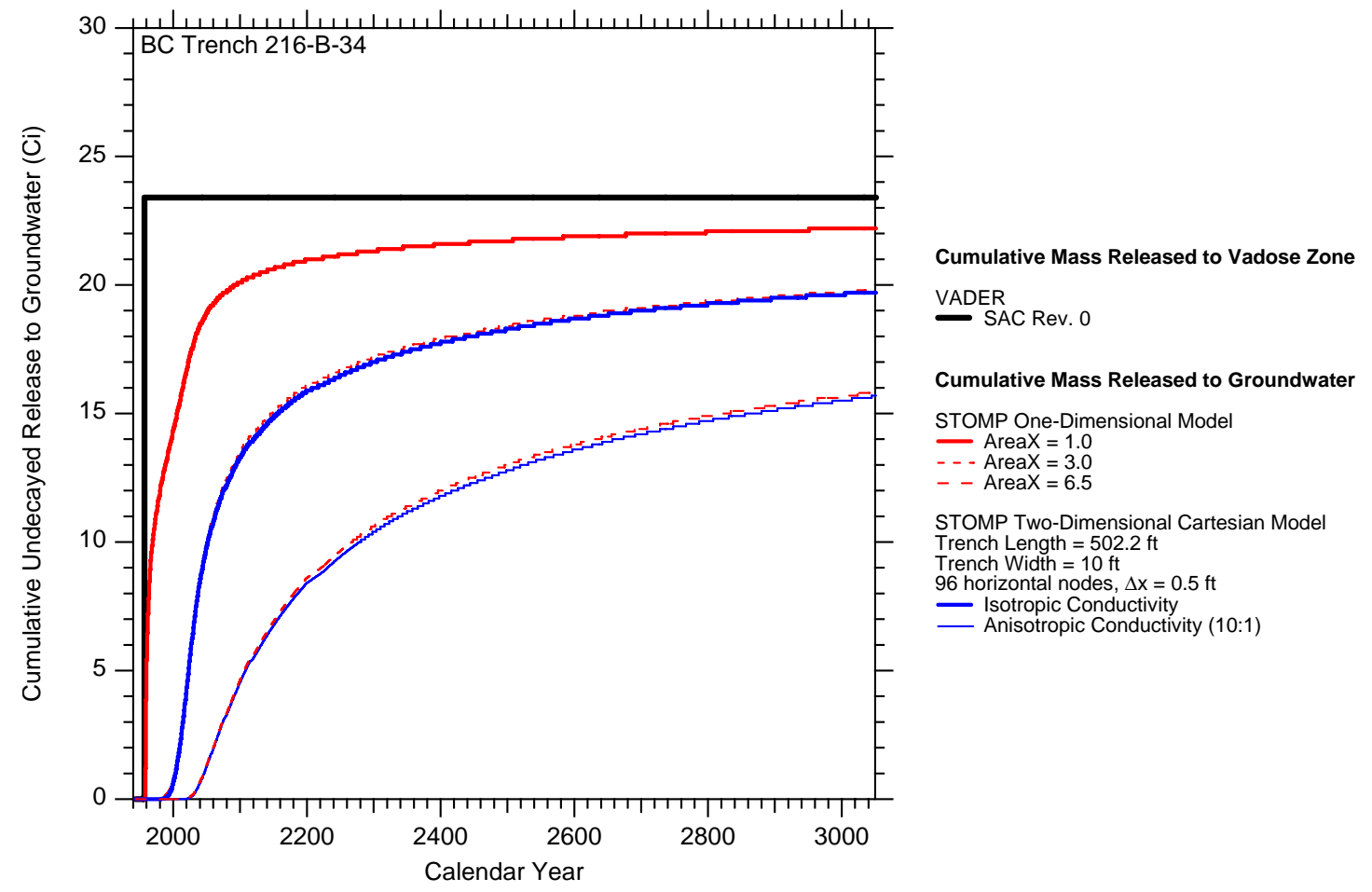

Figure C.15. Vadose Zone Cumulative Release to Groundwater Modeled for Trench 216-B-34 


\section{C.3 Multidimensional Modeling of BC Cribs}

The BC cribs and their respective areas and discharge volumes are listed in Table C.2. The BC cribs are essentially square and were idealized as a two-dimensional circular feature symmetric about the diameter. An idealized two-dimensional cylindrical model was constructed that assumes lateral spreading will be strictly radial outward.

Table C.2. BC Cribs (data from Maxfield 1979)

\begin{tabular}{||c|c|c||}
\hline \hline WIDS Identification & Area (square feet) & Discharge Volume (liters) \\
\hline \hline $216-B-14$ & $40 \times 40=1600$ & $8.71 \times 10^{6}$ \\
\hline $216-B-15$ & $40 \times 40=1600$ & $6.32 \times 10^{6}$ \\
\hline $216-B-16$ & $40 \times 50=2000$ & $5.6 \times 10^{6}$ \\
\hline $216-B-17$ & $40 \times 40=1600$ & $3.41 \times 10^{6}$ \\
\hline $216-B-18$ & $40 \times 40=1600$ & $8.52 \times 10^{6}$ \\
\hline 216-B-19 & $40 \times 40=1600$ & $6.4 \times 10^{6}$ \\
\hline \multicolumn{2}{|l}{ WIDS = Waste Information Data System. } \\
\hline
\end{tabular}

The SAC one-dimensional model for each BC crib was expanded into a two-dimensional axialsymmetric cylindrical model (a 180-degree arc, or half the crib, represented with results scalable to represent the whole crib). The vertical resolution (580, 0.15-meter-grid cells) was retained, and the x-axis was resolved several ways. Ideally, the model should be resolved to the same degree horizontally ( 0.15 meter) as vertical to avoid numerical dispersion, but for the high volume (relative to disposal area) the number of nodes necessary to accomplish this leads to a model too large to solve practically with available computer systems. Instead, several successively finer resolutions were simulated for the first crib (216-B-14) to demonstrate convergence in the release history with finer resolution. It is notable that lower resolution leads to greater lateral flow (due to numerical dispersion in the horizontal dimension), which in turn leads to lower release predictions. This indicates the need to use full resolution in twodimensional models if release is not to be systematically under-predicted in SAC analyses.

Liquid and analyte discharges were converted to density-type sources and assigned to the topmost nodes in the grid index range covering the inner 13.7 meters (the radius of a circle with the same area as a typical BC crib), representing half the source term (again, consistent with the axial-symmetric treatment). Note that the area given in Table C.2 does not match the area declared in WIDS and the SAC database; often the WIDS area is larger than the true footprint.

Hanford soil is anisotropic, considered about 10 times more conductive in the horizontal dimension than in the vertical. To consider this feature, each crib was modeled twice, once with isotropic properties and once with 10:1 anisotropy in saturated hydraulic conductivity.

Once the release histories for the multidimensional model runs were available, the one-dimensional model was rerun with several AreaX (area scaling parameter) values. By trial-and-error, an AreaX scaling factor that would cause the one-dimensional model to produce releases similar to the twodimensional model (with explicit treatment of lateral flow) was determined. For all BC cribs, the value AreaX $=1.5$ provided the best match for isotropic conductivity and AreaX $=3.0$ provided the best match for anisotropic (10:1 ratio) conductivity. 
Figures C.16 through C.24 shows simulated vadose zone release to groundwater results for BC crib 216-B-14 for various horizontal resolutions of the two-dimensional cylindrical model for the early years 1944 to 2000 for both isotropic and anisotropic (10:1) conductivity. Note that increasing release with increasing resolution, showing the need for a highly resolved two-dimensional model to preclude substantially under predicting release. The highest model resolution simulated was 580 vertical ( 0.15 meter) by 192 horizontal ( 0.43 meter) nodes, for a total model grid of 111,360 nodes. Ideally, the horizontal should be resolved to 0.15-meter nodes also, but this would yield a model domain of more than 300,000 nodes, too large to simulate with available equipment in a reasonable time. As it was, the final resolution (111,360 nodes) could only be simulated on the analysis stations (paper.pnl.gov or plastic.pnl.gov) and not on any RANSAC compute node due to the memory demands of such a large domain. Hence, the release for the highest resolution should be seen as close, but not quite as high as the release that would be predicted for the fully resolved (0.15-meter grid) model if it were run.

Also displayed in Figure C.16 are the release results for the one-dimensional model for AreaX $=1.0$ (SAC Rev. 0 default) and for AreaX = 1.5, which approximates the isotropic release history, and AreaX = 3.0, which approximates the anisotropic (10:1) release history. The one-dimensional model is shown to slightly under predict annual releases from the crib in early years (up to about 1980) and slightly over predict annual releases thereafter.

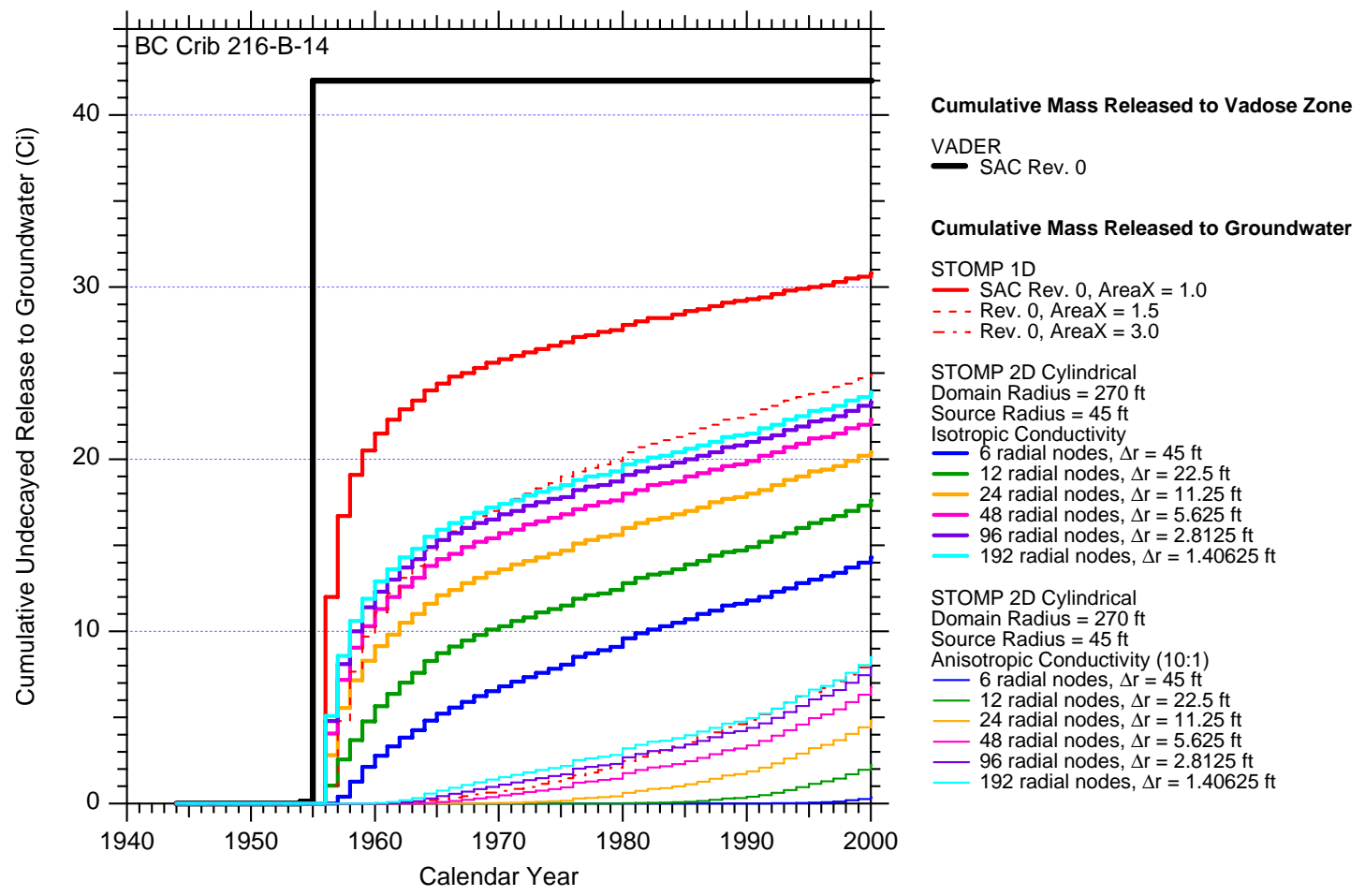

Figure C.16. Vadose Zone Cumulative Release to Groundwater Modeled for Crib 216-B-14 (1944 to 2000) 


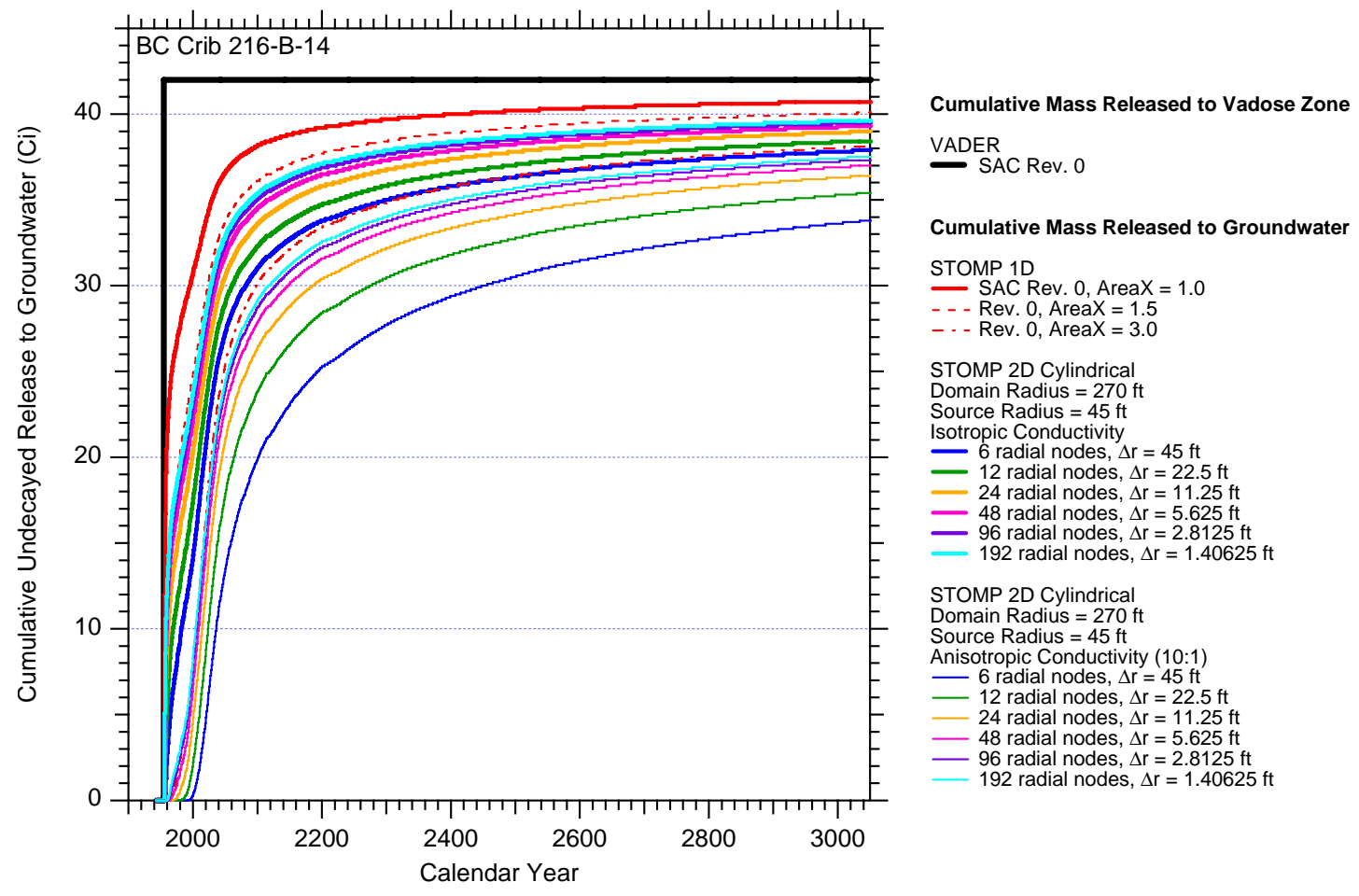

Figure C.17. Vadose Zone Cumulative Release to Groundwater Modeled for Crib 216-B-14

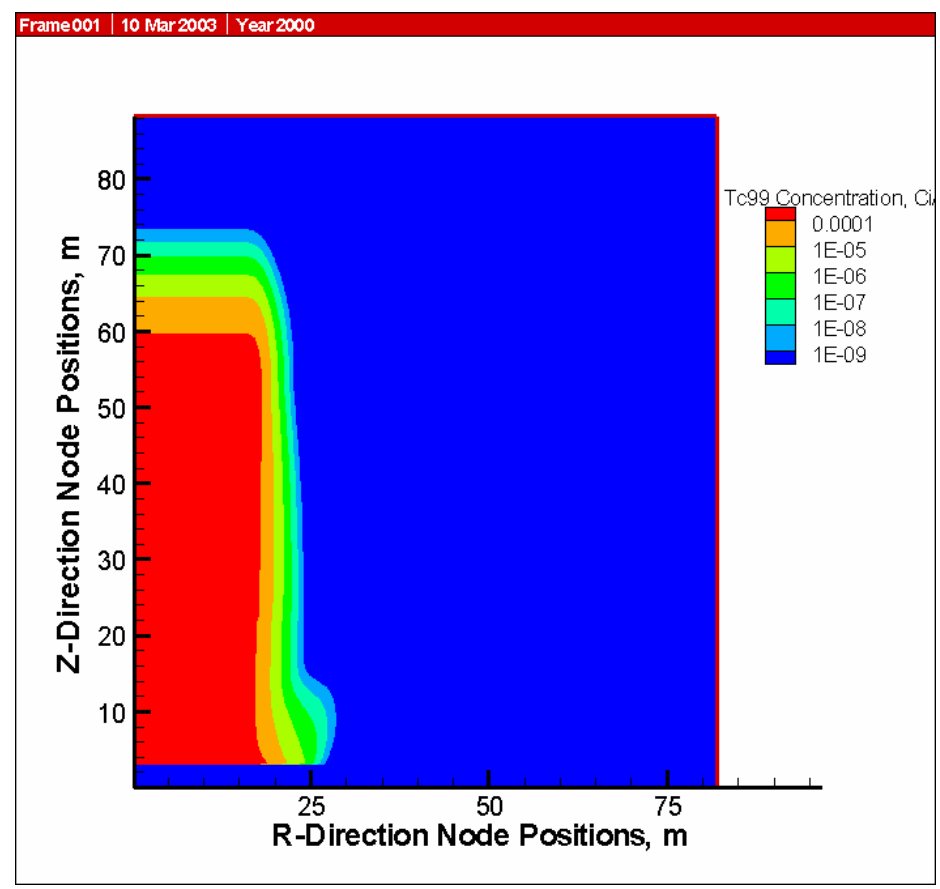

Figure C.18. Tc-99 Concentration $\left(\mathrm{Ci} / \mathrm{m}^{3}\right)$ of Two-Dimensional Axial-Symmetric (192 radial nodes) Isotropic Model of Crib 216-B-14 (center of crib is the left-hand side and the water table is the bottom of the domain) 


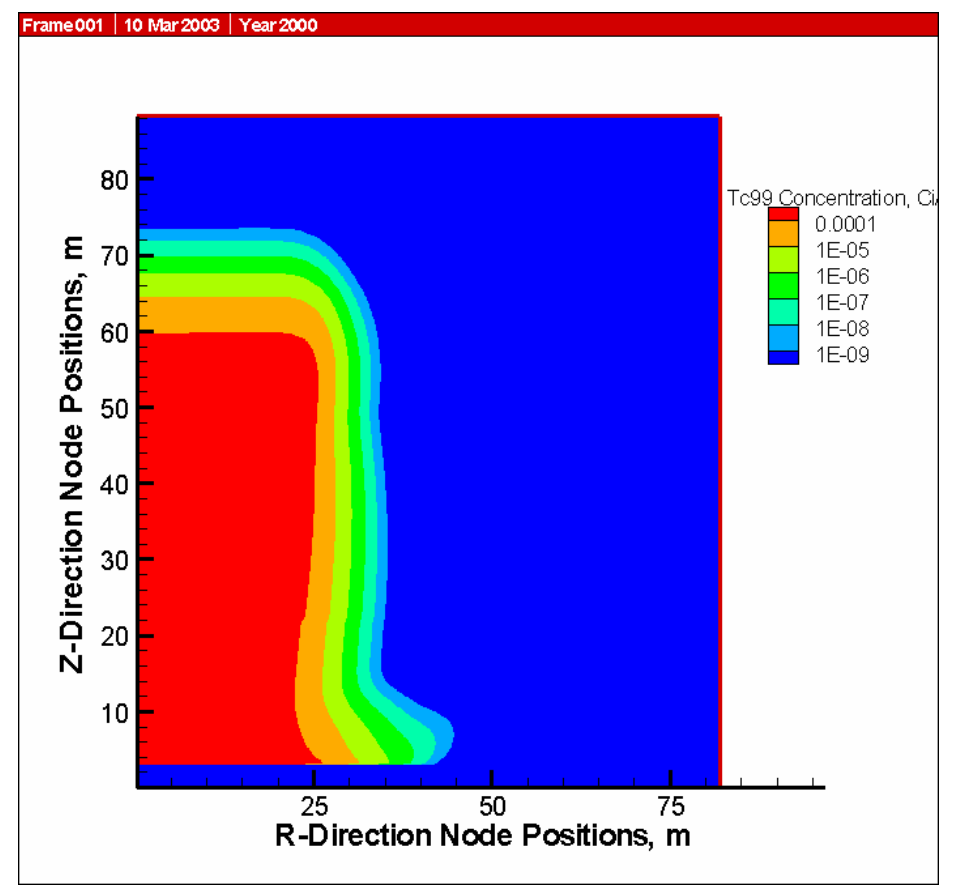

Figure C.19. Tc-99 Concentration $\left(\mathrm{Ci} / \mathrm{m}^{3}\right)$ of Two-Dimensional Axial-Symmetric (192 radial nodes) Anisotropic (10:1 conductivity ratio) Model of Crib 216-B-14 (center of crib is the lefthand side and the water table is the bottom of the domain)

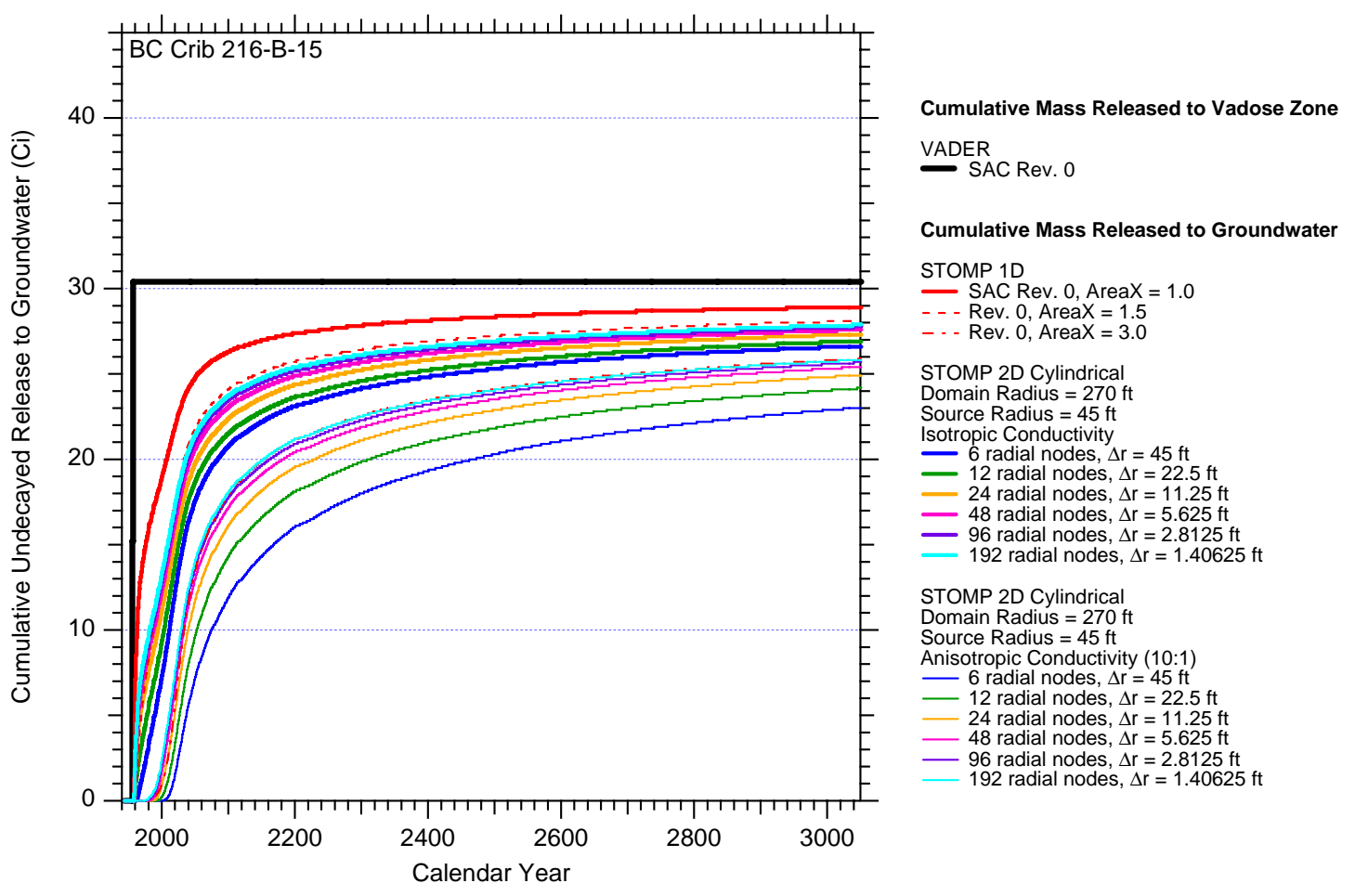

Figure C.20. Vadose Zone Cumulative Release to Groundwater Modeled for Crib 216-B-15 


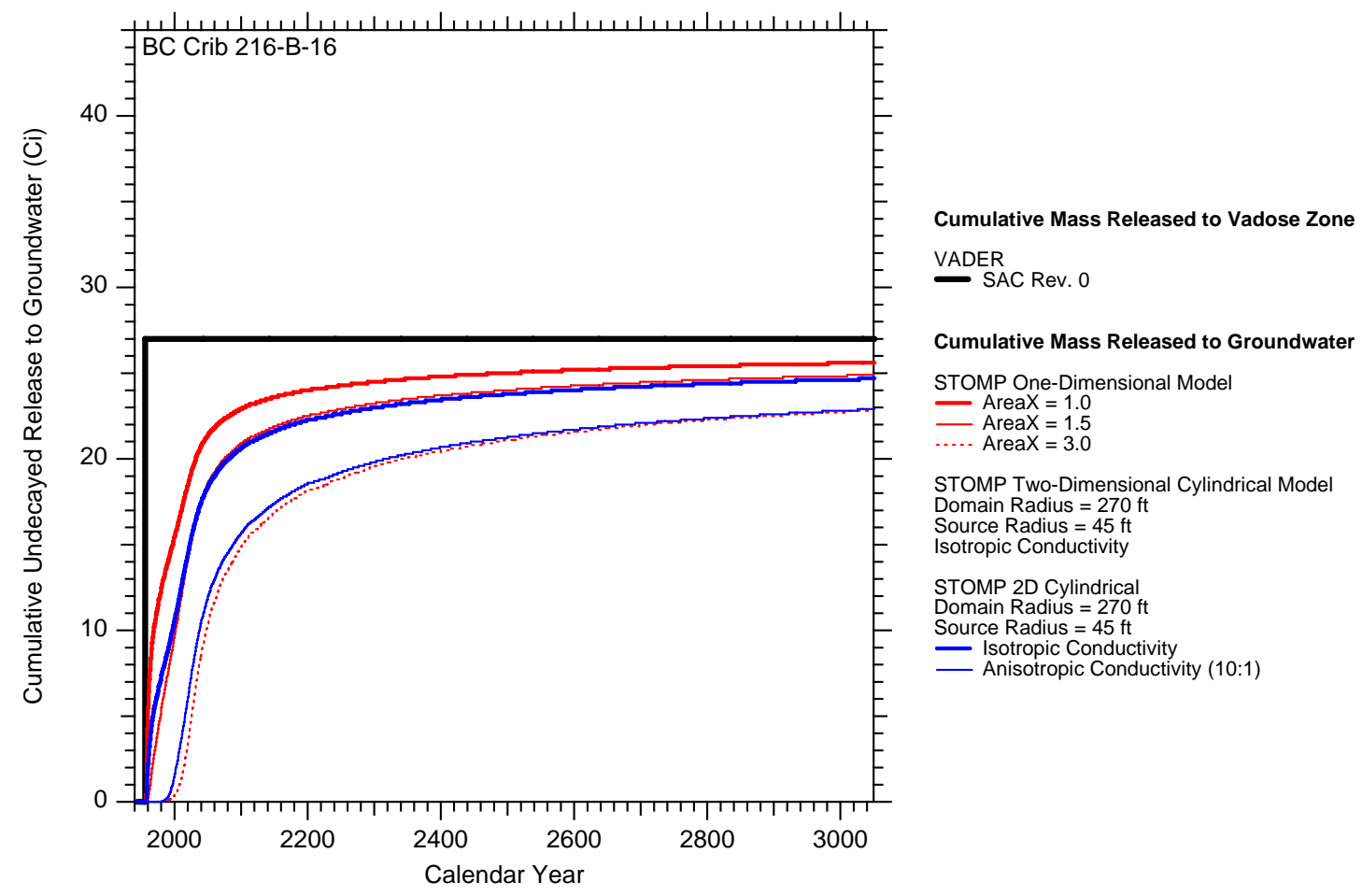

Figure C.21. Vadose Zone Cumulative Release to Groundwater Modeled for Crib 216-B-16

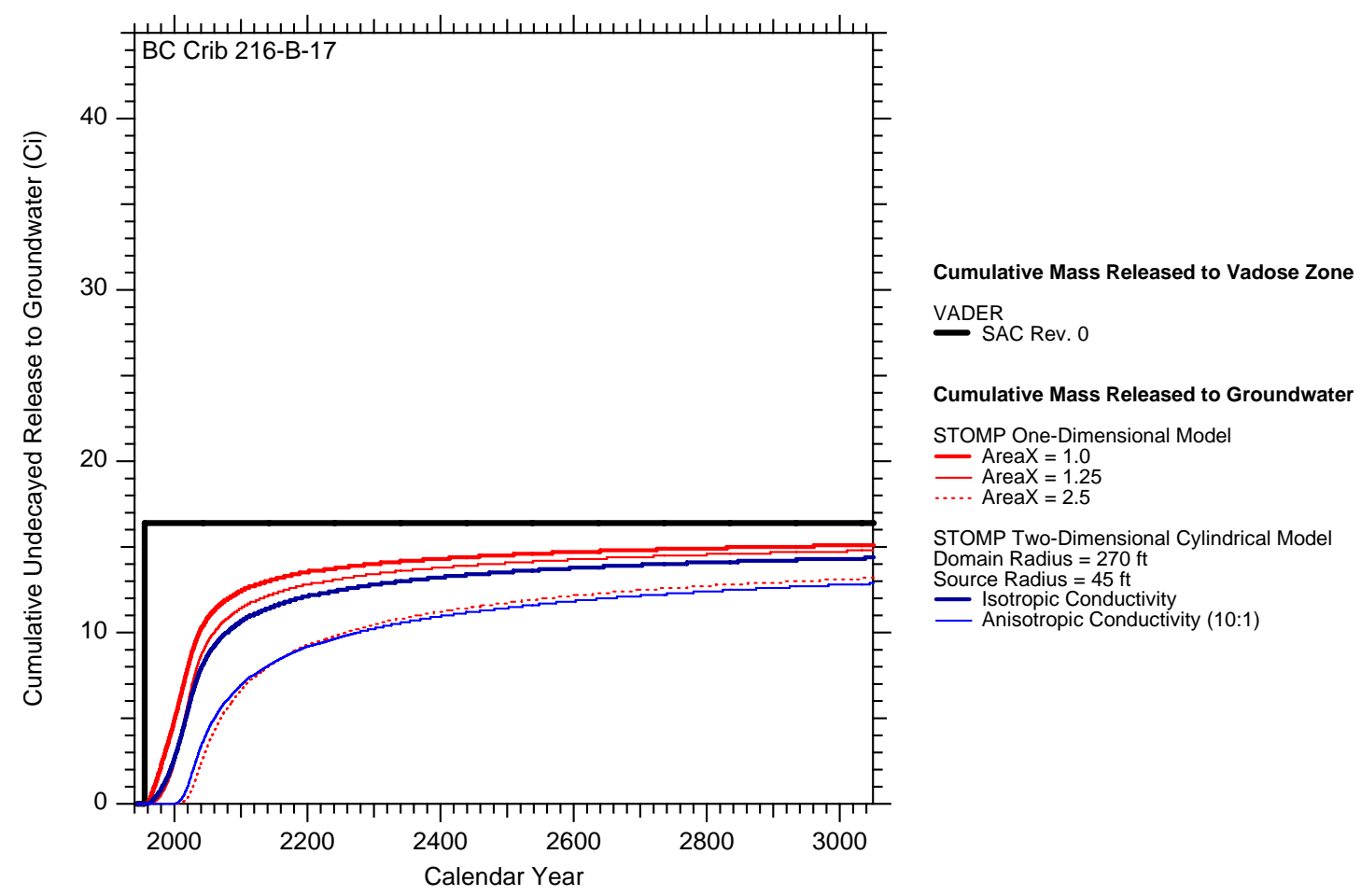

Figure C.22. Vadose Zone Cumulative Release to Groundwater Modeled for Crib 216-B-17 


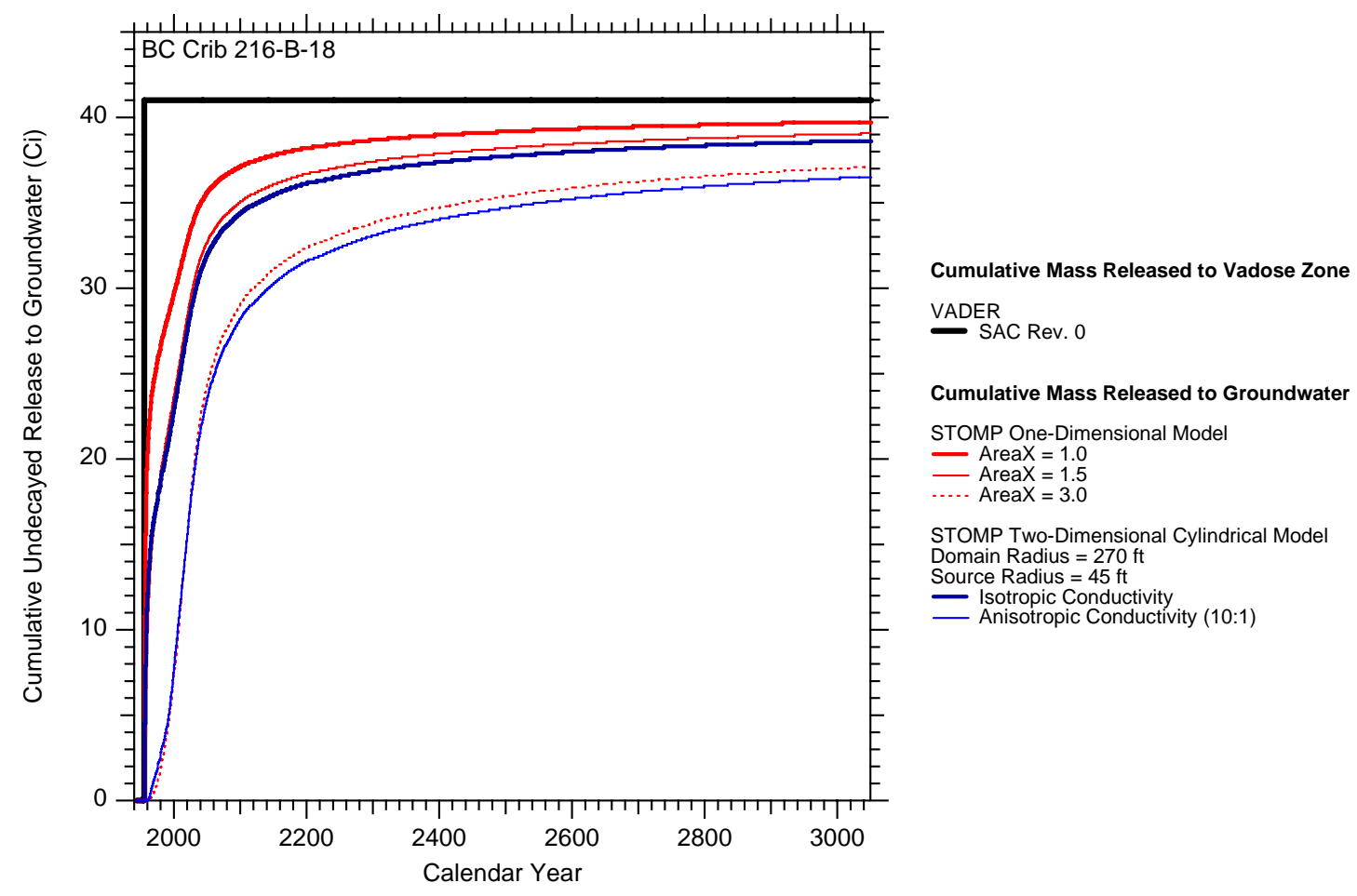

Figure C.23. Vadose Zone Cumulative Release to Groundwater Modeled for Crib 216-B-18

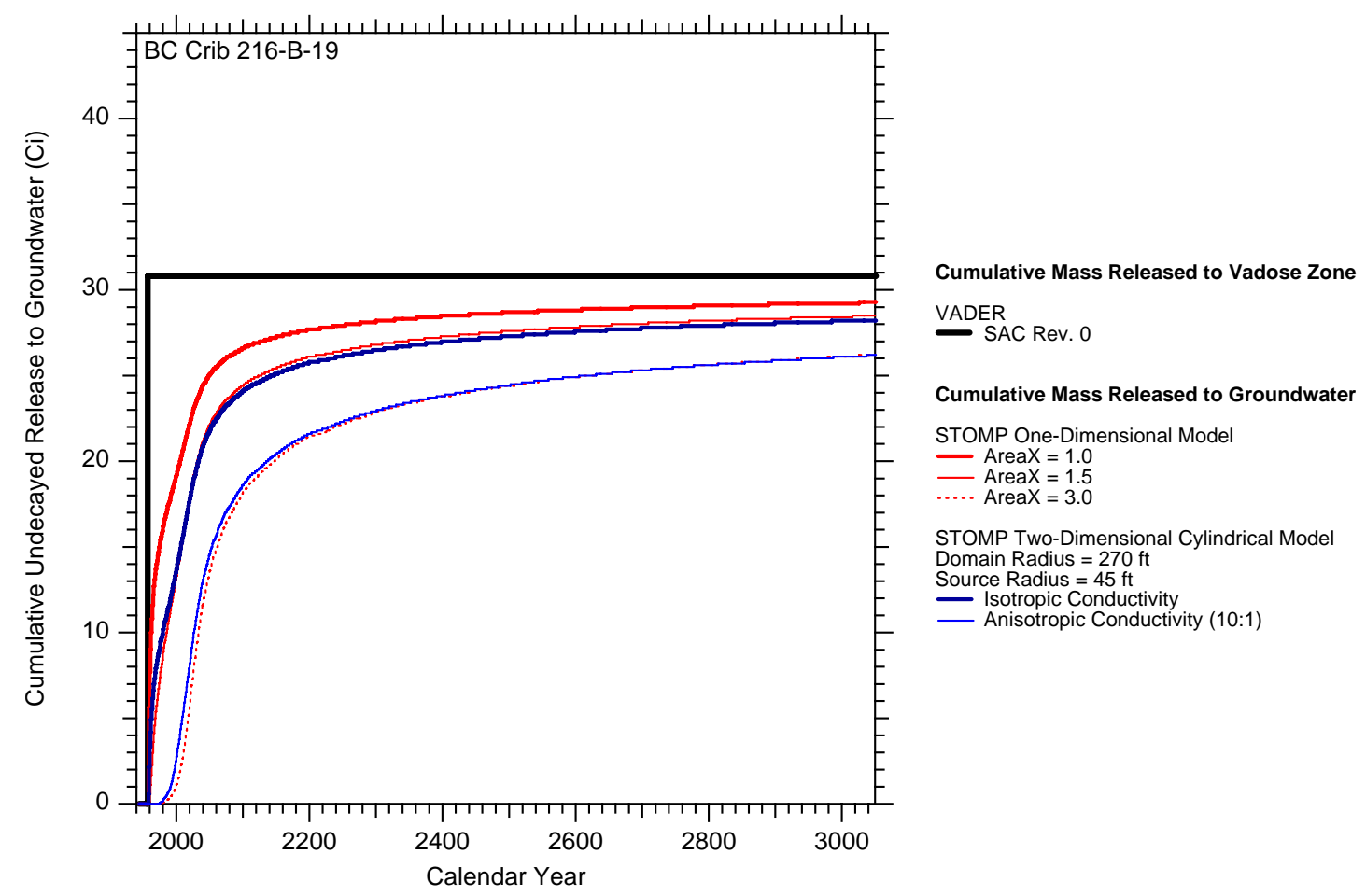

Figure C.24. Vadose Zone Cumulative Release to Groundwater Modeled for Crib 216-B-19 


\section{C.4 Computer Simulation Time}

An important implication of two-dimensional simulation in the SAC context is the simulation time required to solve for vadose zone transport of analytes. As a stochastic simulator, SAC will invoke a STOMP model of a vadose zone site for a number of cases equal to the number of realizations times the number of analytes. Ideally, locations with liquid discharges (such as the BC cribs and trenches) would be modeled as two-dimensional features. However, if the computer time required to perform the number of two-dimensional cases required is too great, a problem of feasibility arises.

The times required to solve the various one- and two-dimensional simulations of the crib 216-B-14 provides a basis for consideration. Table C.3 provides the timing results. Note all time are for simulations on a Pentium 4 processor, except the highest resolution grid which had to be run on a SAC analysis node due to the high RAM requirements of this resolution grid. The highest resolution twodimensional model, with 111,360 nodes, was too large to run on any RANSAC compute node as it required more RAM than any of the compute nodes are equipped with. The high memory demand of this size model has important implications for inclusion in SAC of a two-dimensional model of the BC cribs. Moreover, this model still wasn't sufficiently resolved (that would require a model with more than 300,000 nodes).

\section{C.5 Summary}

Based on the simulation times in Table C.3 and the simulation results shown earlier, several points can be made with respect to SAC Rev. 1 implementation:

1. If a two-dimensional capability is desired, the SPLIB solver is substantially faster for grid domains over 20,000 nodes and should be made standard for STOMP in SAC.

2. If a two-dimensional model were to be used directly in SAC, the time required to solve the vadose zone segment of SAC would increase starkly. For crib 216-B-14, more than 15 hours were required at a grid resolution that was nearly sufficient. In a production run with 25 realizations and 10 analytes, this would imply 3,750 hours of computer time for just one crib, or 22,500 hours for the six BC cribs. Spread over 132 compute nodes (assuming these were equipped with enough RAM to carry the problem), it would take 170 hours, or about one week, just to solve for the six BC cribs. Worse, these time estimates were based on runs on 2.2-GHz processors; 128 of the 132 compute nodes on RANSAC are 1.0-GHz processors (about three times slower). And this only for the BC cribs; there are many other liquid-discharge sites that make good candidates for two-dimensional simulation in SAC. It is clear that direct two-dimensional treatment of liquid discharge waste sites remains impractical, requiring at least RAM upgrades to the entire SAC cluster and unacceptably long simulation times to solve.

3. However, the results also demonstrate that the one-dimensional model can be made to approximate the direct two-dimensional model by selecting an appropriate value of the vadose zone wetted area based on detailed two-dimensional modeling. 
Table C.3. Computer Simulation Time for Various One- and Two-Dimensional STOMP Models of 216-B-14 Crib (Pentium 4, 2.2-GHz processor running under Linux)

\begin{tabular}{||c|c|c|c|c|c||}
\hline \hline \multicolumn{3}{|c|}{ Number of Nodes in Direction } & \multirow{2}{*}{ Solution Time(s) } \\
& $\theta$ & $Z$ & $\begin{array}{c}\text { Total Number of } \\
\text { Nodes }\end{array}$ & $\begin{array}{c}\text { Banded Matrix } \\
\text { Solver }\end{array}$ & SPLIB Solver \\
\hline \hline 1 & 1 & 580 & 580 & 137 & 129 \\
\hline 6 & 1 & 580 & 3,480 & 960 & 955 \\
\hline 12 & 1 & 580 & 6,960 & 2,081 & 2,055 \\
\hline 24 & 1 & 580 & 13,920 & 4,910 & 4,501 \\
\hline 48 & 1 & 580 & 27,840 & 21,835 & 9,522 \\
\hline 192 & 1 & 580 & 55,680 & & 20,588 \\
\hline
\end{tabular}

(a) Simulated on Pentium III, 1.3-GHz processor instead because RAM was insufficient on any RANSAC compute node for this large of grid domain.

It is recommended that for the BC cribs and trenches the one-dimensional model continue to be used in SAC Rev. 1, but with vadose zone wetted area scaling factors derived from the simulations performed in this report.

\section{C.6 Projected Impact on Initial Assessment}

To demonstrate the change from following these calibration factors, the total technetium-99 release from all BC cribs and trenches was simulated both using the SAC Rev. 0 approach (effectively AreaX = 1.0) and with the vadose zone wetted area scaling parameters derived in this study. The results are shown in Figure C.25. Note the difference predicted by year 2000; 449 curies released to the aquifer in the initial assessment model (one-dimensional model, AreaX =1.0) compared to only 18.2 curies released in the one-dimensional model with scaling factors drawn from the detailed two-dimensional models. Based on the more detailed modeling, the absence of a detected technetium plume in groundwater monitoring data for this area, the much lower release is considered much more realistic.

\section{C.7 References}

Bryce RW, CT Kincaid, PW Eslinger, and LF Morasch (eds.). 2002. An Initial Assessment of Hanford Impact Performed with the System Assessment Capability. PNNL-14027, Pacific Northwest National Laboratory, Richland, Washington.

Maxfield HL. 1979. Handbook - 200 Areas Waste Sites. RHO-CD-673, Volumes I and II, Rockwell Hanford Company, Richland, Washington. 


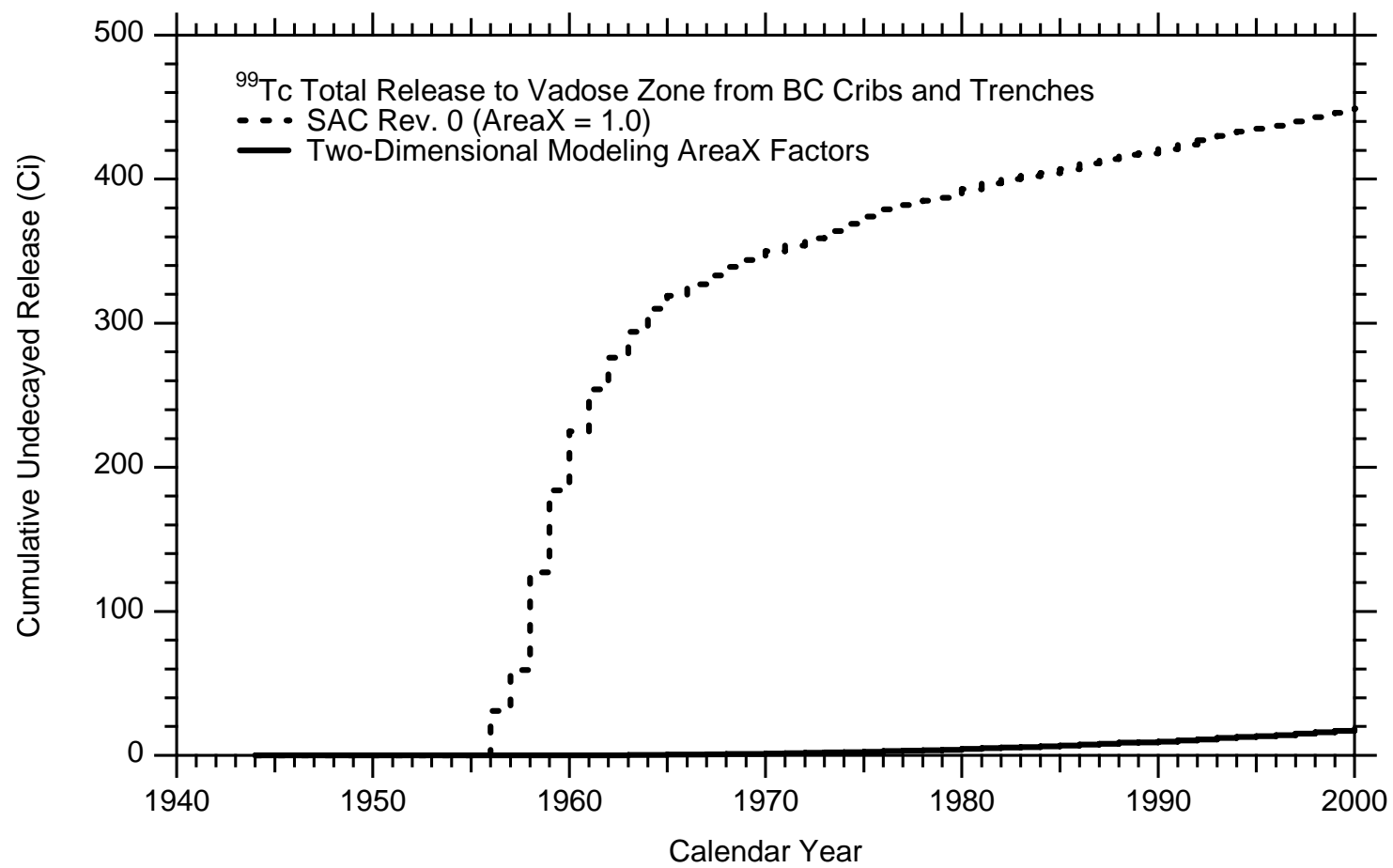

Figure C.25. Total Annual Release from all BC Cribs and Trenches Simulated in SAC Rev. 0 Initial Assessment and with Vadose Zone Wetted Area Scaling Parameters Conditioned to Direct Two-Dimensional Simulations 


\section{Distribution}

(Distribution is by electronic copy.)

No. of

Copies

3 DOE Office of River Protection

M.E. Burandt

H6-60

R. W. Lober

S.A. Wiegman

6 DOE Richland Operations Office

B. L. Charboneau

A6-33

B. L. Foley

R. D. Hildebrand

J. G. Morse

K. M. Thompson

DOE Public Reading Room

5 CH2M HILL Hanford Group, Inc.

M. Connelly

H6-03

J. G. Field

J. G. Kristofzski

F. M. Mann

W. J. McMahon

3 Washington Closure

K. R. Fecht

H4-21

E. T. Feist

S. G. Weiss

2 Fluor Federal Services

R. Khaleel

R. J. Puigh

E6-17

E6-17

6 Fluor Hanford, Inc.

B. A. Austin

J. V. Borghese

L. R. Fitch

B. H. Ford

T. W. Fogwell

J. Hoover
No. of

Copies

47 Pacific Northwest National Laboratory

R. L. Aaberg K3-54

M. P. Bergeron K9-36

B. N. Bjornstad K6-81

C. A. Brandt K9-04

R. W. Bryce (5) E6-35

A. L. Bunn K6-85

K. J. Cantrell K6-81

D. W. Engel K5-12

P. W. Eslinger K6-04

J. C. Evans, Jr. K6-96

M. J. Fayer K9-33

E. J. Freeman K9-36

V.L. Freedman K9-36

M. D. Freshley K9-33

G. W. Gee K9-33

T. J. Gilmore K6-96

D. G. Horton K6-81

C. T. Kincaid K9-33

G. V. Last (5) K6-81

C. A. LoPresti K5-12

B. A. Napier K3-54

W. J. Martin K6-81

T. B. Miley K6-04

C. J. Murray K6-81

I. C. Nelson K3-54

W. E. Nichols K9-33

B.E. Opitz K6-75

G. W. Patton K6-75

C. L. Rakowski K9-33

J. V. Ramsdell, Jr K3-54

R. G. Riley K6-96

M. L. Rockhold K9-36

P. A. Scott K9-46

R. J. Serne P7-22

D. L. Strenge K3-54

P. D. Thorne K9-33

M. D. Williams K6-96

S. K. Wurstner K9-36

Hanford Technical Library $\quad$ H2-53 